NUREG/CR-5164

BNL-NUREG-52153

\title{
A SIMPLIFIED MODEL FOR CALCULATING EARLY OFFSITE CONSEQUENCES FROM NUCLEAR REACTOR ACCIDENTS
}

\author{
I.K. Madni, E.G. Cazzoli, and M. Khatib-Rahbar
}

July 1988

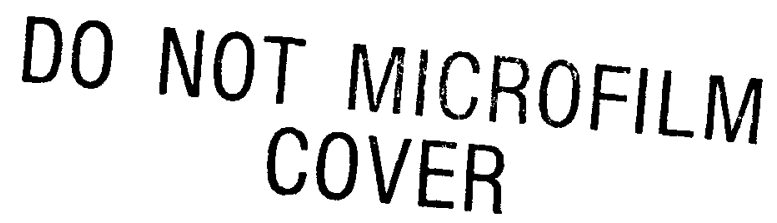

DEPARTMENT OF NUCLEAR ENERGY, BROOKHAVEN NATIONAL LABORATORY UPTON, LONG ISLAND, NEW YORK 11973

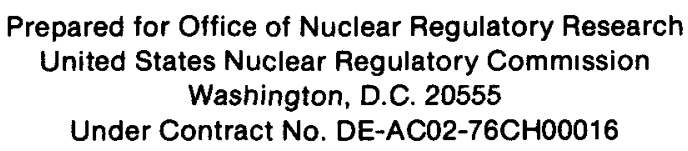




\section{DISCLAIMER}

This report was prepared as an account of work sponsored by an agency of the United States Government. Neither the United States Government nor any agency Thereof, nor any of their employees, makes any warranty, express or implied, or assumes any legal liability or responsibility for the accuracy, completeness, or usefulness of any information, apparatus, product, or process disclosed, or represents that its use would not infringe privately owned rights. Reference herein to any specific commercial product, process, or service by trade name, trademark, manufacturer, or otherwise does not necessarily constitute or imply its endorsement, recommendation, or favoring by the United States Government or any agency thereof. The views and opinions of authors expressed herein do not necessarily state or reflect those of the United States Government or any agency thereof. 


\section{DISCLAIMER}

Portions of this document may be illegible in electronic image products. Images are produced from the best available original document. 
NUREG/CR--5164

TI88 016973

\section{A SIMPLIFIED MODEL FOR CALCULATING EARLY OFFSITE CONSEQUENCES FROM NUCLEAR REACTOR ACCIDENTS}

I.K. Madni, E.G. Cazzoli, and M. Khatib-Rahbar

Manuscript Completed - June 1988

Published - July 1988

\begin{abstract}
ACCIDENT ANALYSIS GROUP
SAFETY AND RISK EVALUATION DIVISION DEPARTMENT OF NUCLEAR ENERGY BROOKHAVEN NATIONAL LABORATORY UPTON, LONG ISLAND, NEW YORK 11973
\end{abstract}

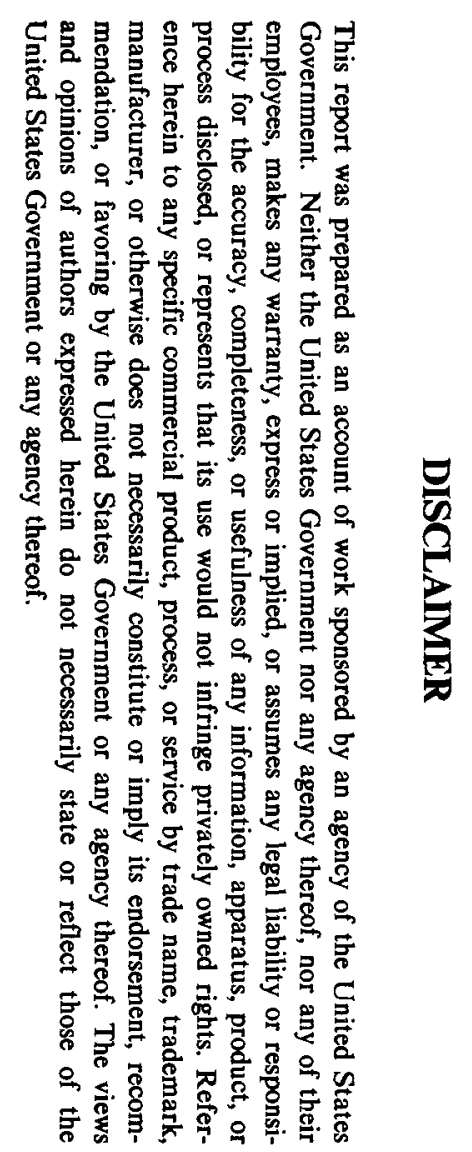

\footnotetext{
Prepared for

OFFICE OF NUCLEAR REGULATORY RESEARCH UNITED STATES NUCLEAR REGULATORY COMMISSION CONTRACT NO. DE-ACO2-76CHOOO16 FIN A-3268
} 


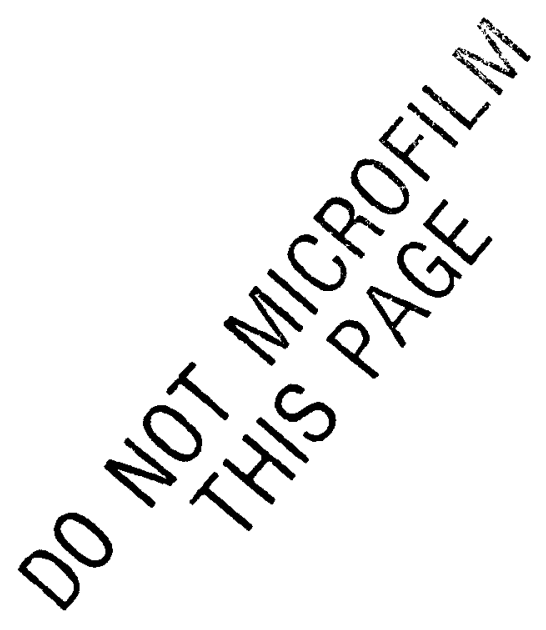

DISCLAMMER

This report was prepared as an account of work aponeored by an agency of the United States Government. Neither the United States Government nor any agency thereof, nor any of their employees, nor any of their contractors, subcontractors, or their employees, makes any warranty, exprese or implied, or asuumes any legal liability or responsibility for the accuracy, completenese, or usefulnees of any information, apparatus, product, or proceses disclosed, or represents that its use would not infinge privately owned rights. Reference herein to any epecific commercial product, process, or nervice by trade name, trademark, manufacturer, or otherwise, does not necessarily conatitute or imply its endorsement, recommendation, or favoring by the United States Government or any agency, contractor or subcontractor thereof. The views and opinions of authors expreased herein do not necessarily state or reflect those of the United States Government or any agency, contractor or subcontractor thereof.

Printed in the United States of America

Available from

National Technical Information Service

U.S. Department of Commerce

5285 Port Royal Road

Springfield, VA 22161

NTIS price codes:

Printed Copy: A09; Microfiche Copy: A01 


\section{ABSTRACT}

A personal computer-based model, SMART, has been developed that uses an integral approach for calculating early offsite consequences from nuclear reactor accidents. The solution procedure uses simplified meteorology and involves direct analytic integration of air concentration equations over time and position. This is different from the discretization approach currently used in the CRAC2 and MACCS codes. The SMART code is fast-running, thereby providing a valuable tool for sensitivity and uncertainty studies. The code was benchmarked against both MACCS version 1.4 and CRAC2. Results of benchmarking and detailed sensitivity/uncertainty analyses using SMART are presented. 


\section{ACKNOWLEDGEMENTS}

The authors gratefully acknowledge the valuable help provided by A. Tingle in the early phase of this work. The authors are also grateful to W.T. Pratt and R.A. Bari for reviewing and making many useful remarks on the manuscript, and to M. Jamgochian, J. Mulman, and S. McGuire of the U.S. Nuclear Regulatory Commission, Office of Research for their continued support.

A note of appreciation is due to L. Seymore and D. Miesell for their patience in typing the manuscript. 
TABLE OF CONTENTS

Page

ABSTRACT $\ldots \ldots \ldots \ldots \ldots \ldots \ldots \ldots \ldots \ldots \ldots \ldots \ldots \ldots \ldots \ldots \ldots \ldots \ldots \ldots \ldots \ldots \ldots \ldots \ldots$

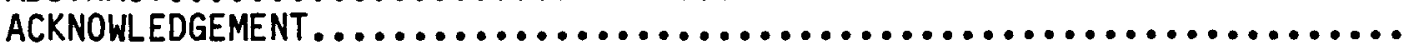

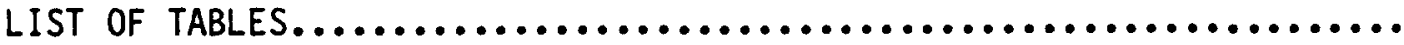

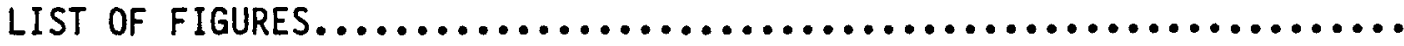

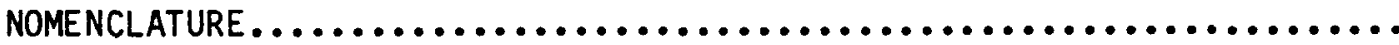

EXECUTIVE SUMMARY.

1. INTRODUCTION.................................... 1

2. MODEL DESCRIPTIONS................................ 3

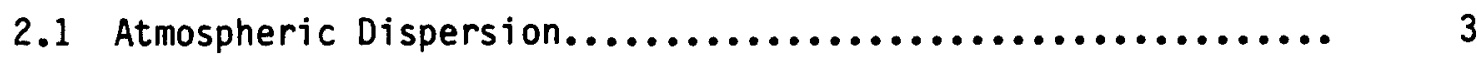

2.1.1 Diffusion Equation and Air Concentration............ 3

2.1.2 Dispersion Parameters and Weather Data.............. 5

2.2 Corrections to Air Concentration..................... 8

2.2.1 Dry Deposition............................... 8

2.2.2 Wet Deposition................................ 9

2.2.3 Radioactive Decay and Daughter Buildup............... 9

2.2.4 Building Wake Effects.......................... 11

2.2.5 Plume Rise................................. 12

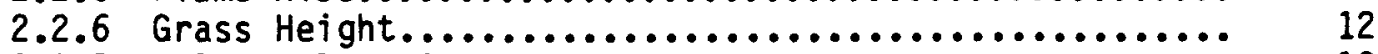

2.2.7 Release Duration............................. 13

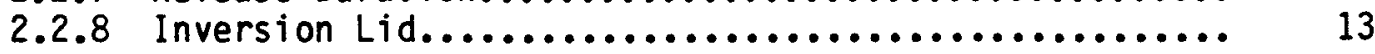

2.3 Dose Calculations................................ 13

2.3.1 Dose Pathways................................. 13

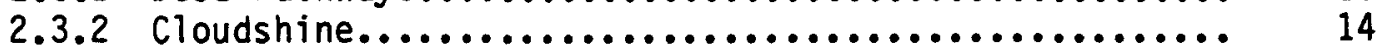

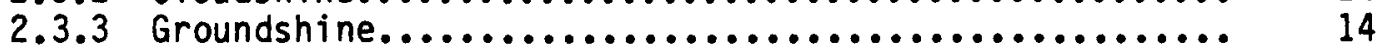

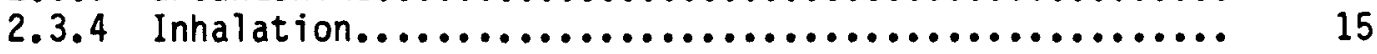

2.4 Health Effects................................. 15

3. RESULTS....................................... 17

3.1 Computing Time Requirements.......................... 17

3.2 Benchmark Comparisons with CRAC2 and MACCS ................ 17

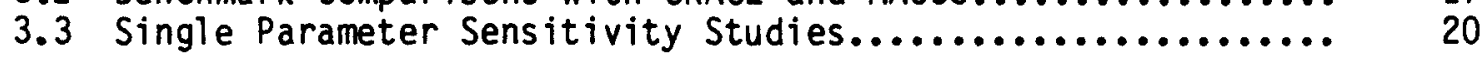

3.3.1 Sensitivity to Plume Dispersion and

Building Wake Effects........................... 20

3.3 .2 Sensitivity to Source Terms..................... 24 
TABLE OF CONTENTS

3.4 Multi-parameter Sensitivity and Uncertainty Analysis........

3.4.1 Selection of Independent Variables..................

27

3.4.2 Correlation of Output to Input Uncertainties......... 28

3.4.3 Statistical Data Reduction...................... 41

3.4 .4 Conclusions.................................. 41

4. CONCLUSIONS....................................... 48

5. REFERENCES ..................................... 49

APPENDICES

A. User's Guide....................................... A-1

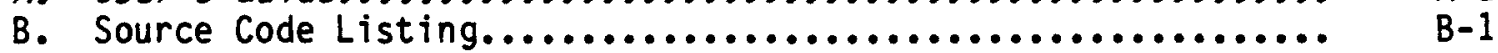

C. PWR and BWR Core Inventories......................... $\quad$ -

D. CRAC2 and MACCS Dose Conversion Factors................. D-1

E. Sample Interactive Input and Output................... E-1

F. Results for the Sensitiity Study to Source Terms: Doses and Probabilities of Early Injuries for Sampled Weather

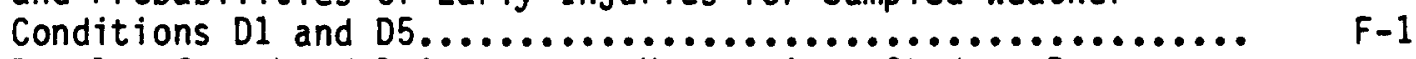

G. Results for the Multiparameter Uncertainty Study: Doses Calculated Using CRAC2 and MACCS Dose Conversion Factors..... G-1 


\section{LIST OF TABLES}

Table

Title

Page

2.1 Relation of Stability Classes to Weather Conditions.......... 7

2.2 Curve Fitting Coefficients for Stability Classes A through F... 7

3.1 Input Variables Used for Benchmarking of the Present Code with CRAC2 and MACCS.................................. 18

3.2 Dispersion Parameters as a Function of Distance Calculated by the Models.

3.3 Comparison of Early Fatality Probabilities Calculated by CRAC2 and MACCS Models: Weather Stability Class A, Wind Speed $1 \mathrm{~m} / \mathrm{s}$.. 25

3.4 Weights Used to Collapse Individual Releases to Iodine--and Cesium--Equivalent Releases............................. 25

3.5 Parameter Space for Sensitivity Analysis to Source Terms....... 25

3.6 Total Dose to Bone Marrow as a Function of Distance; Case D1.... 26

3.7 Probability of Early Death as a Function of Distance; Case D1... 26

3.8 Total Dose to Bone Marrow as a Function of Distance, Case D5.... 26

3.9 Probability of Early Death as a Function of Distance, Case D5... 26

3.10 Input Other Than Source Terms for the Full Uncertainty Analysis. 29

3.11 PRCCs for Whole Body Dose - CRAC2........................ 31

3.12 PRCCs for Probability of Early Fatality - CRAC2............. 32

3.13 PRCCs for Total Dose to Thyroid - MACCS................... 33

3.14 PRCCs for Probability of Early Injury - MACCS............... 34

3.15 PRCCs for Probability of Early Death - MACCS............... 35

3.16 Multiparameter Uncertainty Analysis: Total Bone Marrow Dose Using CRAC2 Dose Conversion Factors..................... 42

3.17 Multiparameter Uncertainty Analysis: Total Bone Marrow Dose Using MACCS Dose Conversion Factors................... 42 


\section{LIST OF TABLES}

Table

Title

Page

3.18 Multiparameter Uncertainty Analysis: Probability of Early Death Calculated by the CRAC2 Health Effect Mode1............ 42

3.19 Multiparameter Uncertainty Analysis: Probability of Early Death Calculated by the MACCS Health Effect Model.............. 42

3.20 Multiparameter Uncertainty Analys is with Larger Sample Size: Total Dose to Bone Marrow Calculated with MACCS Dose

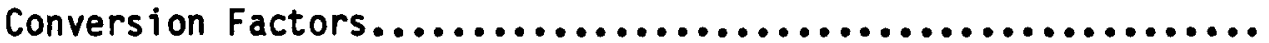

3.21 Multiparameter Uncertainty Analysis with Larger Sample Size: Probability of Early Death Calculated by the MACCS Health Effects Model.

3.22 Total Cancer Deaths Calculated by MACCS for Zion Clusters 1 and 26. 


\section{LIST OF FIGURES}

Figure

Title

Page

2.1 Horizontal dispersion coefficient, oy, vs. downwind distance from source for different atmospheric stability

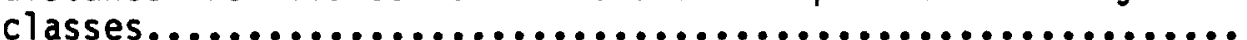

2.2 Vertical dispersion coefficient, $\sigma_{z}$, vs. downwind distance from source for different, atmospheric stability classes...... 6

3.1 Total dose to bone marrow vs. distance for weather class $A$, average wind speed $5 \mathrm{~m} / \mathrm{s} \ldots \ldots \ldots \ldots \ldots \ldots \ldots \ldots \ldots \ldots \ldots \ldots \ldots \ldots . . \ldots \ldots$

3.2 Total dose to bone marrow vs. distance for weather class $D$, average wind speed $5 \mathrm{~m} / \mathrm{s} \ldots \ldots \ldots \ldots \ldots \ldots \ldots \ldots \ldots \ldots \ldots \ldots \ldots$

3.3 Total dose to bone marrow vs. distance for weather class $F$, average wind speed $1 \mathrm{~m} / \mathrm{s} . \ldots \ldots \ldots \ldots \ldots \ldots \ldots \ldots \ldots \ldots . . \ldots \ldots \ldots$

3.4 Total dose to bone marrow vs. distance for various dispersion parameter formulations, using CRAC2 dose conversion factors: weather 05

3.5 Total dose to bone marrow vs. distance for various dispersion parameter formulations, using MACCS dose conversion factors: weather D5.

3.6 Total dose to bone marrow vs. iodine-equivalent release CRAC2 results at 1 mile...............................

3.7 Total dose to bone marrow vs. Cs-equivalent release - CRAC2 results at 1 mile......................................

3.8 Total dose to bone marrow vs. I 2 release - CRAC2 results at 1 mile........................................

3.9 Total dose to bone marrow vs. $C_{s}$ release - CRAC2 results at 1 mile...........................................

3.10 Total dose to bone marrow vs. dispersion models - CRAC2 results at 1 mile..................................... 38

3.11 Total dose to bone marrow vs. weather stability class CRAC2 results at $1 \mathrm{mile} .0 .000000000000000000000000$

3.12 Total lung dose vs. dry deposition velocity - CRAC2 results at 1 mile. 


\section{LIST OF FIGURES}

Figure

Title

Page

3.13 Probability of early fatality vs. dispersion model - MACCS results at 0.5 mile...................................

3.14 Probability of early fatality vs. weather stability class MACCS results at 0.5 mi le........................... 40

3.15 Probability of early fatalities vs. dispersion model - MACCS results at 5 miles...................................... 40

3.16 Comparison between CRAC2 and MACCS calculations - probability of early fatality vs. distance.

3.17 Probability of early fatality vs. distance - MACCS calculations for LHS sample sizes of 100 and $300 \ldots \ldots \ldots \ldots \ldots . . .44$

3.18 Uncertainties in total dose to bone marrow at 2 miles calculated by SMART code.............................. 46

3.19 Uncertainties in probability of early death at 2 miles calculated by SMART code. 
NOMENCLATURE

\begin{tabular}{|c|c|c|}
\hline Symbol & Description & Unit \\
\hline $\bar{A}$ & building cross-sectional area & $m^{2}$ \\
\hline $\mathrm{Br}$ & breathing rate of receptor & $\mathrm{m}^{3} / \mathrm{s}$ \\
\hline$c$ & shape factor & --- \\
\hline$D_{C}$ & cloudshine dose & rem \\
\hline $\mathrm{D}_{\mathrm{g}}$ & groundshine dose & rem \\
\hline $\mathrm{D}_{i}^{0}$ & total inhalation dose & rem \\
\hline$f_{d}$ & $\begin{array}{l}\text { correction factor to air concentration } \\
\text { due to dry deposition }\end{array}$ & --- \\
\hline$f_{W}$ & $\begin{array}{l}\text { correction factor to air concentration } \\
\text { due to wet deposition }\end{array}$ & -- \\
\hline$F_{C \infty}$ & cloud-dose conversion factor & rem-m $m^{3} / C i-s$ \\
\hline $\mathrm{Fg}$ & integral ground-dose conversion factor & rem $-m^{2} / C i$ \\
\hline$F_{\text {in }}$ & inhalation dose conversion factor & $\mathrm{rem} / \mathrm{Ci}$ \\
\hline $\mathrm{h}$ & height of release & $\mathbf{m}$ \\
\hline$k_{x}, K_{y}, K_{z}$ & $\begin{array}{l}\text { diffusivities in the } x, y \text {, and } z \text { direction, } \\
\text { respectively }\end{array}$ & $\mathrm{m}^{2} / \mathrm{s}$ \\
\hline Q & time-integrated source strength & $\mathrm{Ci}$ \\
\hline$Q^{\circ}$ & radionuclide inventory in core & $\mathrm{Ci}$ \\
\hline$Q^{\prime}$ & release rate of radionuclides from source & $\mathrm{Ci} / \mathrm{s}$ \\
\hline $\mathrm{R}$ & rainfall rate & $\mathrm{mm} / \mathrm{hr}$ \\
\hline$t$ & time & $\mathbf{s}$ \\
\hline $\bar{u}$ & mean wind speed in the $x$-direction & $\mathrm{m} / \mathrm{s}$ \\
\hline$v_{d}$ & dry deposition velocity & $\mathrm{m} / \mathrm{s}$ \\
\hline$v_{W}$ & equivalent wet deposition velocity & $\mathrm{m} / \mathrm{s}$ \\
\hline$x$ & horizontal coordinate along the wind & m \\
\hline y & horizontal cross-wind coordinate & m \\
\hline$z$ & vertical coordinate & $\mathrm{m}$ \\
\hline $\bar{z}$ & effective height of the plume & m \\
\hline$\Delta t$ & duration of rain & $\mathbf{s}$ \\
\hline$\lambda$ & radioactive decay rate & $s^{-1}$ \\
\hline$\Lambda$ & $\begin{array}{l}\text { fractional rate of material removed. } \\
\text { due to rain }\end{array}$ & $s^{-1}$ \\
\hline$\sigma_{y}$ & horizontal dispersion coefficient & $\mathrm{m}$ \\
\hline$\sigma_{Z}$ & vertical dispersion coefficient & m \\
\hline$x^{2}, x_{T}$ & $\begin{array}{l}\text { time integrated air concentration of a } \\
\text { radionuclide }\end{array}$ & $\mathrm{Ci}-\mathrm{s} / \mathrm{m}^{3}$ \\
\hline$x_{D}$ & $\begin{array}{l}\text { total ground concentration of a } \\
\text { radionuclide }\end{array}$ & $\mathrm{Ci} / \mathrm{m}^{2}$ \\
\hline$\frac{\text { Subscript }}{D}$ & $\frac{\text { Description }}{\text { related to daughter product }}$ & \\
\hline$I, j$ & related to radionuclide I & \\
\hline p & related to parent & \\
\hline
\end{tabular}




\section{EXECUTIVE SUMMARY}

The Reactor Safety Study (RSS) presented the first comprehensive assessment of the risk from core meltdown accidents at two nuclear power plants. The CRAC model was developed as part of the RSS to calculate the health and economic consequences of accidental releases of radionuclides into the environment. Following the publication of the RSS, several other consequence models were developed. CRAC2, an improvement over CRAC, became available in 1982. In addition, the CRACIT computer code was developed by Pickard, Lowe, and Garrick (PLG) and first used in the Zion and Indian Point PRAs. This was followed by the development of the MELCOR Accident Consequence Code System (MACCS).

CRAC2 and MACCS are currently used to calculate severe accident risk by the U.S. Nuclear Regulatory Commission and their contractors. However, uncertainties in estimated consequences are large and were not quantified as part of the recently published Draft Reactor Risk Reference Document (NUREG-1150). Due to major differences in the predictions of these detailed and complex computer models, a need exists for an independent capability to address modeling and health consequence assumptions embodied in the various models. This verification tool should be efficient and sufficiently accurate to carry out sensitivity and uncertainty analyses.

This report presents a Personal Computer-based model that uses an integral approach for calculating early off-site consequences resulting from nuclear power plant accidents. The computing time requirements for a typical calculation on a mainframe computer using this model are two orders of magnitude lower than those of CRAC2 and MACCS codes, thus providing a valuable tool for sensitivity and uncertainty studies. The model predicts time-integrated air concentration of each radionuclide at any location from release as a function of timeintegrated source strength using the Gaussian plume model. The concentration can be calculated at the centeriine of a Gaussian profile or, optionally, as an average over the cross-section based on a top-hat distribution. The solution procedure involves direct analytic integration of air concentration equations over time and position. This is different from the discretization approach currently used in CRAC2 and MACCS codes.

The present model uses simplified meteorology. Dispersion parameters are calculated from exponential fits to the Pasquill-Gifford curves for six atmospheric stability classes designated $A$ to $F$, and from an approximation as indicated in Regulatory Guide 1.145 for the seventh stability class G (extremely stable).

Following the approach in CRAC2 and MACCS, special features are modeled which effectively modify the basic Gaussian plume formulation. They include dry and wet deposition, radioactive decay and daughter buildup, reactor building wake effects on plume mixing, the inversion lid effect, the effect of plume rise due to buoyancy or momentum of the released activity, release duration, and grass height. The building wake correction to the dispersion parameters is derived from Slade. Also included are options for CRAC2 and MACCS building wake effects in order to facilitate sensitivity and uncertainty studies. 
Once the air and ground concentrations of the radionuclide are estimated, the early dose to an individual is calculated via three pathways: cloudshine, short-term groundshine, and inhalation. The dose calculations are performed in the same manner as CRAC2 and MACCS depending on which health effects model is chosen as the input option. The health effects models in both CRAC2 and MACCS are included in the code for calculating early fatalities. The health effects model in MACCS for early injuries is also included. This Simplified Model for calculating Atmospheric Radionuclide Iransport and Health Effects is câlled the SMART code.

The present code was benchmarked against both MACCS version 1.4 and CRAC2. A sensitivity study to plume dispersion parameters was performed, showing that the models included in the codes can produce a fairly large uncertainty in calculated doses up to two mi les from the release point. A sensitivity study to source terms which covered almost the entire spectrum of accident release for a BWR showed that uncertainties in dose calculations span about one order of magnitude, and increase to two or three orders of magnitude in the calculation of health effects. A multi-parameter sensitivity analysis revealed that the uncertainty in all results is dominated by the choice of weather conditions, dry deposition velocity, and to a lesser degree by radionuclide releases. The uncertainty introduced by the calculation of dispersion parameters, however, can still be significant in the calculation of health effects at large distances from the release point. 


\section{INTRODUCTION}

A severe accident in a nuclear power plant could release radionuclides in the form of noble gases, halogens, and aerosols to the containment. A breach of containment would then allow a fraction of these radionuclides to escape into the environment. The Reactor Safety Study (RSS) presented the first comprehensive assessment of the risk to society from nuclear power plant accidents. The CRAC model was developed as part of the RSS to calculate the health and economic consequences of accidental releases of radionuclides into the atmosphere [1]. Following publication of the RSS, several other consequence models were devel-

oped [2]. CRAC2, an improvement over CRAC, became available in 1982 [3]. In addition, CRACIT was developed by Pickard, Lowe, and Garrick (PLG) and first used in the Zion and Indian Point PRAs. This was followed by the development of the MELCOR Accident Consequence Code System (MACCS) [4].

CRAC2 and MACCS are used as the basis for severe accident risk assessments by the U.S. Nuclear Regulatory Commission. However, uncertainties in estimated consequences are large and were not quantified as part of the recently published Draft Reactor Risk Reference Document [5]. Due to major differences in the predictions of these detailed and complex computer models, a need exists for an independent capability to address modeling and health consequence assumptions embodied in the various models. This verification tool should be efficient and sufficiently accurate in order to carry out sensitivity and uncertainty analyses.

This report presents a Personal Computer-based model that uses an integral approach for calculation of early off-site consequences resulting from nuclear power plant accidents. The computing time requirements for a typical calculation on a mainframe computer using this model are two orders of magnitude lower than those of CRAC2 and MACCS codes, thus providing a valuable tool for sensitivity and uncertainty studies. The model predicts time-integrated air concentration of each radionuclide at any location from release as a function of timeintegrated source strength using the Gaussian plume model [6]. The concentration can be calculated at the centerline of a Gaussian profile or, optionally, as an average over the cross-section based on a top-hat distribution. The solution procedure involves direct analytic integration of air concentration equations over time and position. This is different from the discretization approach currently used in CRAC2 and MACCS codes.

The present model uses simplified meteorology. Dispersion parameters are calculated from exponential fits to the Pasquill-Gifford curves for six atmospheric stability classes designated $A$ to $F$, and from an approximation as indicated in Regulatory Guide 1.145 for the seventh stability class G (extremely stable).

Following the approach in CRAC2 and MACCS, special features are modeled which effectively modify the basic Gaussian plume formulation. They include dry and wet deposition, radioactive decay and daughter buildup, reactor building wake effects on plume mixing, the inversion lid effect, the effect of plume rise due to buoyancy or momentum of the released activity, release duration, and grass height. The building wake correction to the dispersion parameters is derived from Reference [6]. Also included are options for CRAC2 and MACCS building wake effects in order to facilitate sensitivity and uncertainty studies. 
Once the air and ground concentrations of the radionuclide are estimated, the early dose to an individual is calculated via three pathways: cloudshine, short-term groundshine, and inhalation. The dose calculations are performed in the same manner as CRAC2 and MACCS depending on which health effects model is chosen as the input option. The health effects models in both CRAC2 and MACCS are included in the code for calculation of early fatalities. The health effects model in MACCS for early injuries is also included. This Simplified Model for calculating Atmospheric Radionuclide Transport and health effects is called the SMART code.

Detailed descriptions of models used in this study are provided in Chapter 2. Results of various calculations and comparisons with results from CRAC2 and MACCS calculations are presented in Chapter 3. Chapter 4 lists a summary of the conclusions from this study. In addition, several appendices are included in this report that provide a user's guide along with sample input and output data, subroutine flowcharts, data dictionary, a listing of the source code, and the nuclide data base, dose conversion factors, and other related information. 


\section{DESCRIPTION OF MODELS}

This chapter provides a detailed description of the models used in this study, including a derivation of the basic Gaussian plume model and its various modifications, dose calculations, and health effects.

\subsection{Atmospheric Dispersion}

A severe accident in a nuclear power plant could release radionuclides in the form of noble gases, halogens, and aerosols to the containment atmosphere. A breach of containment would then allow a fraction of these radionuclides to escape into the environment where it would undergo atmospheric dispersion.

An assessment of the impact of such releases to the general public requires the calculation of atmospheric and ground concentrations of each radionuclide at various distances from the reactor, where public exposure may occur. The air concentrations depend on wind speed and atmospheric turbulence. The latter is difficult to measure directly and is conveniently related to measurable meteorological quantities, such as temperature gradients, or Richardson number.

\subsubsection{Diffusion Equation and Air Concentration}

When released into the atmosphere, radioactive gases and aerosols will follow prevailing winds and be diffused due to cumulative effects of atmospheric turbulence. Predictions of dispersion in the lower atmosphere are most commonly made from the semi-empirical 'Gaussian plume' model [6]. This model is used widely for analyzing the dispersion of atmospheric pollutants, due to its economy of computing time, simplified input requirements, and reasonable agreement with experimental data over flat terrain. For repetitive calculations, and for sensitivity studies, the use of this model is therefore justified.

In this model, the governing equations are derived by starting with the classical Fick's law diffusion equations. These equations are solved assuming that the coefficients of diffusivity are constants. In the resulting expressions, the diffusivity coefficients are then allowed to become dependent on both space and atmospheric stability conditions in order to fit the plume model to experimental data. For an ideal, non-isotropic, infinite atmosphere, the diffusion equation in cartesian coordinates is:

$$
\frac{D x}{D t}=K_{x} \frac{\partial^{2} x}{\partial x^{2}}+K_{y} \frac{\partial^{2} x}{\partial y^{2}}+K_{z} \frac{\partial^{2} x}{\partial z^{2}}
$$

where $\frac{D}{D t}$ is the particle derivative operator, and $x$ is the concentration $\left(\mathrm{Ci} / \mathrm{m}^{3}\right)$ of a particular radionuclide.

With an average wind speed $\bar{u}$ in the $x$-direction, eq. (2.1) is modified to

$$
\frac{\partial x}{\partial t}+\bar{u} \frac{\partial x}{\partial x}=K_{x} \frac{\partial^{2} x}{\partial x^{2}}+K_{y} \frac{\partial^{2} x}{\partial y^{2}}+K_{z} \frac{\partial^{2} x}{\partial z^{2}}
$$


where $y$ is horizontally cross-wind, and $z$ is the vertical direction.

If we consider the concentration as being due to a point source emitting contaminant at a constant rate of $Q^{\prime} \mathrm{Ci} / \mathrm{s}$, then, $\mathrm{ax} / \mathrm{at}=0$. Furthermore, diffusion in the direction of the wind is neglected, or $K_{x}=0$. The above equation then reduces to

$$
\bar{u} \frac{\partial x}{\partial x}=k_{y} \frac{\partial^{2} x}{\partial y^{2}}+k_{z} \frac{\partial^{2} x}{\partial z^{2}}
$$

with boundary conditions corresponding to the source term at the release point, and $\frac{\partial x}{\partial y}=\frac{\partial x}{\partial z}=0$ (from symmetry) at the plume centerline.

The solution of this equation is [9]

$$
x=\frac{Q^{\prime}}{2 \pi \bar{u} \sigma_{y} \sigma_{z}} \exp \left[-\left(\frac{y^{2}}{2 \sigma_{y}^{2}}+\frac{z^{2}}{2 \sigma_{z}^{2}}\right)\right]
$$

where $\sigma_{y}, \sigma_{z}$ are, respectively, the horizontal and vertical dispersion coefficients, given by

$$
\sigma_{y}=\sqrt{\frac{2 x K_{y}}{u}} ; \sigma_{z}=\sqrt{\frac{2 x K_{z}}{u}} \text {. }
$$

Postulated releases from reactor accidents would be at some altitude $h$ above ground level, hence the earth's surface would be a barrier to downward diffusion and expansion of the plume. A conservative estimate of this effect can be made by assuming the ground to be a perfect reflector of the contaminants. An image source is placed at an altitude of $-h$, and the solution is obtained as

$$
x=\frac{Q^{\prime}}{2 \pi \bar{u} \sigma_{y} \sigma_{z}} \exp \left[-y^{2} / 2 \sigma_{y}{ }^{2}\right]\left\{\exp \left[-\frac{(z+h)^{2}}{2 \sigma_{z}{ }^{2}}\right]+\exp \left[-\frac{\left(z-h^{2}\right)}{2 \sigma_{z}{ }^{2}}\right]\right\} .
$$

The concentration at $z=0$, i.e., the receptor or observer is at ground level, is

$$
x=\frac{Q^{\prime}}{\pi \bar{u} \sigma_{y} \sigma} \exp \left[-\left(\frac{y^{2}}{2 \sigma_{y}{ }^{2}}+\frac{h^{2}}{2 \sigma_{z}^{2}}\right)\right] .
$$

For a release of finite duration, $\tau$, the time-integrated source strength, $Q$ (Ci), is given by:

$$
Q=\int_{0}^{\tau} Q^{\prime} d t
$$

and the time integrated (total, cumulative) concentration, $x_{T}\left(\mathrm{C} i-s / \mathrm{m}^{3}\right)$, is similarly defined as:

$$
x_{T}=\int_{0}^{T} x d t
$$


Eq. (2.7) then becomes

$$
X_{T}=\frac{Q}{\pi \bar{u} \sigma_{y} \sigma_{z}} \exp \left[-\left(\frac{y^{2}}{2 \sigma_{y}{ }^{2}}+\frac{h^{2}}{2 \sigma_{z}{ }^{2}}\right)\right] \text {. }
$$

In Eqs. (2.7) and (2.10), note that a ground-level release $(h=0)$ gives a conservative estimate of concentration, and hence should be used if the height of release is not known. In all subsequent sections of this report, $x$ instead of $x_{T}$ will be used to denote time integrated air concentration.

\subsubsection{Dispersion Parameters and Weather Data}

The dispersion parameters, $\sigma_{y}$ and $\sigma_{z}$, given by Eq. (2.5) are functions of constant diffusivities $k_{y}$ and $k_{z}$, respectively, and would, therefore, vary as $x$ from the point of release for a given wind speed. However, these dispersion parameters are found to depend also on the atmospheric stability conditions. A more realistic model of dispersion would, therefore, use experimental values of $\sigma_{y}$ and $\sigma_{z}$ to calculate radionuclide concentrations.

Pasquill [8] proposed a simple scheme in which he presented information on lateral and vertical spreading of a plume as functions of six atmospheric stability classes designated $A$ to $F$ (see Table 2.1). Table 2.1 also includes stability classifications as defined by NRC Reg. Guide 1.23. Gifford [6] converted the plume spreading data into families of curves of the standard deviations, $\sigma_{y}$ and $\sigma_{z}$, of the plume concentration distribution. These curves are frequently called the Pasquill-Gifford (P-G) curves (see Figures 2.1 and 2.2).

It can be seen from the figures that the dispersion parameters are increasing functions of $x$. The influence of atmospheric stability on $\sigma_{y}$ is shown to be minimal. However, $\sigma_{z}$ increases very rapidly with distance for unstable atmospheres and much less rapidly for stable atmospheres. For the present study, these curves were fitted by the following exponential expressions:

$$
\begin{aligned}
& \sigma_{y}(x)=\exp \left[s y_{0}+s y_{1} \ln (x)+s y_{2} \ln (x)^{2}\right] \\
& \sigma_{z}(x)=\exp \left[s z_{0}+s z_{1} \ln (x)+s z_{2} \ln (x)^{2}\right] .
\end{aligned}
$$

The coefficients in these curve-fit equations are listed in Table 2.2. The seventh stability condition, type $G$, (extremely stable) has been approximated by the following relations [9], and are in accordance with Reg. Guide 1.145.

$$
\begin{aligned}
& \sigma_{z}(G)=3 / 5 \sigma_{z}(F) \\
& \sigma_{y}(G)=2 / 3 \sigma_{y}(F) .
\end{aligned}
$$




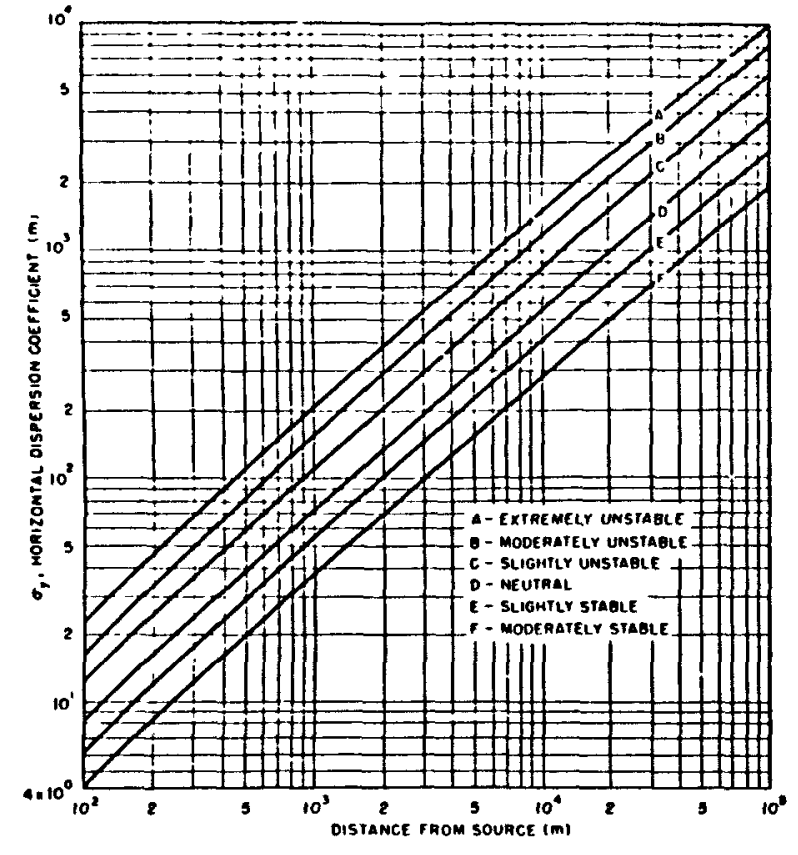

Figure 2.1. Horizontal dispersion coefficlent, $\sigma_{y}$, vs. downwind distance from source for different atmospheric stability classes [6].

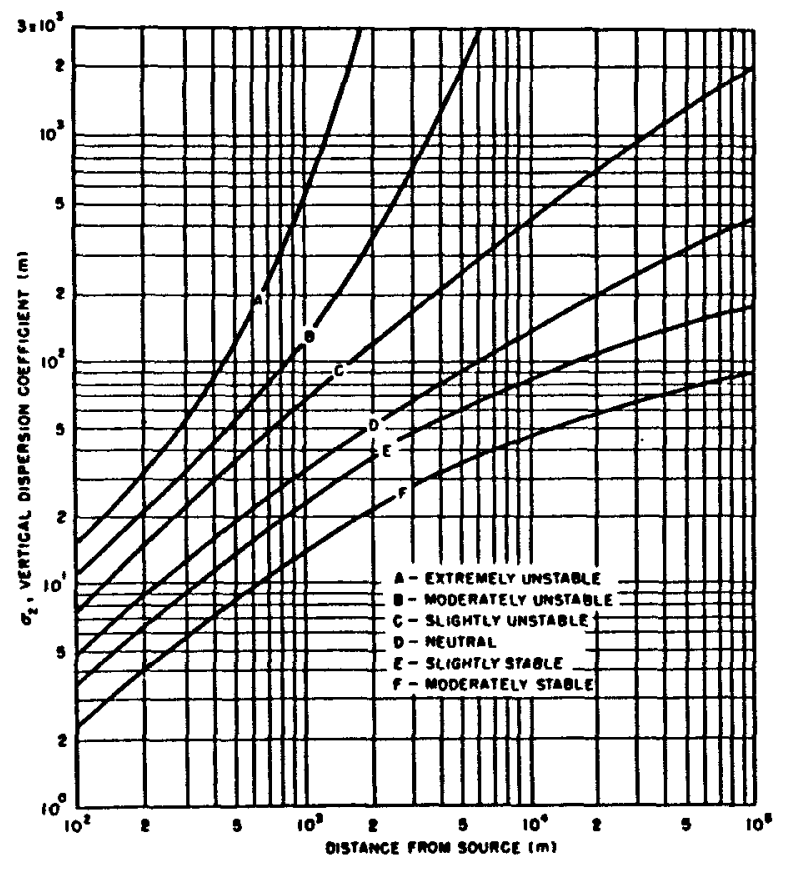

í
Figure 2.2. Vertical dispersion coefficient, va. downind distance from source for different atmospheric stability classes [6]. 
Table 2.1 Relation of Stability Classes To Weather Conditions

\begin{tabular}{|c|c|c|c|c|c|c|c|}
\hline $\begin{array}{c}\text { Stability } \\
\text { Class }\end{array}$ & $\bar{A}$ & $\bar{B}$ & $\bar{c}$ & $D$ & $\bar{E}$ & $F$ & G \\
\hline$\frac{\Delta T}{\Delta z}\left({ }^{\circ} \mathrm{C} / 100 \mathrm{~m}\right)$ & $\leq 1.9$ & $\begin{array}{l}-1.9 \\
-10.7\end{array}$ & $\begin{array}{l}-1.7 \\
-1.05\end{array}$ & $\begin{array}{l}-1.5 \\
-60.5\end{array}$ & $\begin{array}{l}0.5 \\
10.5\end{array}$ & $\begin{array}{l}1.5 \\
4.0\end{array}$ & $>4.0$ \\
\hline
\end{tabular}

\begin{tabular}{|c|c|c|c|c|c|}
\hline \multirow{3}{*}{$\begin{array}{l}\text { Surface wind } \\
\text { speed, } \mathrm{m} / \mathrm{sec}\end{array}$} & \multirow{2}{*}{\multicolumn{3}{|c|}{ Daytime Insolation }} & \multicolumn{2}{|c|}{ Nighttime Conditions } \\
\hline & & & & \multirow{2}{*}{$\begin{array}{c}\text { Thin overcast } \\
\text { or }>4 / 8 \\
\text { cloudiness }\end{array}$} & \multirow{2}{*}{ cioudiness } \\
\hline & Strong & Moderate & slight & & \\
\hline $\begin{array}{r}<2 \\
2 \\
4 \\
6 \\
>6\end{array}$ & $\begin{array}{l}A \\
A-B \\
B \\
C \\
C\end{array}$ & $\begin{array}{l}A-B \\
B \\
B-C \\
C-D \\
D\end{array}$ & $\begin{array}{l}B \\
C \\
C \\
D \\
D\end{array}$ & $\begin{array}{l}E \\
D \\
D \\
D\end{array}$ & $\begin{array}{l}F \\
E \\
D \\
D\end{array}$ \\
\hline
\end{tabular}

*Applicabie to heavy overcast, day or night.

$\star \star T h e$ degree of cloudiness is defined as that fraction of the sky above

the local apparent horizon wich is covered by clouds.
A-Extremely unstable
B-Moderately unstable
D-Neutral*
G-Extremely stable
C-Slightly unstable
E-Slightly stable
F-Moderately stable

Table 2.2 Curve Fitting Coeffictents for Atmosphertc Stability Classes A through F

\begin{tabular}{|l|r|r|r|}
\hline \multicolumn{1}{|c|}{ Stability Class } & \multicolumn{1}{c|}{$s y_{0}$} & $s y_{1}$ & \multicolumn{1}{c|}{$s y_{2}$} \\
\hline F (moderately stable) & -3.559 & 1.160 & $-1.719 \times 10^{-2}$ \\
E (slightly stable) & -2.817 & 1.066 & $-1.147 \times 10^{-2}$ \\
D (neutral) & -2.546 & 1.077 & $-1.252 \times 10^{-2}$ \\
C (slightly unstable) & -1.969 & 1.022 & $-8.377 \times 10^{-3}$ \\
B (moderately unstable) & -1.961 & 1.111 & $-1.405 \times 10^{-2}$ \\
A (extremely unstable) & -1.790 & 1.151 & $-1.733 \times 10^{-2}$ \\
\hline Stability class & $s z_{0}$ & $s z_{1}$ & $s 2_{2}$ \\
\hline F (moderately stable) & -4.539 & 1.412 & $-5.45 \times 10^{-2}$ \\
E (slightly stable) & -4.213 & 1.443 & $-5.471 \times 10^{-2}$ \\
D (neutral) & -3.162 & 1.197 & $-3.459 \times 10^{-2}$ \\
C (slightly unstable) & -2.981 & 1.212 & $-2.538 \times 10^{-2}$ \\
B (moderately unstable) & 2.693 & -0.781 & 0.158 \\
A (extremely unstable) & 9.430 & -3.393 & 0.425 \\
\hline
\end{tabular}


The P-G curves of Figures 2.1 and 2.2 were also fitted by Martin and Tikvart. These curve-fits have been used by the consequence code CRAC2 [3]. Several other investigators have also proposed parametrizations of $\sigma_{y}$ and $\sigma_{z}$ to match the measured data of plume dispersion. Most of these have been reviewed by Gifford [10]. The work of Rogers and Gamertsfelder has also been referred to by Wilson et al. [11].

\subsection{Corrections to Air Concentration}

The basic Gaussian plume model is modified to take into account dry and wet deposition, radioactive decay and daughter buildup, reactor building wake effects on plume mixing, the inversion lid effect, plume rise due to buoyancy, release duration, and grass height. These modifications are based on approaches available in the literature, and are similar in approach to CRAC2 and MACCS models.

\subsubsection{Dry Deposition}

The processes of deposition are very complex, and thus approximations are the most desirable approach for consequence models.

The standard way of dealing with dry deposition is to assume that, if $x(x, y, 0)$ is the ground-level time-integrated concentration in $\mathrm{Ci}-\mathrm{s} / \mathrm{m}^{3}$, the total activity deposited by the passing cloud $\left(\mathrm{Ci} / \mathrm{m}^{2}\right)$ is given by

$$
x_{D}(x, y)=v_{d} x(x, y, 0)
$$

where $v_{d}$ is a proportionality constant, called the 'deposition velocity' $(\mathrm{m} / \mathrm{s})$. Deposition can occur by gravitational settling, turbulent and molecular diffusion, and inertial impaction [12], and depends on several factors, including the size and shape of particles, their chemical properties, ground roughness, nature of vegetation, and atmospheric stability. Values of $v_{d}$ can range from $10^{-6}$ to $0.2 \mathrm{~m} / \mathrm{s}$ [13]. For release from reactor accidents, $v_{d}$ can be expected to be in the range 0.001 to $0.1 \mathrm{~m} / \mathrm{s}$ [14]. The value of $0.01 \mathrm{~m} / \mathrm{s}$ was chosen for use in the Reactor Safety Study. In the SMART code, it is left as a user input value for each radionuclide, including gases, defaulting to 0.01 $\mathrm{m} / \mathrm{s}$. Deposition velocities for the noble gases are taken to be zero.

At significant distances downwind, the equation for air concentration must be modified to account for the loss of the deposited contaminants. This effect can be incorporated by multiplying the source terms for $x$ by [9]:

$$
f_{d}=\exp \left(\frac{-v_{d} x}{\bar{u} \bar{z}}\right)
$$

where $\bar{z}$ is the effective height of the plume given by

$$
\bar{z}=\checkmark \frac{\pi}{2} \sigma_{z} \exp \left(\frac{h^{2}}{2 \sigma_{z}{ }^{2}}\right)
$$




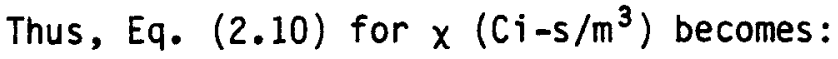

$$
x=\frac{Q}{\pi \bar{u} \sigma_{y} \sigma_{z}} \exp \left[-\left(\frac{v_{d} x}{\bar{u} \bar{z}}+\frac{y^{2}}{2 \sigma_{y}{ }^{2}}+\frac{h^{2}}{2 \sigma_{z}{ }^{2}}\right)\right]
$$

\subsubsection{Wet Deposition}

The potential for rain during atmospheric transport of the plume must also be considered. The radioactive particles (and gases) will be deposited due to rain onto the ground, by a process called washout or wet deposition. A number of techniques have been suggested in the literature. The approach used here is the one discussed in RSS Appendix 6 [14] and in Reference [15]. The fractional rate of material removed from the piume, $\Lambda\left(s^{-1}\right)$, is expressed empirically [16] in the form:

$$
\Lambda=C R
$$

where $R$ is the rainfall rate $(\mathrm{mm} / \mathrm{hr})$, and $\mathrm{C}$ is the proportionality constant. For stable and neutral atmospheric conditions $C$ is set to $10^{-4} \mathrm{hr} / \mathrm{mm}-\mathrm{s}$ while for unstable conditions $C$ is set to $10^{-3} \mathrm{hr} / \mathrm{mm}-\mathrm{s}$ [17]. $\Lambda$ can vary from $10^{-5}$ to $10^{-2} \mathrm{~s}^{-1}$. This effect is incorporated into the SMART model via a correction factor for the air concentration

$$
f_{W}=\exp [-\Lambda \Delta t]
$$

where $\Delta t=t-t_{0}$ is the duration of rain from its onset time, $t_{0}$.

Combining both dry and wet deposition, Eq. (2.10) becomes

$$
x=\frac{Q}{\pi \bar{u} \sigma_{y} \sigma_{z}} \exp \left[-\left(\frac{v_{d} x}{\bar{u} \bar{z}}+\Lambda \Delta t+\frac{y^{2}}{2 \sigma_{y}{ }^{2}}+\frac{h^{2}}{2 \sigma_{z}{ }^{2}}\right)\right] \text {. }
$$

The total activity deposited on the ground due to both dry and wet deposition $\left(\mathrm{Ci} / \mathrm{m}^{2}\right)$ can be calculated from:

$$
x_{D}=\left(v_{d}+v_{w}\right) x
$$

where $v_{w}$ is an equivalent 'wet' deposition velocity given by

$$
v_{w}=\frac{\Delta \Delta t \bar{u} \bar{z}}{x}
$$

\subsubsection{Radioactive Decay and Daughter Buildup}

Let $Q_{i}^{\circ}$ represent the inventory of radionuclide $I$ in the core at the time of reactor actident. Following an accident in which release of radionuclides to containment takes place, the source of radionuclide $I$ in containment available for release to the environment is

$$
F_{I}^{0}=f_{I} Q_{I}^{0}
$$


This source undergoes radioactive decay according to:

$$
-\frac{d F_{I}}{d t}=\lambda_{I} F_{I} \text {. }
$$

This equation has a solution of the form

$$
F_{I}(t)=F_{I}^{\circ} e^{-\lambda_{I} t}
$$

Thus, the source leaking into the environment following containment failure at $t=t_{c}$ will be

$$
Q_{I}=f_{I} Q_{I}^{\circ} e^{-\lambda_{I} t} c
$$

At any distance $x$ downwind of the plume release, the strength of nuclide I will be

$$
Q_{I}=f_{I} Q_{I}^{\circ} e^{-\lambda_{I}\left(t_{c}+x / \bar{u}\right)}
$$

If the decay of a radionuclide (parent) leads to the buildup of a daughter product $D$, the source of the daughter in containment available for release to the environment, is

$$
F_{D}=f_{D} Q_{D}^{\circ}
$$

where $Q_{D}^{\circ}$ is the inventory of $D$ in the core. This source undergoes radioactive decay, and buildup from the decay of its parent $P$ according to

$$
\frac{d F_{D}}{d t}=\lambda_{P} F_{p}-\lambda_{D} F_{D}
$$

whose solution is

$$
F_{D}(t)=F_{D}^{0} e^{-\lambda_{D} t}+\frac{\lambda_{P} F_{P}^{0}}{\lambda_{P}-\lambda_{D}}\left[e^{-\lambda_{D} t}-e^{-\lambda_{P} t}\right] \text {. }
$$

At the time of containment failure, the source of daughter nuclide into the environment will be

$$
Q_{D}=f_{D} Q_{D}^{0} e^{-\lambda_{D} t} c+\frac{\lambda_{p} f_{p} Q_{p}^{0}}{\lambda_{p}-\lambda_{D}}\left[e^{-\lambda_{D} t} c-e^{-\lambda_{p} t} c\right] .
$$

At any distance $x$ downwind of the plume release, the strength of the daughter nuclide $D$ will be determined by 


$$
\begin{aligned}
Q_{D}= & f_{D} Q_{D}^{0} e^{-\lambda_{D}\left(t_{c}+x / u\right)}+\frac{\lambda_{p} f_{p} Q_{p}^{0}}{\lambda_{p}-\lambda_{D}}\left[e^{-\lambda_{D}\left(t_{c}+x / u\right)}-e^{-\lambda_{p}\left(t_{c}+x / u\right)}\right] \\
& +\frac{f_{p} Q_{p}^{0} e^{-\lambda_{p} t_{c}}}{\lambda_{p}-\lambda_{D}}\left[e^{-\lambda_{D} x / u}-e^{-\lambda_{p} x / u}\right] .
\end{aligned}
$$

The first two terms in Eq. (2.31) are the source at $x$ from decay of initial daughter release into the environment, and the last term is the additional source at $x$ due to parent decay during plume travel.

Eq. (2.20) is modified to account for this effect and becomes

$$
x=\frac{Q(x)}{\pi \bar{u} \sigma_{y} \sigma_{z}} \exp \left[-\left(\frac{V_{d} x}{\bar{u} \bar{z}}+\Lambda \Delta t+\frac{y^{2}}{2 \sigma_{y}{ }^{2}}+\frac{h^{2}}{2 \sigma_{z}{ }^{2}}\right)\right]
$$

where $Q(x)$ is given by Eq. (2.26) for any nuclide, including parent, and by Eq. (2.31) for a daughter product. Equation (2.32) is solved directly for $x$ at any distance $x$ from the source, assuming constant meteorolgical conditions. This is in contrast to the approach in CRAC2 and MACCS which is based on discretization of the distance coordinate into mesh intervals over which meteorological changes are allowed.

\subsubsection{Building Wake Effects}

The diffusion formulas presented thus far have assumed the emitter to be a point source. In fact, when the effluent plume emerges from the reactor building, its dispersion into the atmosphere is increased by the turbulence in the wake region. This effect needs to be incorporated in calculating potential exposures. The default correction used in the present study is the one presented in section 3 of Meteorology and Atomic Energy [6]. According to this, an adjustment is made to the dispersion coefficients in Eq. (2.32) for air concentration as follows:

$$
\begin{aligned}
& \sigma_{y}^{\prime}=\left(\sigma_{y}^{2}+\frac{c A}{\pi}\right) 1 / 2 \\
& \sigma_{z}^{\prime}=\left(\sigma_{z}^{2}+\frac{c A}{\pi}\right) 1 / 2
\end{aligned}
$$

Where $\sigma_{j}^{\prime}$ and $\sigma^{\prime}$ are the corrected horizontal and vertical standard deviations of plume material, $A$ is the cross-sectional area of the building perpendicular to the wind, and $c$ is the shape factor, which can have values in the range 0.5 to 2. Reg. Guide 1.4 indicates that the building wake correction should be used in the first eight hours following release, with a shape factor $c$ of $1 / 2$ and the minimum cross-sectional area of the reactor building only.

Alternately, as was proposed by Holland [18] and is employed in CRAC and MACCS, a virtual point source can be assumed, that would produce a Gaussian plume, having dimensions comparable to those of the reactor building. 
Any modification proposed to date is only an approximation and cannot be expected to be valid within the wake region of the reactor building. However, the adjustments presented here have the advantage of being a simple and economical approximation to account for this very complicated effect in calculating air concentrations further downwind. For complex building shapes, no reliable simple guidelines are presently available.

\subsubsection{Plume Rise}

The release height $h$ in Eq. (2.32) is adjusted to account for plume rise on release, due to buoyancy $[19,3]$. The equation for the corrected height $h^{\prime}$ is

$$
h^{\prime}=2.6\left(\frac{F}{\pi s}\right)^{1 / 3}+h
$$

where $F$ is a buoyancy flux parameter given by $[4,20]$ as:

$$
F=8.79 \times 10^{-6} Q_{H}
$$

$Q_{H}$ is the thermal release in watts, $\bar{u}$ is the average wind speed $(\mathrm{m} / \mathrm{s})$ encountered during the rise, and $s$ is a stability parameter which depends on the ambient temperature and the lapse rate of the atmosphere. Values of $s=8.7 x$ $10^{-4}$ and $1.75 \times 10^{-3}$ for $E$ and $F$ stability classes, respectively, as in CRAC2, are used. These numbers are obtained from temperature lapse rates in Reg. Guide 1.23. The numbers in MACCS are obtained assuming the lapse rate for $E$ and $F$ stability are in the middle of the range specified in the Reg. Guide, and are lower.

For neutral or unstable conditions (A to $D)$, the following relation is used $[4,21]$.

$$
h^{\prime}=1.6 F^{1 / 3} x^{2 / 3} u^{-1}+h
$$

where $x$ is the distance travelled by the plume.

Buoyant plume rise may not occur if the high energy release gets trapped due to increased turbulence in the building wake. For this, a critical wind speed $u^{\prime}(\mathrm{m} / \mathrm{s})$ is applied, above which plume rise is suppressed:

$$
u^{\prime}=\left(\frac{9.09 F}{L}\right)^{1 / 3}
$$

where $L$ is the height of the reactor building $(m)$.

\subsubsection{Grass Height}

The vertical dispersion parameter from Pasquill-Gifford curves, $\sigma_{z}(x)$, is adjusted for surface roughness as recommended in [22] and implemented in CRAC2 and MACCS, to be more appropriate for a roughness of $10 \mathrm{~cm}$, as follows: 


$$
\sigma_{z}=\sigma_{Z P-G}\left(\begin{array}{l}
10 \mathrm{~cm} \\
3 \mathrm{~cm}
\end{array}\right)^{0.2}=1.27 \sigma_{Z P-G}
$$

Alternatively, $\sigma_{z}(x)$ can be obtained from fits to Smith's curves presented in Reference [13] with correction factors for various roughnesses ranging from $1 \mathrm{~cm}$ to $400 \mathrm{~cm}$.

\subsubsection{Release Duration}

For a release of longer duration $T$ with the wind direction nominally constant, the time-averaged plume will probably be wider due to increased horizontal dispersion than it would be for a release of shorter duration $T_{E}$. This effect has been included simply by

$$
\sigma_{y}=\sigma_{y P-G}\left(\frac{T}{T_{E}}\right)^{n}
$$

The horizontal dispersions from $P-G$ curves are based on experiments where the release duration is a few minutes.

In CRAC2, $T_{E}$ is taken to be 3 minutes; $n=0.2$ for $3<T \leq 60$ minutes and $n=0.25$ for $60<T \leq 600$ minute. The same scheme is used in the present study.

\subsubsection{Inversion Lid}

The atmospheric boundary layer is capped by a very stable layer, whose base forms an effective barrier to the upward growth of a plume. This is called the inversion lid. Estimates of the height of this lid $\mathrm{H}$ can be obtained from Holzworth [23]. In the present model, $\sigma_{z}$ is allowed to grow to a maximum of $0.8 \mathrm{H}$, where $H$ is a user-input value.

\subsection{Dose Calculations}

Once the atmospheric and ground level concentrations, $x$ and $x_{0}$, for each radionuclide are determined, the radiation dose accumulated by indibiduals can be considered in two phases: the initial or acute phase during and shortly after passage of the radioactive cloud, and the latent phase sometime after the cloud passage.

\subsubsection{Dose Pathways} ways:

Radiation doses in the early phase can be received via the following path-

1. Direct external exposure to radiation emitted by radionuclides in the passing cloud (cloudshine),

2. early external exposure to radiation from radionuclide deposited on the ground (short-term groundshine), and

3. internal exposure due to inhalation of radionuclides from the cloud (inhalation). 
Doses in the latent phase can be received via ingestion of contaminated food and drink by deposited radionuclides, inhalation of resuspended radionuclides, as well as long term exposure to groundshine. Early effects are more significant for determining the necessary emergency response actions, and are currently the only effects included within the scope of this study.

of all the radionuclides released, the number considered significant for consequence calculations is 54 species as in CRAC2 (see also Appendix 6 of Reference [14]). A list of these radionuclides, along with their half-lives, can be found in Appendix $C$.

The dose calculations are performed in the same manner as CRAC2 or MACCS depending on which health effect model is chosen as the input option.

\subsubsection{Cloudshine}

The cloud exposure, $E_{c}$, is numerically equal to the integrated air concentration, $x\left(\mathrm{C} i-s / \mathrm{m}^{3}\right)$. The biological dose (rem) to organ $j$ due to cloudshine is calculated from:

$$
D_{c}^{j}=\sum_{i=1}^{N} x_{j}\left(F_{C \infty}\right)_{j}^{j}\left(\frac{F_{C}}{F_{C \infty}}\right)_{i}^{j} S F_{c}
$$

where $x_{i}$ is the integrated air concentration $\left(\mathrm{C} i-s / \mathrm{m}^{3}\right)$ of nuclide $i$ at the reference location, and $\left(F_{C_{\infty}}\right)_{j}^{j}$ is the cloud-dose conversion factor for nuclide $i$ $\left(\right.$ rem $\left.-m^{3} / \mathrm{Ci}-\mathrm{s}\right)$.

Values of $F_{C \infty}$ taken from RSS Table VI C-1 [14] are tabulated in Appendix D. They are based on the assumption that the cloud is semi-infinite, having uniform concentration of radioactive material equal to that at its centerline. A correction factor $\left(F_{c} / F_{c \infty}\right)$ is applied to account for the fact that the cloud is finite and that the receptor need not be at its centerline. The correction factors which effectively reduce the dose, are tabulated as functions of $\sigma_{7}$ and $\bar{z} / \sigma_{7}$ where $\bar{z}$ is the effective height of the plume. They have been taken from RSS fable VI 8-1 [14], and were originally presented in Meteorology and Atomic Energy [6]. MACCS uses a somewhat different correction factor based on $\sqrt{\sigma_{y}{ }^{\circ}}$ as the effective plume size [20]. The dose is further reduced by multiplying by an appropriate shielding factor $\left(S F_{C}\right)$ for cloud exposure, which depends on the emergency response action.

\subsubsection{Groundshine}

Radioactive material from the passing cloud would be deposited on the ground and penetrate into structures, vehicles, etc., and would continue to emit gamma radiation long after the cloud has passed. The interest here is in the early exposure, which would be significant even if emergency plans included relocation. 
The biological dose (rem) to organ $j$ from external exposure to gamma radiation emitted by deposited radionuclides is:

$$
D_{g}^{j}=\sum_{i=1}^{N} x_{D i}\left(F_{g}\right)_{i}^{j} S F_{g}
$$

where $D^{j}$ is the total groundshine dose $(\text { rem })_{j}$ to organ $j, x_{D_{i}}$ is the ground concentration of radionuclide $i\left(\mathrm{Ci} / \mathrm{m}^{3}\right),\left(F_{g}\right)_{j}^{j}$ is the integral ground-dose conversion factor for nuclide $i$ and organ $j\left(r e m-m^{2} / C i\right)$, SF $g$ is a shielding factor to account for ground roughness, structures vehicles, etc. and depends on the emergency action.

The ground-dose conversion factor, $F_{g}$, is derived for a point one meter above a smooth surface, and includes radioactive decay and daughter buildup. Values of $\mathrm{Fg}$ for whole body, total marrow, and lung are tabulated for 1 day and 7 days in Appendix $D$. They were taken from Table A-3 of Reference [24]. An interpolation procedure is used for exposure durations between one and seven days, and an extrapolation procedure for durations less than one day.

\subsubsection{Inhalation}

Radionuclides retained in the body by inhalation will continuously deliver a dose to the body or its specific organs until they are removed by biological elimination or radioactive decay. Inhalation is included in the early phase because the amount entering the body depends on conditions in the passing cloud and the receptor's activity level at that time.

The dose due to inhaled radionuclides is calculated from:

$$
D_{i}^{j}=\sum_{i=1}^{N} x_{i}\left(F_{i n}\right)_{i}^{j} B r
$$

where $D_{j}^{j}$ is the total inhalation dose ${ }_{j}$ (rem) to organ $j, B r$ is the breathing rate of the receptor $\left(\mathrm{m}^{3} / \mathrm{s}\right)$, and $\left(\mathrm{F}_{i n}\right)_{i}^{j}$ is the dose conversion factor (rem/Ci in-

Values of $F_{i n}$ were taken from Table A-4 in Reference [24], and are tabulated in Appendix $D$ over various time periods ranging up to 30 years. The breathing rate is a user-input quantity and depends on the person's age and activity level. A default value equal to $2.66 \times 10^{-4} \mathrm{~m}^{3} / \mathrm{s}$ has been used in the code.

\subsection{Health Effects}

The health effects models of both MACCS and CRAC2 are included in SMART for early health effects only. These effects are early deaths and injuries modelled 
for organ specific doses from the three pathways. The dose conversion factors for each pathway and organ are given in Appendix $D$.

MACCS uses the hazard function approach to calculate early fatalities as discussed in Reference [25]. First, the cumulative hazard is calculated as:

$$
H=\ln (2)\left(D / D_{50}\right)^{V}
$$

where $D$ is the dose and $D_{50}$ is the dose required for producing an effect in $50 \%$ of the exposed individuals, and $v$ determines the steepness of the dose effect curve. That fatality risk is then given as:

$$
\text { Risk }=1-e^{-\left(H_{1}+H_{2}+H_{3}+H_{4}\right)}
$$

where $H_{1}$ is for red marrow, $\mathrm{H}_{2}$ is for lungs, and $\mathrm{H}_{3}$ and $\mathrm{H}_{4}$ are for the lower large intestine and small intestine. The risk is assigned a threshold of .005.

In CRAC2, the dose response is piece-wise linear due to irradiation of the bone marrow, lung, and GI tract. The total risk is then:

$$
R=R_{1}+\left(1-R_{1}\right) R_{2}+\left(1-R_{1}\right)\left(1-R_{2}\right) R_{3}
$$

where $R_{1}, R_{2}$, and $R_{3}$ are the risks to the three organs, respectively. MACCS gives somewhat higher risk, principally because the lung dose is now considered more effective in producing fatalities, and also because the hazard function gives some risk at lower doses.

The effect of the model differences is that MACCS predicts a higher probability for small numbers of deaths while CRAC2 predicts a higher probability for large numbers of deaths.

Early injuries in MACCS are also calculated using the hazard function except that the cumulative hazard is not summed as in Eq. (2.45). Rather, the risk of lung impairment, prodromal vomiting, hypothyroidism, and thyroid ablation are calculated separately. Several other injuries can be defined, although only persons who did not suffer early death are considered.

Early injuries in the CRAC2 model are calculated as in Eq. (2.46) using doses to the whole body, lungs, and lower large intestinal wall. The dose response is discussed in Appendix VI of Reference [14]. The risk of death is subtracted from the risk of injury.

The lifetime risk of latent cancer is not calculated. 


\section{RESULTS}

An interactive computer code, SMART, (Appendix B) was developed, incorporating the integral models introduced in the previous section. Simplified dispersion models from CRAC2 [3] and MACCS [4] were also included as calculational options.

This chapter provides a discussion of results obtained using this code, along with comparisons to CRAC2 and MACCS calculations, and results of detailed sensitivity and uncertainty analyses of the various input and model parameters.

\subsection{Computing Time Requirements}

A typical single-weather MACCS or CRAC2 calculation of doses and health effects on a mainframe computer (VAX 11/785) uses approximately 10 minutes of running time. The present model can perform more than 500 such calculations in the same time. On an IBM AT personal computer, a full calculation using this model takes about 30 seconds.

\subsection{Benchmark Comparisons with CRAC2 and MACCS}

The present code was benchmarked by comparing results for Cs-137 air concentration, total dose to organs and health effects, with single-weather calculations performed by CRAC2 and MACCS version 1.4. The input data for all calculations was taken from Reference [26]. The radiological releases corespond to the largest release cluster as defined in Reference [26] for an early containment failure due to direct heating (Cluster 1). The core inventory selected was for a PWR operating at 3412 MWth power. For the remainder of the input, CRAC2 and MACCS default values were chosen $[3,4]$. Table 3.1 lists all the input variables used in these comparisons. Six separate calculations were performed with each computer code, for atmospheric stability classes $A, D$ and $F$, and wind speeds of 1 and $5 \mathrm{~m} / \mathrm{s}$. Each case was labeled with the corresponding weather condition ( $A 1, A 5, D 1, D 5, F 1, F 5)$. Test D1 was also performed with dry deposition velocity equal to zero. In all cases, the present code was exercised using plume dispersion models consistent with those present in the code being compared with.

The last test ( $D 1$ with $v_{d}=0$ ) showed agreement of results to better than four percent between the present code and both CRAC2 and MACCS for distances beyond one and one half mile from the source. However, large deviations, in some instances as large as one hundred percent, were observed in all the other cases. These discrepancies were traced to the calculation of plume dispersion parameters which, in the present code, are computed at a given location, while in CRAC2 and MACCS are averages over a spacial mesh. The good agreement obtained for case D1 without dry deposition is due to the elimination of the dominant term in Eq. (2.17) for air concentration, in which the vertical dispersion coefficient appears as an exponent.

Table 3.2 lists the values of plume dispersion parameters versus distance as calculated by CRAC2 and MACCS version 1.4 for weather stability classes $A$, D and $F$. In the table are also shown the values calculated by the independent polynominal - fit to the $P-G$ curves developed for the present code. The three models calculate dispersion parameters which can vary by as much as fifty 
Table 3.1 Input Variables Used for Benchmarking of Present Code with CRAC2 and MACCS

\begin{tabular}{|c|c|c|}
\hline Parameter & Value & Units \\
\hline Power Level & 3412 & Mwth \\
\hline \multicolumn{3}{|l|}{ Release Fractions } \\
\hline $\mathrm{Xe}$ & .9 & \\
\hline I & .706 & \\
\hline Cs & .4 & \\
\hline Te & .4 & \\
\hline$S r$ & .05 & \\
\hline Ru & .4 & \\
\hline La & .003 & \\
\hline $\mathrm{Ce}$ & .003 & \\
\hline $\mathrm{Ba}$ & .05 & \\
\hline Time of Release & 0. & hours \\
\hline Duration of Release & 0.5 & hours \\
\hline Height of Release & 0. & m \\
\hline Energy of Release & 0. & watts \\
\hline Width of Building & 100. & $m$ \\
\hline Height of Building & 25. & m \\
\hline Dry Deposition Velocity & .01 & $\mathrm{~m} / \mathrm{s}$ \\
\hline Breathing Rate & $2.66 \times 10^{-4}$ & $\mathrm{~m}^{3} / \mathrm{s}$ \\
\hline Rain Time & 0. & $\mathbf{s}$ \\
\hline Cloud Shine Shielding Factor & .75 & \\
\hline Ground Shine Shielding Factor & .33 & \\
\hline Atmospheric Stability Class & $A, D, F$ & \\
\hline Average Wind Speed & $1 ., 5$ & $\mathrm{~m} / \mathrm{s}$ \\
\hline
\end{tabular}


Table 3.2 Dispersion Parameters vs. Distance as Calculated by Different Consequence Models.

Weather Stability Class A

\begin{tabular}{|r|r|r|r|}
\hline & \multicolumn{3}{|c|}{$\sigma_{y}(\mathrm{~m})$} \\
\hline & CRAC & MACCS & $\begin{array}{c}\text { Present } \\
\text { Mode 1 }\end{array}$ \\
\cline { 2 - 4 } Distance (m) & & & \\
800 & 159.5 & 142 & 206.8 \\
1600 & 368.2 & 366 & 390.3 \\
2400 & 556.3 & 572 & 615 \\
3200 & 749 & 770 & 929 \\
4000 & 831 & 962 & 1128 \\
4800 & 1109 & 1150 & 1319 \\
5600 & 1284 & 1340 & 1506 \\
6400 & 1456 & 1520 & 1685 \\
7200 & 1626 & 1700 & 1861 \\
8000 & 1795 & 1880 & 2034 \\
9600 & 2043 & 2140 & 2369 \\
11300 & 2371 & 2490 & 2699 \\
\hline
\end{tabular}

Weather Stability Class D

\begin{tabular}{|r|r|r|r|}
\hline 800 & 92.1 & 69.6 & 76.2 \\
1600 & 173.5 & 158 & 140 \\
2400 & 250.4 & 240 & 219 \\
3200 & 324.8 & 320 & 331 \\
4000 & 397.3 & 397 & 401 \\
4800 & 469 & 472 & 470 \\
5600 & 539 & 547 & 537 \\
6400 & 608 & 692 & 602 \\
7200 & 676 & 764 & 666 \\
8000 & 743 & 870 & 728 \\
9600 & 843 & 1010 & 851 \\
11300 & 975 & 1180 & 971 \\
\hline
\end{tabular}

Weather Stability Class F

\begin{tabular}{|r|l|l|l|}
\hline 800 & 69.7 & 45.2 & 42.4 \\
1600 & 108 & 87.6 & 74.2 \\
2400 & 145 & 128 & 115 \\
3200 & 181 & 166 & 174 \\
4000 & 216 & 241 & 211 \\
4800 & 251 & 277 & 247 \\
5600 & 285 & 313 & 282 \\
6400 & 318 & 348 & 316 \\
7200 & 352 & 383 & 349 \\
8000 & 385 & 435 & 382 \\
9600 & 433 & 504 & 446 \\
11300 & 498 & 588 & 508 \\
\hline
\end{tabular}

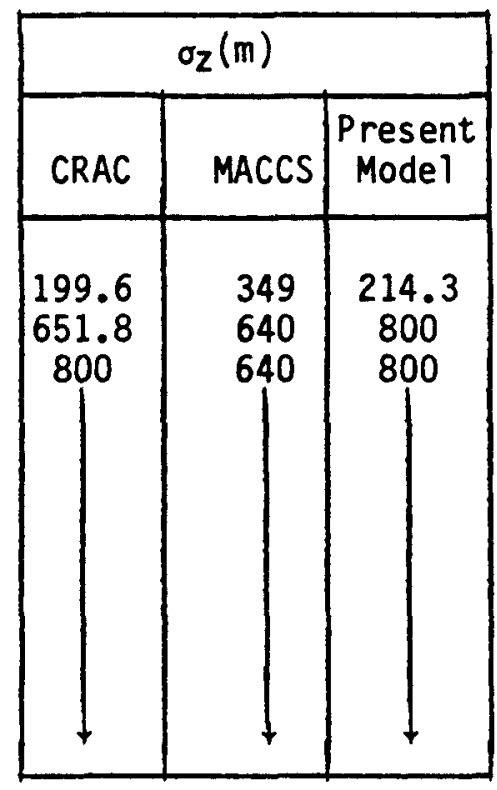

\begin{tabular}{|r|r|r|}
\hline 29.14 & 23.1 & 34.2 \\
52.33 & 40.7 & 50.2 \\
69.77 & 57.8 & 68.3 \\
84.4 & 71 & 91.1 \\
97.3 & 83 & 104 \\
108.9 & 94 & 116 \\
119.6 & 105 & 127 \\
129.5 & 124 & 138 \\
138.9 & 133 & 147 \\
147.7 & 146 & 156 \\
160.2 & 163 & 173 \\
175.7 & 182 & 189 \\
\hline
\end{tabular}

\begin{tabular}{|l|l|l|}
\hline 18.4 & 15.7 & 23.4 \\
27.1 & 22.9 & 28 \\
33 & 28.7 & 33.4 \\
37.7 & 33.8 & 40.1 \\
41.5 & 42.8 & 43.9 \\
44.7 & 46.8 & 47.2 \\
47.6 & 50.6 & 50.2 \\
50.1 & 54.3 & 52.9 \\
52.5 & 57.7 & 55.4 \\
54.6 & 62.7 & 57.7 \\
57.5 & 69.9 & 61.8 \\
60.9 & 76.3 & 65.4 \\
\hline
\end{tabular}


percent, especially near the release point, where building wake effects are more important. Furthermore, this difference gets magnified in the calculation of air concentration due to non-linearities in Eq. (2.17).

Therefore, for the benchmarking study, all the above cases were repeated using dispersion parameters obtained from either CRAC2 or MACCS. In addition, the distance was adjusted in the present code to reflect the "average" position at which CRAC2 and MACCS compute air concentration in a spacial mesh. The latter change was retained for all subsequent calculations. Figures 3.1 through 3.3 illustrate results of a benchmark comparison of total bone marrow dose versus distance for tests $A 5, D 5$ and $F 1$ integral model and CRAC2 and MACCS differential models. Similar results were obtained for all other weather conditions, and doses to different organs. Calculations from the integral model are seen to agree to within three percent or better with both CRAC2 and MACCS for all distances. The small difference can be explained through two mechanisms. Firstly, CRAC2 and MACCS integrate differential equations in a series of spacial meshes, while the present code solves a single integrated equation at a given point. Secondly, the input values obtained from the codes for the dispersion parameters are not exact but are truncated, in some instances, to within one half of one per cent. As previously stated, even such a small deviation can produce a comparatively large uncertainty in results as shown in the next section.

In conclusion, the present code and models were shown to reproduce with good agreement the results obtained with both CRAC2 and MACCS version 1.4 .

\subsection{Single Parameter Sensitivity Studies}

Two sensitivity studies were performed, using the present code. Fist, the impact of plume dispersion parameters and building-wake effects models on calculated doses was examined (Section 3.3.1). This single-parameter sensitivity analysis was done because in a full study, as described in section 3.4, parameters which dominate the uncertainties tend to overshadow less important parameters, and it was felt that the uncertainty introduced by these models had to be fully analyzed first in order to assess their impact on the dose calculations. Second, sensitivity to source term magnitude alone was examined (see section 3.3.2).

\subsubsection{Sensitivity to Plume Dispersion and Building Wake Effects}

The input data for this study was the same as used in benchmark analysis (Table 3.1), and the same weather stability classes (Al through F5) were analyzed. Doses delivered to various organs were compared for distances up to five miles. Doses to different organs were qualitatively similar for all stability classes, with uncertainty, ranging between fifty and one hundred percent of the largest calculated value at a half mile from the release point; between twenty and forty percent at one mile, and between five and twenty percent at two miles. For larger distances, this uncertainty approaches zero. Figures 3.4 and 3.5 show the calculated total dose to bone marrow for weather stability class $D$ and average wind speed of $5 \mathrm{~m} / \mathrm{s}$. 


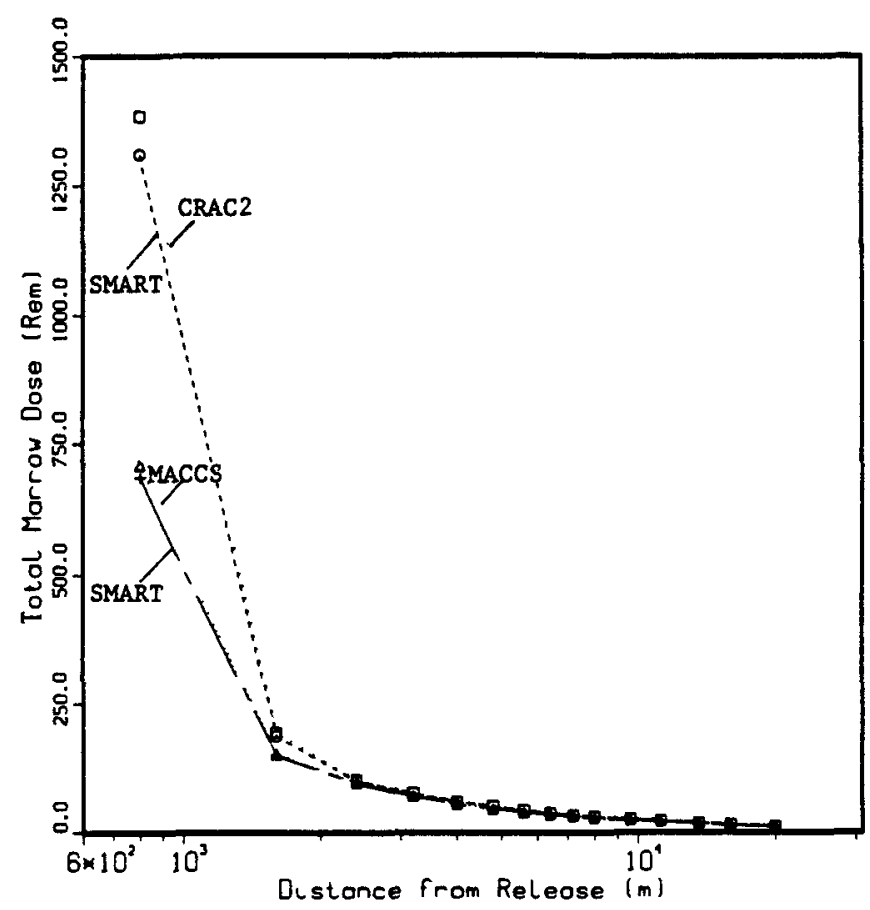

Figure 3.1 Total dose to bone marrow versus distance for weather stability class $A$, average wind speed $5 \mathrm{~m} / \mathrm{s}$.

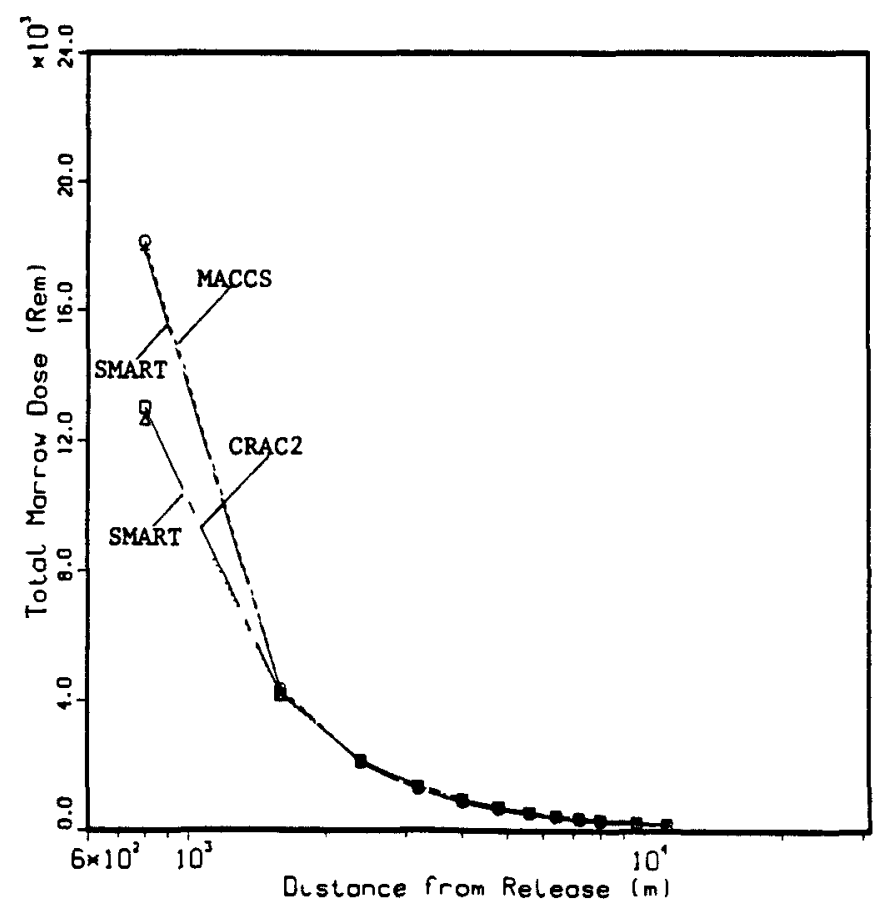

Figure 3.2 Total dose to bone marrow versus distance for weather stability Class $D$, average wind speed $5 \mathrm{~m} / \mathrm{s}$. 


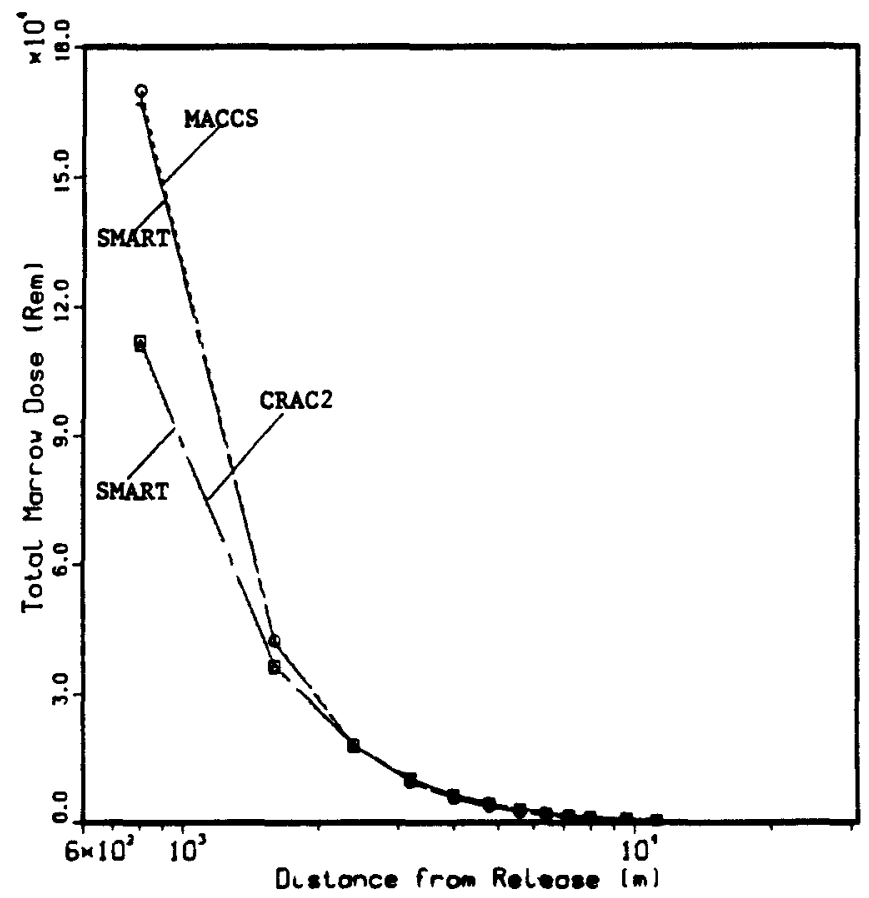

Figure 3.3 Total dose to bone marrow versus distance for weather stability class $F$, average wind speed $1 \mathrm{~m} / \mathrm{s}$.

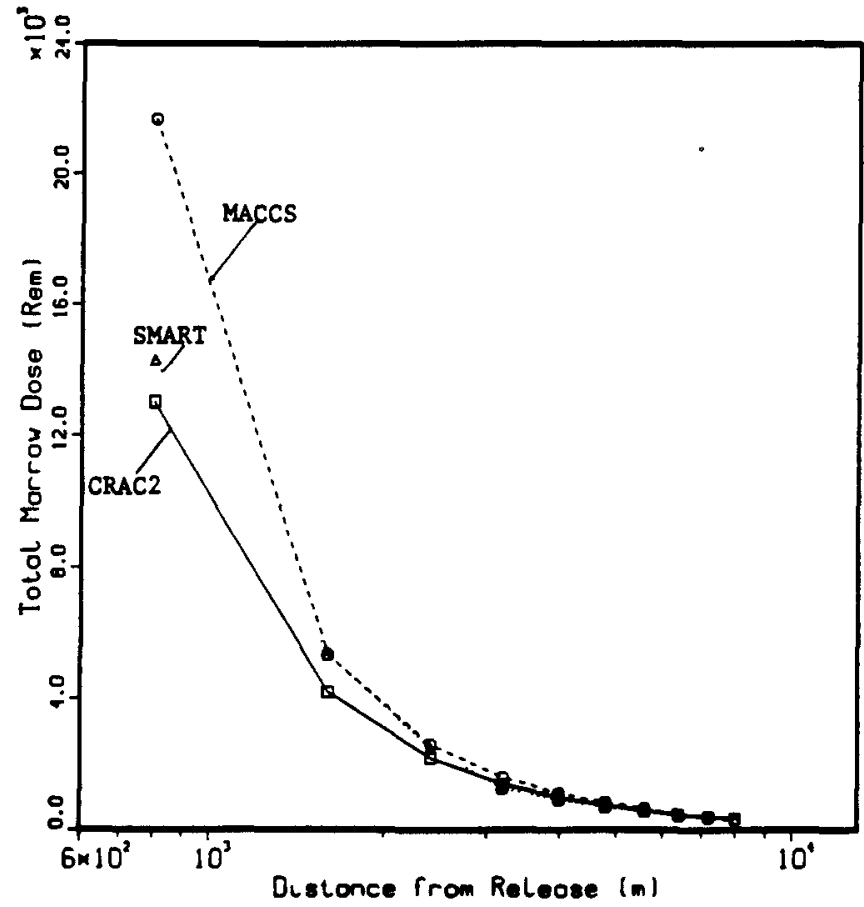

Figure 3.4 Total dose to bone marrow versus distance for various dispersion parameter formulations using CRAC2 dose conversion factors: weather $D 5$. 


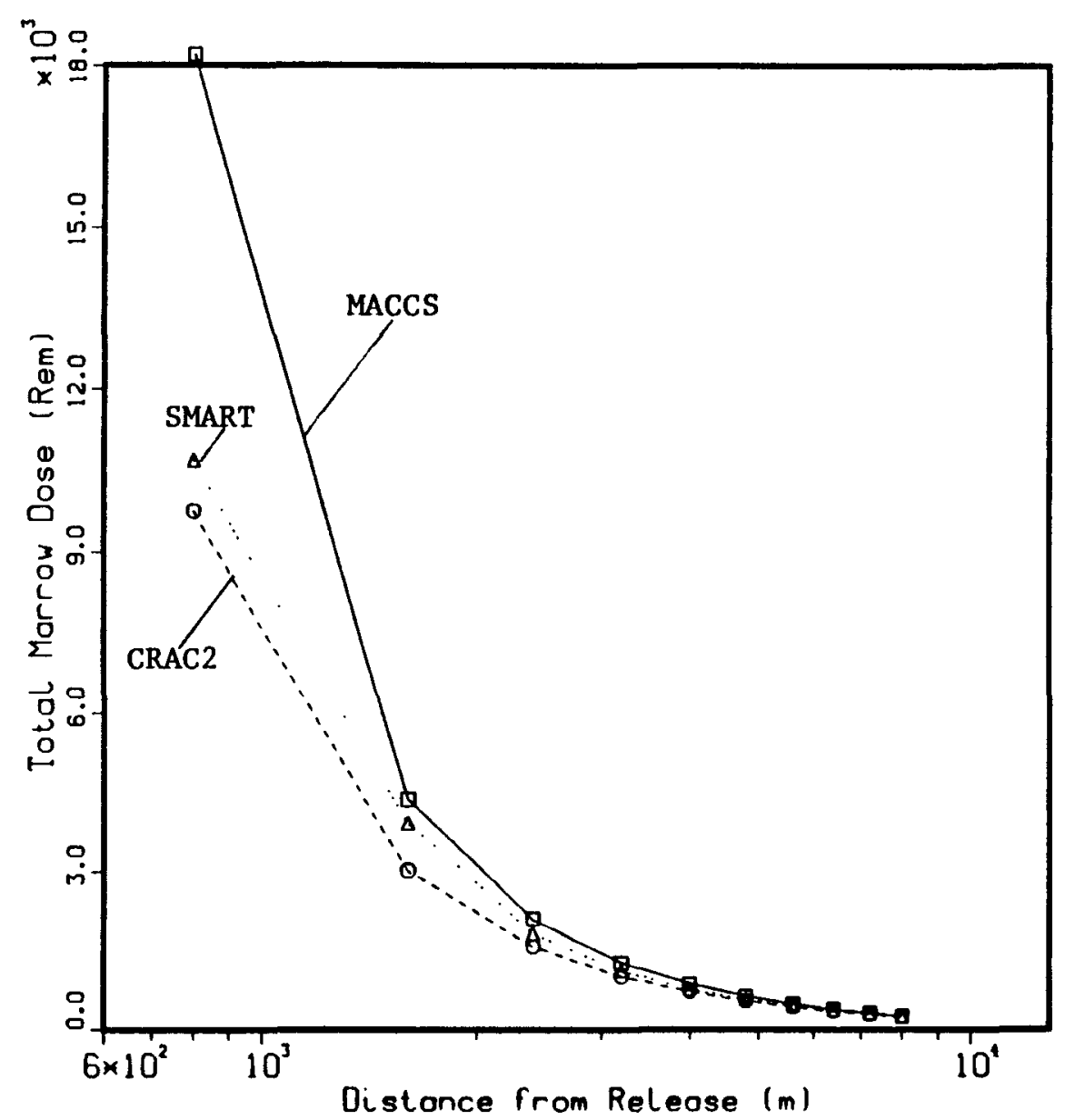

Figure 3.5 Total dose to bone marrow versus distance for various dispersion parameter formulations using MACCS dose conversion factors: weather 05 . 
As can be readily seen, the dispersion models used in MACCS predict larger doses at shorter distances for these weather conditions; for other weather conditions, the CRAC2 models predict higher doses, but the band in uncertainties remains approximately the same. The effect on the calculation of health effects could be dramatic if, for a given release, the models used in one code yielded sub-threshold doses and hence no effects, while the models used in the other code computed finite mortality and injury probabilities. For the large source term cluster used in the present analysis, such a dramatic effect was not seen due to calculated doses being well beyond the threshold. However, differences of a few percent in the probability of early fatalities were observed in those cases where mortality rate was less than $100 \%$ (see, for example, Table 3.3).

In conclusion, the dispersion parameters and building wake effects models used in the existing codes can introduce a significant uncertainty in calculated doses within a few miles of the release point.

\subsubsection{Sensitivity to Source Terms}

The Quasar project provided a full uncertainty analysis on the Source Term Code Package (STCP) results of a postulated short term station blackout accident at a BWR with MARK I containment [31]. The results covered a wide spectrum of containment failure modes (leak to massive rupture, early to late failures) and hence radionuclide releases. Discrete distributions for nine release groups modeled in the STCP, were obtained. Following these results, paired correlations were imposed between iodine and cesium, strontium and barium, and lanthanum and cerium releases. The parameter space used to generate release fractions is shown in Table 3.5 .

A set of 100 independent releases was generated using a stratified Monte Carlo (Latin Hypercube Sampling) technique [30]. Two sets of calculations, for weather stability class $D$ and windspeed of $1 \mathrm{~m} / \mathrm{s}$ and $5 \mathrm{~m} / \mathrm{s}$, respectively, were performed with the SMART integral code using MACCS dose conversion factors and health effect models. The core inventory was that of a BWR, scaled according to the Peach Bottom operating power levels. Time, energy and height of release were zero, with duration of release 1 hour. All other inputs were the default values suggested for the MACCS model.

Tables 3.6 and 3.7 show the results for total dose to bone marrow and probability of early death for the D1 set of calculations. Tables 3.8 and 3.9 show the same results for the D5 set. Results for the other outputs calculated by the code can be found in Appendix F.

A regression analysis of the results showed only weak correlations to the $\mathrm{Xe}, \mathrm{Te}$, and $\mathrm{Sr} / \mathrm{Ba}$ groups. All other groups had partial rank correlation coefficients of less than 0.4 in absolute value for all distances.

This result was not surprising because the nine release groups are not in general correlated. Hence, for instance, a high I/Cs source term can be predicted by the LHS program together with very low refractory releases. Doses and health effects, however, are dependent on the global source term. In both calculational sets, the relative uncertainty for doses is approximately the same. One order of magnitude separates the results for extremely low and extremely high releases. The probability of early death is narrowly distributed for 
Table 3.3 Comparison of Early Fatality Probabilities Calculated by CRAC2 and MACCS Models for a Large Release Cluster, Weather Stability Class A, Wind Speed $1 \mathrm{~m} / \mathrm{s}$

Probability of Early Fatalities

\begin{tabular}{|c|c|c|}
\hline & \multicolumn{2}{|c|}{ CRAC2 Health-effect Models } \\
\hline $\begin{array}{c}\text { Distance } \\
\text { (m) }\end{array}$ & $\begin{array}{c}\text { CRAC2 } \\
\text { Dispersion } \\
\text { Model }\end{array}$ & $\begin{array}{c}\text { MACCS } \\
\text { Dispersion } \\
\text { Mode1 }\end{array}$ \\
\hline 800 & 1 & 1 \\
1600 & 1 & 1 \\
2400 & .09 & .15 \\
3200 & .1 & .05 \\
4000 & 0. & .003 \\
4800 & 0. & 0. \\
5600 & 0. & 0. \\
6400 & 0. & 0. \\
7200 & 0. & 0. \\
8000 & 0. & 0. \\
9600 & 0. & 0. \\
11300 & 0. & 0. \\
\hline
\end{tabular}

\begin{tabular}{|c|c|}
\hline \multicolumn{2}{|c|}{ MACCS Health-effect Models } \\
\hline $\begin{array}{c}\text { CRAC2 } \\
\text { Dispersion } \\
\text { Mode? }\end{array}$ & $\begin{array}{c}\text { MACCS } \\
\text { Dispersion } \\
\text { Model }\end{array}$ \\
\hline $\begin{array}{l}1 \\
1 \\
.97 \\
.64 \\
.48 \\
.21 \\
.13 \\
.08 \\
.06 \\
.04 \\
.02 \\
.01\end{array}$ & $\begin{array}{l}1 \\
1 \\
.96 \\
.61 \\
.33 \\
.19 \\
.11 \\
.07 \\
.05 \\
.03 \\
.02 \\
.01\end{array}$ \\
\hline
\end{tabular}

Table 3.4 Weights Used to Collapse Individual Releases to lodine and Cesium-Equivalent Releases. [31]

\begin{tabular}{|c|c|c|}
\hline & Early Weight & Late Weight \\
\hline $\mathrm{Xe}$ & 0.1 & 0.001 \\
$\mathrm{I}_{2}$ & 1.0 & 0.1 \\
$\mathrm{Cs}$ & 0.1 & 1.0 \\
$\mathrm{Te}$ & 0.8 & 0.14 \\
$\mathrm{Se}$ & 0.99 & 0.7 \\
$\mathrm{Ru}$ & 2.15 & 1.3 \\
$\mathrm{La}$ & 8.4 & 2.6 \\
$\mathrm{Ce}$ & 7.6 & 5.4 \\
$\mathrm{Ba}$ & 0.66 & 0.2 \\
\hline
\end{tabular}

Table 3.5 Parameter Space for Sensitivity Analysis to Source Terms

\begin{tabular}{|c|c|c|c|c|c|}
\hline Grp & $\begin{array}{c}\text { Min } \\
\text { Release } \\
\text { Fraction }\end{array}$ & $\begin{array}{c}\text { Max } \\
\text { Release } \\
\text { Fraction }\end{array}$ & \multicolumn{3}{|c|}{ Remarks } \\
\hline $\mathrm{Xe}$ & .1 & 1. & \multirow{4}{*}{\multicolumn{3}{|c|}{ All piecewise uniform distributions }} \\
\hline$I_{2}$ & 1.E-04 & .75 & & & \\
\hline Cs & 5.E-04 & .7 & & & \\
\hline Te & $1.3 E-05$ & .48 & & & \\
\hline Sr & $6.4 E-06$ & .7 & \multirow{5}{*}{ Correlations } & & \\
\hline Ru & $2.5 E-10$ & 1.E-04 & & & \\
\hline La & 1.E-04 & .018 & & $\mathrm{I}_{2}, \mathrm{Cs}$ & .9 \\
\hline $\mathrm{Ce}$ & 1.E-06 & .026 & & $\mathrm{Sr}, \mathrm{Ba}$ & .9 \\
\hline $\mathrm{Ba}$ & 5.E-06 & .67 & & $\mathrm{La}, \mathrm{Ce}$ & .9 \\
\hline
\end{tabular}


Table 3.6 Total Dose to Bone Marrow as a Function of Distance; Case 01

\begin{tabular}{|c|c|c|c|c|c|c|c|}
\hline DIST. (MI) & MIN & MAX & $5-T H$ & $50-T H$ & $95-T H$ & AVER & SIGMA \\
\hline 0.5 & $1.740 E+03$ & $2.842 E+04$ & $2.178 E+03$ & $5.332 E+03$ & $1.815 E+04$ & $6.930 E+03$ & $5.335 E+03$ \\
1.0 & $3.614 E+02$ & $5.746 E+03$ & $4.531 E+02$ & $1.092 E+03$ & $3.678 E+03$ & $1.416 E+03$ & $1.077 E+03$ \\
2.0 & $1.235 E+02$ & $1.939 E+03$ & $1.551 E+02$ & $3.725 E+02$ & $1.244 E+03$ & $4.815 E+02$ & $3.645 E+02$ \\
3.0 & $6.886 E+01$ & $1.089 E+03$ & $8.684 E+01$ & $2.088 E+02$ & $7.016 E+02$ & $2.712 E+02$ & $2.063 E+02$ \\
4.0 & $4.303 E+01$ & $6.933 E+02$ & $5.451 E+01$ & $1.312 E+02$ & $4.456 E+02$ & $1.713 E+02$ & $1.311 E+02$ \\
5.0 & $2.386 E+01$ & $3.976 E+02$ & $3.037 E+01$ & $7.307 E+01$ & $2.513 E+02$ & $9.611 E+01$ & $7.403 E+01$ \\
10.0 & $7.617 E+00$ & $1.423 E+02$ & $9.729 E+00$ & $2.419 E+01$ & $8.559 E+01$ & $3.218 E+01$ & $2.551 E+01$ \\
20.0 & $2.267 E+00$ & $5.667 E+01$ & $3.064 E+00$ & $8.268 E+00$ & $3.084 E+01$ & $1.086 E+01$ & $9.334 E+00$ \\
\hline
\end{tabular}

Table 3.7 Probability of Early Death as a Function of Distance; Case DI

\begin{tabular}{|c|c|c|c|c|c|c|c|}
\hline DIST.(MI) & MIN & MAX & $5-T H$ & $50-T H$ & $95-T H$ & AVER & SIGMA \\
\hline 0.5 & $1.000 \mathrm{E}+00$ & $1.000 \mathrm{E}+00$ & $1.000 \mathrm{E}+00$ & $1.000 \mathrm{E}+00$ & $1.000 \mathrm{E}+00$ & $1.000 \mathrm{E}+00$ & 0.0 \\
1.0 & $4.473 \mathrm{E}-01$ & $1.000 \mathrm{E}+00$ & $8.442 \mathrm{E}-01$ & $1.000 \mathrm{E}+00$ & $1.000 \mathrm{E}+00$ & $9.765 \mathrm{E}-01$ & $8.608 \mathrm{E}-02$ \\
2.0 & $8.066 \mathrm{E}-03$ & $1.000 \mathrm{0}+00$ & $1.829 \mathrm{E}-02$ & $5.057 \mathrm{E}-01$ & $1.000 \mathrm{E}+00$ & $5.183 \mathrm{E}-01$ & $4.090 \mathrm{E}-01$ \\
3.0 & $1.274 \mathrm{E}-03$ & $1.000 \mathrm{E}+00$ & $2.708 \mathrm{E}-03$ & $5.001 \mathrm{E}-02$ & $1.000 \mathrm{E}+00$ & $2.359 \mathrm{E}-01$ & $3.514 \mathrm{E}-01$ \\
4.0 & $3.030 \mathrm{E}-04$ & $1.000 \mathrm{E}+00$ & $6.435 \mathrm{E}-04$ & $9.630 \mathrm{E}-03$ & $7.915 \mathrm{E}-01$ & $1.064 \mathrm{E}-01$ & $2.414 \mathrm{E}-01$ \\
5.0 & $4.989 \mathrm{E}-05$ & $5.478 \mathrm{E}-01$ & $1.072 \mathrm{E}-04$ & $1.517 \mathrm{E}-03$ & $8.703 \mathrm{E}-02$ & $2.090 \mathrm{E}-02$ & $7.760 \mathrm{E}-02$ \\
10.0 & $1.431 \mathrm{E}-06$ & $6.767 \mathrm{E}-03$ & $3.248 \mathrm{E}-06$ & $4.518 \mathrm{E}-05$ & $1.698 \mathrm{E}-03$ & $3.549 \mathrm{E}-04$ & $1.011 \mathrm{E}-02$ \\
20.0 & $0.000 \mathrm{E}+00$ & $2.885 \mathrm{E}-04$ & $5.960 \mathrm{E}-08$ & $1.103 \mathrm{E}-06$ & $4.992 \mathrm{E}-05$ & $1.035 \mathrm{E}-05$ & $3.428 \mathrm{E}-05$ \\
\hline
\end{tabular}

Table 3.8 Total Dose to Bone Marrow versus Distance; Case D5

\begin{tabular}{|c|c|c|c|c|c|c|c|}
\hline DIST. (MI) & MIN & MAX & 5-TH & $50-\mathrm{TH}$ & 95-TH & AVER & SIGMA \\
\hline $\begin{array}{r}0.5 \\
1.0 \\
2.0 \\
3.0 \\
4.0 \\
5.0 \\
10.0 \\
20.0\end{array}$ & $\begin{array}{l}1.841 E+02 \\
5.074 E+01 \\
2.070 E+01 \\
5.868 E+00 \\
3.067 E+00 \\
5.076 E+01 \\
1.916 E+00 \\
4.387 E-01\end{array}$ & $\begin{array}{l}2.763 E+03 \\
7.186 E+02 \\
2.876 E+02 \\
1.749 E+02 \\
1.178 E+02 \\
7.126 E+01 \\
2.635 E+01 \\
6.181 E+00\end{array}$ & $\begin{array}{l}2.283 E+02 \\
6.279 E+01 \\
2.465 E+01 \\
1.508 E+01 \\
9.887 E+00 \\
6.161 E+00 \\
2.354 E+00 \\
5.344 E-01\end{array}$ & $\begin{array}{l}5.155 E+02 \\
1.397 E+02 \\
5.714 E+01 \\
3.499 E+01 \\
2.373 E+01 \\
1.435 E+01 \\
5.306 E+01 \\
1.206 E+00\end{array}$ & $\begin{array}{l}1.603 E+03 \\
4.167 E+02 \\
1.668 E+02 \\
1.016 E+02 \\
6.846 E+01 \\
4.149 E+01 \\
1.543 E+01 \\
3.716 E+00\end{array}$ & $\begin{array}{l}6.476 E+02 \\
1.729 E+02 \\
6.940 E+01 \\
4.204 E+01 \\
2.835 E+01 \\
1.724 E+01 \\
6.438 E+00 \\
1.505 E+00\end{array}$ & $\begin{array}{l}4.692 E+02 \\
1.204 E+02 \\
4.756 E+01 \\
2.906 E+01 \\
1.961 E+01 \\
1.180 E+01 \\
4.351 E+00 \\
1.046 E+00\end{array}$ \\
\hline
\end{tabular}

Table 3.9 Probability of Early Death Versus Distance; Case D5

\begin{tabular}{|l|c|c|c|c|c|c|c|}
\hline DIST. (MI) & MIN & MAX & $5-T H$ & $50-T H$ & $95-T H$ & AVER & SIGMA \\
\hline 0.5 & $4.969 \mathrm{E}-02$ & $1.000 \mathrm{E}+00$ & $1.035 \mathrm{E}-01$ & $9.912 \mathrm{E}-01$ & $1.000 \mathrm{E}+00$ & $7.312 \mathrm{E}-01$ & $3.482 \mathrm{E}-01$ \\
1.0 & $8.454 \mathrm{E}-04$ & $1.000 \mathrm{E}+00$ & $1.435 \mathrm{E}-03$ & $1.991 \mathrm{E}-02$ & $7.140 \mathrm{E}-01$ & $1.147 \mathrm{E}-01$ & $2.315 \mathrm{E}-01$ \\
2.0 & $5.716 \mathrm{E}-05$ & $2.073 \mathrm{E}-01$ & $8.148 \mathrm{E}-05$ & $1.185 \mathrm{E}-03$ & $2.843 \mathrm{E}-02$ & $8.357 \mathrm{E}-03$ & $2.382 \mathrm{E}-02$ \\
3.0 & $1.550 \mathrm{E}-06$ & $3.443 \mathrm{E}-02$ & $1.800 \mathrm{E}-05$ & $2.596 \mathrm{E}-04$ & $6.114 \mathrm{E}-03$ & $1.416 \mathrm{E}-03$ & $4.150 \mathrm{E}-03$ \\
4.0 & $1.788 \mathrm{E}-07$ & $9.490 \mathrm{E}-03$ & $5.245 \mathrm{E}-06$ & $7.823 \mathrm{E}-05$ & $1.830 \mathrm{E}-03$ & $4.120 \mathrm{E}-04$ & $1.166 \mathrm{E}-03$ \\
5.0 & $8.941 \mathrm{E}-07$ & $2.013 \mathrm{E}-03$ & $1.222 \mathrm{E}-06$ & $1.711 \mathrm{E}-05$ & $3.998 \mathrm{E}-04$ & $8.931 \mathrm{E}-05$ & $2.489 \mathrm{E}-04$ \\
10.0 & $5.960 \mathrm{E}-08$ & $9.882 \mathrm{E}-05$ & $5.960 \mathrm{E}-08$ & $8.345 \mathrm{E}-07$ & $1.958 \mathrm{E}-05$ & $4.436 \mathrm{E}-06$ & $1.215 \mathrm{E}-05$ \\
20.0 & $0.000 \mathrm{E}+00$ & $1.252 \mathrm{E}-06$ & $0.000 \mathrm{E}+00$ & $0.000 \mathrm{E}+00$ & $2.384 \mathrm{E}-07$ & $4.947 \mathrm{E}-08$ & $1.534 \mathrm{E}-07$ \\
\hline
\end{tabular}


short distances from the source, where doses are in general saturated close to or above the one hundred percent mortality rate for all releases considered. The uncertainty in early death becomes wider for larger distances. Dose thresholds for health effects are extremely low in the MACCS model, and even low doses produce a finite probability of early death.

The two tests could be combined, which is roughly equivalent to a single test of LHS sample of 200, with additional uncertain variable being the wind speed, uniformly distributed with discrete values of 1 and $5 \mathrm{~m} / \mathrm{s}$. Almost all distribution would be wider by about two orders of magnitude, which is more than the uncertainty introduced by the source terms alone. The impact of weather conditions on uncertainties of consequences is investigated in more detail in the next section.

\subsection{Multi-Parameter Sensitivity and Uncertainty Analysis}

Alpert et al. [27] and Kocher et al. [28] performed multiparameter sensitivity and uncertainty studies on health and economic consequences using the CRAC2 code. Alpert's analysis was done primarily as a demonstration of uncertainty techniques, and included source term magnitude and release characteristics, and a few but not all parameters related to the dispersion and deposition models. The choice of parameter spaces appears to be arbitrary. Also included were parameters such as evacuation speed, which are not modeled in the present code. The analysis of Kocher et al was extended to the selection of weather bin sampling and dose conversion factors, but only used two classes of radionuclide release fractions and characteristics. Kaiser also performed sensitivity analysis of CRAC2 [29]. Kaiser's study considered evacuation parameters, health physics models, population distribution, and characteristics of the source term. In general, all of these analyses showed that the results are sensitive to the magnitude of the source terms. The analysis of Kocher et al also showed some sensitivity to the selection of weather sequences in bin-sampling. No published sensitivity/uncertainty study on the MACCS computer code has been published to date.

This section presents a full multi-parameter, sensitivity/uncertainty analysis of consequences using the present integral code, which has been benchmarked against the more sophisticated CRAC2 and MACCS differential codes.

A set of input parameters described in Section 3.4 .1 was chosen, with parameter spaces and distributions taken from appropriate sources. The LHS technique [30] was applied to this set, and one hundred separate calculations were performed for both the CRAC2 and MACCS models. Doses delivered to different organs and health effects (output) were then correlated to the independent (input) variables through a rank regression analysis as described in Section 3.4.2. Statistical information is provided in Section 3.4.3, and conclusions are presented in Section 3.4.4.

\subsubsection{Selection of Independent Variables.}

A set of twenty-three independent input variables was selected; and were grouped as follows: 
i) Radionuclide releases and release characteristics: The results obtained from the QUASAR analysis were used, as in Section 3.3.1. Since no global correlation among release groups was observed, as previously mentioned, two independent variables were added in the regression analysis, collapsing all releases to early iodine--and late cesium-weighted effects [32]. The weights used are listed in Table 3.4. The QUASAR analysis [31] also provided discrete distributions for release time, duration, height and energy of release. These parameters were properly correlated to each other following the QUASAR results.

ii) Plume Dispersion Models: A discrete distribution was provided for the choice of plume dispersion formulations, with equal weight for each model.

iii) Weather Conditions: The Peach Bottom atmospheric data file for MACCS [33] was analyzed. Rather than sampling weather bins, as is done in MACCS, weather stability classes were provided with their relative frequency of occurrence. Average wind speed and rainfall rate were provided as distributions. It was found that a weak correlation existed between stability class and wind speed, and this correlation was therefore added to the LHS program input. It should be noted that the rainfall rate distribution provides for a 92 percent no-rain probability at the site. Hence, the effect of rain on concentration depletion from the plume can be expected to be minimal in the correlation analysis. This means that the importance of wet deposition in the distribution of uncertainties cannot be assessed in the present study. Such an assessment would require a single-parameter sensitivity study to wet deposition, or a specialized multi-parameter analysis using data restricted to rain conditions.

iv) Input parameters with associated uncertainties: Parameter spaces and distributions were taken from the literature, namely; Dry deposition velocity [14], breathing rate [15], the rain depletion coefficient [17]. In addition, the height of the inversion lid was chosen as either $1000 \mathrm{~m}$ or $800 \mathrm{~m}$. This primarily affects weather stability classes $A$ and $B$. For cloudshine and groundshine shielding factors, wide ranges were chosen to cover a variety of emergency response actions. Dose conversion factors and health effects models were not considered as independent parameters in this analysis. However, the sensitivity analysis has included both CRAC2 and MACCS dose conversion factors and health effects models as choices in input. Tables 3.5 and 3.10 list all the independent parameters that are input to the Latin Hypercube Sampling program, which generates appropriate random vectors for the present code.

\subsubsection{Correlation of Output to Input Uncertainties:}

Two sets of one hundred independent calculations were performed with the SMART integral code, using the dose conversion factors and health effects models in CRAC2 and MACCS, respectively. As in Section 3.3.1, the core inventory was that of a BWR, scaled according to the Peach Bottom operating power levels. Results were stored for analysis at ten distances from the release point, 
$-29-$

Table 3.10 Input Other Than Source Terms for the Full Uncertainty Analysis

\begin{tabular}{|c|c|c|}
\hline Parameter & Parameter Space & Comments \\
\hline Release Time (hours) & $0-4.3$ & Piecewise Uniform \\
\hline $\begin{array}{l}\text { Duration of Release } \\
\text { (hours) }\end{array}$ & $6-12.7$ & Normal Distribution \\
\hline Height of Release (m) & $0-30$ & Uniform Distribution \\
\hline Energy of Release (watts) & $0-1 \cdot E+10$ & Log Uniform Distribution \\
\hline Dispersion Models & $\begin{array}{l}1=\text { Polynomial } \\
2=\text { CRAC2 } \\
3=\text { MACCS }\end{array}$ & $\begin{array}{l}\text { User Distribution with } \\
\text { Equal Weights }\end{array}$ \\
\hline Weather Stability $\mathrm{Cl}$ asses & $A-F$ & $\begin{array}{l}\text { User Distribution with Weights } \\
\text { (probability of occurrence) } \\
\text { obtained from weather file [33] }\end{array}$ \\
\hline Average Wind Speed $(\mathrm{m} / \mathrm{s})$ & $.1-10.7$ & \multirow[t]{2}{*}{$\begin{array}{l}\text { Piecewise Log Uniform Distribu- } \\
\text { tions obtained from [33] }\end{array}$} \\
\hline Rainfall Duration (s) & $0-3600$ & \\
\hline $\begin{array}{l}\text { Dry Deposition Velocity } \\
(\mathrm{m} / \mathrm{s})\end{array}$ & $0.001-.1$ & Log Uniform Distribution \\
\hline Breathing Rate $\left(\mathrm{m}^{3} / \mathrm{s}\right)$ & 9.E-05-5.E-04 & $\begin{array}{l}\text { Triangular Distribution with } \\
\text { apex at } 3.33 \times 10^{-4}\end{array}$ \\
\hline $\begin{array}{l}\text { Cloudshine Shielding } \\
\text { factor }\end{array}$ & $.1-.9$ & \multirow{2}{*}{ Uniform Distributions } \\
\hline $\begin{array}{l}\text { Groundshine Shielding } \\
\text { factor }\end{array}$ & $.1-.9$ & \\
\hline Rain Depletion Coefficient & $1 . E-05-.01$ & Log Uniform Distribution \\
\hline Inversion Lid (m) & $800-1000$ & $\begin{array}{l}\text { Discrete Distribution with Equal } \\
\text { Weights }\end{array}$ \\
\hline
\end{tabular}

Correlations: Release time, duration $\quad-.9$

Release time, energy -.8

Weather class, wind speed -.6

Shielding factors $\quad .9$ 
ranging from one half to 350 miles. For the CRAC2 run the following output was saved; total dose to whole body, bone marrow, lung, thyroid and lower large intestinal wall, together with probability of early fatality. For the MACCS calculations, total dose to stomach, bone marrow, lung, thyroid, small intestinal tract, lower large intestinal wall, and probability of early injury and early fatality, were saved.

A statistical program, PCCSRC [34], was used to correlate outputs to inputs. Partial rank correlation coefficients (PRCC), standardized rank regression coefficients (SRRC), partial correlation coefficients (PCC), and standardized regression coefficients (SRC) were produced. Some PRCC results are shown in Tables 3.11 through 3.15. PRCC's below .3 in absolute value are not shown. PRCC's for all other output exhibited similar behavior. Two parameters exhibit very strong correlations in most cases: (1) weather stability class, and (2) dry deposition velocity. Output correlations to iodine and cesium equivalent releases and individual releases were weak. Other parameters which provide weak correlations are: (1) breathing rate, (2) groundshine shielding factor, (3) wind speed, and (4) choice of dispersion model. The $R^{2}$ for dose parameters, which is an indication of the goodness of a linear fit of the data, was seen to be acceptable for all cases. For the probability of early fatality, there is no fit beyond 3 miles for CRAC2, and beyond 50 miles for MACCS. Beyond these distances the dependent parameters are zero, that is no consequences are predicted. This analysis was repeated with a sample set of 300 independent observations. No change was observed in the PRCC's. Another sample set of 100 observations was analyzed, discarding height of release, energy, cloudshine shielding factor and inversion layer lid, which never ranked better than the tenth place for any of the outputs. In this sample set, weather stability class was fixed at $D$ (the most probable), and wind speed and rain rate distributions were provided for class $D$ weather only. PRCC results did not change overall, except that the weak correlations observed in the analysis with the original 100 LHS sample, became stronger.

Scatter plots of all outputs were produced for the original LHS100 sample. These confirmed the PRCC analysis and no non-linear or oscillatory effect was found. Figures 3.6 through 3.11 show total dose to bone marrow at 1 mile from source as a function of a few independent inputs used for the CRAC2 analysis, and are typical of all results. Figures 3.6 through 3.9 demonstrate the weak correlations to releases. For Iodine and Cesium-equivalent releases, (Figs 3.6 and 3.7), the poor correlation is probably due to overwhelming effect of weather and dry deposition parameters. As noted in the previous section, the results were not surprising as far as individual group releases are concerned (Figs 3.8 and 3.9), since the total dose is a function of the total release from all groups. Individual release groups contribute only a small fraction to the total dose. Figures 3.11 and 3.12 illustrate the stronger correlations between total dose and weather stability class and dry deposition velocity. Figures 3.13 through 3.15 support the conclusions reached in section 3.3 regarding threshold effects as influenced by choice of dispersion models. Even though the uncertainty in probability of early fatality is dominated by weather stability class close to the source (see Fig. 3.14), a noticeable dependence of probabilityquantiles to the choice of dispersion model is evidenced in Figure 3.13. Correlation to weather stability class is seen to diminish with increasing distance while dependence on dispersion model increases (compare Figs 3.13 and 3.15 ). The effect of dispersion model near the threshold of fatalities was most evident 
Table 3.11 PRCC's for Whole Body Dose - CRAC2

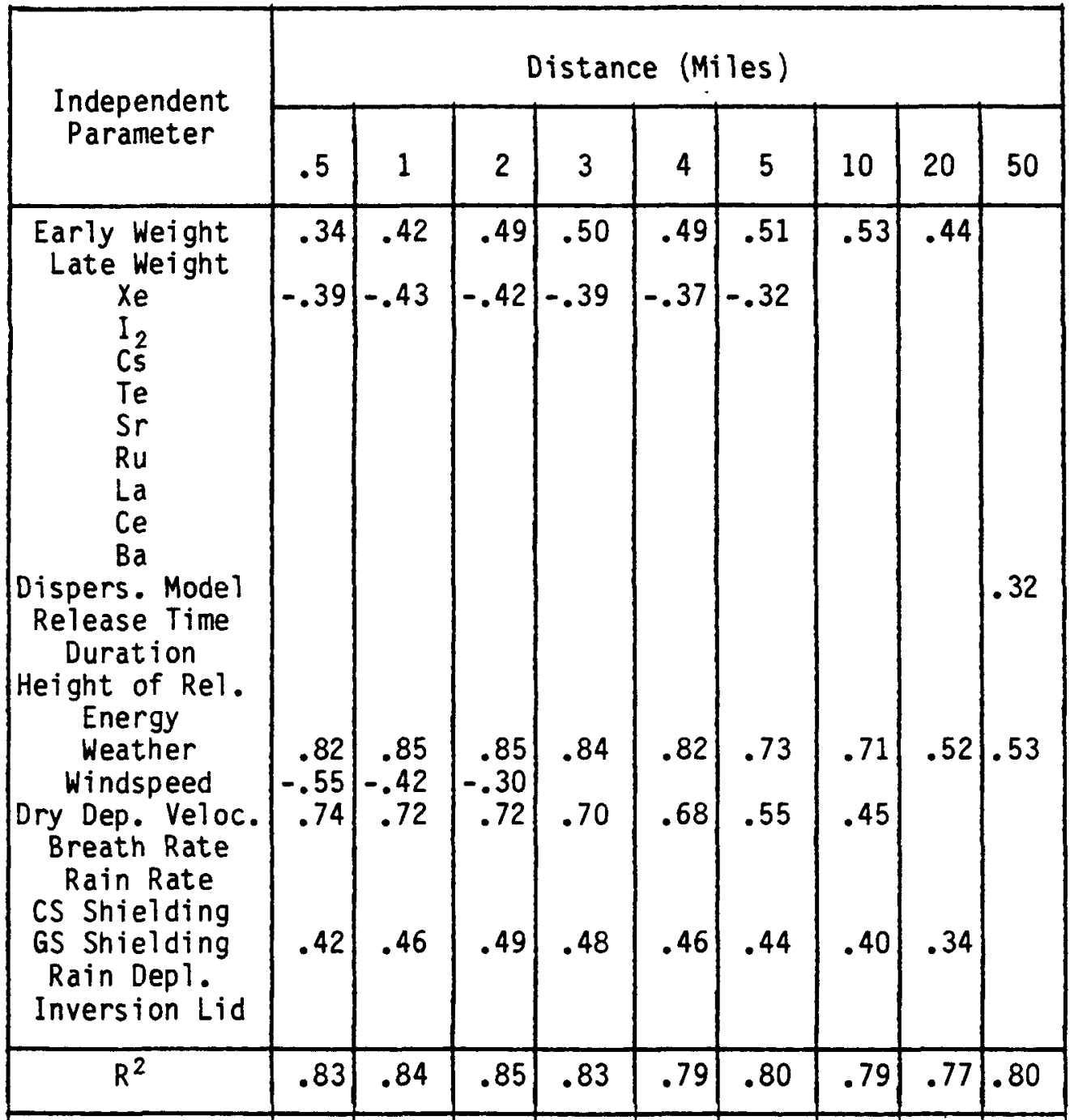


Table 3.12 PRCC's for Probability of Early Fatality - CRAC2

\begin{tabular}{|c|c|c|c|c|c|c|c|c|c|}
\hline \multirow{2}{*}{$\begin{array}{l}\text { Independent } \\
\text { Parameter }\end{array}$} & \multicolumn{9}{|c|}{ Distance (Miles) } \\
\hline & .5 & 1 & 2 & 3 & 4 & 5 & 10 & 20 & 50 \\
\hline $\begin{array}{c}\text { Early Weight } \\
\text { Late Weight } \\
\text { Xe } \\
\mathrm{I}_{2} \\
\text { Cs } \\
\text { Te } \\
\text { Sr } \\
\text { Ru } \\
\text { La } \\
\text { Ce } \\
\text { Ba } \\
\text { Dispers. Model } \\
\text { Release Time } \\
\text { Duration } \\
\text { Height of Rel. } \\
\text { Energy } \\
\text { Weather } \\
\text { Windspeed } \\
\text { Dry Dep. Veloc. } \\
\text { Breath Rate } \\
\text { Rain Rate } \\
\text { CS Shielding } \\
\text { GS Shielding } \\
\text { Rain Depl. } \\
\text { Inversion Lid }\end{array}$ & $\begin{array}{r} \\
.63 \\
-.35 \\
.48\end{array}$ & $\begin{array}{r}.69 \\
.51\end{array}$ & $\begin{array}{r}.50 \\
.30\end{array}$ & -.30 & & & & & \\
\hline$R^{2}$ & .68 & .68 & .39 & .33 & 0 & 0 & 0 & 0 & 0 \\
\hline
\end{tabular}


Table 3.13 PRCC's for Total Dose to Thyroid - MACCS

\begin{tabular}{|c|c|c|c|c|c|c|c|c|c|}
\hline \multirow{2}{*}{$\begin{array}{l}\text { Independent } \\
\text { Parameter }\end{array}$} & \multicolumn{9}{|c|}{ Distance (Miles) } \\
\hline & .5 & 1 & 2 & 3 & 4 & 5 & 10 & 20 & 350 \\
\hline $\begin{array}{c}\text { Early Weight } \\
\text { Late Weight } \\
\text { Xe } \\
\mathrm{I}_{2} \\
\text { Cs } \\
\text { Te } \\
\text { Sr } \\
\text { Ru } \\
\text { La } \\
\text { Ce } \\
\text { Ba } \\
\text { Dispers. Model } \\
\text { Release Time } \\
\text { Duration } \\
\text { Height of Rel. } \\
\text { Energy } \\
\text { Weather } \\
\text { Windspeed } \\
\text { Dry Dep. Veloc. } \\
\text { Breath Rate } \\
\text { Rain Rate } \\
\text { CS Shielding } \\
\text { GS Shielding } \\
\text { Rain Depl. } \\
\text { Inversion Lid }\end{array}$ & $\begin{array}{r}.41 \\
-.48 \\
.43\end{array}$ & $\begin{array}{r}.41 \\
-.49 \\
.39\end{array}$ & $\begin{array}{r}.39 \\
-.45 \\
.41\end{array}$ & $\begin{array}{r}.39 \\
-.43 \\
.42\end{array}$ & $\begin{array}{r}.39 \\
-.42 \\
.42\end{array}$ & $\begin{array}{r}.37 \\
-.36 \\
.41\end{array}$ & $\begin{array}{c}.36 \\
-.31 \\
.42\end{array}$ & $\begin{array}{r}.38 \\
-.72 \\
.37\end{array}$ & $\begin{array}{r}.48 \\
-.80\end{array}$ \\
\hline $\mathrm{R}^{2}$ & .9 & .88 & .87 & .86 & .85 & .83 & .83 & .84 & .82 \\
\hline
\end{tabular}


Table 3.14 PRCC's for Probability of Early Injury - MACCS

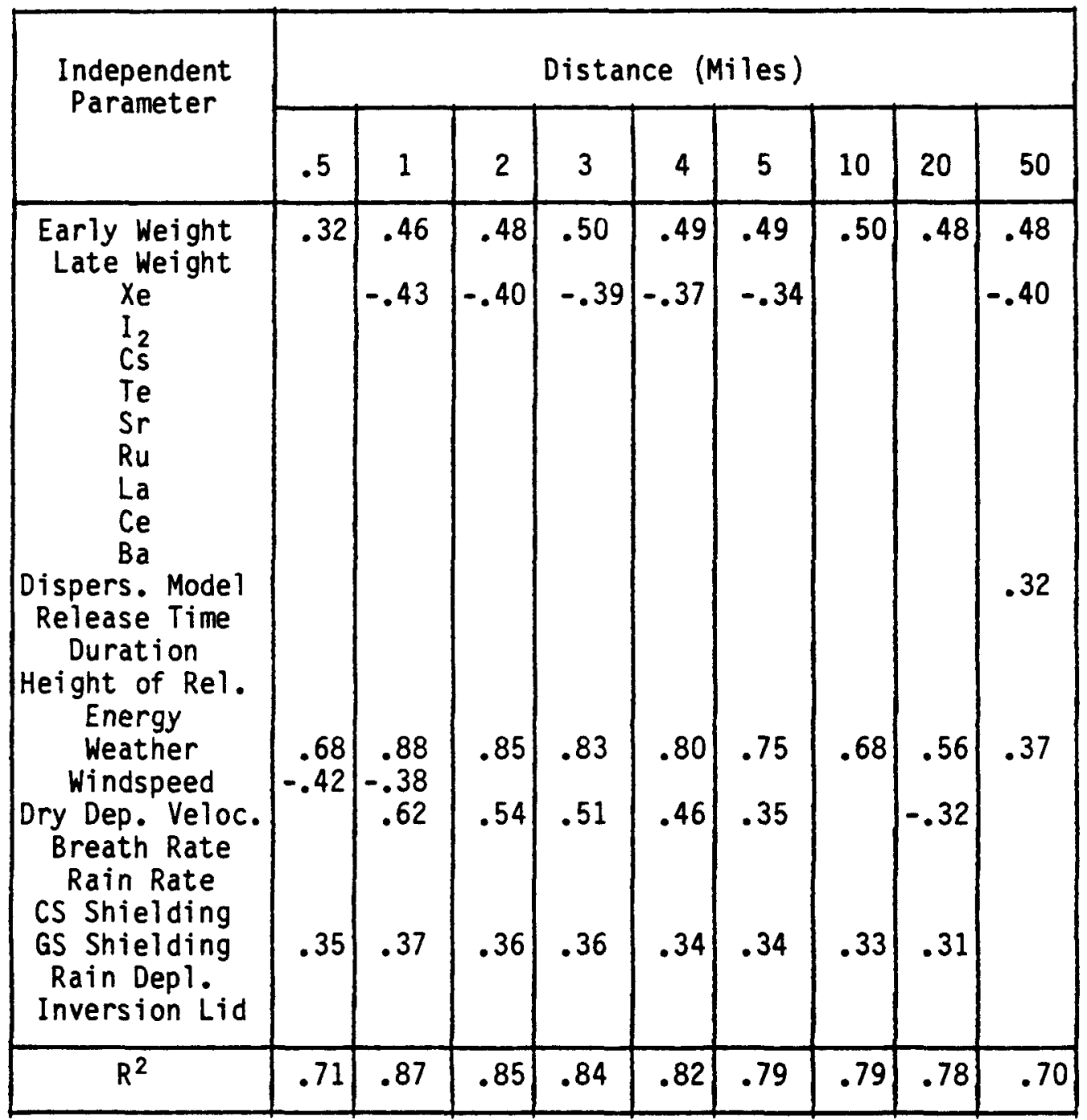


Table 3.15 PRCC's for Probability of Early Death - MACCS

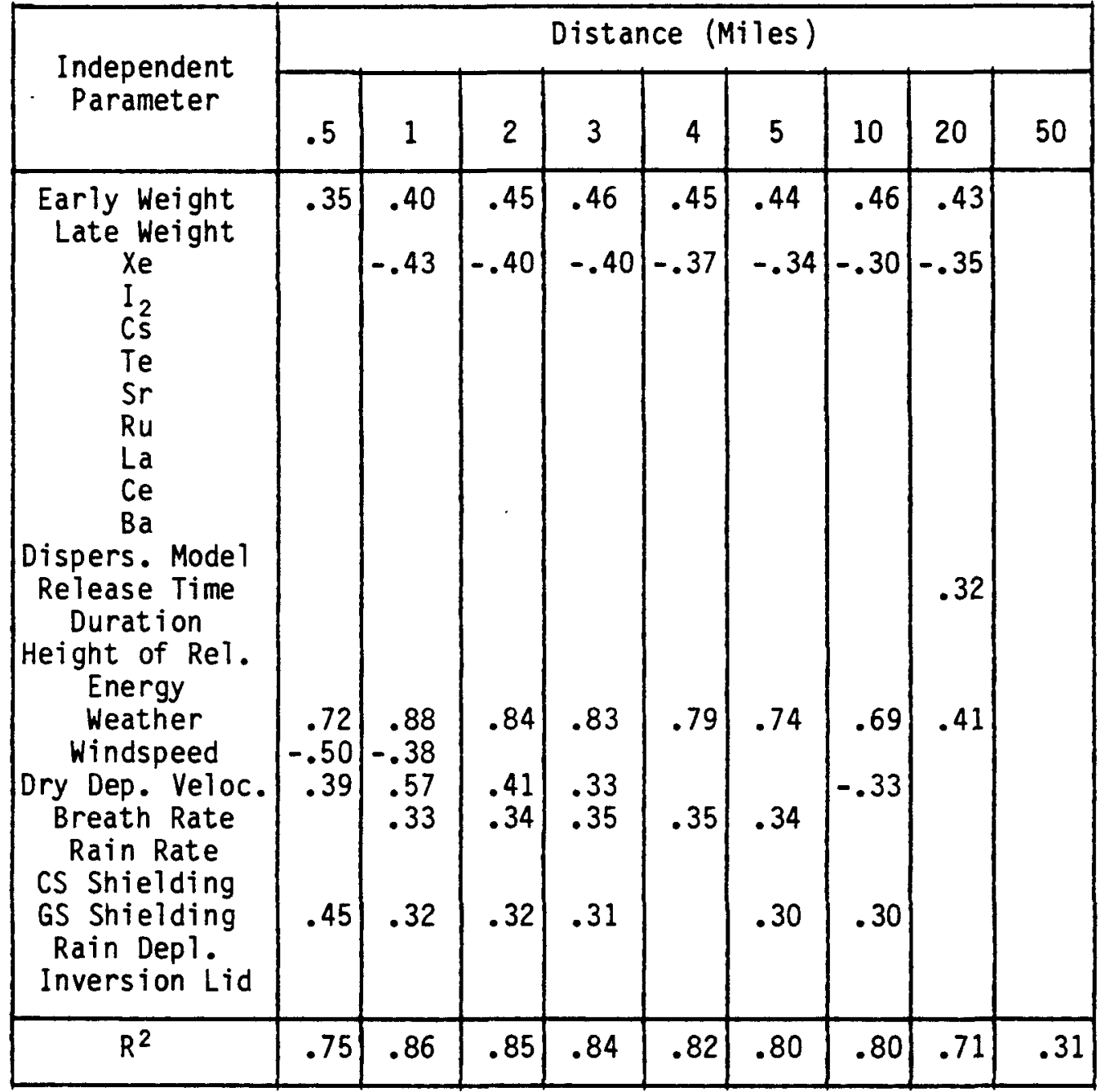




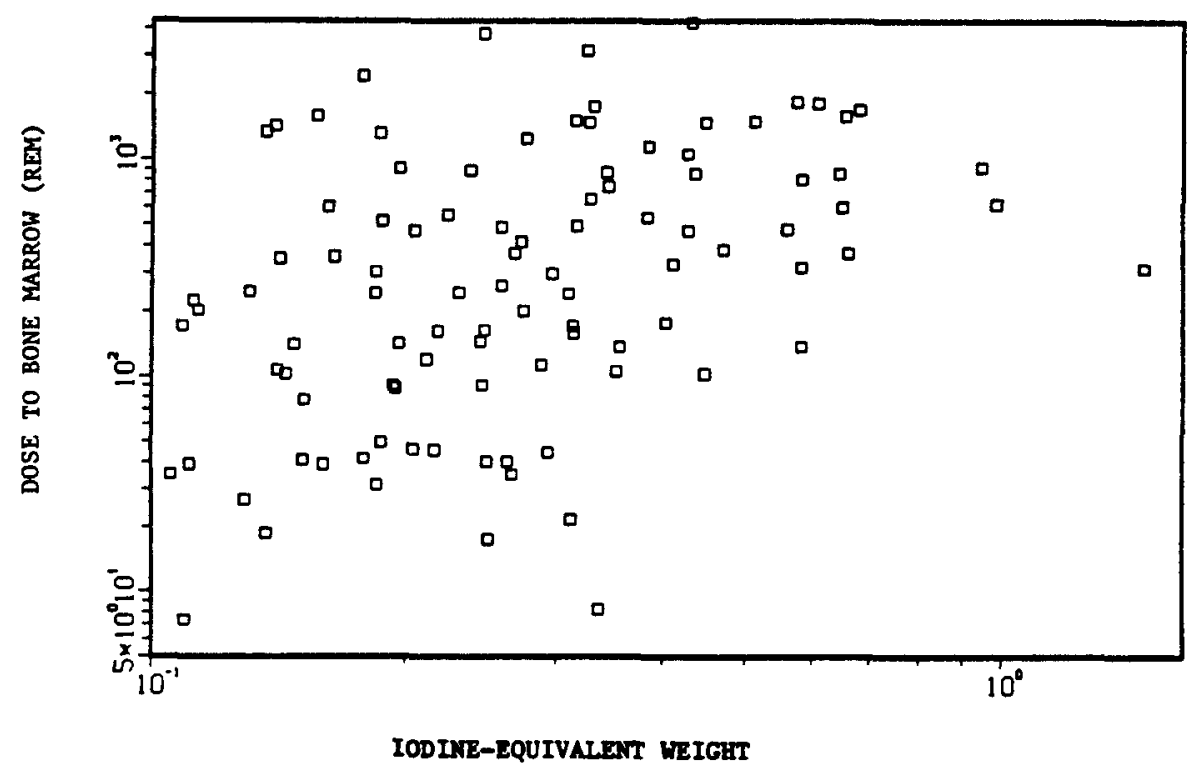

Figure 3.6 Total dose to bone marrow versus lodine-equivalent release, CRAC2 results at 1 mile.

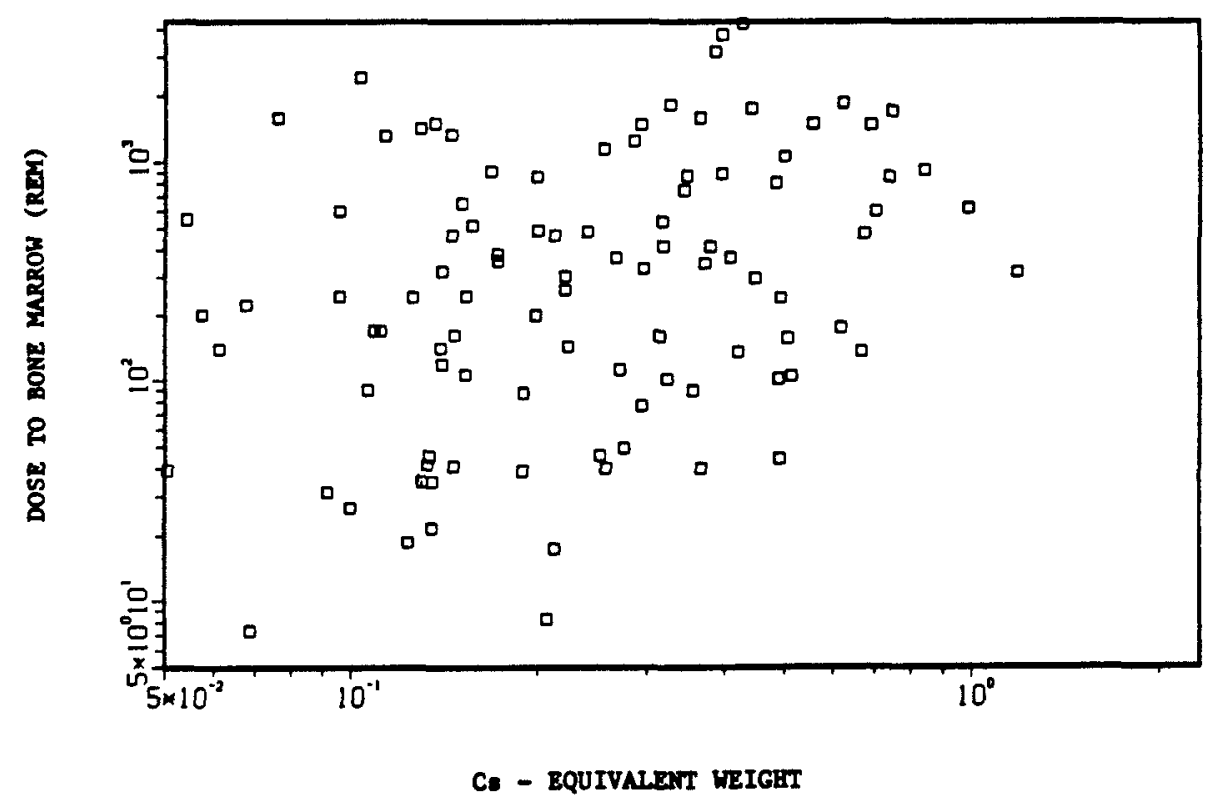

Figure 3.7 Total dose to bone marrow versus Cs-equivalent release, CRAC2 results at 1 mile. 


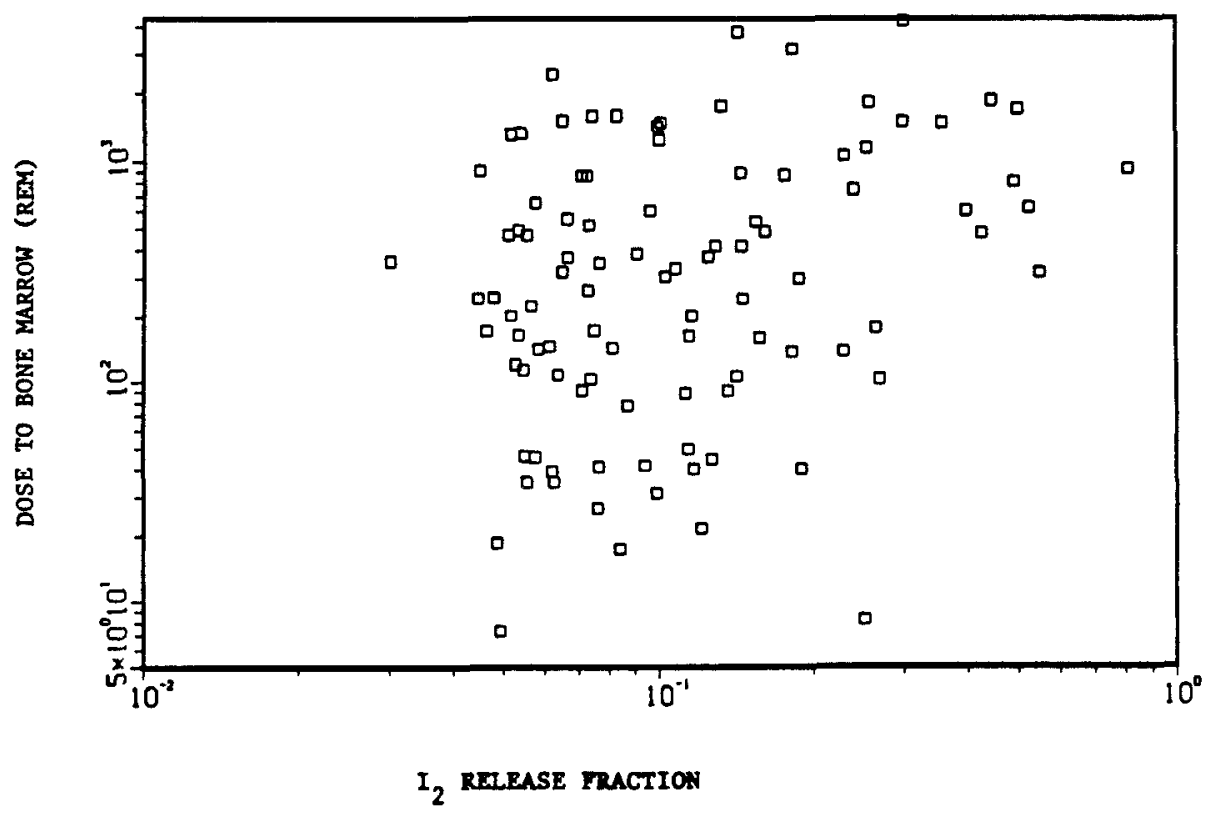

Figure 3.8 Total dose to bone marrow versus $I_{2}$ release, CRAC2 results at 1 mile.

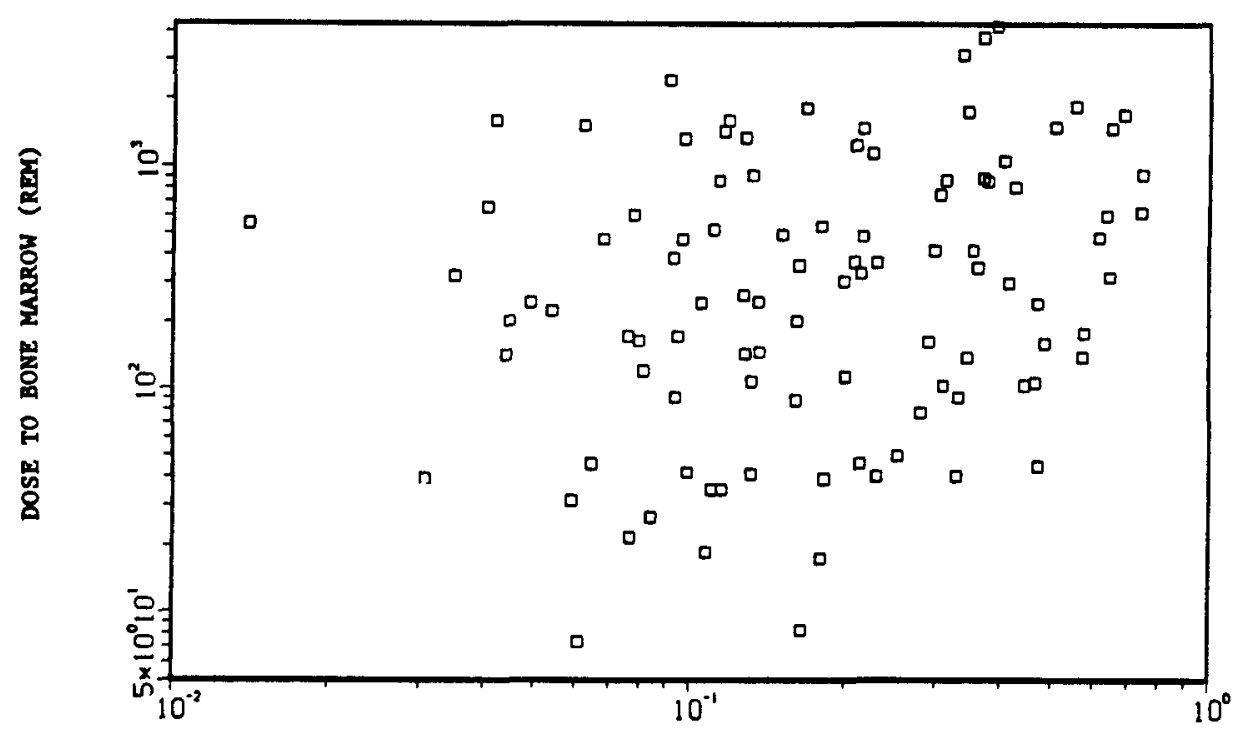

C. RELEASE FRACTION

Figure 3.9 Total dose to bone marrow versus Cs release, CRAC2 results at 1 mile. 


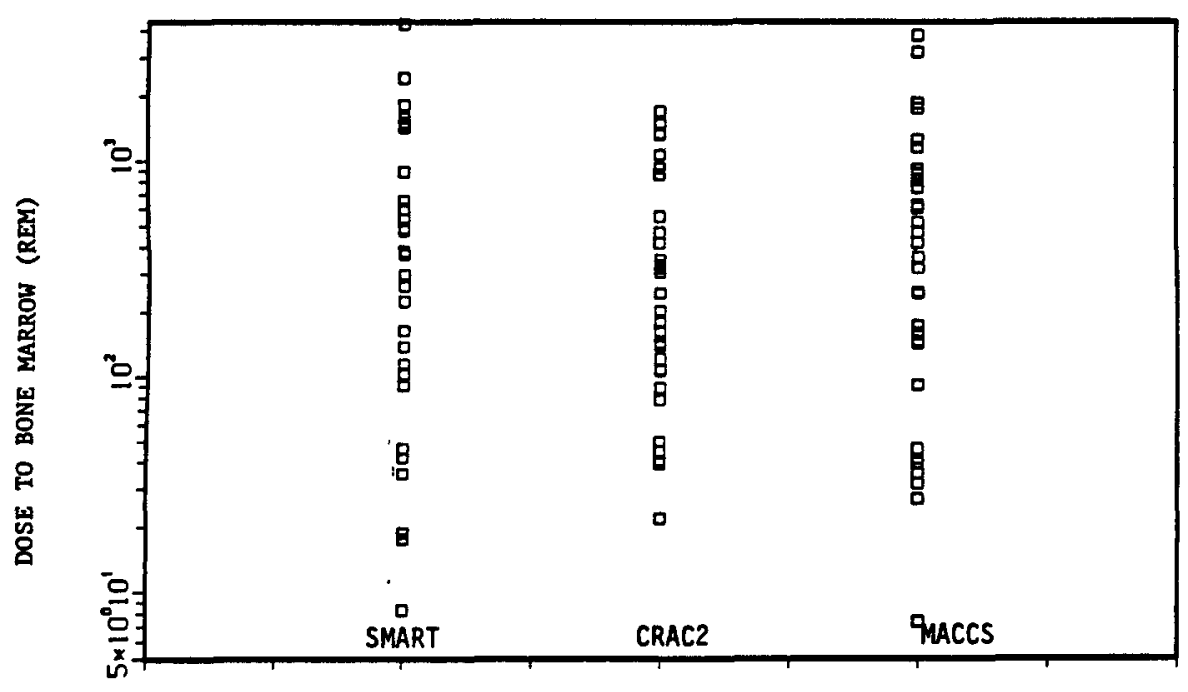

YODEL

Figure 3.10 Total dose to bone marrow versus dispersion models, CRAC2 results at 1 mile.

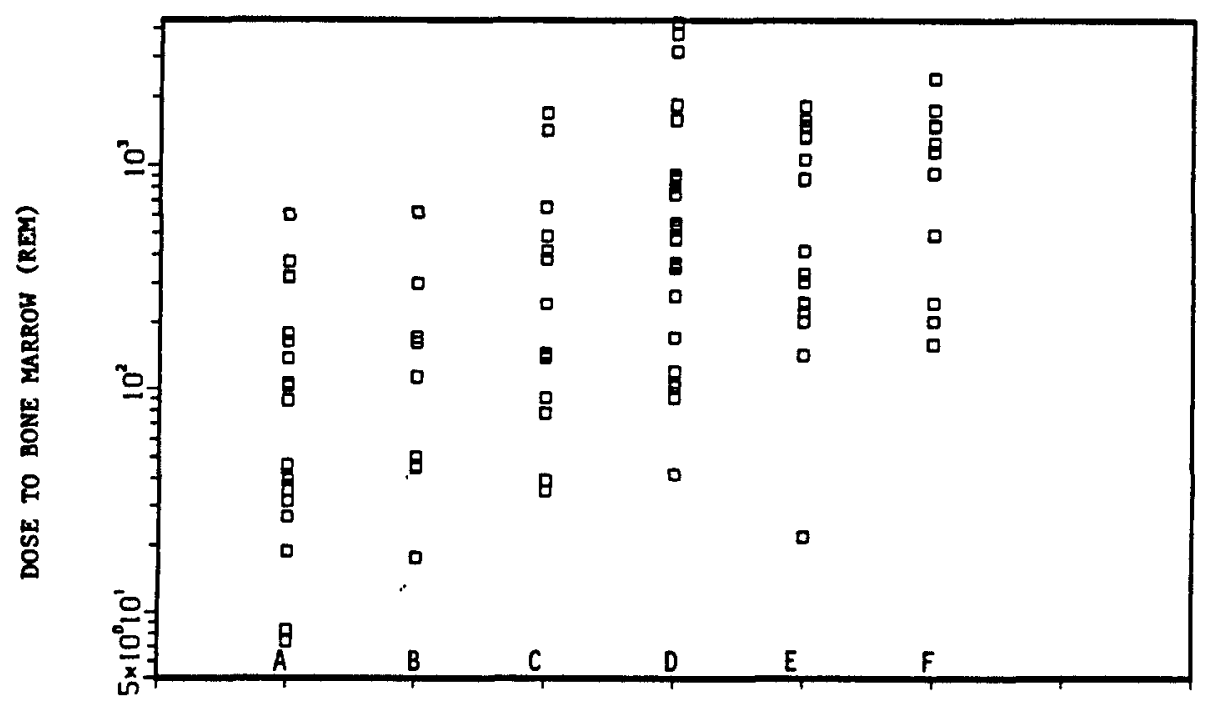

WEATHER STABILITY CLASS

Figure 3.11 Total dose to bone marrow versus weather stability class - CRAC2 results at 1 mile. 


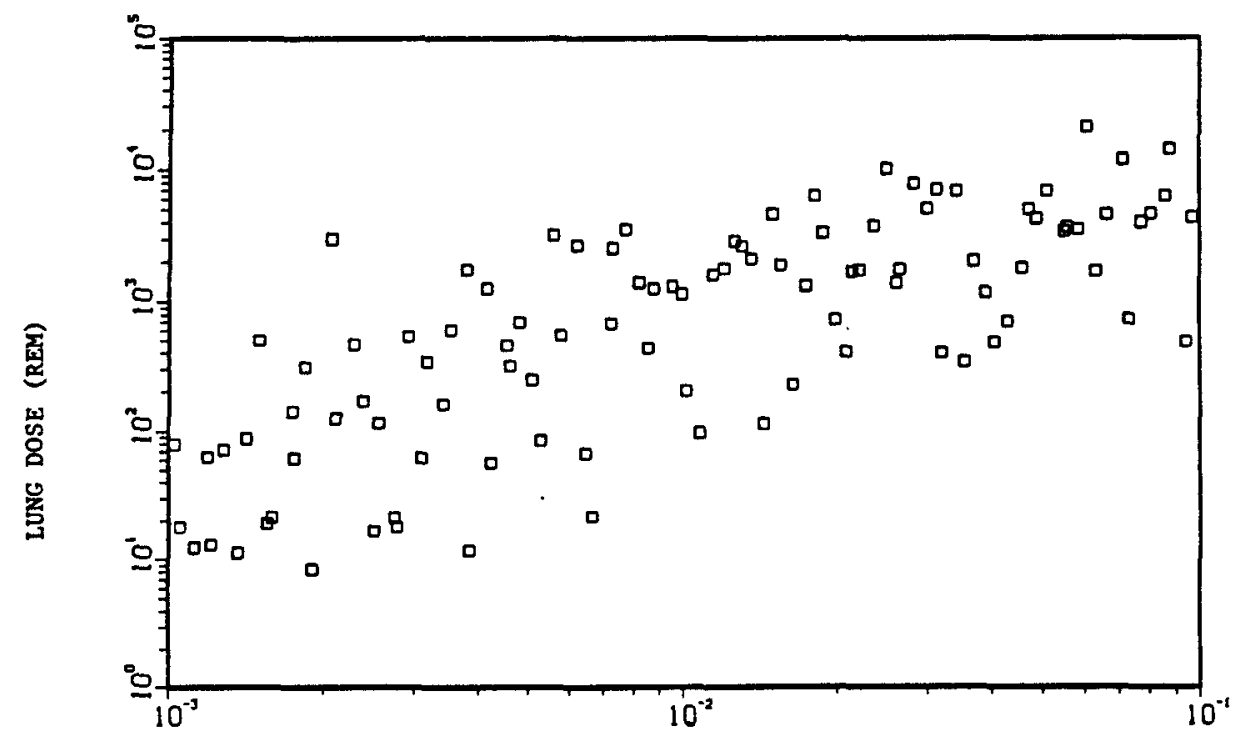

DRY DEPOSITION VELOCIIY ( $/ \mathrm{a})$

Figure 3.12 Total lung dose vs ary deposition velolty - CRAC2 results at 1 mile.

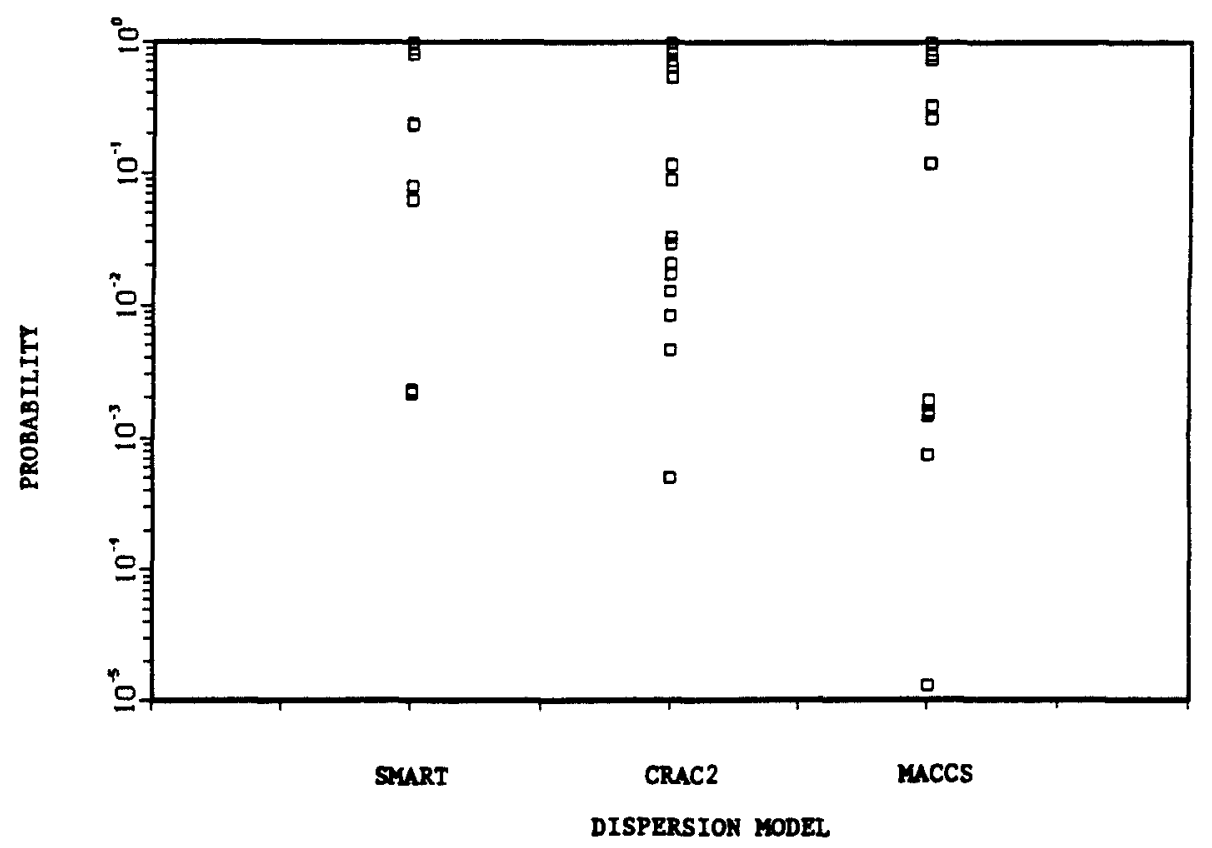

Figure 3.13 Probability of early fatality vs. dispersion model - MACCS results at 0.5 mile. 
$-40-$

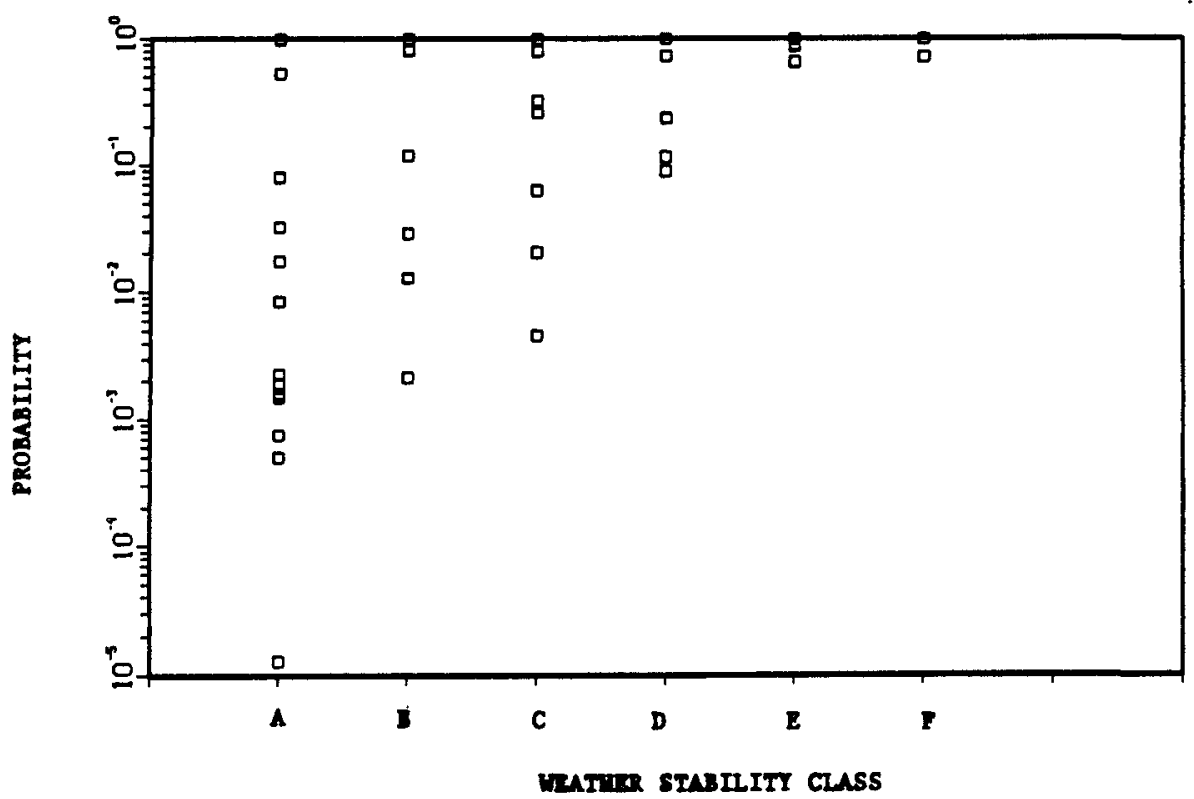

Figure 3.14 Probability of early fatality $r$. Wather stabflity class maccs results at 0.5 mile.

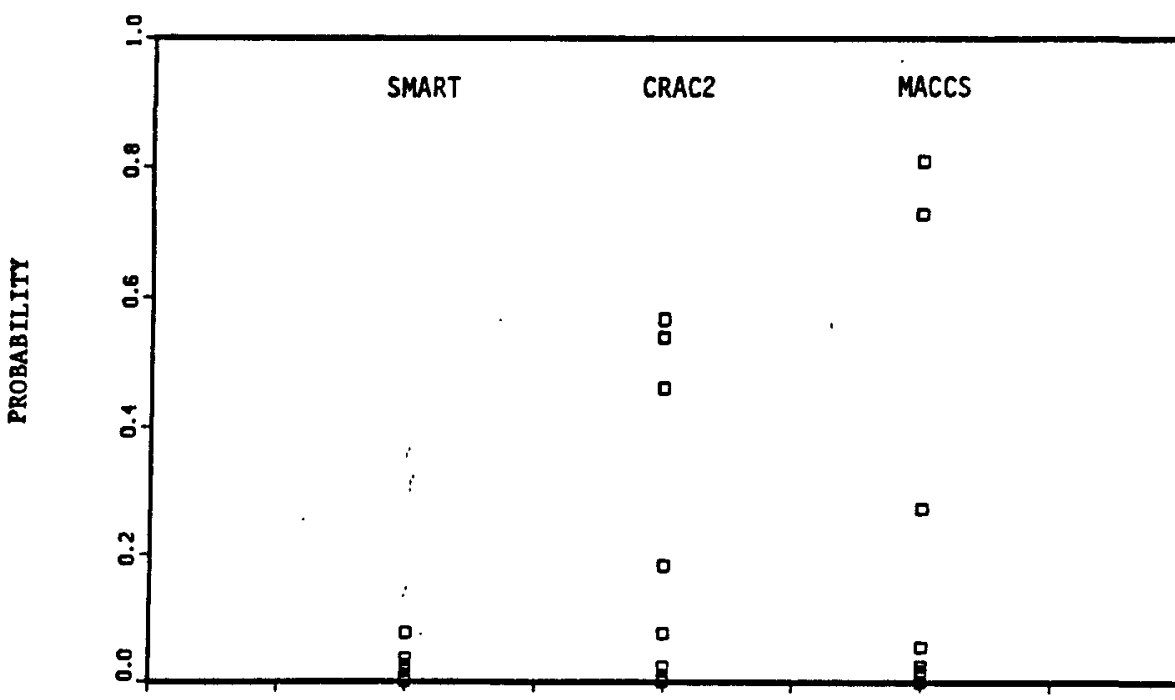

YODEE

Figure 3.15 Probability of early fatality vs. dispersion model; Maccs results at 5.0 miles. 
in the calculation of probability of early fatality at 50 miles for weather stability class D only. The only contribution to non-zero probability of early deaths is from the MACCS dispersion model, which in 2 cases (seven percent of the time), leads to doses slightly above threshold.

\subsubsection{Statistical Data Reduction}

Tables 3.16 and 3.17 show the quantiles, mean values and standard deviations for total marrow dose calculated respectively with CRAC2 and MACCS dose conversion factors. Results for other organs can be found in Appendix $G$. Doses to individual organs, as calculated by CRAC2 and MACCS are seen to be very similar with the exception of lung dose, for which MACCS predictions are much higher. However, when comparing probabilities of early fatality (Tables 3.18 and 3.19), the predictions of finite probabilities of early death from MACCS persist much further away from source than from CRAC2. This happens because the CRAC2 mode1 has a step-like threshold for early fatalities, while the MACCS model exhibits exponential decay with decrease in dose. Figure 3.16 shows comparisons of percentile envelopes for early fatality probability as computed by the two health effects models. The fifth quantile for CRAC2 is zero for all distances, and hence is not visible.

The same results for the 300 LHS sample test for MACCS are shown in Tables 3.20 and 3.21. As noted in the previous section, PRCCs were not affected by the increase in sample size. However, uncertainties increased by at least one order of magnitude because extreme weather samples were polled more often. Figure 3.17 illustrates the difference in quantiles and average values for the probability of early fatalities between the two tests with different sample sizes.

\subsubsection{Conclusions}

The results of the uncertainty and sensitivity analyses presented in this and the previous sections do not contradict the earlier studies of the CRAC2 code. Uncertainty due to weather conditions had been investigated in Reference [28] by comparing results of the 29 weather bins used in the code to results generated from 50 weather bins constructed by the authors. A low to moderate sensitivity of consequences to bin sampling was observed. In the present analysis, by using weather and rain distributions in an LHS technique, a possibiy wider range of weather data was sampled, hence increasing the sensitivity of the results to weather stability class and average wind speed. Neither of the earlier uncertainty analyses had included the dry deposition velocity as an independent parameter. Low sensitivity to radionuclide releases is due in part to non-correlated release group distributions, and in part to a more narrow parameter space than the one used, for instance, in Reference [27]. In our analysis, the iodine-weighted releases varied between 0.12 and 1.04 , while in Reference [27] this parameter varied between 0.07 and 1.43 .

Moreover, uncertainties related to releases were shown in Section 3.3 .2 to span approximately one order of magnitude for doses. In the full multiparameter analysis these uncertainties increased to more than three orders of magnitude, hence uncertainty due to source terms is overwhelmed by uncertainties in other parameters, which the PRCC analysis showed to be more strongly correlated to the outputs. Low probability of rain for the Peach Bottom site makes rain rate and wet depletion models unimportant in a general, multi-parameter analysis. The 
Table 3.16 Multiparameter Uncertainty Analysis: Total Bone Marrow Dose Using CRAC2 Dose Conversion Factors

\begin{tabular}{|c|c|c|c|c|c|c|c|}
\hline OIST. (MI) & MIN & MAX & $5-T H$ & $50-T H$ & $95-T H$ & AVER & SIGMA \\
\hline 0.5 & $2.114 E+01$ & $1.266 E+04$ & $1.042 E+02$ & $9.397 E+02$ & $5.061 E+03$ & $1.774 E+03$ & $2.401 E+03$ \\
1.0 & $7.355 E+00$ & $4.265 E+03$ & $2.416 E+01$ & $3.114 E+02$ & $1.841 E+03$ & $167035+02$ & $7.768 E+02$ \\
2.0 & $6.503 E-05$ & $8.191 E+02$ & $5.094 E+00$ & $7.683 E+01$ & $3.662 E+02$ & $1.266 E+02$ & $1.410 E+02$ \\
3.0 & $3.102 E-09$ & $4.306 E+02$ & $2.896 E+00$ & $4.532 E+01$ & $2.094 E+02$ & $6.988 E+01$ & $7.656 E+01$ \\
4.0 & $1.614 E-13$ & $2.705 E+02$ & $1.980 E+00$ & $2.888 E+01$ & $1.397 E+02$ & $4.529 E+01$ & $4.932 E+01$ \\
5.0 & $8.995 E-18$ & $1.580 E+02$ & $1.255 E+00$ & $1.729 E+01$ & $9.206 E+01$ & $2.738 E+01$ & $3.007 E+01$ \\
10.0 & $1.785 E-24$ & $4.844 E+01$ & $5.351 E-01$ & $5.929 E+00$ & $3.375 E+01$ & $9.169 E+00$ & $9.932 E+00$ \\
20.0 & $7.907 E-25$ & $1.602 E+01$ & $8.835 E-02$ & $1.600 E+00$ & $9.944 E+00$ & $2.842 E+00$ & $3.235 E+00$ \\
50.0 & $2.050 E-25$ & $2.996 E+00$ & $5.305 E-03$ & $4.433 E-01$ & $2.530 E+00$ & $7.074 E-01$ & $7.825 E-01$ \\
350.0 & $2.886 E-2 B$ & $6.544 E-02$ & $7.368 E-05$ & $1.815 E-03$ & $3.001 E-02$ & $6.598 E-03$ & $1.115 E-02$ \\
\hline
\end{tabular}

Table 3.17 Multiparameter uncertainty Analysis: Total Bone Marrow Using MaCCS Dose Conversion Factors

\begin{tabular}{|c|c|c|c|c|c|c|c|}
\hline DIST. (MI) & MIN & $M A X$ & $5-T H$ & $50-T H$ & $95-T H$ & AVER & SIGMA \\
\hline 0.5 & $1.439 E+01$ & $8.697 E+03$ & $6.538 E+01$ & $7.572 E+02$ & $4.833 E+03$ & $1.357 E+03$ & $1.709 E+03$ \\
1.0 & $9.767 E-02$ & $1.304 E+03$ & $6.066 E+00$ & $1.372 E+02$ & $7.136 E+02$ & $2.268 E+02$ & $2.531 E+02$ \\
2.0 & $4.132 E-06$ & $4.673 E+02$ & $3.203 E+00$ & $5.287 E+01$ & $2.749 E+02$ & $8.600 E+01$ & $9.094 E+01$ \\
3.0 & $2.030 E-10$ & $2.599 E+02$ & $1.887 E+00$ & $3.083 E+01$ & $1.532 E+02$ & $5.004 E+01$ & $5.267 E+01$ \\
4.0 & $1.076 E-14$ & $1.658 E+02$ & $1.330 E+00$ & $2.057 E+01$ & $1.010 E+02$ & $3.293 E+01$ & $3.465 E+01$ \\
5.0 & $5.338 E-20$ & $9.816 E+01$ & $8.481 E-01$ & $1.269 E+01$ & $6.394 E+01$ & $2.010 E+01$ & $2.127 E+01$ \\
10.0 & $1.748 E-24$ & $3.472 E+01$ & $4.303 E-01$ & $4.816 E+00$ & $2.578 E+01$ & $7.481 E+00$ & $7.937 E+00$ \\
20.0 & $5.138 E-25$ & $1.012 E+011$ & $4.981 E-02$ & $1.009 E+00$ & $6.187 E+00$ & $1.794 E+00$ & $1.998 E+00$ \\
50.0 & $2.089 E-25$ & $2.515 E+00$ & $3.675 E-03$ & $3.557 E-01$ & $2.028 E+00$ & $5.725 E-01$ & $6.282 E-01$ \\
350.0 & $3.006 E-28$ & $5.413 E-02$ & $2.080 E-05$ & $6.906 E-04$ & $2.944 E-02$ & $5.433 E-03$ & $9.953 E-03$ \\
\hline
\end{tabular}

Table 3.18 multiparameter Uncertainty Analysts: Probability of Early Death Calculated by the CRAC2 Health Effect Model

\begin{tabular}{|c|c|c|c|c|c|c|c|}
\hline DIST. (MI) & MIN & MAX & $5-T H$ & $50-T H$ & $95-T H$ & AVER & SIGMA \\
\hline 0.5 & $0.000 E+00$ & $1.000 E+00$ & $0.000 E+00$ & $1.000 E+00$ & $1.000 E+00$ & $6.286 E-01$ & $4.752 E-01$ \\
1.0 & $0.000 E+00$ & $1.000 E+00$ & $0.000 E+00$ & $0.000 E+00$ & $1.000 E+00$ & $3.129 E-01$ & $4.512 E-01$ \\
2.0 & $0.000 E+00$ & $1.000 E+00$ & $0.000 E+00$ & $0.000 E+00$ & $1.731 E-02$ & $1.274 E-02$ & $9.979 E-02$ \\
3.0 & $0.000 E+00$ & $4.148 E-02$ & $0.000 E+00$ & $0.000 E+00$ & $0.000 E+00$ & $4.148 E-04$ & $4.127 E-03$ \\
4.0 & $0.000 E+00$ & $0.000 E+00$ & $0.000 E+00$ & $0.000 E+00$ & $0.000 E+00$ & $0.000 E+00$ & $0.000 E+00$ \\
5.0 & $0.000 E+00$ & $0.000 E+00$ & $0.000 E+00$ & $0.000 E+00$ & $0.000 E+00$ & $0.000 E+00$ & $0.000 E+00$ \\
10.0 & $0.000 E+00$ & $0.000 E+00$ & $0.000 E+00$ & $0.000 E+00$ & $0.000 E+00$ & $0.000 E+00$ & $0.000 E+00$ \\
20.0 & $0.000 E+00$ & $0.000 E+00$ & $0.000 E+00$ & $0.000 E+00$ & $0.000 E+00$ & $0.000 E+00$ & $0.000 E+00$ \\
50.0 & $0.000 E+00$ & $0.000 E+00$ & $0.000 E+00$ & $0.000 E+00$ & $0.000 E+00$ & $0.000 E+00$ & $0.000 E+00$ \\
\hline
\end{tabular}

Table 3.19 Multi-parameter Uncertainty Analysis: Probability of Early Death Calculated by the MACCS Kealth Effect Model

\begin{tabular}{|c|c|c|c|c|c|c|c|}
\hline DIST. (MI) & MIN & MAX & $5-T H$ & $50-T H$ & $95-T H$ & AVER & SIGMA \\
\hline 0.5 & $1.287 E-05$ & $1.000 E+00$ & $1.541 E-03$ & $1.000 E+00$ & $1.000 E+00$ & $7.321 E-01$ & $4.066 E-01$ \\
1.0 & $0.000 E+00$ & $1.000 E+00$ & $2.414 E-06$ & $2.582 E-02$ & $1.000 E+00$ & $2.755 E-01$ & $3.922 E-01$ \\
2.0 & $0.000 E+00$ & $8.869 E-01$ & $4.768 E-07$ & $8.122 E-04$ & $2.864 E-01$ & $4.423 E-02$ & $1.278 E-01$ \\
3.0 & $0.000 E+00$ & $2.179 E-01$ & $1.192 E-07$ & $2.078 E-04$ & $5.437 E-02$ & $8.593 E-03$ & $2.762 E-02$ \\
4.0 & $0.000 E+00$ & $7.948 E-02$ & $2.980 E-08$ & $4.873 E-05$ & $1.489 E-02$ & $2.495 E-03$ & $8.976 E-03$ \\
5.0 & $0.000 E+00$ & $2.091 E-02$ & $0.000 E+00$ & $1.040 E-05$ & $3.765 E-03$ & $6.043 E-04$ & $2.307 E-03$ \\
10.0 & $0.000 E+00$ & $1.339 E-03$ & $0.000 E+00$ & $4.470 E-07$ & $1.733 E-04$ & $3.438 E-05$ & $1.450 E-04$ \\
20.0 & $0.000 E+00$ & $2.128 E-05$ & $0.000 E+00$ & $0.000 E+00$ & $1.669 E-06$ & $4.870 E-07$ & $2.369 E-06$ \\
50.0 & $0.000 E+00$ & $7.749 E-07$ & $0.000 E+00$ & $0.000 E+00$ & $2.980 E-08$ & $1.490 E-08$ & $9.363 E-08$ \\
\hline
\end{tabular}


Table 3.20 Multiparameter Uncertainty Analysis With Larger Sample Size: Total Dose to Bone Marrow Calculated with MACCS Dose Conversion Factors

\begin{tabular}{|c|c|c|c|c|c|c|c|}
\hline OIST.(MI) & MIN & MAX & $5-T H$ & $50-T H$ & $95-T H$ & AVER & SIGMA \\
\hline 0.5 & $1.266 E+01$ & $4.026 E+04$ & $5.658 E+01$ & $6.325 E+02$ & $6.306 E+03$ & $1.672 E+03$ & $3.481 E+03$ \\
1.0 & $2.804 E-03$ & $5.096 E+03$ & $5.390 E+00$ & $1.132 E+02$ & $1.123 E+03$ & $2.842 E+02$ & $5.538 E+02$ \\
2.0 & $6.469 E-07$ & $2.054 E+03$ & $2.019 E+00$ & $4.592 E+01$ & $4.165 E+02$ & $1.049 E+02$ & $1.937 E+02$ \\
3.0 & $3.113 E-07$ & $1.224 E+03$ & $1.436 E+00$ & $2.606 E+01$ & $2.439 E+02$ & $6.057 E+01$ & $1.110 E+02$ \\
4.0 & $6.606 E-09$ & $8.241 E+02$ & $1.038 E+00$ & $1.711 E+01$ & $1.518 E+02$ & $3.967 E+01$ & $7.265 E+01$ \\
5.0 & $3.219 E-12$ & $5.384 E+02$ & $8.238 E-01$ & $1.062 E+01$ & $8.651 E+01$ & $2.424 E+01$ & $4.494 E+01$ \\
10.0 & $6.208 E-19$ & $2.204 E+02$ & $4.780 E-01$ & $4.169 E+00$ & $3.340 E+01$ & $9.122 E+00$ & $1.724 E+01$ \\
20.0 & $7.898 E-37$ & $5.575 E+01$ & $5.711 E-02$ & $9.133 E-01$ & $8.249 E+00$ & $2.290 E+00$ & $4.721 E+00$ \\
50.0 & $1.870 E-37$ & $2.125 E+01$ & $9.031 E-03$ & $3.151 E-01$ & $3.371 E+00$ & $8.609 E-01$ & $2.184 E+00$ \\
350.0 & $0.000 E+00$ & $2.480 E-01$ & $2.330 E-05$ & $5.305 E-04$ & $3.471 E-02$ & $6.614 E-03$ & $1.841 E-02$ \\
\hline
\end{tabular}

Table 3.21 Multiparameter Uncertainty Analysis With Larger Sample Size: Probability of Early Death Calculated by the MACCS Health Effects Model

\begin{tabular}{|c|c|c|c|c|c|c|c|}
\hline DIST. (MI) & MIN & MAX & $5-\mathrm{TH}$ & $50-\mathrm{TH}$ & 95-TH & AVER & SIGMA \\
\hline $\begin{array}{r}0.5 \\
1.0 \\
2.0 \\
3.0 \\
4.0 \\
5.0 \\
10.0 \\
20.0 \\
50.0\end{array}$ & $\mid \begin{array}{l}2.199 E-05 \\
0.000 E+00 \\
0.000 E+00 \\
0.000 E+00 \\
0.000 E+00 \\
0.000 E+00 \\
0.000 E+00 \\
0.000 E+00 \\
0.000 E+00\end{array}$ & $\begin{array}{l}1.000 E+00 \\
1.000 E+00 \\
1.000 E+00 \\
1.000 E+00 \\
1.000 E+00 \\
1.000 E+00 \\
2.825 E-01 \\
3.829 E-03 \\
1.402 E-04\end{array}$ & $\begin{array}{l}1.383 E-03 \\
1.431 E-06 \\
8.941 E-08 \\
2.980 E-08 \\
0.000 E+00 \\
0.000 E+00 \\
0.000 E+00 \\
0.000 E+00 \\
0.000 E+00\end{array}$ & $\begin{array}{l}1.000 E+00 \\
1.300 E-02 \\
6.157 E-04 \\
1.122 E-04 \\
2.879 E-05 \\
5.364 E-06 \\
2.980 E-07 \\
0.000 E+00 \\
0.000 E+00\end{array}$ & $\mid \begin{array}{l}1.000 E+00 \\
1.000 E+00 \\
8.696 E-01 \\
1.427 E-01 \\
3.354 E-02 \\
8.255 E-03 \\
3.620 E-04 \\
6.407 E-06 \\
2.980 E-07\end{array}$ & $\begin{array}{l}7.081 E-01 \\
2.401 E-01 \\
7.744 E-02 \\
3.566 E-02 \\
1.391 E-02 \\
5.270 E-03 \\
1.041 E-03 \\
1.443 E-05 \\
5.827 E-07\end{array}$ & {$\left[\begin{array}{l}4.094 \mathrm{E}-01 \\
3.741 \mathrm{E}-01 \\
2.286 \mathrm{E}-01 \\
1.517 \mathrm{E}-01 \\
7.869 \mathrm{E}-02 \\
5.826 \mathrm{E}-02 \\
1.628 \mathrm{E}-02 \\
2.207 \mathrm{E}-04 \\
8.123 \mathrm{E}-06\end{array}\right.$} \\
\hline
\end{tabular}




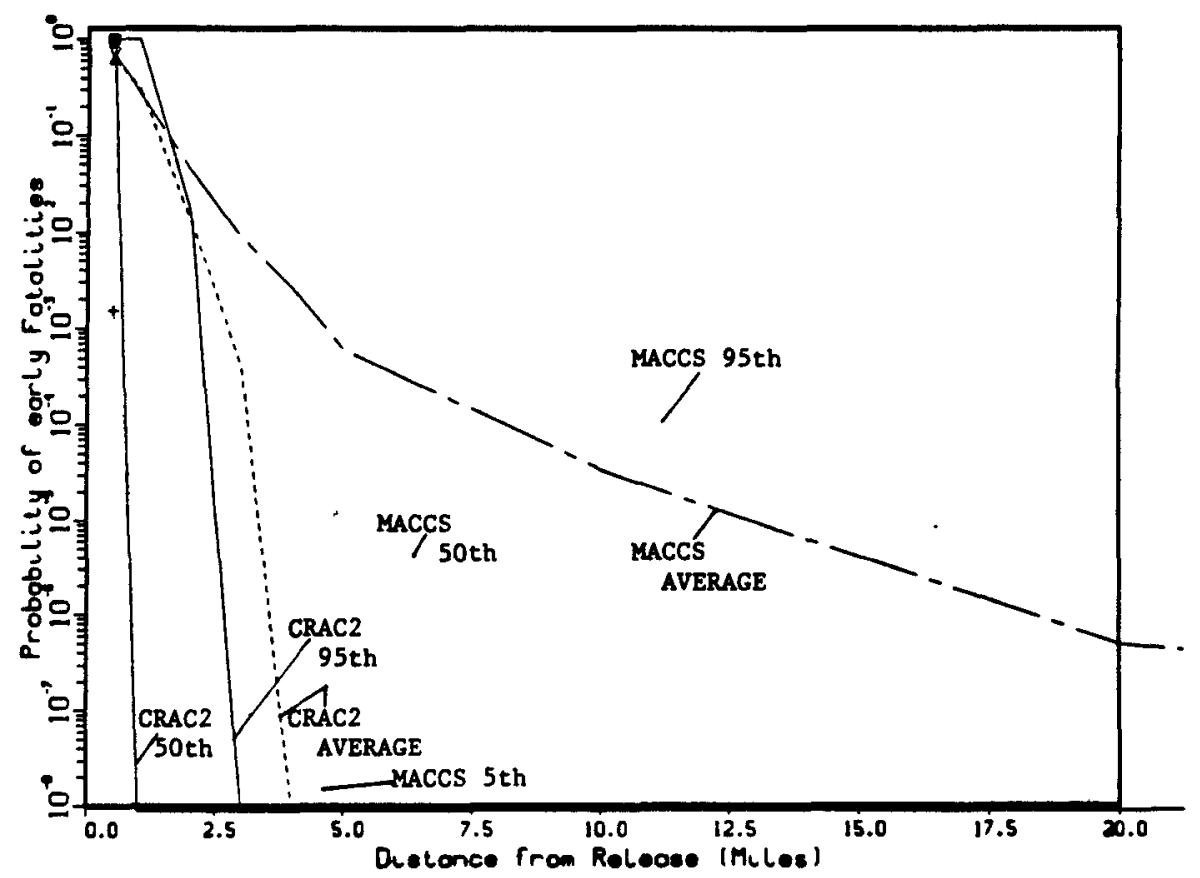

Figure 3.16 Cemperison between CRAC2 and maCCs calculations - probability of early fatality $r s$. distance.

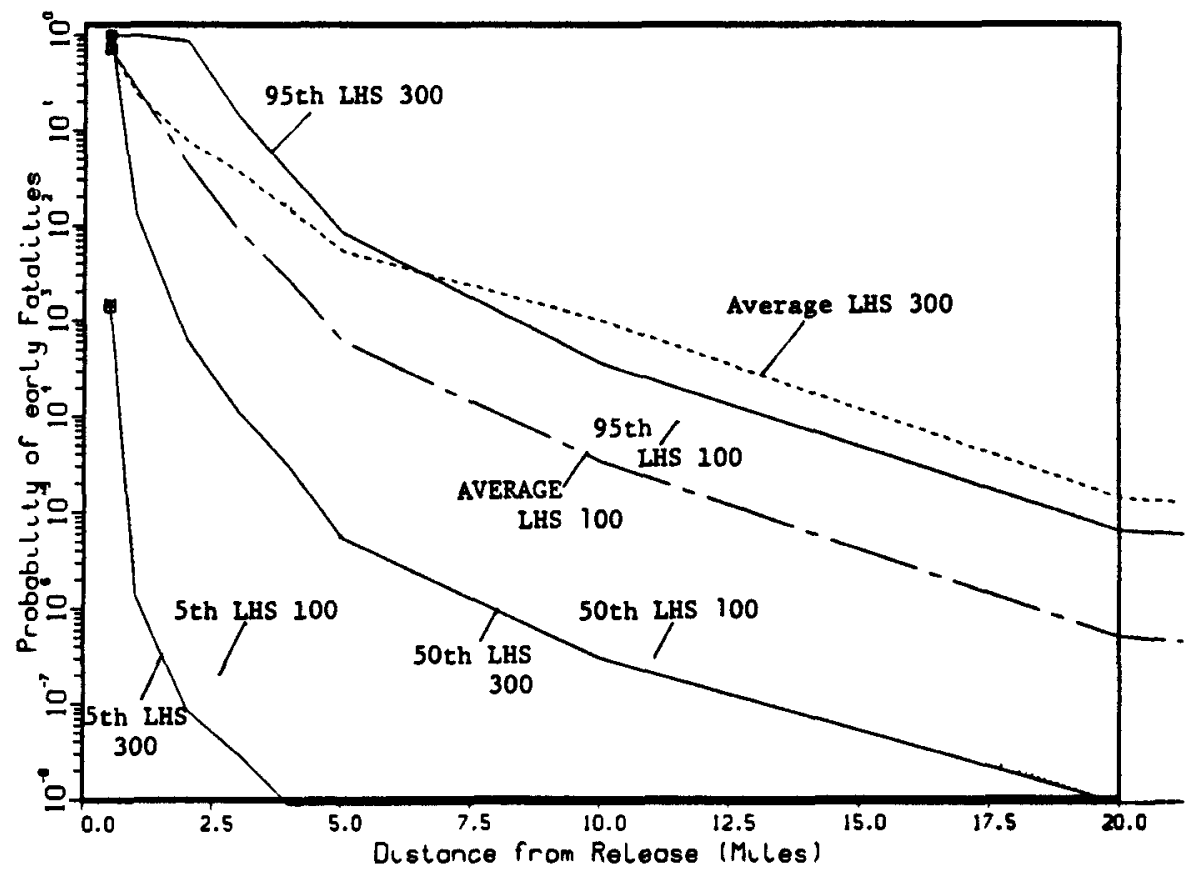

Figure 3.17 Comparison of LHS sample size - MACCS probability of early fatality vs. distance. 
dependence of uncertainties on weather conditions (stability class, windspeed) is so strong that perhaps bin sampling in the codes should be re-evaluated, to ensure that more samples be taken from extreme weather conditions.

An illustration of this dependence is shown in Figures 3.18 and 3.19 . Uncertainties of fifth and ninety fifth percentiles for dose to marrow calculated by the SMART code using MACCS dose conversion factors at two miles increase by one order of magnitude for the larger sample size, and are three orders of magnitude wider than the uncertanties related to source terms alone. The increase in dose uncertainty is magnified in the calculation of probability of early death. Minima for the LHS100 and LHS 300 results are several orders of magnitude below the fifth percentile while for the sensitivity study to source terms alone they are still within the scale shown in the figures.

Again, weather-driven uncertainty is so large that quoting mean values for consequences does not properly represent the results, and the usage of quantiles provides a more meaningful estimate. For instance, Table 3.22 shows results for total cancer deaths from MACCS calculations for two $2 i$ on releases [26], namely, cluster 1, and cluster 26, which are respectively the largest and smallest releases considered. The mean consequences for the two releases are vastly different. However, the consequence distributions are seen to overlap.

A more careful review of the data on dry and wet deposition velocities should be performed, and uncertainties in these parameters narrowed if possible, since they are major contributors to uncertainty in consequences. As evidenced in the literature, the currently used dispersion models are not valid beyond 50 miles of the release point, while they still appear to contribute substantially to the uncertainties. For distances up to 2 miles, building wake effect is very important. Finally, as concluded in Reference [29], the CRAC2 health effect model for probability of early death predicts zero mortality rates beyond a very short distance from the release point (three miles in the present calculations, two miles in the sensitivity analys is of [29]). MACCS models predict in general higher mortality rates up to that point, and a finite probability of early death that persists up to $50 \mathrm{miles.}$ 


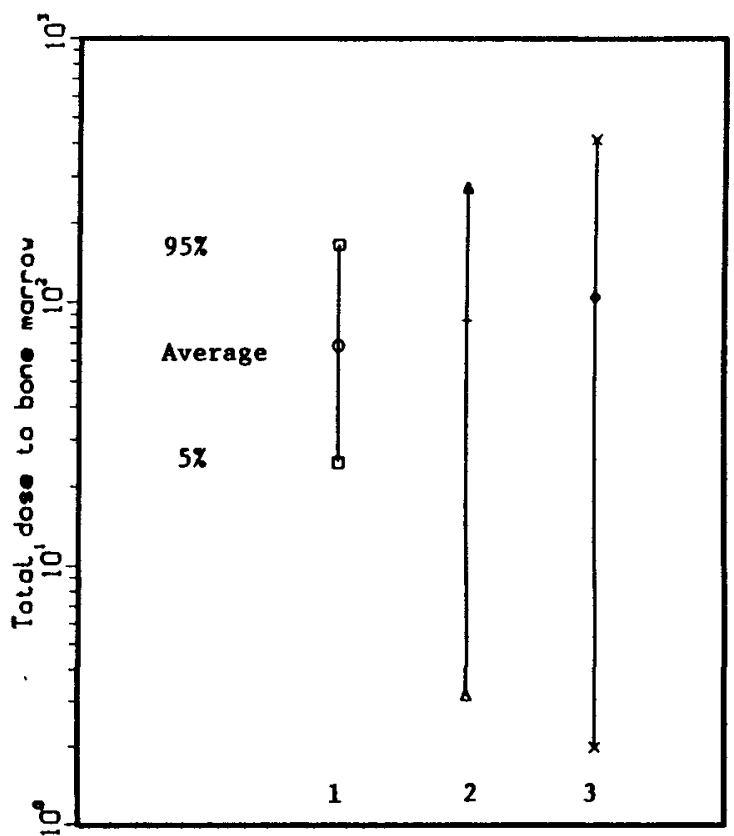

1 = source terms

uncertainty (D5)

2,3 = multiparameter

uncertainty

2 - sample size of 100

3 - sample s1ze of 300

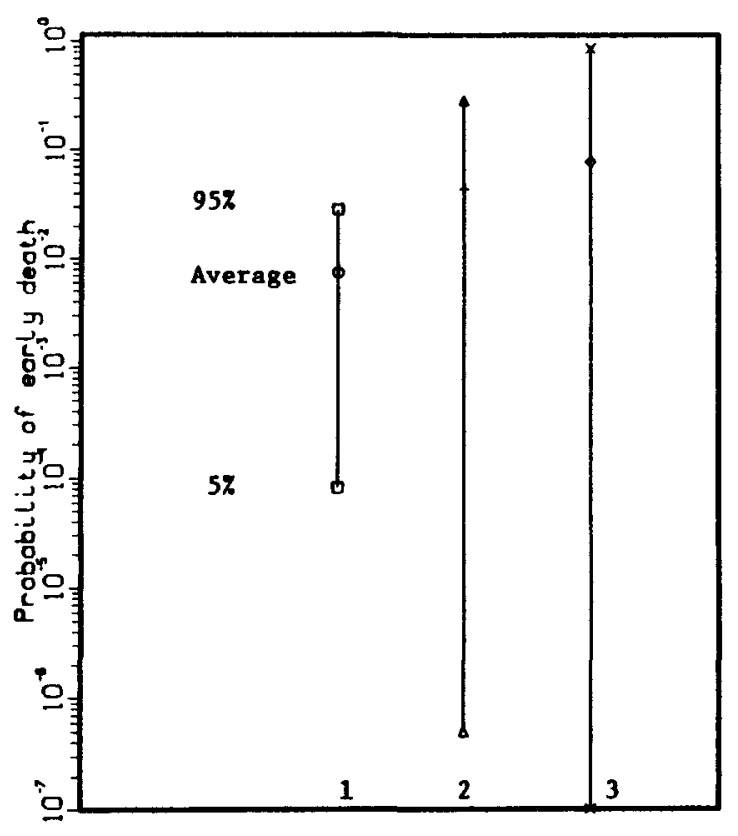

i
Figure 3.18 Uncertainty in total dose to bone marrow at 2 miles calculated by SMART code.
Figure 3.19 Uncertainties in probabillty of early death at 2 miles calculated by SMART code. 
Table 3.22 Total Cancer Deaths Calculated by MACCS for ZION Clusters 1 and 26.

\begin{tabular}{|c|l|l|l|r|r|r|r|}
\hline Cluster & $\begin{array}{l}\text { Iodine- } \\
\text { Equivalent } \\
\text { Weight }\end{array}$ & $\begin{array}{l}\text { Total Mean } \\
\text { Cancer } \\
\text { Deaths }\end{array}$ & 5 th & 50 th & 95th & 99th & Peak \\
\hline 1 & 301 & 18100 & 2500 & 14000 & 49900 & 75600 & 105000 \\
26 & .12 & 448 & 35 & 265 & 1660 & 4350 & 8270 \\
Ratio $1 / 26$ & 25.1 & 40.4 & 71.4 & 52.8 & 30.1 & 17.4 & 12.7 \\
\hline
\end{tabular}




\section{CONCLUSIONS}

A personal computer-based model has been developed that uses an integral approach for calculating early offsite consequences from nuclear reactor accidents. The computing time requirements for a typical calculation on a mainframe computer using this model are over two orders of magnitude lower than those of CRAC2 and MACCS codes, thus providing a valuable tool for sensitivity and uncertainty studies. The model uses simplified meteorology and predicts the timeintegrated air concentration of each radionuclide at any distance from the point of release as a function of the time-integrated source strength using the Gaussian plume model. The solution procedure involves direct analytic integration of air concentration equations over time and position. This is different from the discretization approach currently used in the CRAC2 and MACCS codes. Following the approach in CRAC2 and MACCS, the model includes dry and wet deposition, radioactive decay and daughter buildup, and the effects of reactor building wake, inversion lid, plume rise, release duration, and grass height. Early dose to an individual is calculated via cloudshine, short-term groundshine, and inhalation. The dose calculations are performed in the same manner as CRAC2 and MACCS. The health effect models in both CRAC2 and MACCS are included for the calculation of early fatalities. The health effects model in MACCS for early injuries is also included.

The present code was benchmarked against both MACCS version 1.4 and CRAC2. A sensitivity study to plume dispersion parameters showed that the models included in the codes can produce a fairly large uncertainty in calculated doses up to two miles from release point. An uncertainty analysis related to the magnitude of the source terms, which covered almost the entire spectrum of accident releases for a BWR, showed that uncertanties in dose calculations span about one order of magnitude, and increase to two or three orders of magnitude in the calculation of health effects. A multi-parameter uncertainty analysis revealed that the uncertainty in all results is dominated by the choice of weather conditions, dry deposition velocity, and to a lesser degree by radionuclide releases. The uncertainty introduced by the calculation of dispersion parameters, however, can still be significant in the calculation of health effects at large distances from the release point. 


\section{REFERENCES}

1. Wall, I. B. et al., "Overview of the Reactor Safety Study Consequence Mode1," NUREG-0340, U.S. Nuclear Regulatory Commission, 1977.

2. OECD, "International Comparison Study of Reactor Accident Consequence Models," Committee on the Safety of Nuclear Installation, Nuclear Energy Agency, Organization for Economic Cooperation and Development, June 1983.

3. Ritchie, L. T. et al., "Calculations of Reactor Accident Consequences Version 2 User's Guide," NUREG/CR-2326 (SAND81-1994), Sandia National Laboratories, February 1983.

4. Chanin, D. I. et al., "MELCOR Accident Consequence Code System Vol. I User's Guide," NUREG/CR-4691 (SAND86-1562), Sandia National Laboratories, 1987.

5. "Reactor Risk Reference Document", NUREG-1150, Draft, February 1987.

6. Slade, D. H. (Ed.), Meteorology and Atomic Energy 1968, U.S. Atomic Energy Commission, TID-24190, 1968.

7. Lamarsh, J. R., Nuclear Reactor Theory, Addison-Wesley, Reading, MA, 1966.

8. Pasquill, F., "The Estimation of the Dispersion of Windborne Material," Meteorol. Mag., 90 (1063): 33-49, 1961.

9. Lamarsh, J. R., Introduction to Nuclear Engineering, 2nd Ed., AddisonWesley, Reading, MA, 1983.

10. Gifford, F. A., "A Review of Turbulent Diffusion Typing Schemes," Nuclear Safety, Vol. 17, pp. 68-86, 1976.

11. Wilson, R. et al., "Report to the American Physical Society of the Study Group on Radionuclide Release from Severe Accidents at Nuclear Power Plants," Reviews of Modern Physics, Vol. 57, No. 3, Part II, July 1985.

12. Horst, T. W., "A Surface Depletion Model for Deposition from a Gaussian Plume," Atmospheric Environment, Vol. 11, pp. 41-46, 1977.

13. Hosker, Jr., R. P., "Estimates of Dry Deposition and Plume Depletion Over Forests and Grassland," Physical Behavior of Radioactive Contaminants in the Atmosphere, IAEA STI/PUB/354, International Atomic Energy Agency, Vienna, p. 291, 1974.

14. "Reactor Safety Study: Appendix 6: Calculation of Reactor Accident Consequences," U.S. Nuclear Regulatory Commission, WASH-1400, NUREG-75/014, October 1975.

15. "PRA Procedures Guide - A Guide to the Performance of Probabilistic Risk Assessments for Nuclear Power Plants," U.S. Nuclear Regulatory Commission, NUREG/CR-2300, Vol. 2, January 1983. 
16. Ritchie, L. T., Brown, W. D., and Wayland, J. R., "Effects of Rainstorms and Runoff on Consequences of Nuclear Reactor Accidents," SAND76-0429, Sandia National Laboratories, Albuquerque, NM, 1976.

17. Ritchie, L. T., Aldrich, D. C., and Blond, R. M., "Weather Sequence Sampling for Risk Calculations," Transactions of the American Nuclear Society, Vol. 18, p. 113, 1981.

18. Holland, J. Z., "A Meteorological Survey of the Oak Ridge Area: Final Report Covering the Period 1948-52," USAEC Report OR0-99, Weather Bureau, Oak Ridge, TN, 1953.

19. Briggs, G. A., "Plume Rise Predictions," Lectures on Air Pollution and Environmental Impact Analyses, Workshop Proceedings, American Meteorologi cal Society, Boston, MA, pp. 59-111, 1975.

20. Ritchie, L. T., Chanin, D. I., and Sprung, J. L., MACCS Reference Manual, NUREG/CR-4691 (SAND86-1562), Sandia National Laboratories, Draft Version, May 1987.

21. Hanna, S. R., Briggs, G. A., and Hosker, Jr., R. P., Handbook of Atmospheric Diffusion, DOE/TIC-11223, U.S. Department of Energy, Springfield, VA, 1982 .

22. "American Meteorological Society Workshop on Stability Classification Schemes and Sigma Curves - Summary and Recommendations," Bullet in of the American Meteorological Society, Vol. 58, 1977.

23. Holzworth, G. C., "Mixing Heights, Wind Speeds, and Potential for Urban Air Pollution Throughout the Contiguous United States," AP-101, U.S. EPA, Office of Air Programs, Research Triangle Park, NC, 1972.

24. Lewis, E. E., Nuclear Power Reactor Safety, John Wiley \& Sons, NY, 1977.

25. Evans, J. S., Moeller, D. W., and Cooper, D. W., "Health Effects Model for Nuclear Power Plant Accident Consequence Analys is," NUREG/CR-4214 (SAND857185), Sandia National Laboratories, July 1985.

26. M. Khatib-Rahbar et al., "Evaluation of Severe Accident Risks and Potential for Risk Reduction: Zi on Power Plant", NUREG/CR-4551, Brookhaven National Laboratory, February 1987.

27. D.J. Alpert et al., "A Demonstration Uncertainty/Sensitivity Analysis Using the Health and Economic Consequence Model CRAC2; NUREG/CR-4199 (Sand841824), Sandia National Laboratories, May 1985.

28. D.C. Koeher et al., "Sensitivity and Uncertainty Studies of the CRAC2 Computer Code", Risk Analysis Vol. 7, No. 4, pp 497-507, 1987. 
29. G. D. Kaiser, "Implications of Reduced Source Terms for Ex-Plant Conseqence Modeling and Emergency Planning", Nuclear Safety, Vol. 27, No. 3, JulySeptember 1986, pgg 369-384.

30. R. L. Iman and M. J. Shortencarier, "A FORTRAN 77 Program and User's Guide for the Generation of Lat in Hypercube and Random Sampler for use with Computer Models", NUREG/CR-3624 (SAND84-2365), Sandia National Laboratories, March 1984.

31. M. Khatib-Rahbar et a1., "On the Uncertainties in Core Melt Progression, Fission Product Release and Pressurization Loads for a BWR Mark I Containment", BNL Technical Report A-3286 (2-20-88).

32. D. J. Alpert et al., "Relative Importance of Individual Elements to Reactor Accident Consequences Assuming Equal Release Fractions", NUREG/CR-4467, SAND85-2575 (March 1986).

33. D. C. Aldrich, "Technical Guidance for Siting Criteria Development", NUREG/CR-2239 (1982).

34. R. Iman et al., "A FORTRAN77 Program and User's Guide for the Calculation of Partial Correlation and Standardized Regression Coefficients", NUREG/CR4122, June 1985. 
A-1

APPENDIX A

User's Guide 
Compliation and use of the program

The commands used to complle and run SMART on a VAX mainframe computer ere: FORTRAN SMART

IINT SKART

RON SMART

On a PC, the program can be divided into sections for editing and compliling ease. In the example given below, the following sections were defined: SMMAIN (main program), subroutines COXP,BFFBC and a section named SMSUBS whioh includes all other subroutines.

These were complied with the PROFORT IBY complier and afterwards linked with the default IBM FORTRAN Iinker:

PROFORT SMYAIN

PROFORT COMP

PROFORT EFFEC

PROFORT SMSUBS

LINK SMMAIN+COKP+EFFEC+SMSUBS;

The executable file thus generated occupies approximatly 124K memory. To run the program, enter the command:

SMMAIN.

Output from the run is saved on TAPE2 (FOROOZ.DAT On a VAX, FORTZ on a PC).

Caution should be exercised in using the printout option on a PC, since a large output with individual nuclide contribution to doses can be generated. It is suggested that this option be used only on a mainframe computer. Abbreviated output is saved on the same tape. All doses are expressed in Rems, even if internally the code uses Bq units for MaCCS calculations.

SMART executes interactively. Most parameters can be changed at run time. Appendix $B$ shows most of the menu of questions which must be answered. In a batch version, as the one used for the sensitivity/uncertainty analysis with input generated by an external code, the interactive reader subroutine must be replaced.

Data bases are provided as inputs. PWR and BWR core inventories (1n Ci) for 54 nuclides are contalned in flles PWR.DAT and BWR.DAT. In the present data bases, reference power is respectively 3412 and 3578 kwth.

At run time, inventories are converted to Sv if KaCCs dose conversion factors are used. These files also provide nuclide half lives, parent-daughter relationships and $a$ map of radionuclides to the nine groups Noble Gases, Iodines, Cs, Te, Sr, Ru, La, Ce and $\mathrm{Ba}$.

In each of these files, the following data is also defined:

Distances from release points at which concentrations are calculated.

Default dose conversion factor tables to be used.

P.G. curves fitting parameters.

Deposition velocity and breathing rate.

Deposition velocity is assumed to be zero by SMART for all noble gases.

Default conversion tables, which can be changed at run time,for 
CRAC2 are:

Ground-shine: 0 to 1 day

Inhalation red marrow 0 to 7 days

Inhalation ILIV 0 to 30 years

Inhalation thyroid 0 to 30 years

Inhalation lung 0 to 30 years.

Two data bases are provided for CRAC2 and MACCS dose conversion tables, DOSECR.DAT and DOSEMACCS.DAT.

The first file contains the following tabular data for each of the 54 nuclides :

Cloudshine dose conversion factors for whole body, total

marrow, lung, thyrold and ILIW.

Groundshine conversion factors for the same organs for one day exposure.

Groundshine conversion factors for 7 days exposure.

Whole body inhalation conversion factors, 0-2 days.

Marrow Inhalation factors, 0-2 days, 0-7 days, 0-30 days,

$0-30$ years.

III inhalation conversion factors, same exposures as marrow.

Thyroid conversion factors, same exposures as marrow.

Iung conversion factors, $0-2$ days, $0-7$ days, $0-30$ days, $0-1$ year, 0-30 years.

Skeleton conversion factors, same exposures as lung.

All the data was taken from Reference [24]. A comparison w1th CRAC2 dose conversion tables was performed and a few inconsistencies corrected to reflect data used in CRAC2. Some tables, as the whole body inhalation, are missing in [24], and taken directly from the CRAC2 data base.

DOSEMACCS.DAT contains the following dose conversion factors for each of the 54 nuclides:

cloudshine,

Groundshine 8 hours,

groundshine 7 days,

iffetime inhalation,

for stomach, small intestine, lungs, red marrow, thyroid and IIIW. The data was extracted from the dose conversion factor file provided for MACCS 1.4 .

Subroutine description

SMART: main program.

RDRCR: this subroutine reads CRAC2 dose conversion factors file (TAPE1).

Core inventory (in Ci), default values, P.G. curves

coefficients and distances at which doses and consequences are calculated are also input here (TAPE3I).

COMP: this subroutine calculates a1r concentrations and doses.

EFFBC: this subroutine calculates health effects with both CRAC2 and MACCS models. 
A-4

CROUT: th1s subroutine outputs CRAC2 data. All doses are in Rem units.

SIG: this subroutine calculates dispersion parameters using a polynomial fit to P.G. curves.

RDR2: th1s subroutine controls all interactive input.

SHINCF: this subroutine calculates finite cloud effect on cloud-shine.

POL2: this subroutine interpolates for finite cloud effect.

RDRMA: this subroutine reads MACCS dose oonversion factors file (TAPEI). Core inventory (in C1), default values, P.G. curves coefficients and distances at which doses and consequences are calculated are also input here (TAPB31). Core inventory is converted to Sv units for consistency with MACCS calculations.

MAOUT: this subroutine outputs MACCS data. All doses are in Rem units.

REST: this subroutine resets to zero arrays used in the calculations for all distances; this subroutine is called if calculations are to be repeated from the beginning.

SIGCR: this subroutine calculates dispersion parameters using the CRAC2 and MACCS models.

ZZBAR: this subroutine celculates the effective height of the plume. 


\section{B-1}

APPENDIX B

Source Code Listing 


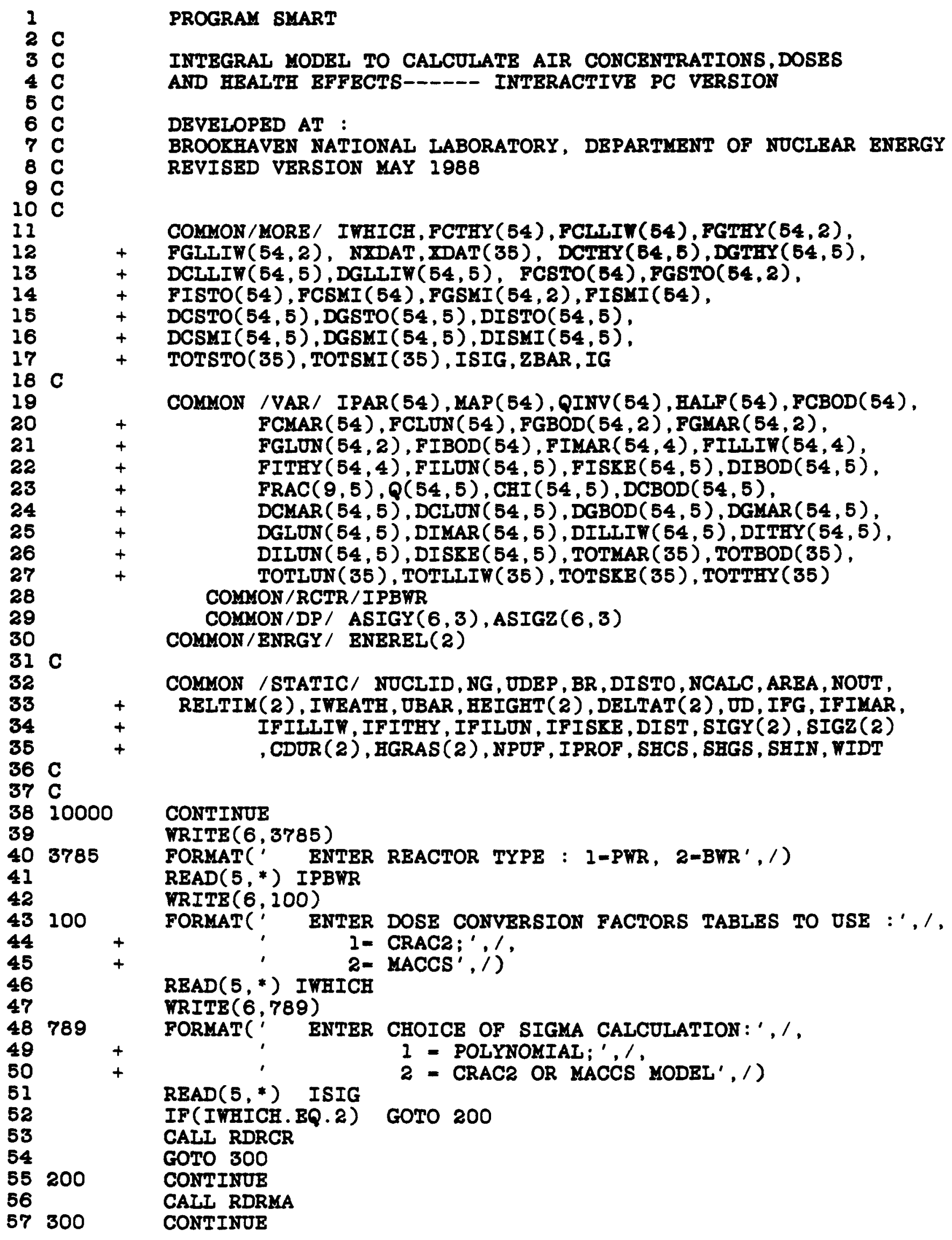




$\begin{array}{ll}58 & \text { CALI RDR2 } \\ 59 & \text { CALL COMP } \\ 60 & \text { CAIL REST } \\ 61 & \text { WRITE(6,600) } \\ 62600 & \text { FORMAT( IF YOU WISH TO REPEAT, BNTER I', } 1) \\ 63 & \text { READ(5,*) IREDO } \\ 64 & \text { IF(IREDO. BQ.I) GOTO } 10000 \\ 65 \mathrm{C} & \\ 66 \mathrm{C} & \\ 67 & \text { STOP } \\ 68 & \text { BND }\end{array}$

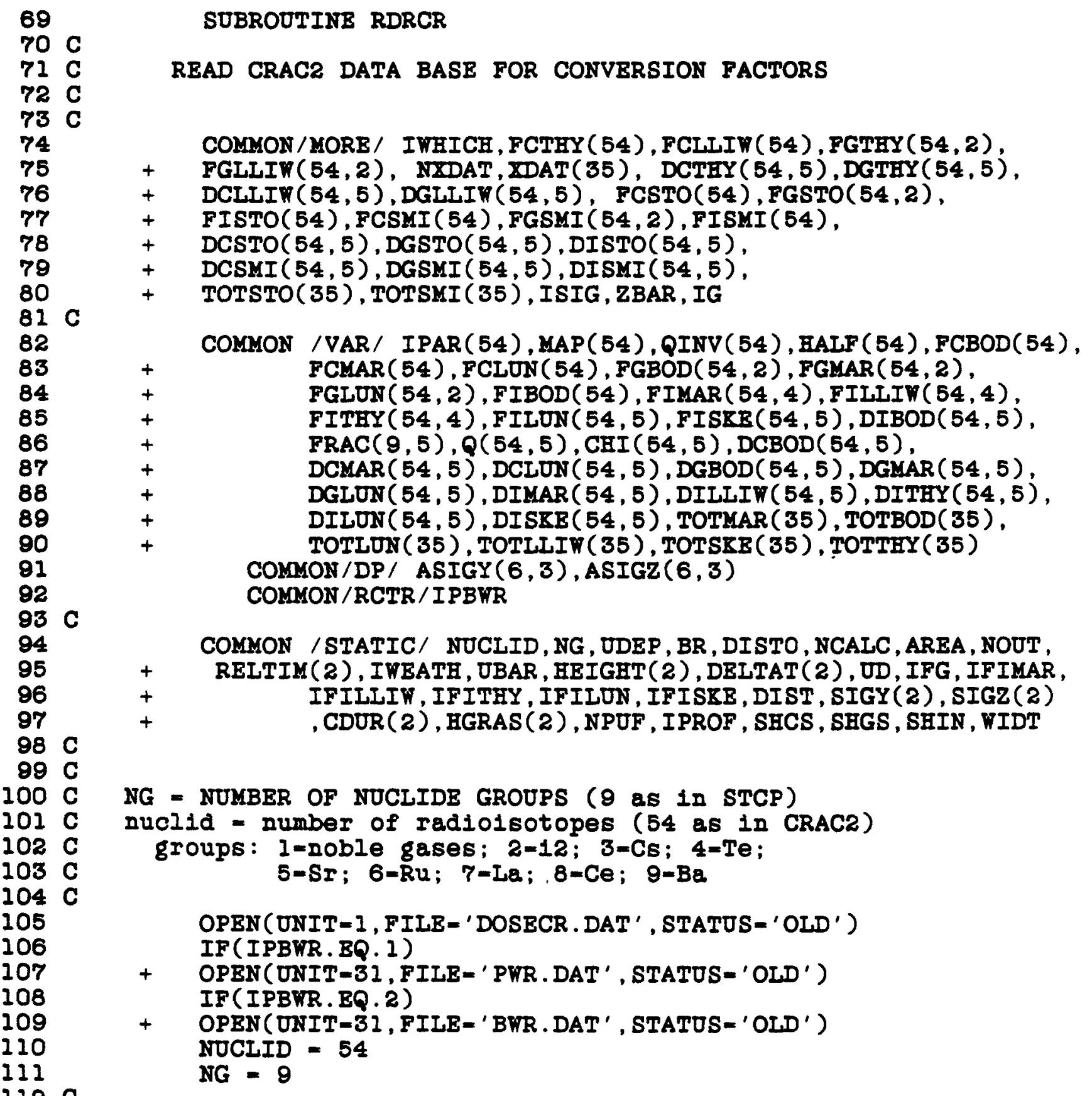




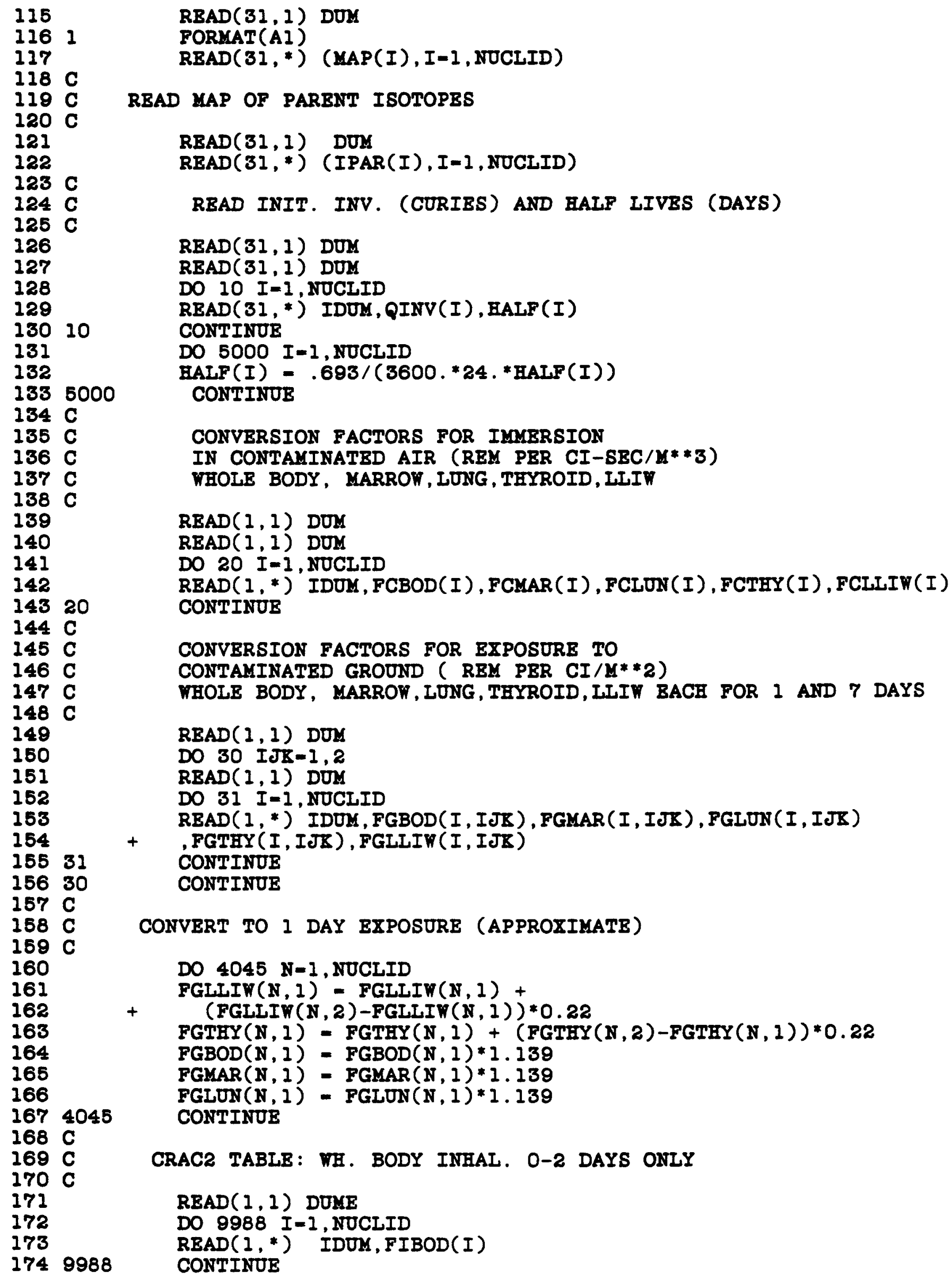

$\operatorname{RBAD}(31,1)$ DUM

$134 \mathrm{C}$

$135 \mathrm{C}$

$136 \mathrm{C}$

$137 \mathrm{C}$

$138 \mathrm{C}$

CRAC2 TABLE: WH. BODY INHAL, O-2 DAYS ONLY

$\operatorname{READ}(1,1)$ DOME

DO 9988 I=1, NUCLID

$\operatorname{RBAD}(1, *)$ IDUK, FIBOD(I)

CONTINUE 
$175 \mathrm{C}$

$176 \mathrm{C}$

$177 \mathrm{C}$

$178 \mathrm{C}$

$179 \mathrm{C}$

$180 \mathrm{C}$

181

182

183

18440

$185 \mathrm{C}$

$186 \mathrm{C}$

$187 \mathrm{C}$

$188 \mathrm{C}$

189

180

191

19250

$193 \mathrm{C}$

$194 \mathrm{C}$

$195 \mathrm{C}$

$196 \mathrm{C}$

197

198

189

20060

$201 \mathrm{C}$

$202 \mathrm{C}$

$203 \mathrm{C}$

$204 \mathrm{C}$

205

206

207

20870

209 C

$210 \mathrm{C}$

$211 \mathrm{C}$

$212 \mathrm{C}$

213

214

215

21680

$217 \mathrm{C}$

$218 \mathrm{C}$

$219 \mathrm{C}$

220

221

222

$223 \mathrm{C}$

$224 \mathrm{C}$

$225 \mathrm{C}$

226

227

$228 \mathrm{C}$

$229 \mathrm{C}$

$230 \mathrm{C}$

231

232

233

23490
CONVBRSION FACTORS FOR INBALED

RADIONOCLIDBS (RBM/CI)

MARRON, 0-2 DAYS, 0-30 DAYS, 0-30 YBARS

$\operatorname{READ}(1,1)$ DUM

DO $40 I=1$, NUCLID

$\operatorname{RBAD}(1, *) \operatorname{IDOM},(\operatorname{FIMAR}(I, J), J=1,4)$

CONTINUE

SAME, LOWER IAARGE INTESTINE WALI, 0-2 DAYS, 0-7 DAYS, 0-30 DAYS

$\operatorname{RBAD}(1,1)$ DDM

DO $50 \quad I=1$, NOCIID

$\operatorname{RBAD}(1, *)$ IDUM, (FILIIR(I, J ), J=I,4)

CONTINUE

SAYE, THYROID,

0-2 DAYS, 0-7 DAYS, 0-30 DAYS

$\operatorname{READ}(1,1)$ DOM

DO $60 I=1$, NOCLID

$\operatorname{READ}(1, *)$ IDUM, (FITHY $(I, J), J=1,4)$

CONTINUE

SAME, LUNG

0-2 DAYS, 0-30 DAYS, 0-30 YBARS

$\operatorname{READ}(1,1)$ DUM

DO $70 I=1$, NOCLID

$\operatorname{RBAD}(1, *)$ IDUM, (FILUN $(I, J), J=1,5)$

CONTINUE

SAME, SKELETON

0-2 DAYS, 0-7 DAYS, 0-30 DAYS, 0-1 YBAR, 0-30 YEARS

$\operatorname{READ}(1,1)$ DUM

DO $80 I=1$, NUCLID

$\operatorname{READ}(1, *) \operatorname{IDUM},(\operatorname{FISKE}(I, J), J=1,5)$

CONTINUE

GRID DATA

$\operatorname{READ}(31,1)$ DUM

$\operatorname{READ}(31, *)$ NXDAT

$\operatorname{READ}(31, *)(X D A T(I), I=1, \operatorname{NXDAT})$

READ DEFAOLT VALOES FOR IF'S

$\operatorname{READ}(31,1)$ DUM

READ (31, *) IFG, IFIMAR, IFILIIW, IFITHY, IFILON

DISPERSION COEFFICIENTS CURVE FITTING PARAKETERS

$\operatorname{RBAD}(31,1)$ DOM

DO $90 \quad I=1,6$

$\operatorname{RBAD}(31, *)$ IDUM, JDUM, (ASIGY $(I, J), J=1,3)$

CONTINOE 


$$
\text { B-6 }
$$

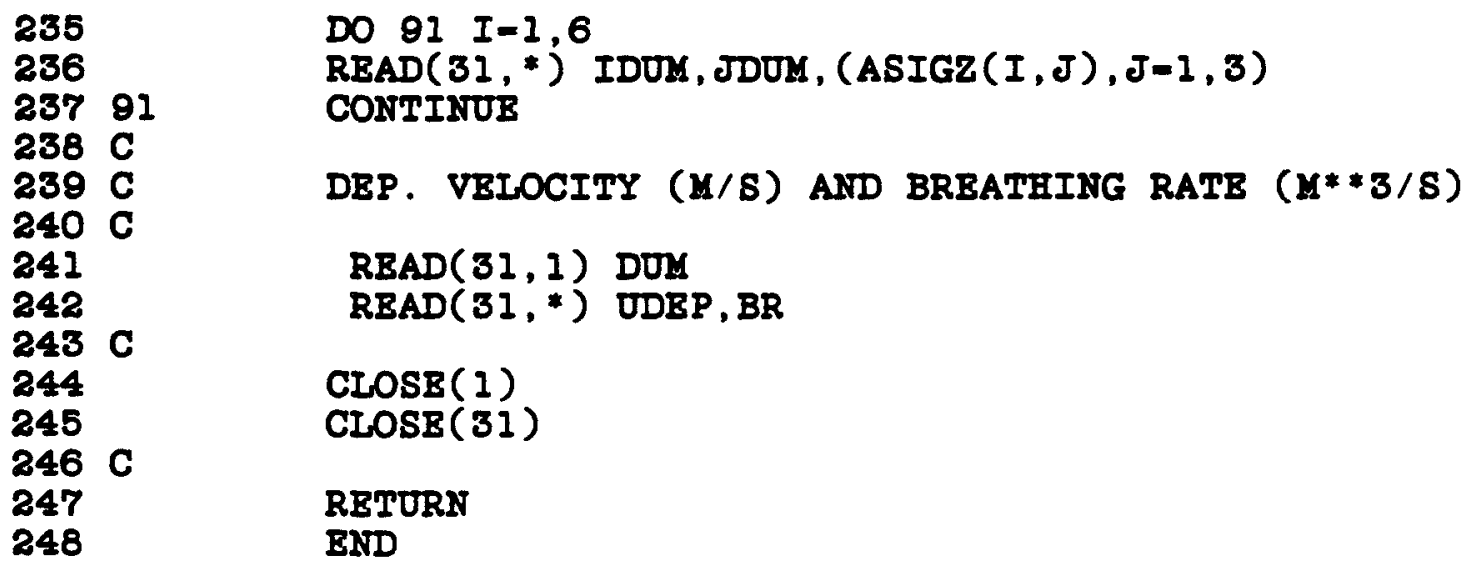




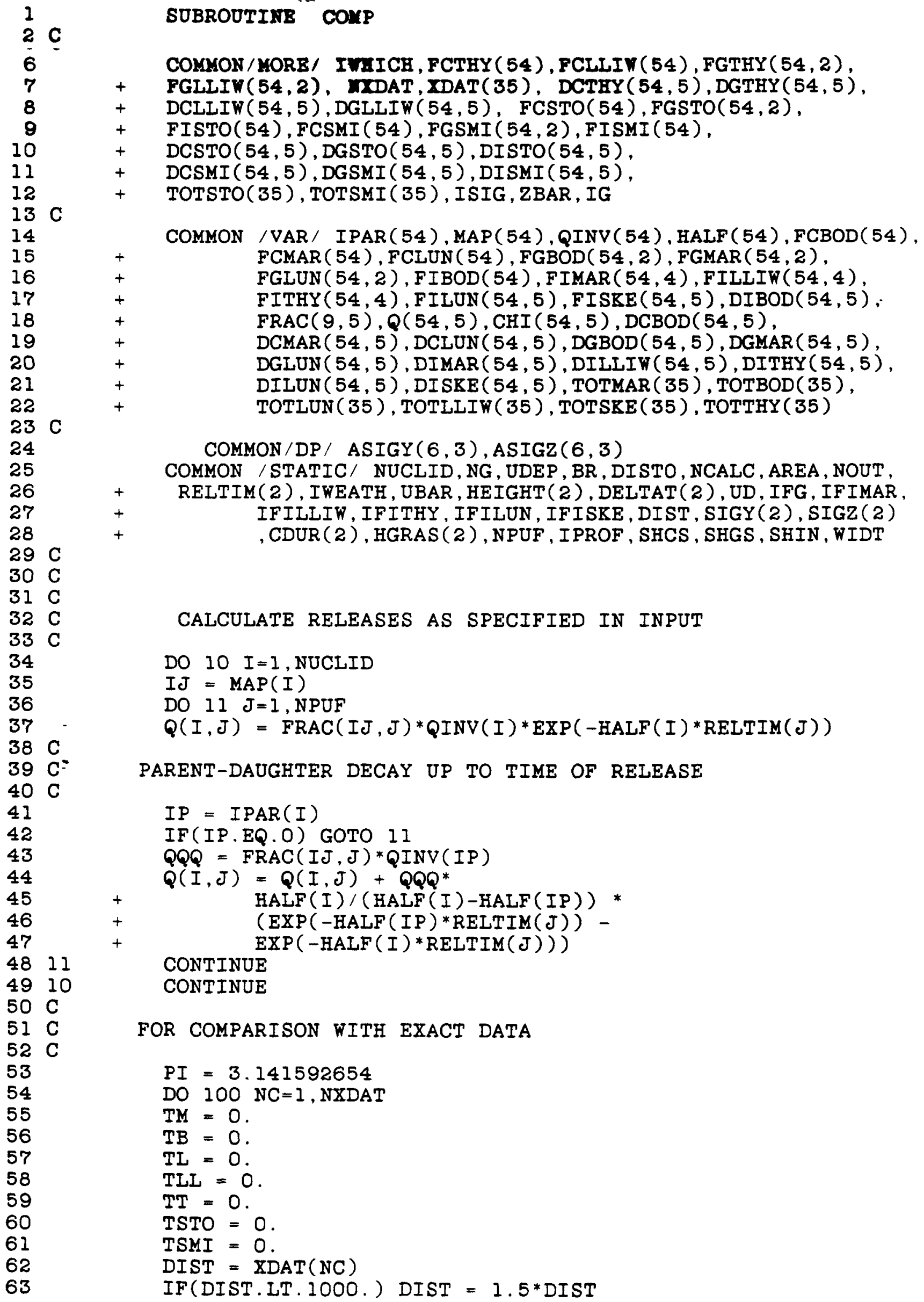




$$
\text { B-8 }
$$

$64 \mathrm{C}$

65

66

67

68

69

70

71

$\begin{array}{ll}72 & 47\end{array}$

$73 \mathrm{C}$

$74 \mathrm{C}$

$75 \mathrm{C}$

76

77

78

$79 \mathrm{C}$

$80 \mathrm{C}$

81

82

83

84

$85 \mathrm{C}$

$86 \mathrm{C}$

$87 \mathrm{C}$

88

$89 \mathrm{C}$

$90 \mathrm{C}$

$91 \mathrm{C}$

92

93

94

95

96

97

98

99

100

101

102

103

1043789

105

106

107

108

109

110

111

112

113

11410000

115

116

$117 \mathrm{C}$

$118 \mathrm{C}$

$119 \mathrm{C}$

120

121
FIRST SPATIAL CORRECTED FOR COMP. WITH CRAC

$D X=0$.

IF (NC.IT: (NXDAT-1)) DX = (XDAT (NC+1)-DIST) $/ 2$.

$\operatorname{IF}$ (NC.IT. 3) DX $=0$.

DO $999 \mathrm{NP}=1, \mathrm{NPUF}$

IF (NC.NE.1) GOTO 47

HITE $=0.0$

IF (HEIGHT (NP) . GT . AREA) HITE = HEIGHT(NP)

CONTINUE

CALCULATE SIGMAY AND SIGMAZ

DXPOL $=0$.

IF (ISIG.EQ. I) CALL SIG(NP,SY,SZ,DXPOI)

IF (ISIG.EQ.2) CALL SIGCR(NP,NC,SY,SZ,DX)

SIGY (NP) $=$ SY
SIGZ(NP) $=S Z$
ZMAX $=1000$.
CAP $=.8$

USE THIS IF IN MACCS ZMAX $=800$.

IF (IWHICH.EQ.2) CAP $=.64$

IF (SIGZ (NP).GT. (CAP*ZMAX)) SIGZ(NP) = CAP*ZMAX

CALCULATE CENTERLINE DOSE

TIMEI $=(D I S T+D X) /$ UBAR

CALL ZZBAR(NP, DX, TIMEI, HITE)

ZBAR $=\operatorname{SQRT}(2 . / \mathrm{PI}) * \operatorname{SIGZ}(\mathrm{NP}) * \operatorname{EXP}(\mathrm{HITE} * * 2 / 2 . / \mathrm{SIGZ}(\mathrm{NP}) * * 2)$

DENOM $=$ PI*UBAR*SIGY (NP)*SIGZ(NP)

DENOMI = 3./2. *SQRT (2. *PI)*UBAR*SIGY (NP)*SIGZ(NP)

$\mathrm{ZZ4}=\operatorname{HITE} * * 2 /\left(2 .{ }^{*} \operatorname{SIGZ}(\mathrm{NP}) * * 2\right)$

TIME $=$ DIST $/$ UBAR

DO $101 \mathrm{~N}=1$, NUCLID

$\mathrm{KKK}=\mathrm{MAP}(\mathrm{N})$

UDD $=$ UDEP

IF (KKR.NE.1) GOTO 3789

$U D D=0$.

CONTINUE

$Z Z I=U D D *(D I S T+D X) /(U B A R * Z B A R)$

ALAMW $=1 . E-05$

IF (IWEATH.GT. 3) ALAMW = 1.E-O2

$2 Z 2=$ ALAMW $*$ DELTAT $(N P)$

$2 Z 3=\operatorname{HALF}(\mathrm{N}) *$ TIME

$\mathrm{SUM}=\mathrm{ZZI}+\mathrm{ZZ2}+\mathrm{ZZ4}$

$Q Q=0.0$

IF (Z23.GT.90.) GOTO 10000

$Q Q=Q(N, N P) * \operatorname{EXP}(-2 Z 3)$

CONTINUE

$I P=\operatorname{IPAR}(\mathrm{N})$

IF (IP.EQ.O) GOTO 475

CORRECTION FOR PARENT-DAUGHTER

$I J K=\operatorname{MAP}(N)$

$Q Q Q=Q(I P, N P)$

$E X I=0$.

IF ((HALF (IP)*TIME).GT. 90.) GOTO 11000 


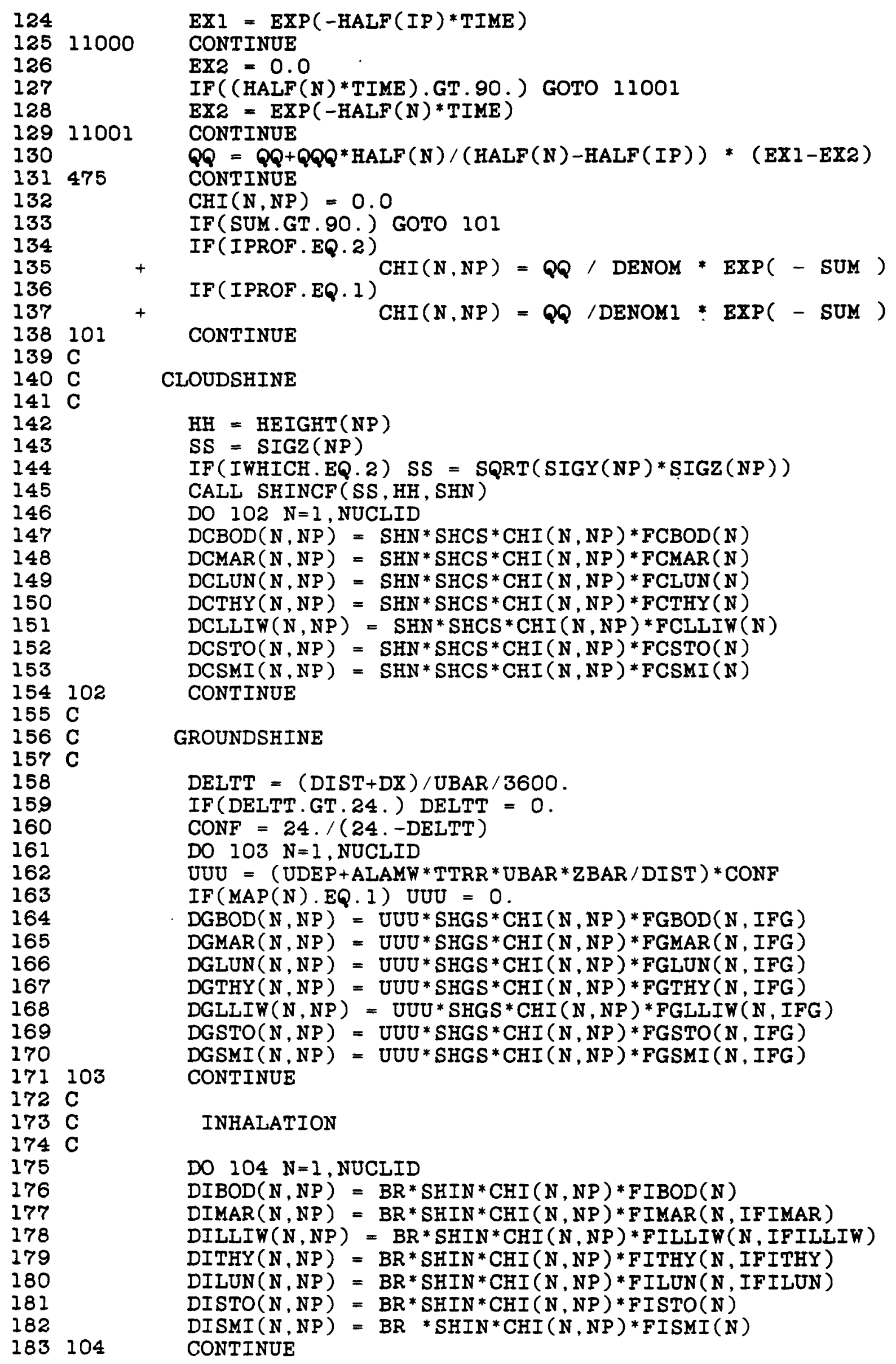


$184 \mathrm{C}$

$185 \mathrm{C}$

186

187

188

189

190

191

192

193

$194 \quad 105$

195999

196

197

198

199

200

201

202

203

204

205

2063786

207100

$208 \mathrm{C}$

$209 \mathrm{C}$

210

211

C

C
DO $105 \mathrm{~N}=1$, NUCLID

$T B=T B+\operatorname{DIBOD}(\mathrm{N}, \mathrm{NP})+\operatorname{DCBOD}(\mathrm{N}, \mathrm{NP})+\operatorname{DGBOD}(\mathrm{N}, \mathrm{NP})$

$T M=T M+\operatorname{DCMAR}(N, N P)+\operatorname{DGMAR}(N, N P)+\operatorname{DIMAR}(\mathrm{N}, \mathrm{NP})$

$T I=T L+\operatorname{DGLUN}(N, N P)+\operatorname{DCLUN}(N, N P)+\operatorname{DILUN}(N, N P)$

$T I L=T L I+D C L L I W(N, N P)+D G L I I W(N, N P)+\operatorname{DILIIW}(N, N P)$

$T T=T T+\operatorname{DCTHY}(N, N P)+\operatorname{DGTHY}(N, N P)+\operatorname{DITHY}(N, N P)$

TSTO $=$ TSTO $+\operatorname{DCSTO}(N, N P)+\operatorname{DGSTO}(N, N P)+\operatorname{DISTO}(N, N P)$

TSMI $=$ TSMI $+\operatorname{DCSMI}(N, N P)+\operatorname{DGSMI}(N, N P)+\operatorname{DISMI}(N, N P)$

CONTINUE

CONTINUE

TOTSTO(NC) $=$ TSTO

TOTSMI (NC) $=$ TSMI

$\operatorname{TOTMAR}($ NC) $=$ TM

$\operatorname{TOTBOD}(\mathrm{NC})=\mathrm{TB}$

TOTLUN (NC) $=$ TL

TOTLLIW (NC) $=$ TLL

TOTTHY (NC) $=$ TT

IF (IWHICH.EQ. 1) CALL CROUT(NC)

IF (IWHICH.EQ.2) CALL MAOUT(NC)

CALL EFFEC(NC)

CONTINUE

CONTINUE

RETURN

END

SUBROUTINE EFFEC(NC)

COMMON / MORE / IWHICH , FCTHY (54), FCLLIW(54), FGTHY $(54,2)$,

FGLLIW $(54,2), \operatorname{NXDAT}, \operatorname{XDAT}(35), \operatorname{DCTHY}(54,5), \operatorname{DGTHY}(54,5)$, DCLIIW $(54,5), \operatorname{DGLIIW}(54,5), \operatorname{FCSTO}(54), \operatorname{FGSTO}(54,2)$, FISTO( 54), FCSMI (54), FGSMI (54,2), FISMI (54), $\operatorname{DCSTO}(54,5), \operatorname{DGSTO}(54,5), \operatorname{DISTO}(54,5)$, $\operatorname{DCSMI}(54,5), \operatorname{DGSMI}(54,5), \operatorname{DISMI}(54,5)$,

TOTSTO( 35 ), TOTSMI ( 35 ), ISIG, ZBAR, IG

COMMON /VAR/ IPAR( 54), MAP(54), QINV( 54), HALF (54), FCBOD( 54), FCMAR (54), FCLUN $(54), \operatorname{FGBOD}(54,2), \operatorname{FGMAR}(54,2)$, FGLUN $(54,2), F I B O D(54), F I M A R(54,4), F I L I I W(54,4)$, FITHY $(54,4)$, FILUN $(54,5), F I S K E(54,5), \operatorname{DIBOD}(54,5)$, $\operatorname{FRAC}(9,5), Q(54,5), \operatorname{CHI}(54,5), \operatorname{DCBOD}(54,5)$, $\operatorname{DCMAR}(54,5), \operatorname{DCLUN}(54,5), \operatorname{DGBOD}(54,5), \operatorname{DGMAR}(54,5)$, $\operatorname{DGLUN}(54,5), \operatorname{DIMAR}(54,5), \operatorname{DILLIW}(54,5), \operatorname{DITHY}(54,5)$, $\operatorname{DILUN}(54,5), \operatorname{DISKE}(54,5), \operatorname{TOTMAR}(35), \operatorname{TOTBOD}(35)$, TOTLUN (35), TOTLIIW(35), TOTSKE (35), TOTTHY (35) COMMON/DP/ $\operatorname{ASIGY}(6,3), \operatorname{ASIGZ}(6,3)$

COMMON /STATIC/ NUCLID, NG, UDEP, BR, DISTO, NCALC, AREA, NOUT, REITIM( (2), IWEATH, UBAR, HEIGHT( (2), DELTAT (2), UD, IFG, IFIMAR, IFILLIW, IFITHY, IFILUN, IFISEE, DIST, SIGY (2), SIGZ(2) , CDUR ( 2 ), HGRAS ( 2 ), NPUF, I PROF , SHCS , SHGS, SHIN, WIDT

REAL*8 HI, H2, H3 , H4, H5, H6, R, RI, ALPHA, BETA, XXX, HTOT

EARLY FATALITIES : LUNG 


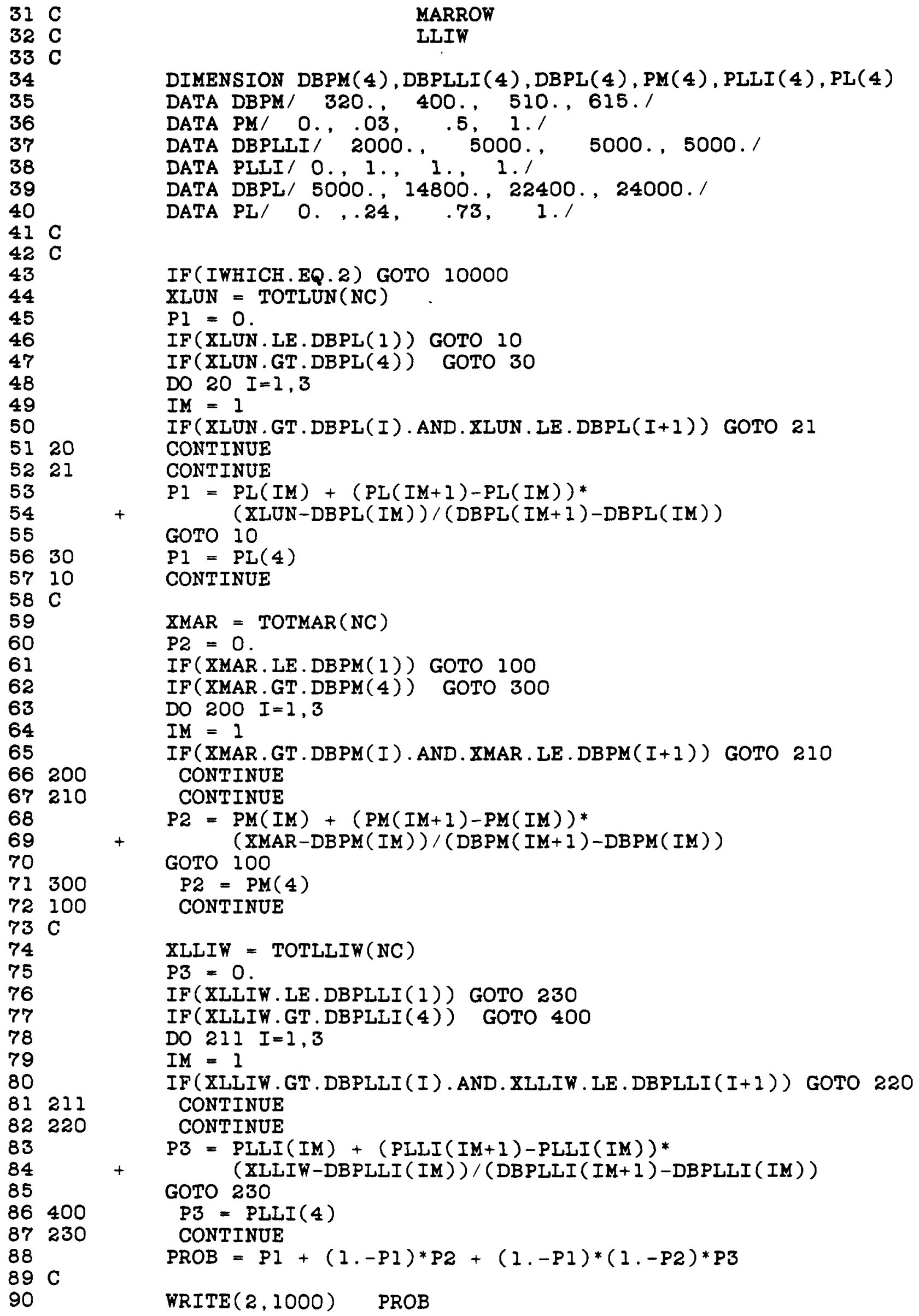




\section{B-12}

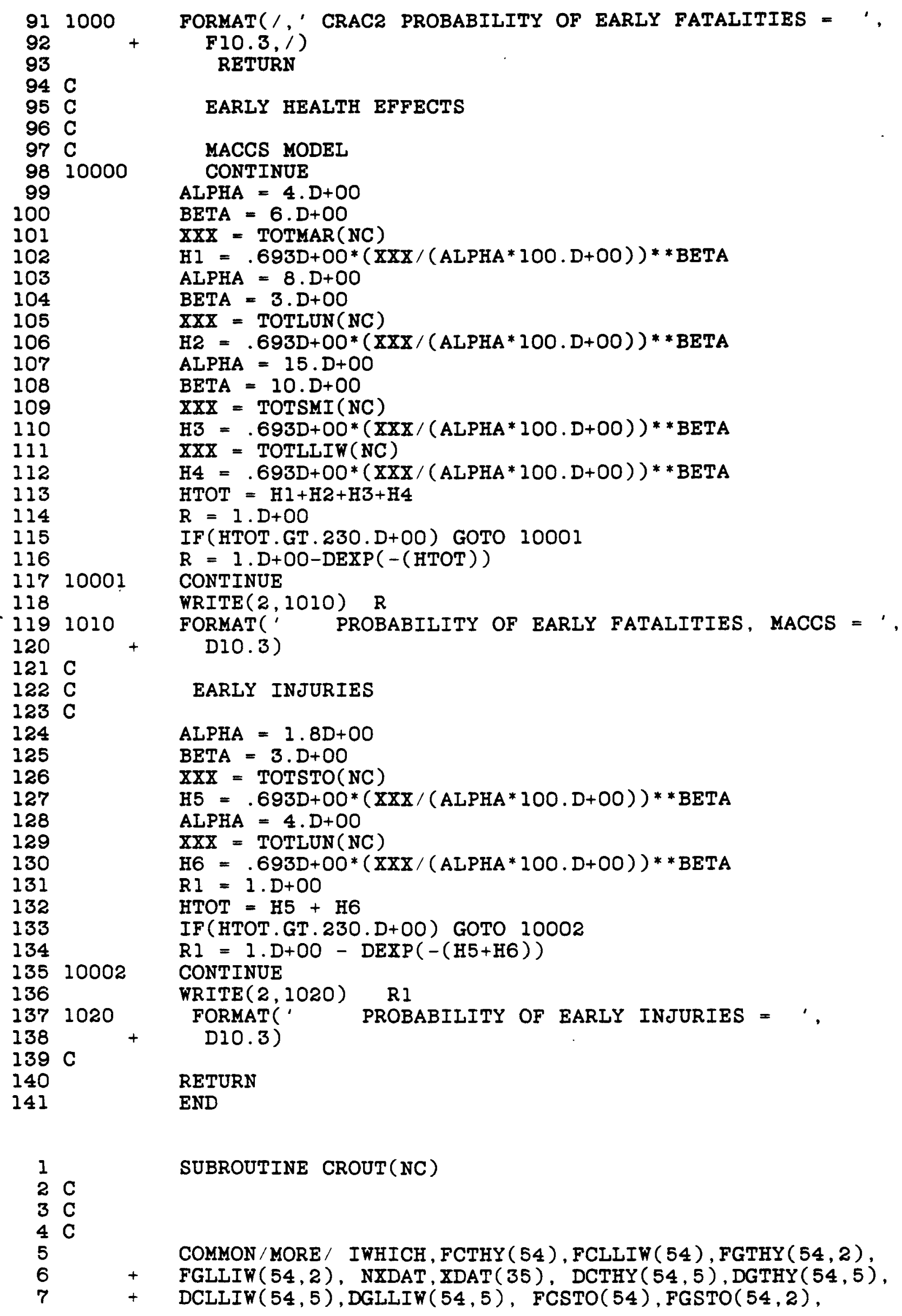




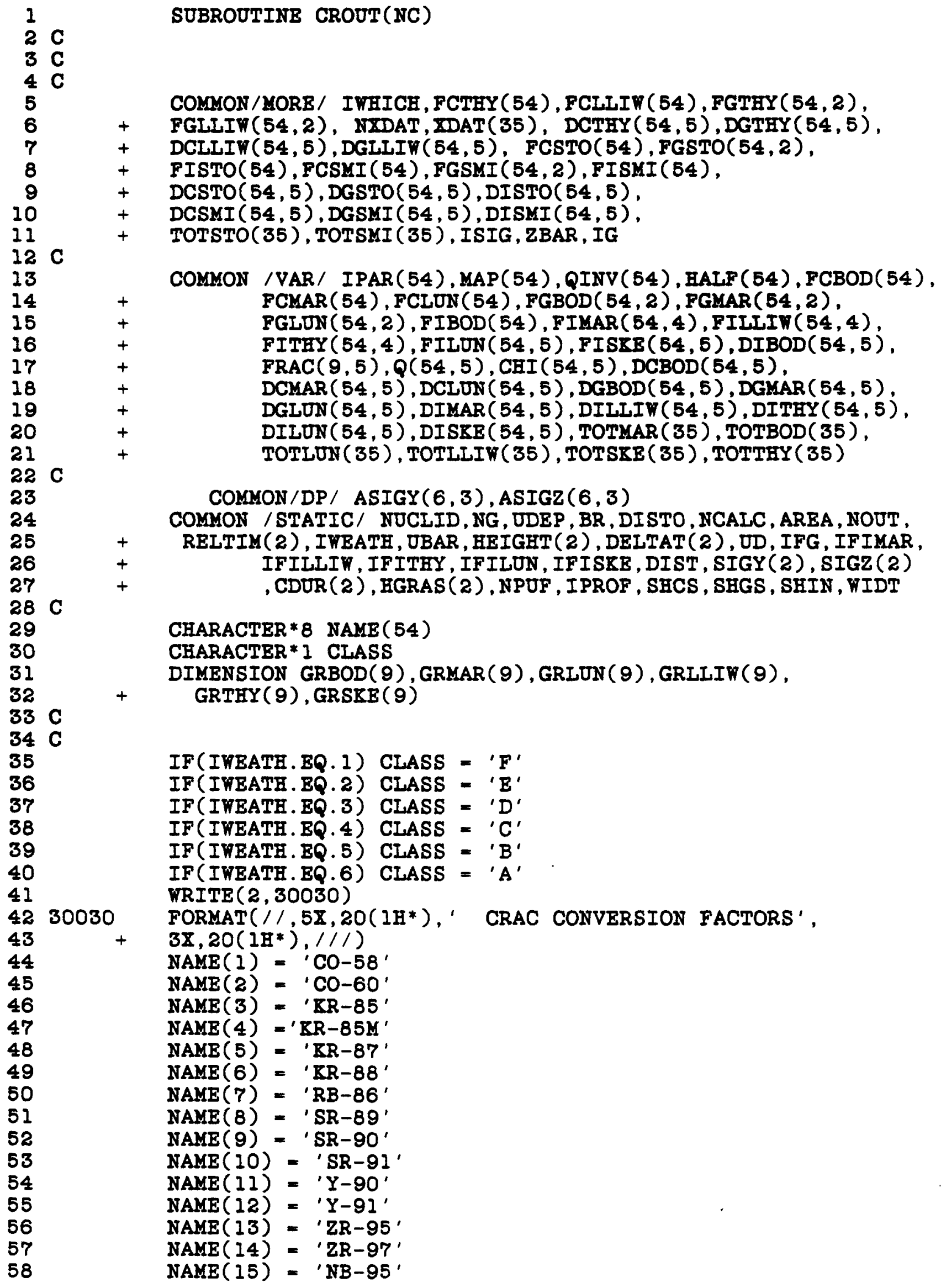




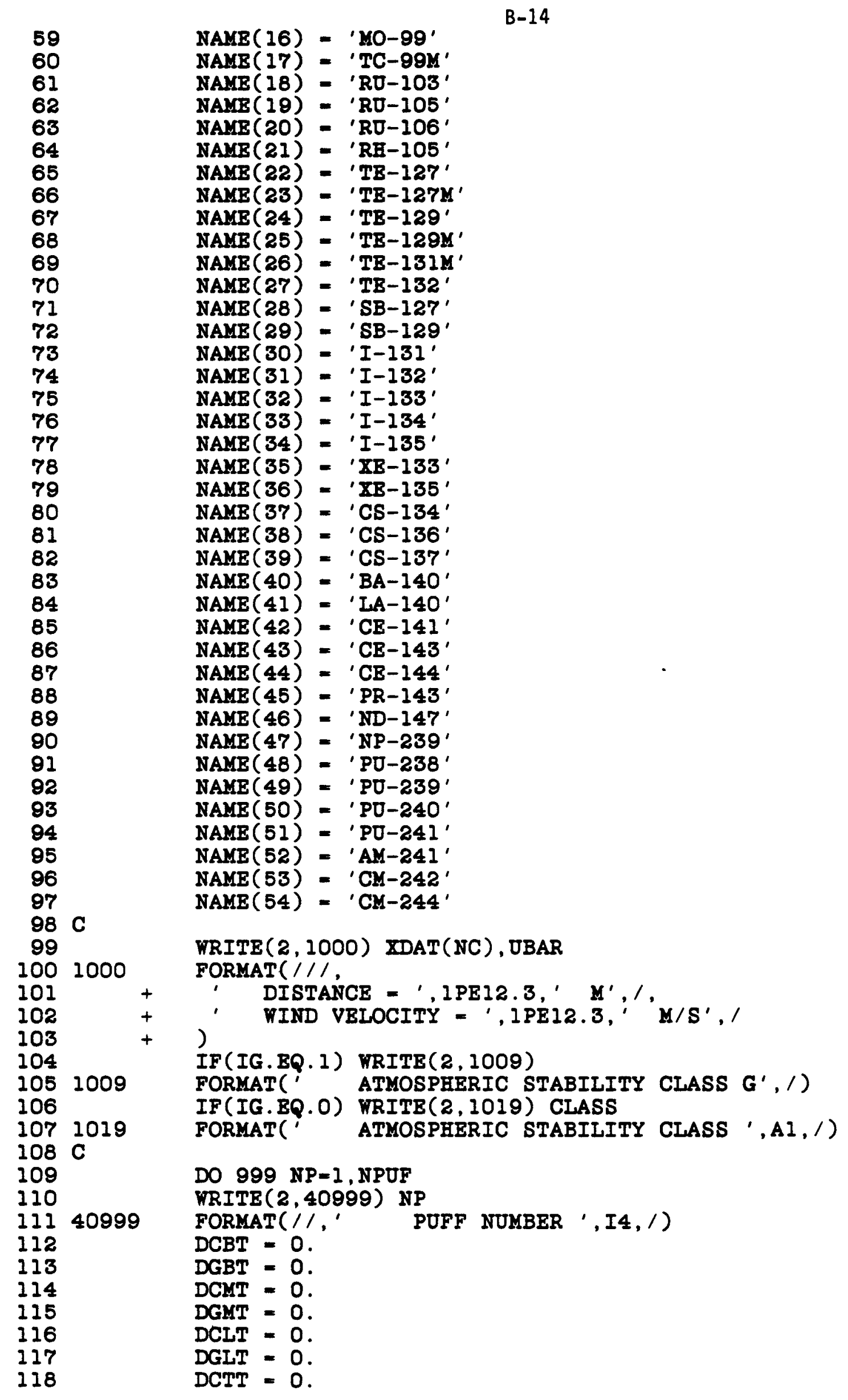


$D G T T=0$.

DCLIT $=0$.

DGIIT $=0$.

122

123

$D I B T=0$.

DIMT $=0$.

DIIT $=0$.

DITT $=0$.

125

126

DIIIT $=0$.

DO $3033 \mathrm{~N}=1$, NUCLID

$D C B T=D C B T+D C B O D(N, N P)$

$D G B T=D G B T+D G B O D(N, N P)$

128

131

132

133

134

135

136

137

138

139

140

141

142

143

144

145

146

147

148

149

150

151

152

153

154

155

156

157

158

159

160

161

162

163

164

165

166

167

168

169

170

171

172

173

174

175

$D C M T=D C K T+D C K A R(N, N P)$

DGMT $=$ DGMT + DGMAR (N,NP)

DCLT $=$ DCLT + DCLON (N,NP)

DGLT = DGLT + DGLUN $(N, N P)$

$D C T T=D C T T+D C T H Y(N, N P)$

DGTT $=$ DGTT + DGTHY $(N, N P)$

DCLIT = DCLLT + DCLIIN (N,NP)

DGLLT = DGLLT + DGLIIW (N,NP)

DIBT $=D I B T+D I B O D(N, N P)$

DIMT = DIMT + DIMAR N,NP)

DIIT $=$ DILT + DIIUN $(N, N P)$

$D I T T=D I T T+D I T H Y(N, N P)$

DILIT $=$ DILIT $+\operatorname{DILIIP(N,NP)}$

3033 CONTINUE

WRITE $(2,20001)$ SIGY(NP), SIGZ(NP)

20001 FORMAT ' HORIZONTAL DISPERSION COEFFICIENT = ',

+ IPEI2.3.' M'.'

$+\quad$ VERTICAI DISPERSION COEFFICIENT = ',

$+\quad$ IPE12.3, $\left.\mathbf{H}^{\prime}, / 1\right)$

$\operatorname{VRITE}(2,2333)$

2333 FORMAT $(1 /, 40 \mathrm{X}$, 'CLOUD SHINE', /)

WRITE $(2,2334)$

2334 FORMAT(2X, 1OX, 'WHOLE BODY ', IX,' YARROW ', IX,

+ IIONG ',' THYROID',

+ I ILIV 1 , /)

IF (NOUT.NB.1) GOTO 3456

DO $2500 \mathrm{~N}=1$, NUCLID

WRITE (2, 2501) NAME(N), DCBOD(N, NP), DCMAR (N, NP), DCLUN (N, NP),

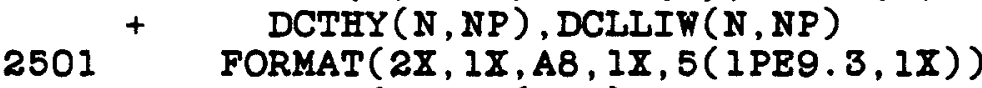

3034 FORMAT $\left(2 \mathrm{X}, 60\left(1 \mathrm{H}_{-}\right), /, 2 \mathrm{X},{ }^{\prime}\right.$ TOTAL ',2X, 5( 1 PE9.3,1X))

2500 CONTINUE

3456 CONTINOE

WRITE (2,3034) DCBT, DCKT, DCLT, DCTT, DCLIT

WRITE $(2,2502)$

2502 FORMAT $(/ /, 40 X$, 'GROUND SHINE', /)

WRITE $(2,2334)$

IF(NOUT.NE.1) GOTO 3457

DO $2600 \mathrm{~N}=1$, NUCLID

VRITE (2, 2501) NAME(N), DGBOD(N,NP), DGMAR(N, NP), DGLUN (N, NP),

$+\operatorname{DGTHY}(N, N P), \operatorname{DGLLIW}(N, N P)$

2600 CONTINUE

3457 CONTINUE

WRITB (2, 3034) DGBT, DGMT, DGLT, DGTT, DGLLT

$\operatorname{VRITE}(2,2503)$

2503 FORMAT $(/ /, 40 \mathrm{X}, '$ INHALATION', /)

$\operatorname{WRITR}(2,2334)$

IF(NOUT.NE.1) GOTO 3458

177

DO $2700 \mathrm{~N}=1$, NUCLID 


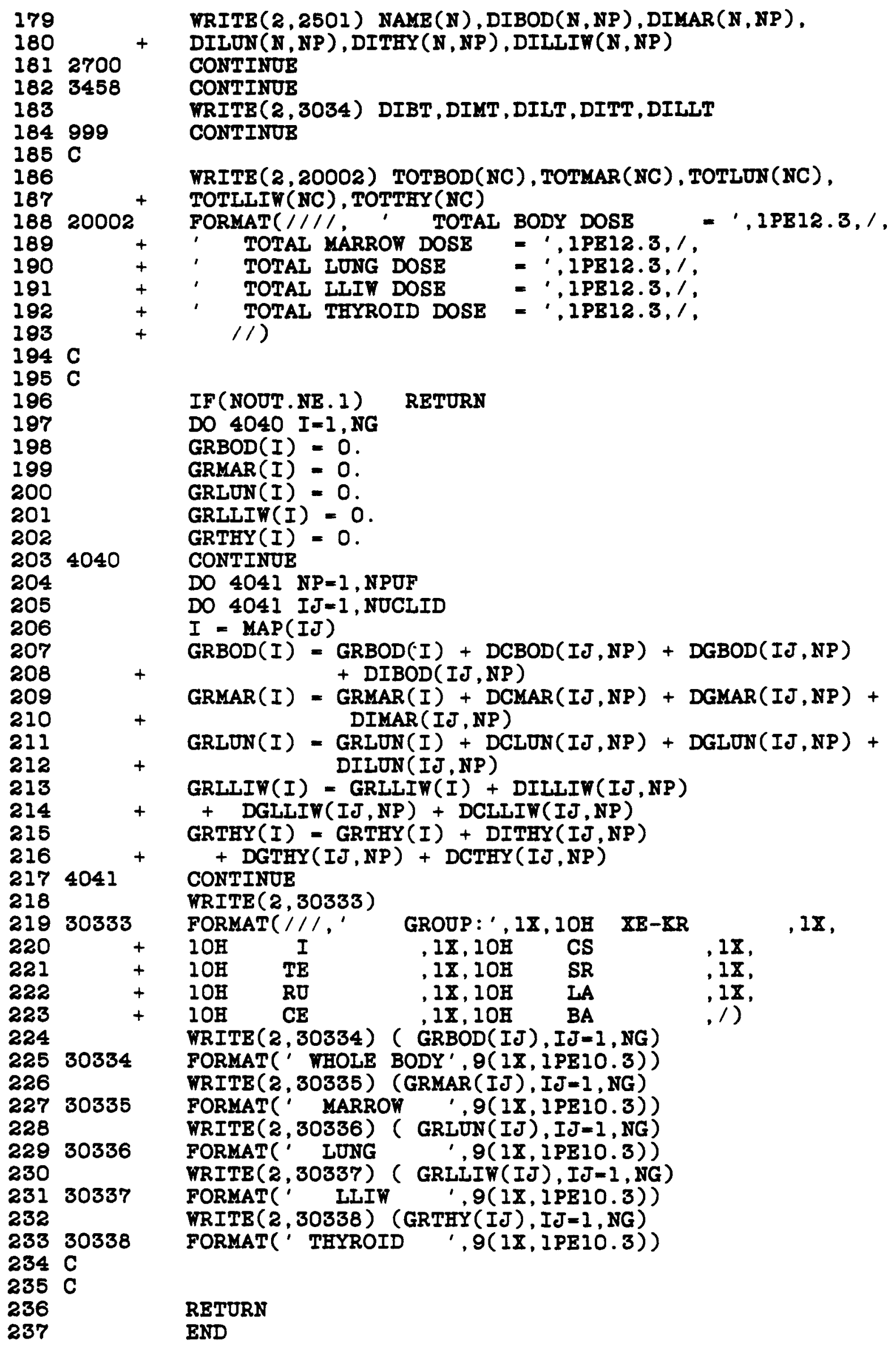


SUBROUTINB SIG(, SY,SZ,DZ)

COMGON/MORE/ IWHICH, FCTHY (54), FCILIW (54), $\operatorname{FGTHY~}(54,2)$,

$+\operatorname{FGLLIW}(54,2)$, WXDAT, $\operatorname{XDAT}(35), \operatorname{DCTHY}(54,5), \operatorname{DGTHY}(54,5)$,

$+\operatorname{DCLIIW}(54,5), \operatorname{DGLLIP}(54,5), \operatorname{FCSTO}(54), \operatorname{PGSTO}(54,2)$,

$+\operatorname{FISTO}(54)$, FCSKI(54), FGSMI (54,2), PISKI(54),

$+\operatorname{DCSTO}(54,5), \operatorname{DGSTO}(54,5), \operatorname{DISTO}(54,5)$,

$+\operatorname{DCSMI}(54,5), \operatorname{DGSMI}(54,5), \operatorname{DISMI}(54,5)$,

$+\operatorname{TOTSTO}(35)$, TOTSMI (35), ISIG, ZBAR, IG
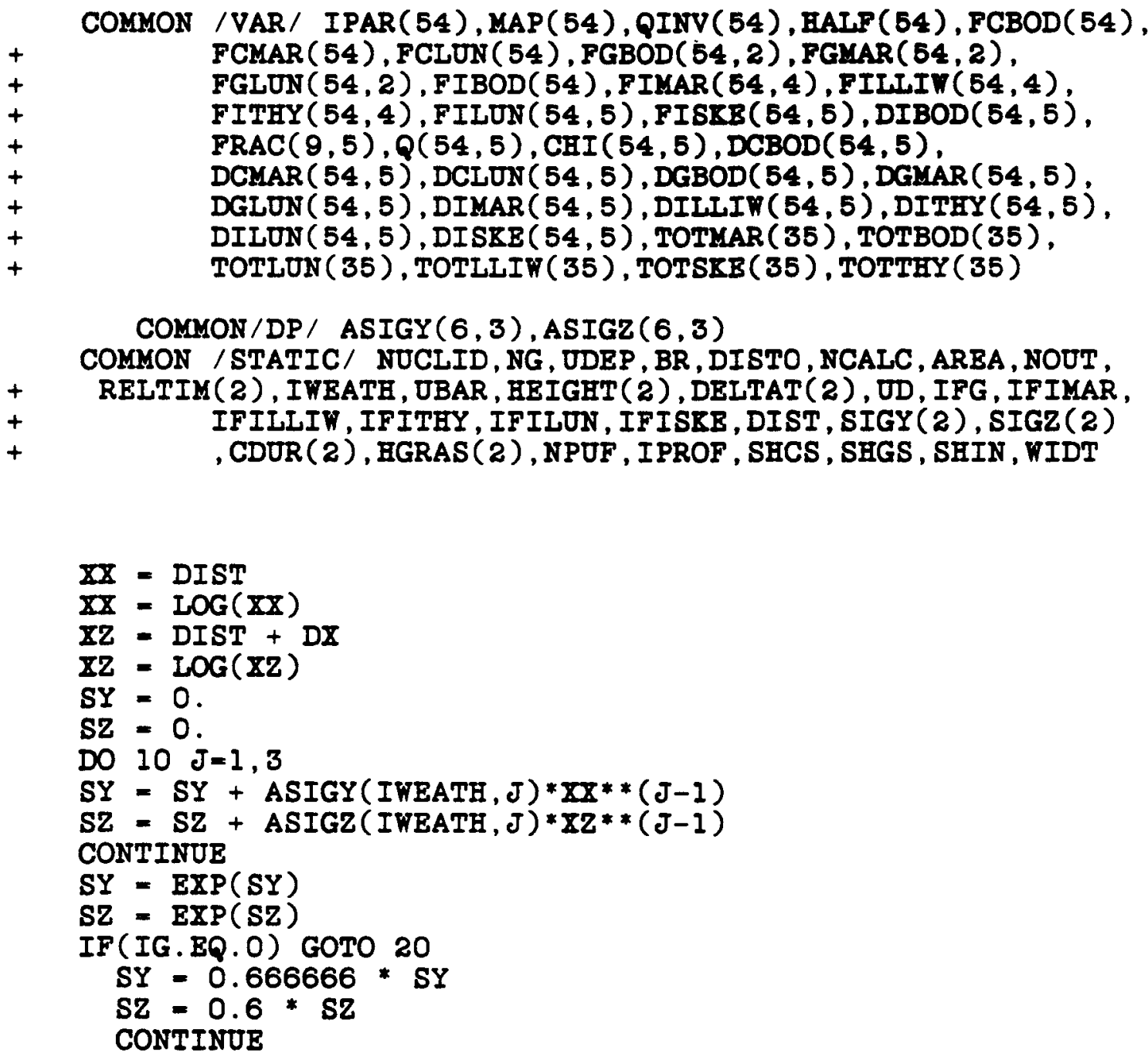

CORRECTIONS FOR DURATION AND HEIGHT OF GRASS

$S Y=S Y * C D U R(B)$

$S Z=S Z *$ HGRAS $(\mathrm{K})$

BOILDING WAKE CORRECTION (GEOMETRIC)

$S Y=\operatorname{SQRT}(S Y * * 2+($ WIDT*AREA $) / 6.28)$

$S Z=S Q R T(S Z * * 2+($ WIDT*AREA $) / 6.28)$

RETURN 
END

288

$299 \mathrm{C}$

$300 \mathrm{C}$

$301 \mathrm{C}$

302

303

304

305

306

307

308

309 C

310

311

312

313

314

315

316

317

318

319

320

321

$322 \mathrm{C}$

323

324

325

326

$327 \mathrm{C}$

328

329

$330 \mathrm{C}$

$331 \mathrm{C}$

$332 \mathrm{C}$

333

33480

335

336

337

338

339

340

341

342

343

34482

345

346

347

348

349

35090

351

352

353

35491

SUBROUTINB RDR2

COMOYON / MORE/ IWHICH, FCTHY (54), FCIIIW(54), FGTHY $(54,2)$,

$+\operatorname{FGLIIT}(54,2)$, NXDAT, XDAT (35), DCTHY $(54,5), \operatorname{DGTHY}(54,5)$,

$+\operatorname{DCLIIT}(54,5), \operatorname{DGLLIT}(54,5)$, FCSTO(54), FGSTO $(54,2)$,

+ FISTO(54), FCSMI(54), PGSMI (54,2), FISMI(54),

$+\operatorname{DCSTO}(54,5), \operatorname{DGSTO}(54,5), \operatorname{DISTO}(54,5)$,

$+\operatorname{DCSMI}(54,5), \operatorname{DGSMI}(54,5), \operatorname{DISMI}(54,5)$,

+ TOTSTO( 35 ), TOTSMI( 35 ), ISIG, ZBAR, IG

COMMON /VAR/ IPAR( 54), MAP(54), QINV(54), HALP(54), PCBOD(54), FCMAR (54), FCLUN (54), FGBOD(54,2), FGMAR $(54,2)$, $\operatorname{FGLON}(54,2), \operatorname{FIBOD}(54), \operatorname{FIMAR}(54,4), \operatorname{FIIIIN}(54,4)$, $\operatorname{FITHY}(54,4), \operatorname{FIIUN}(54,5), \operatorname{FISKB}(54,5), \operatorname{DIBOD}(54,5)$, $\operatorname{FRAC}(9,5), Q(54,5), \operatorname{CHI}(54,5), \operatorname{DCBOD}(54,5)$, $\operatorname{DCMAR}(54,5), \operatorname{DCLUN}(54,5), \operatorname{DGBOD}(54,5), \operatorname{DGMAR}(54,5)$, $\operatorname{DGLON}(54,5), \operatorname{DIMAR}(54,5), \operatorname{DILLIT}(54,5), \operatorname{DITHY}(54,5)$, $\operatorname{DILUN}(54,5), \operatorname{DISKE}(54,5), \operatorname{TOTMAR}(35), \operatorname{TOTBOD}(35)$, TOTLON (35), TOTILIW(35), TOTSKE(35), TOTTHY (35)

COMMON/RCTR/ IPBWR COMMON/DP/ $\operatorname{ASIGY}(6,3), \operatorname{ASIGZ}(6,3)$

COMMON/BNRGY/ ENEREL(2)

COMYON /STATIC/ NUCLID, NG, UDEP, BR, DISTO, NCALC, AREA, NOUT, RELTIM(2), IWBATH, UBAR, HEIGHT( (2), DBLTAT(2), OD, IFG, IFIMAR, IFILLIW, IFITHY, IFILUN, IFISKB, DIST, SIGY (2), SIGZ (2) , CDUR (2), HGRAS (2), NPOF, IPROF, SHCS, SHGS , SHIN, WIDT

DIMENSION PI(6)

DATA PI/ .55, .35, .15,.1,.07, .07/

ON-IINE SELECTION OF INPUTS AND PARAMETERS

$\operatorname{WRITE}(6,80)$

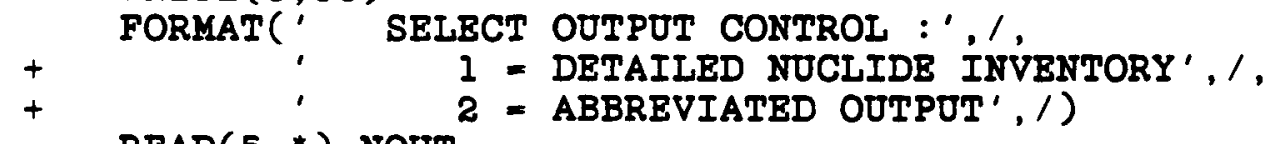

$\operatorname{READ}(5, *)$ NOUT

WRITE $(6,81)$

81 FORMAT(' IF YOU WISH TO REPEAT THE RON WITHOUT',

+ ' CHANGING REMAINING INPUT PARAYETERS, ENTER $i, 1$ )

$\operatorname{READ}(5, *)$ JSEIP

IF (JSKIP.EQ.1) RETURN

$\operatorname{WRITE}(6,82)$

FORMAT(' IF YOU WANT TO CHANGE WBATHER CLASS ONLY ENTER 1',/)

$\operatorname{READ}(5, *)$ ICEW

IF(ICEW.EQ.I) GOTO 83

PPO $=3412$.

IF (IPBWR. BQ.2) PPO $=3578$.

$\operatorname{VRITE}(6,90)$ PPO

FORLAT(' BNTER SCALING FACTOR FOR CORE INV.',/ REFERENCE POWER = ,FI2.1,' YWTH,$/$ )

$\operatorname{READ}(5, *) \quad$ POWER

DO 91 I = I, NUCLID

$\operatorname{QINV}(I)=\operatorname{QINV}(I) *$ POWER 


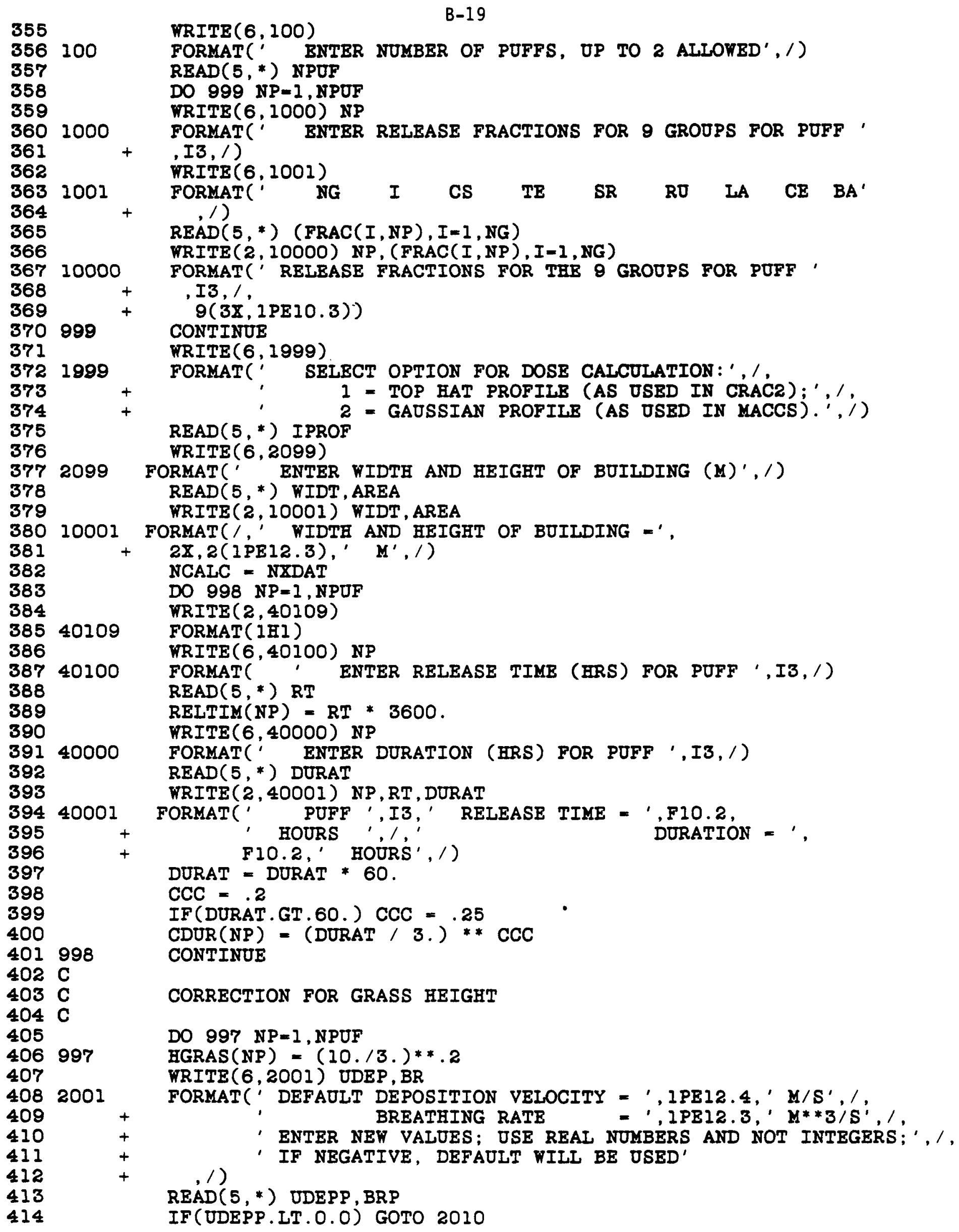




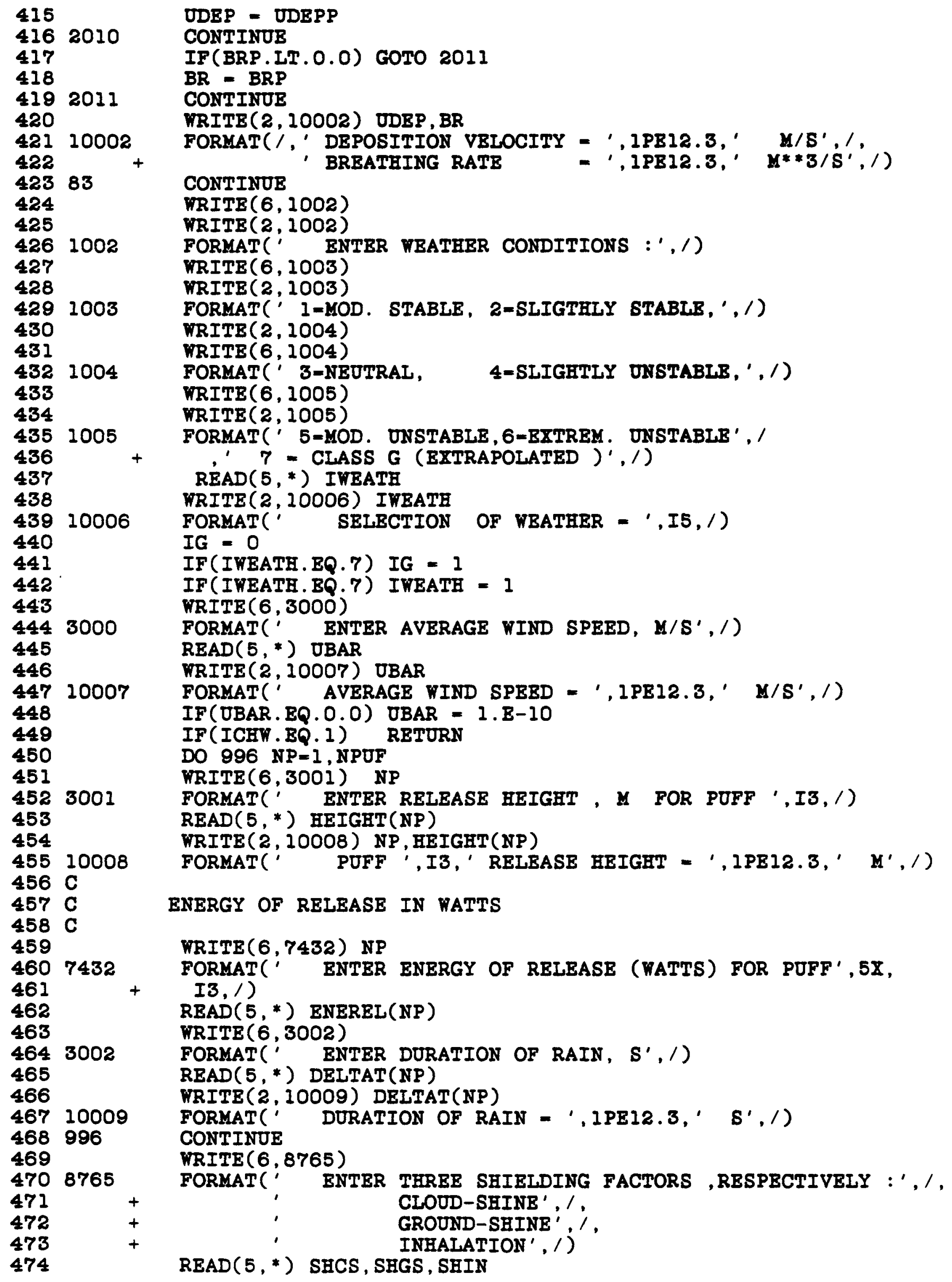




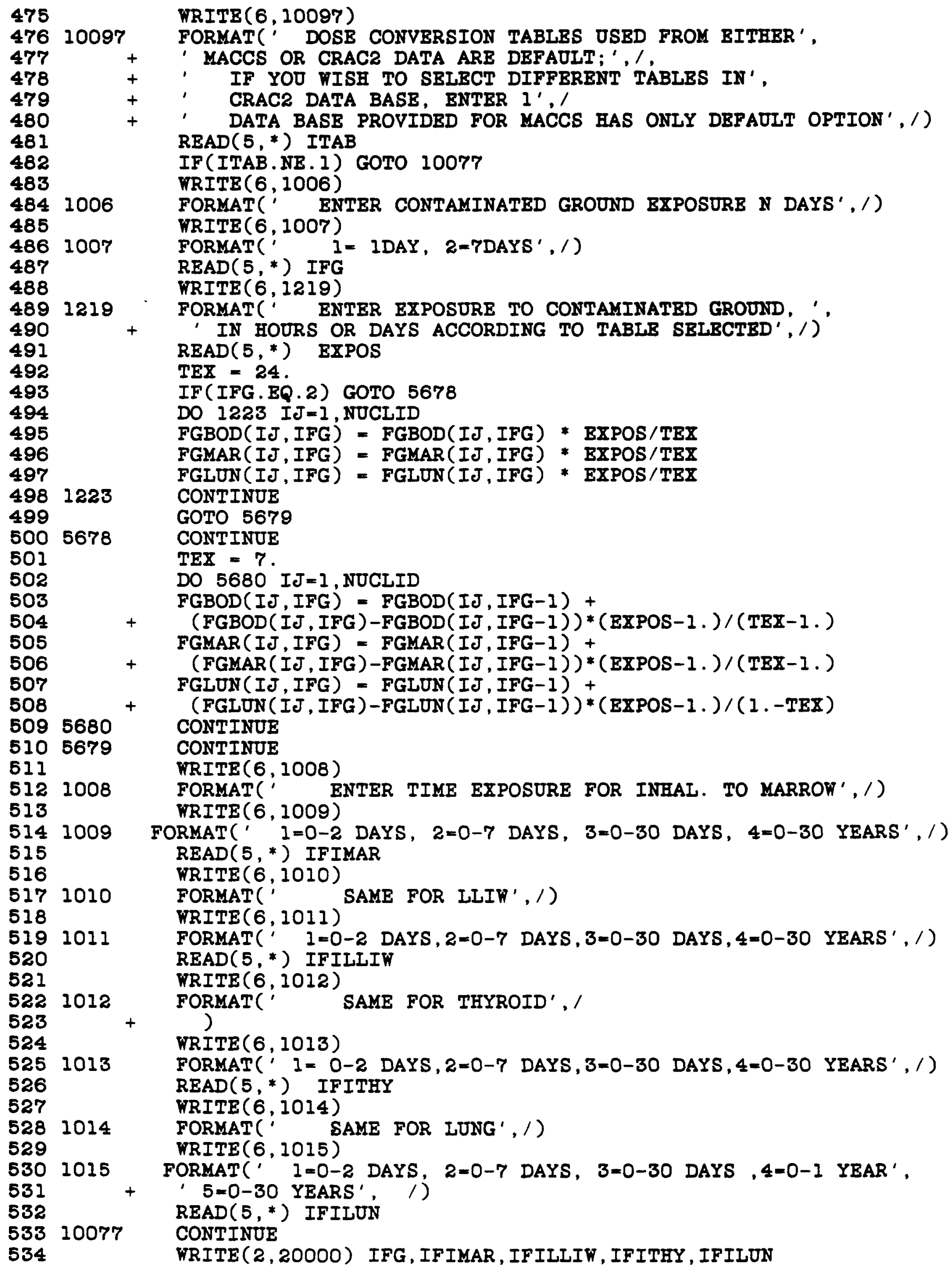


B-22

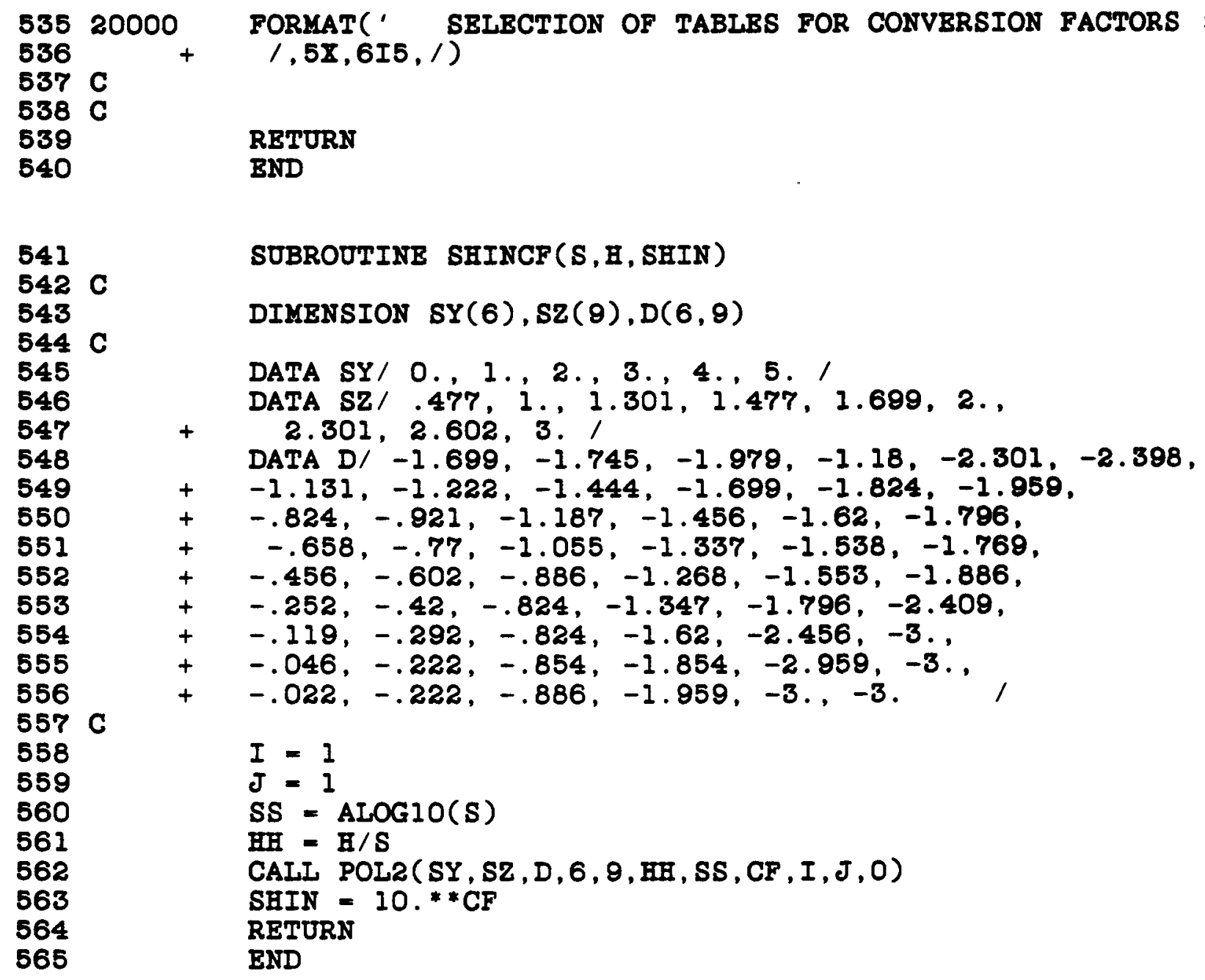

566

$567 \mathrm{C}$

$568 \mathrm{C}$

569

$570 \mathrm{C}$

57110

572

573

574

57520

576

577

578

$579 \mathrm{C}$

58030

581

582

583

58440

SUBROUTINE POLZ (X,Y,Z,IXT, JYT, XP,YP,ZP, I,J, MES)

DIMENSION Z(IXT), Y(JYT), Z(IXT,JYT)

585

586

$\operatorname{IF}(X P . L E . X(I+I))$ GOTO 20

$I=I+I$

IF(I.GE.IXT) GOTO 30

GOTO 10

IF(XP.GE.X(I)) GOTO 30

$I=I-I$

IF(I.LT.1) GOTO 30

GOTO 20

IF(YP.IE.Y(J+1)) GOTO 40

$J=J+I$

IF (J.GE.JYT) GOTO 60

GOTO 30

IF(YP.GE.Y(J)) GOTO 50

$J=J-I$

IF(J.LT.I) GOTO 60

GOTO 40 
591

582

593

594

595

596

$597 \mathrm{C}$

59860

599

60065

601

602

603

604

605

606

607

608

609

610

611

612

61370

614

615

616

61775

618

619

620

621

622

623

624

62585

626

627

628

62990

630

631

632

63395

634

635

636

63710

638

639

640

641

642

$643 \mathrm{C}$

$644 \mathrm{C}$

$645 \mathrm{C}$

646

647

648
$B=(Y P-Y(J)) /(Y(J+1)-Y(J))$

OMA $=1 .-A$

$O M B=1 .-B$

$Z P=O M A * O M B * Z(I, J)+B * O M A * Z(I, J+1)+$

$+\quad A * O M B * Z(I+1, J)+A * B * Z(I+I, J+1)$

RETURN

IF (MES.EQ. O) GOTO 65

RETURN

CONTINUE

IF(I.IT.I.AND.J.IT.I) GOTO 70

IF (I.GE.IXT.AND.J.GE.JYT) GOTO 75

IF (I.IT.I.AND.J.GE.JYT) GOTO 80

IF (I.GE.IXT.AND.J.IT. 1) GOTO 85

IF (I.IT.I.AND.J.IT.JYT) GOTO 90

IF(I.GE.IXT.AND.J.LT.JYT) GOTO 95

IF (I.IT.IXT.AND.J.GE.JYT) GOTO 100

$Z P=(Z(I, I)-Z(I+I, I)) *(X P-X(I)) /$

$+$

$(X(I)-X(I+1))+Z(I, I)$

$I=I$

$J=1$

RETURN

$Z P=Z(1,1)$

$I=I$

$J=1$

RETURN

$Z P=Z(I X T, J Y T)$

$I=I X T-1$

$J=J Y T-I$

RETURN

$80 \quad Z P=Z(I, J Y T)$

$I=I$

$J=J Y T-1$

RETURN

$85 \quad Z P=Z(I X T, I)$

$I=I X T-I$

$J=1$

RETURN

Q $Z \mathrm{ZP}=(\mathrm{Z}(1, J)-Z(1, J+1)) *(Y \mathrm{P}-\mathrm{Y}(J)) /$

$I=1$

$(Y(J)-Y(J+I))+Z(I, J)$

RETURN

$Z P=(Z(I X T, J)-Z(I X T, J+I)) *(Y P-Y(J)) /$

$+(Y(J)-Y(J+I))+Z(I X T, J)$

$I=I X T-I$

RETURN

$100 Z P=(Z(I, J Y T)-Z(I+I, J Y T)) *(X P-X(I)) /$

$J=J Y T-1$

RETURN

END

SUBROUTINE RDRMA

COMMON/YORE/ IWHICH, FCTHY (54), FCLIIW(54), FGTHY $(54,2)$,

$+\quad$ FGLIIW $(54,2), \operatorname{NXDAT}, \operatorname{XDAT}(35), \operatorname{DCTHY}(54,5), \operatorname{DGTHY}(54,5)$,

$+\operatorname{DCLIIW}(54,5), \operatorname{DGLLIT}(54,5), \operatorname{FCSTO}(54), \operatorname{FGSTO}(54,2)$, 


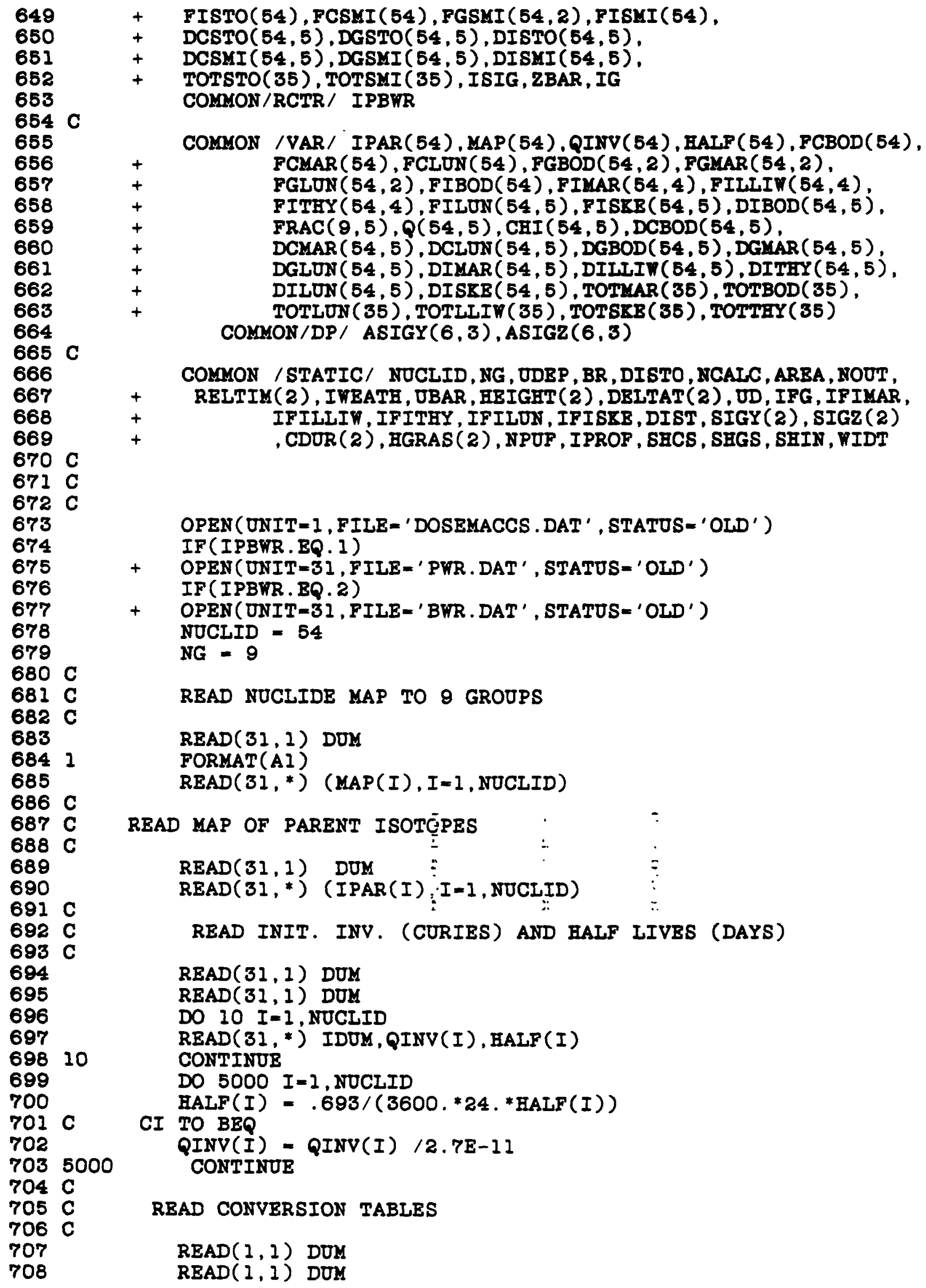


709

710

711

712

713

714

715

716

71760

718

719

720

721

722

723

724

72570

$726 \mathrm{C}$

$727 \mathrm{C}$

$728 \mathrm{C}$

729

730

731

732

733

734

735

736

737

738

739

740

741

742

743

744

745

746

747

748

74980

$750 \mathrm{C}$

$751 \mathrm{C}$

$752 \mathrm{C}$

753

754

755

$756 \mathrm{C}$

$757 \mathrm{C}$

$758 \mathrm{C}$

759

760

761

762

763

764

765

$766 \mathrm{C}$

$767 \mathrm{C}$

$768 \mathrm{C}$

DO $60 \mathrm{I}=1$, NOCLID

$\operatorname{RBAD}(1, *) \operatorname{FCSTO}(I), \operatorname{FGSTO}(I, 1), \operatorname{FGSTO}(I, 2), \operatorname{FISTO}(I)$

$\operatorname{READ}(1, *) \operatorname{FCSHI}(I), \operatorname{FGSUI}(I, 1), \operatorname{FGSHI}(I, 2), \operatorname{FISMI}(I)$

$\operatorname{RBAD}(I, *)$ FCLUN $(I), \operatorname{FGLUN}(I, 1), \operatorname{FGLON}(I, 2), \operatorname{FILON}(I, 1)$

$\operatorname{READ}(1, *) \operatorname{FCMAR}(I), \operatorname{FGMAR}(I, 1), \operatorname{FGMAR}(I, 2), \operatorname{FIMAR}(I, 1)$

$\operatorname{READ}(1, *)$ FCTHY (I), FGTHY $(I, 1), \operatorname{FGTHY}(I, 2), \operatorname{FITHY}(I, I)$

$\operatorname{RBAD}(1, *) \operatorname{FCLIIW}(I), \operatorname{FGLIIW}(I, 1), \operatorname{FGLIIV}(I, 2)$,

$+$

$\operatorname{FILIIW}(I, 1)$

CONTINUE

DO $70 \quad I=1$, NOCLID

$\operatorname{FGSTO}(I, 1)=\operatorname{FGSTO}(I, 1)+(\operatorname{FGSTO}(I, 2)-\operatorname{PGSTO}(I, 1)) * 0.22$

$\operatorname{FGSMI}(I, 1)=\operatorname{FGSMI}(I, 1)+(\operatorname{FGSMI}(I, 2)-\operatorname{PGSMI}(I, 1)) * 0.22$

$\operatorname{FGLUN}(I, I)=\operatorname{FGLUN}(I, I)+(\operatorname{FGLUN}(I, 2)-\operatorname{PGLUN}(I, I)) * 0.22$

$\operatorname{FGMAR}(I, I)=\operatorname{FGMAR}(I, 1)+(\operatorname{PGMAR}(I, 2)-\operatorname{PGMAR}(I, 1)) * 0.22$

$\operatorname{FGTHY}(I, 1)=\operatorname{FGTHY}(I, 1)+(\operatorname{FGTHY}(I, 2)-\operatorname{FGTHY}(I, 1)) * 0.22$

$\operatorname{FGLIIW}(I, 1)=\operatorname{FGLIIW}(I, 1)+(\operatorname{FGLIIW}(I, 2)-\operatorname{FGLIIT}(I, 1)) * 0.22$ CONTINUE

TRANSFORM TO REMS

$\mathrm{ZC}=100$.

DO $80 \quad I=1$, NUCLID

$\operatorname{FGSTO}(I, I)=\operatorname{FGSTO}(I, I) * Z C$

$\operatorname{FGSMI}(I, I)=\operatorname{FGSMI}(I, I) * Z C$

$\operatorname{FGLON}(I, 1)=\operatorname{FGLON}(I, 1) * Z C$

$\operatorname{FGMAR}(I, I)=\operatorname{FGMAR}(I, I) * Z C$

$\operatorname{FGTHY}(I, 1)=\operatorname{FGTHY}(I, 1) * Z C$

$\operatorname{FGLIIW}(I, 1)=\operatorname{FGLLIW}(I, 1) * Z C$

$\operatorname{FCSTO}(I)=\operatorname{FCSTO}(I) * Z C$

$\operatorname{FCSMI}(I)=\operatorname{FCSMI}(I) * Z C$

FCLUN $(I)=\operatorname{FCLUN}(I) * Z C$

$\operatorname{FCMAR}(I)=\operatorname{FCMAR}(I) * Z C$

FCTHY (I ) $=$ FCTHY $(I) * Z C$

FCLIIW $(I)=$ FCLIIW $(I) * Z C$

$\operatorname{FISTO}(I)=\operatorname{FISTO}(I) * Z C$

$\operatorname{FISMI}(I)=$ FISMI(I) * ZC

$\operatorname{FILUN}(I, 1)=\operatorname{FIIUN}(I, I) * Z C$

$\operatorname{FIMAR}(I, I)=\operatorname{FIMAR}(I, I) * Z C$

$\operatorname{FITHY}(I, 1)=\operatorname{FITHY}(I, I) * Z C$

$\operatorname{FILIIW}(I, 1)=\operatorname{FILIIW}(I, 1) * Z C$

CONTINUE

READ SPATIAL GRID DATA

$\operatorname{READ}(31,1)$ DOM

$\operatorname{READ}(31, *)$ NXDAT

$\operatorname{READ}(31, *)$ (XDAT(I), I= 1, NXDAT)

READ DEF.: FOR MACCS ALI = 1

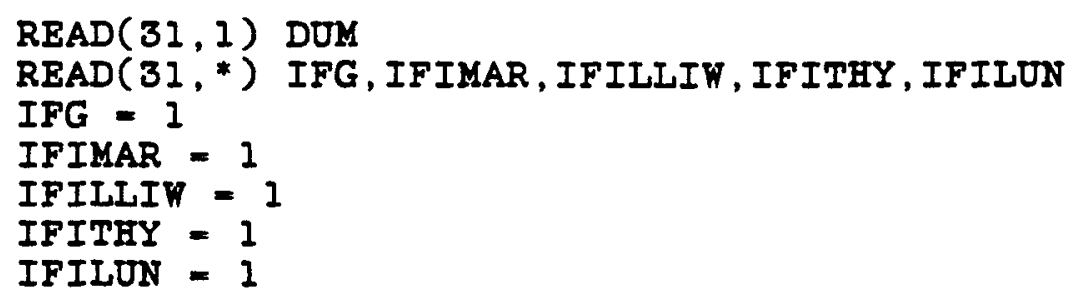

DISPERSION COEFFICIENTS CURVE FITTING PARAMETERS 
769

770

771

77290

773

774

77591

$776 \mathrm{C}$

$777 \mathrm{C}$

$778 \mathrm{C}$

779

780

$781 \mathrm{C}$

$782 \mathrm{C}$

783

784

785

786

787

$788 \mathrm{C}$

$789 \mathrm{C}$

$790 \mathrm{C}$

791

792

793

794

795

796

797

$798 \mathrm{C}$

799

800

801

802

803

804

805

806

807

$808 \mathrm{C}$

809

810

811

812

813

$814 \mathrm{C}$

815

816

817

818

$819 \mathrm{C}$

$820 \mathrm{C}$

821

822

823

824

825

826

C

$\operatorname{READ}(31,1)$ DUM

DO $90 \quad I=1,6$

$\operatorname{RBAD}(31, *)$ IDUM, JDOM, (ASIGY (I, J) , J-1, 3)

CONTINUE

DO $91 \quad I=1,6$

$\operatorname{RBAD}(31, *$ ) IDUM, JDUM, (ASIGZ (I, J) , J=1, 3)

CONTINUE

DEP. VELOCITY $(M / S)$ AND BRBATHING RATB $(M * * 3 / S)$

$\operatorname{READ}(31,1)$ DUM

$\operatorname{READ}(31, *)$ UDEP, BR

CLOSE ( 1 )

CLOSE ( 31 )

RETURN

END

SOBROUTIITE MAOUT(NC)

COMMON / MORE/ IWHICH, FCTHY (54), FCLLIW(54), FGTHY $(54,2)$,

$+$

$+$

$+$

$+$

$+$

$+$

$+$

$+$

$+$

$+$

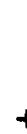

$+$

$+$

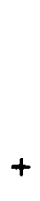

$+$

\section{CHARACTER *8 NAME (54)}

CHARACTER * I CLASS

DIMENSION GRSTO( $(9), \operatorname{GRMAR}(\theta), \operatorname{GRLUN}(\theta), \operatorname{GRLIIV}(\theta)$, $\operatorname{GRSMI}(\theta), \operatorname{GRTHY}(9), \operatorname{GRSKE}(\theta)$

\begin{tabular}{|c|c|}
\hline $\begin{array}{l}\text { IF (IWEATH. BQ. I) } \\
\text { IF (IWEATH. BQ. } 2 \text { ) } \\
\text { IF (IWEATH. BQ. } 3 \text { ) } \\
\text { IF (IWEATH. BQ. } 4 \text { ) } \\
\text { IF (IWEATH. EQ.5) } \\
\text { IF (IWEATH. EQ.6) }\end{array}$ & $\begin{array}{l}\text { CLASS } \\
\text { CLASS } \\
\text { CLASS } \\
\text { CLASS } \\
\text { CLASS } \\
\text { CLASS }\end{array}$ \\
\hline
\end{tabular}


B-27

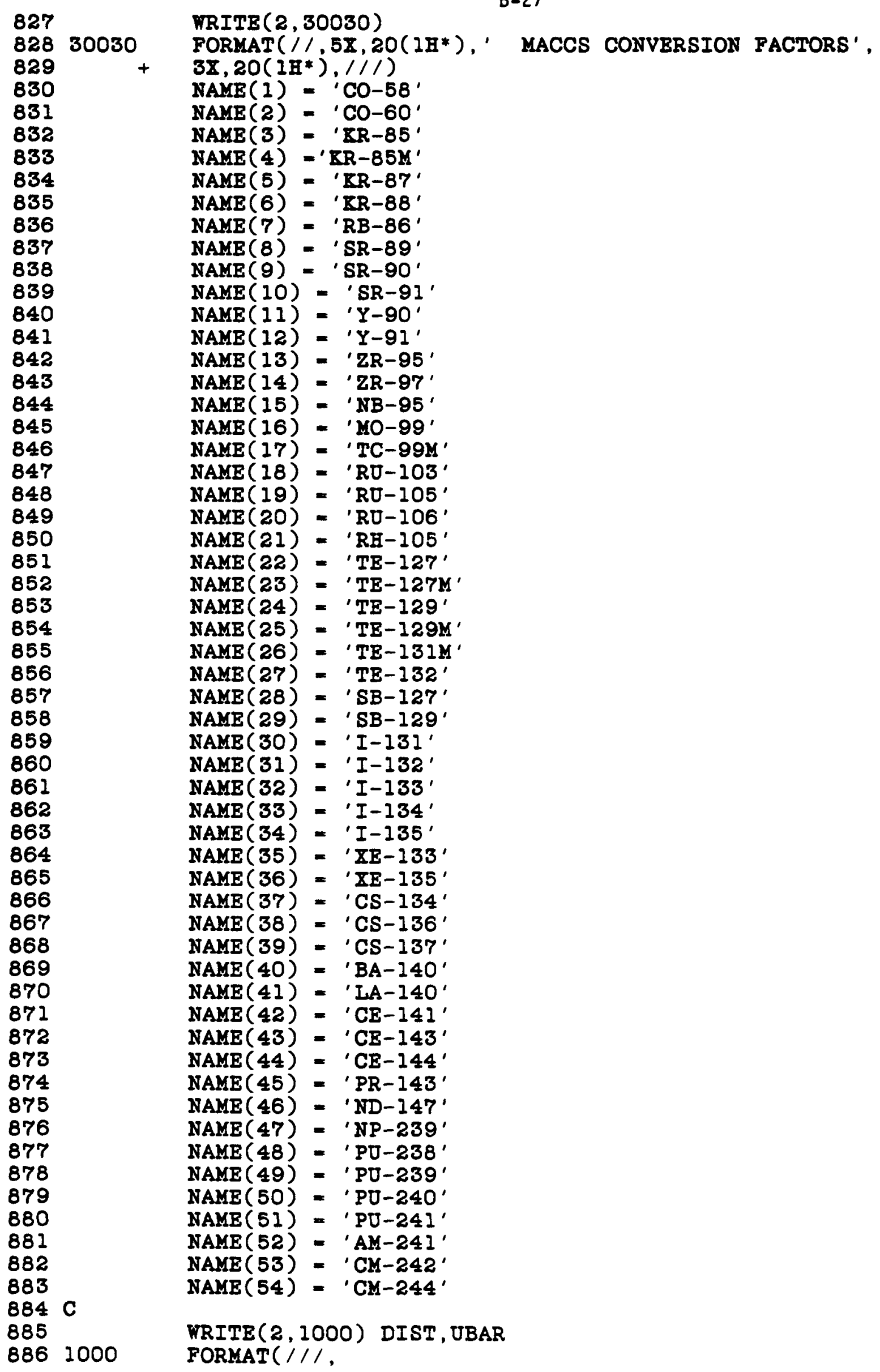




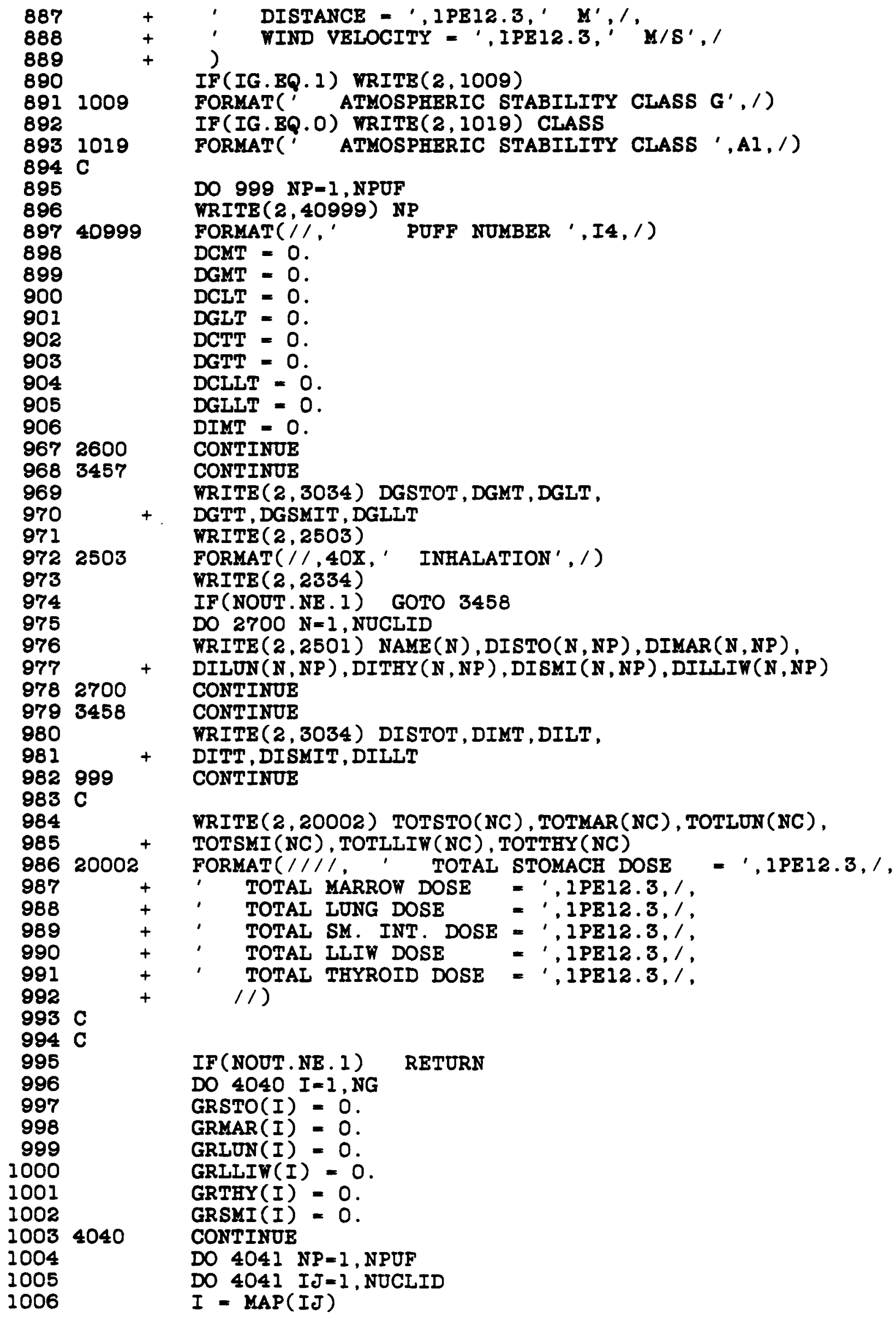


1042

$1043 \mathrm{C}$

$1044 \mathrm{C}$

1045

1046

1047

1048

1049

1050

1051

$1052 \mathrm{C}$

1053

1054

1055

1056

1057

1058

1059

1060

1061

1062

$1063 \mathrm{C}$

1064

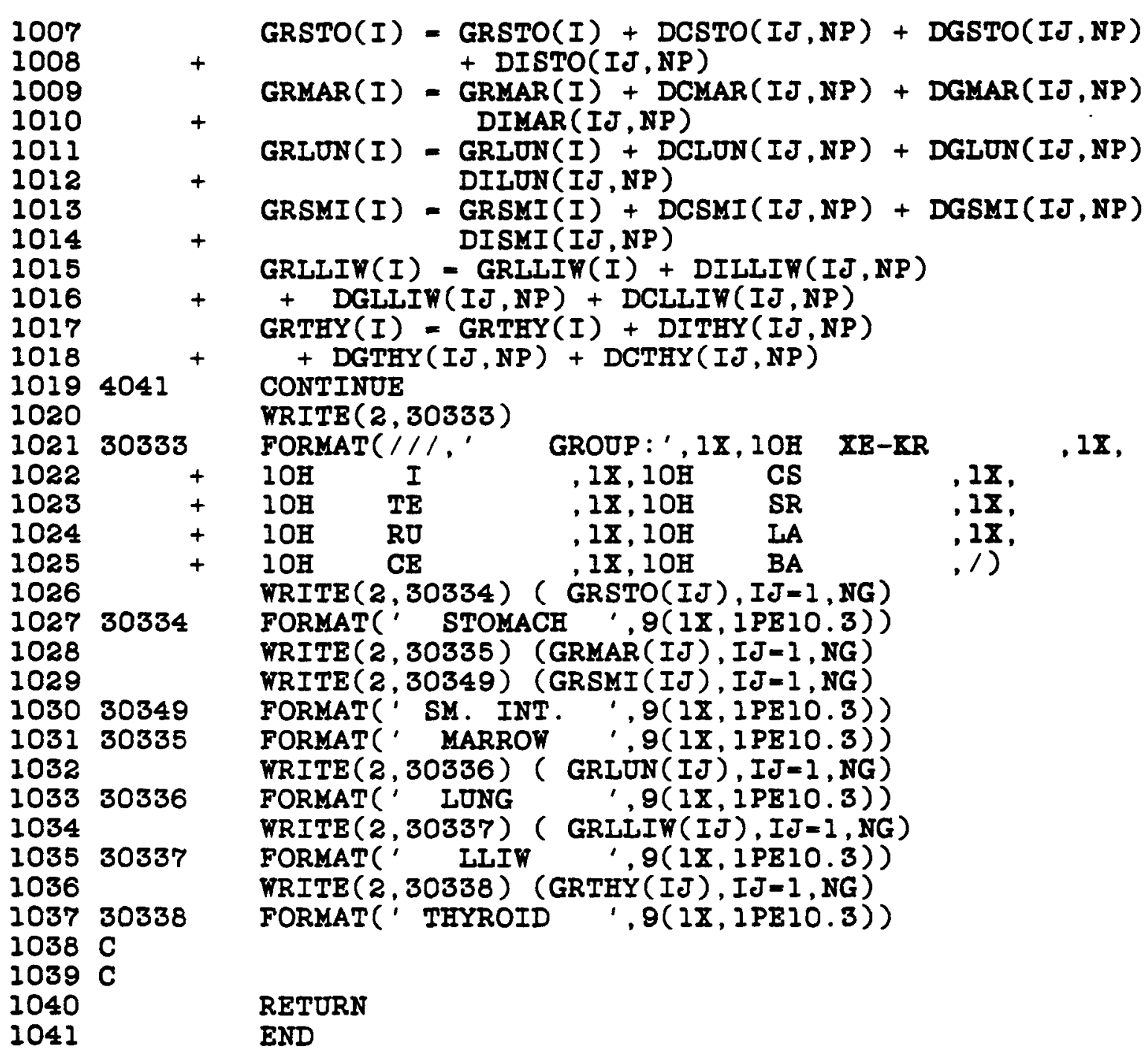

1007

1008

1009

1010

1011

1012

1013

1014

1015

1016

1017

1018

1019

1020

1021

1022

1023

1024

1025

1026

102730334

1028

1029

103030349

103130335

1032

103330336

1034

103530337

1036

103730338

$1038 \mathrm{C}$

$1039 \mathrm{C}$

1040

1041

$\operatorname{GRSTO}(I)=\operatorname{GRSTO}(I)+\operatorname{DCSTO}(I J, N P)+\operatorname{DGSTO}(I J, N P)$ $+\operatorname{DISTO}(I J, N P)$

$+$

$+$

$+$

$+$

4041

30333

FORMAT ( $/ 1 /$.

$1 \mathrm{OH}$

$10 \mathrm{H} \quad \mathrm{TE}$

$1 \mathrm{OH} \quad \mathrm{RO}$

1OH $\quad \mathrm{CE}$

WRITE $(2,30334$ ) ( $\operatorname{GRSTO}(I J), I J=1$, NG)

FORMAT(' STOMACH ', 9(IX, IPE10.3))

WRITE $(2,30335$ ) (GRMAR(IJ), IJ =1, NG)

WRITE $(2,30349)$ (GRSMI(IJ), IJ = 1, NG)

FORMAT(' SM. INT. ', $9(1 \mathrm{X}, 1 \mathrm{PE} 10.3))$

FORMAT(' MARROW ', $9(1 \mathrm{X}, 1 \mathrm{PE} 10.3))$

WRITE $(2,30336)$ ( GRLUN(IJ), IJ=1,NG)

FORMAT(' LUNG ',9(IX,IPE10.3))

WRITE $(2,30337)$ ( $\operatorname{GRLLIF(IJ),~IJ=1,NG)~}$

FORMAT(' IIIW ',9(IX,IPE10.3))

WRITE $(2,30338$ ) (GRTHY(IJ), IJ=1, NG)

FORMAT('THYROID', $9(1 \mathrm{X}, 1$ PEIO.3))

RETURN

END

SUBROUTINE REST

COMMON /MORE / IWHICH, FCTHY (54), FCLIIW (54), FGTHY $(54,2)$, $\operatorname{FGLLIP}(54,2), \operatorname{NXDAT}, \operatorname{XDAT}(35), \operatorname{DCTHY}(54,5), \operatorname{DGTHY}(54,5)$, $\operatorname{DCLIIW}(54,5), \operatorname{DGLIIW}(54,5), \operatorname{FCSTO}(54), \operatorname{FGSTO}(54,2)$, FISTO(54), FCSMI (54), FGSMI (54,2), FISMI (54), $\operatorname{DCSTO}(54,5), \operatorname{DGSTO}(54,5), \operatorname{DISTO}(54,5)$, $\operatorname{DCSMI}(54,5), \operatorname{DGSMI}(54,5), \operatorname{DISMI}(54,5)$, TOTSTO (35), TOTSMI ( 35 ), ISIG, ZBAR, IG

COMMON /VAR/ IPAR( 54), MAP(54), QINV(54), HALF( 54), FCBOD(54), FCMAR (54), FCLUN (54), FGBOD $(54,2), \operatorname{FGMAR}(54,2)$, FGIUN $(54,2), F I B O D(54), F I M A R(54,4), F I I I I N(54,4)$, FITHY $(54,4)$, FILUN $(54,5), F I S K E(54,5), \operatorname{DIBOD}(54,5)$, $\operatorname{FRAC}(9,5), Q(54,5), \operatorname{CHI}(54,5), \operatorname{DCBOD}(54,5)$. $\operatorname{DCMAR}(54,5), \operatorname{DCLUN}(54,5), \operatorname{DGBOD}(54,5), \operatorname{DGMAR}(54,5)$, $\operatorname{DGIUN}(54,5), \operatorname{DIMAR}(54,5), \operatorname{DIILIV}(54,5), \operatorname{DITHY}(54,5)$, $\operatorname{DIIUN}(54,5), \operatorname{DISKE}(54,5), \operatorname{TOTMAR}(35), \operatorname{TOTBOD}(35)$. TOTLON ( 35 ), TOTLLIW ( 35 ), TOTSKE (35), TOTTHY ( 35 ) COMMON/DP/ $\operatorname{ASIGY}(6,3), \operatorname{ASIGZ}(6,3)$

COMMON /STATIC/ NUCLID, NG, UDEP, BR, DISTO, NCALC, AREA, NOOT, 
1065

1066

1067

1068

1069

1070

1071

1072

1073

1074

1075

1076

107710

$1078 \mathrm{C}$

$1079 \mathrm{C}$

1080

1081

1082

$1083 \mathrm{C}$

$1084 \mathrm{C}$

$1085 \mathrm{C}$

1086

1087

1088

1089

1090

1091

1092

$1093 \mathrm{C}$

1094

1095

1096

1097

1098

2099

1100

1101

1102

$1103 \mathrm{C}$

1104

1105

1106

1107

1108

1109

1110

1111

$1112 \mathrm{C}$

$1113 \mathrm{C}$

$1114 \mathrm{C}$

$1115 \mathrm{C}$

$1116 \mathrm{C}$

$1117 \mathrm{C}$

$1118 \mathrm{C}$

$1119 \mathrm{C}$

$1120 \mathrm{C}$

$1121 \mathrm{C}$

$1122 \mathrm{C}$

.

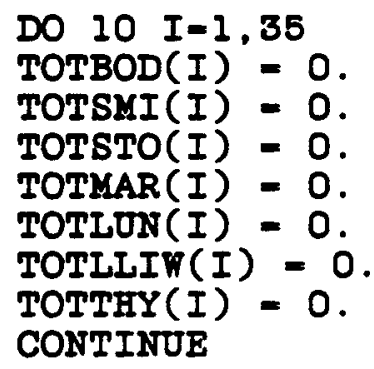

RETURN

END

SUBROUTINE SIGCR (K,NC,SY,SZ,DY)

COMMON / MORE / IWHICH, FCTHY (54), FCLIIW(54), FGTHY (54, 2),

DATA SZI/ 340., 640., 640., 640., 640.,

$+640.640 \ldots 640 ., 640 \ldots 640 ., 640 ., 640.1$ DATA SYI/ 142., 366., 572., 770., 962.,

+ 1150., 1340., 1520., 1700., 1880.,2140.,2490./

CRAC2 A WEATHER

DATA SZ1/ 199.6,651.8,800., 800., 800., 800., 800.,

$+800 \ldots$ 800., 800., 800., 800.l DATA SY1/ 159.5, 368.2, 556.3, 749.,831., 1109.,

+ 1284., 1456., 1626., 1795., 2043., 2371./ 


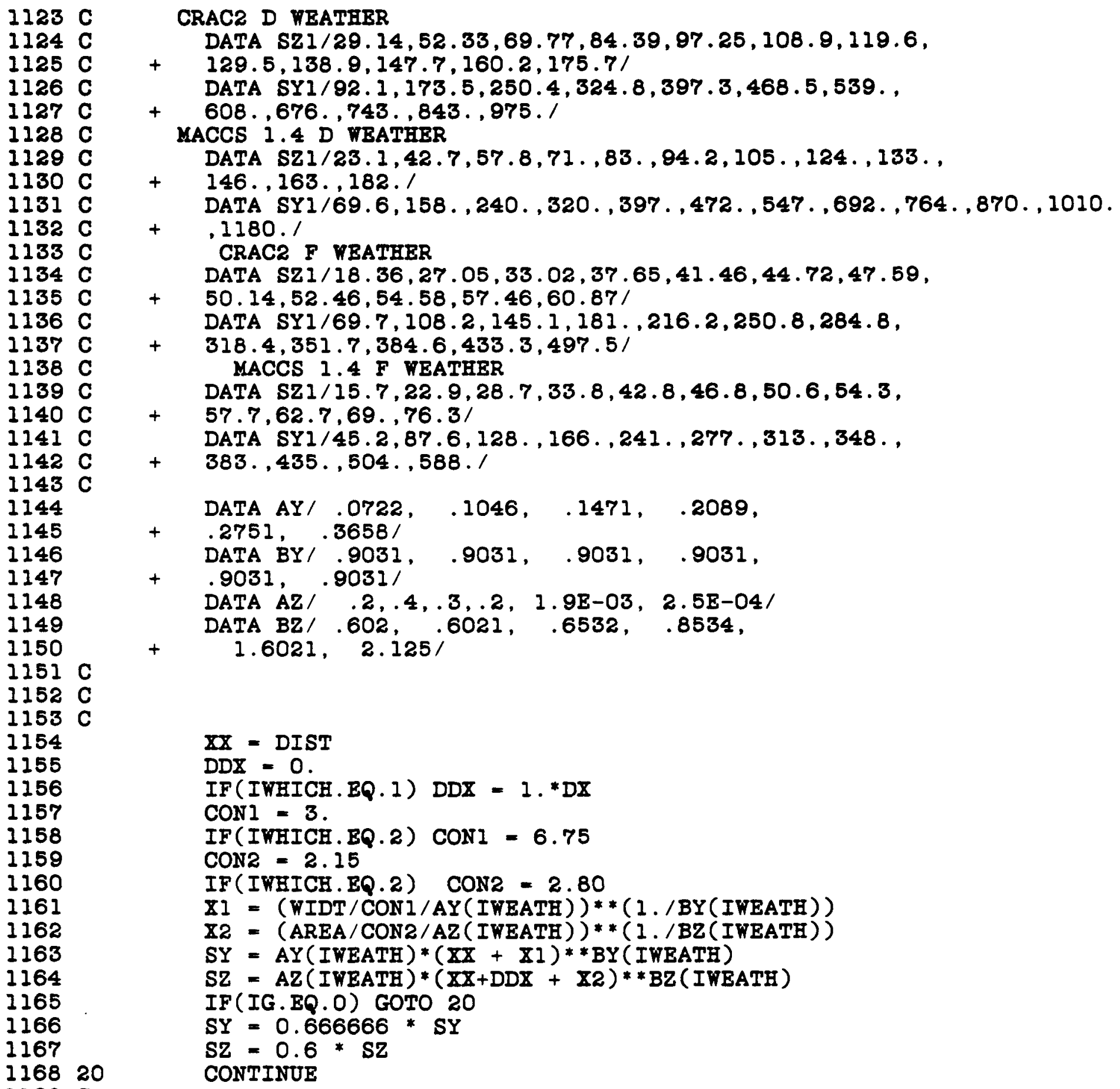

CORRECTIONS FOR DURATION AND HEIGHT OF GRASS

$S Y=S Y * C D U R(E)$

IF (IWHICH. BQ. I) SZ = SZ * HGRAS( $\mathrm{E}$ )

IF (I HHICH. BQ.2) SZ = SZ * 1.27

RETURN

END 
1181

1182

1183

1184

1185

1186

1187

$1188 \mathrm{C}$

1189

1190

1191

1192

1193

1194

1195

1196

1197

1198

1199

$1200 \mathrm{C}$

1201

1202

1203

1204

1205

1206

1207

$1208 \mathrm{C}$

1209

1210

1211

$1212 \mathrm{C}$

$1213 \mathrm{C}$

$1214 \mathrm{C}$

1215

1216

$1217 \mathrm{C}$

1218

1219

1220

1221

1222

1223

$1224 \mathrm{C}$

$1225 \mathrm{C}$

$1226 \mathrm{C}$

1227100

1228

1229

1230

1231

1232

$1233 \mathrm{C}$

$1234 \mathrm{C}$

1235

1236

COMMON/MORE/ I IHICH, FCTHY (54), FCLLIR(54), FGTHY $(54,2)$,

$+\operatorname{PGLIIY}(54,2), \operatorname{NXDAT}, \operatorname{XDAT}(35), \operatorname{DCTHY}(54,5), \operatorname{DGTHY}(54,5)$,

$+\operatorname{DCLIIY}(54,5), \operatorname{DGLIIT}(54,5), \operatorname{FCSTO}(54), \operatorname{FGSTO}(54,2)$,

+ FISTO(54), PCSMI(54), FGSMI( 54, 2), FISMI( 54),

$+\operatorname{DCSTO}(54,5), \operatorname{DGSTO}(54,5), \operatorname{DISTO}(54,5)$,

$+\operatorname{DCSMI}(54,5), \operatorname{DGSMI}(54,5), \operatorname{DISMI}(54,5)$,

+ TOTSTO( 35 ), TOTSMI (35), ISIG, ZBAR, IG

COMMON /VAR/ IPAR(54), MAP(54), QINV(54), $\operatorname{MALF}(54), \operatorname{PCBOD}(54)$, FCMAR (54), FCLUN (54), FGBOD $(54,2), \operatorname{FGMAR}(54,2)$, FGLUN $(54,2)$, FIBOD $(54), \operatorname{FIMAR}(54,4), \operatorname{PIIIIN}(54,4)$, FITHY $(54,4), \operatorname{FIIUN~}(54,5), \operatorname{FISTE}(54,5), \operatorname{DIBOD}(54,5)$, $\operatorname{FRAC}(9,5), Q(54,5), \operatorname{CHI}(54,5), \operatorname{DCBOD}(54,5)$. $\operatorname{DCMAR}(54,5), \operatorname{DCLUN}(54,5), \operatorname{DGBOD}(54,5), \operatorname{DGMAR}(54,5)$, $\operatorname{DGLON}(54,5), \operatorname{DIMAR}(54,5)$, DILIIN $(54,5), \operatorname{DITHY}(54,5)$, $\operatorname{DILON~}(54,5), \operatorname{DISRE}(54,5), \operatorname{TOTMAR}(35), \operatorname{TOTBOD}(35)$, TOTLON ( 35 ), TOTLLIW (35), TOTSKB (35), TOTIHY (35)

COMAON/DP/ ASIGY $(6,3)$, ASIGZ $(6,3)$

COMON/ENRGY/ ENEREL(2)

COMYON /STATIC/ NOCLID, NG, UDEP, BR, DISTO, NCALC, AREA, NOUT, RELTIM(2), IWEATH, UBAR, HEIGHT( (2), DELTAT(2), UD, IFG, IFIMAR, IFILIIW, IF ITHY, IFILON, IFISKE, DIST, SIGY (2), SIGZ(2)

$+$

$+$ , CDUR (2), HGRAS (2), NPUF, IPROF , SHCS, SHGS, SHIN, WIDT

DIMENSION PI(6)

DATA PI/ .55, .35, .15, .1, .07, .07/

$F=8.79 E-06 *$ ENEREL(NP)

VIND $=$ UBAR * ( AREA/10.)** (PI(IWEATH)

WIND $=.5^{*}($ UBAR + WIND $)$

IF VIND VELOCITY IS LESS THAN CRITICAL SPEED, SUPPRESS

UCRIT = SQRT $(9.09 * F /$ AREA $)$

IF (NIND. LT. OCRIT) RETURN

IF(IFEATH.GT.2) GOTO 100

$S=8.7 \mathrm{E}-04$

IF (IWEATH.EQ.I) $S=1.75 E-03$

$\mathrm{DH}=2.6^{*}(\mathrm{~F} / \mathrm{WIND} / \mathrm{S}) * * .33333333$

HITE $=$ HITE $+\mathrm{DH}$

RETURN

NEUTRAL OR UNSTABLE PLUME RISE

CONTINUE

$D E=1.6 * F * * .333333 *$ DISTI **.666666 / WIND

IF (DH.GT. (300. *F/WIND**3)) RETURN

IF ((2.15*SIGZ(NP)).GT. 1000.) RETURN

IF(TIME.GT.3600.) RETURN

HITE = HITE + DH

RETURN

BND 
C-1

1

APPENDIX C

PWR and BWR Core Inventories 
Map of nuclides into 9 groups

$\begin{array}{lllllllllllllllllllllllll}6 & 6 & 1 & 1 & 1 & 1 & 3 & 5 & 5 & 5 & 7 & 7 & 7 & 7 & 7 & 6 & 6 & 6 & 6 & 6 & 6 & 4 & 4 & 4 & 4\end{array}$

$\begin{array}{lllllllllllllllllllllllll}4 & 4 & 4 & 4 & 2 & 2 & 2 & 2 & 2 & 1 & 1 & 3 & 3 & 3 & 9 & 7 & 8 & 8 & 8 & 7 & 7 & 8 & 8 & 8 & 8\end{array}$

8888

Map of parent isotopes

00000000000

$\begin{array}{lllllll}9 & 10 & 0 & 0 & 13 & 0 & 16\end{array}$

$\begin{array}{llllllll}0 & 0 & 0 & 19 & 28 & 0 & 29 & 0\end{array}$

$\begin{array}{lllllll}0 & 0 & 0 & 0 & 26 & 27 & 0\end{array}$

$\begin{array}{llllllll}0 & 0 & 32 & 34 & 0 & 0 & 0 & 0\end{array}$

4000004300053

475405100

Table 2 : Nuclide NUMBER, Inventor Half-life (days)

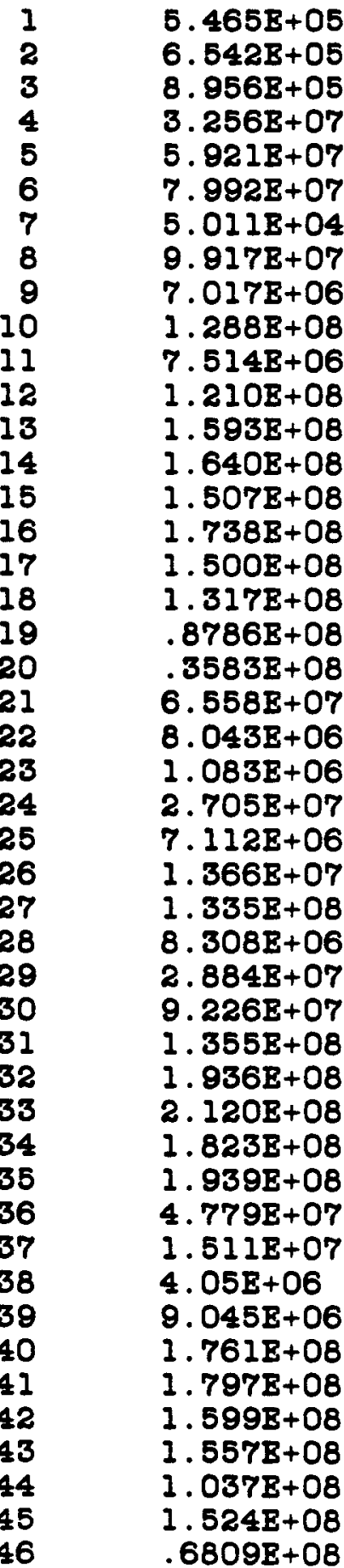

\begin{tabular}{|c|c|}
\hline $\begin{array}{c}71.3 \\
1921 . \\
3919 . \\
.1867 \\
.05278 \\
.1167 \\
18.65 \\
52.0 \\
10260 \\
.395 \\
2.67 \\
58.8 \\
65.5 \\
.70 \\
35.1 \\
2.751 \\
.2508 \\
39.59 \\
.185 \\
369 . \\
1.479 \\
.3896 \\
109 . \\
.04861 \\
33.4 \\
1.25 \\
3.25 \\
3.80 \\
.1808 \\
8.04 \\
.09521 \\
.8667 \\
.03653 \\
.2744 \\
5.29 \\
.3821 \\
752.4 \\
13 . \\
10990 \\
12.79 \\
1.676 \\
32.53 \\
1.375 \\
284.4 \\
13.58 \\
10.99\end{array}$ & 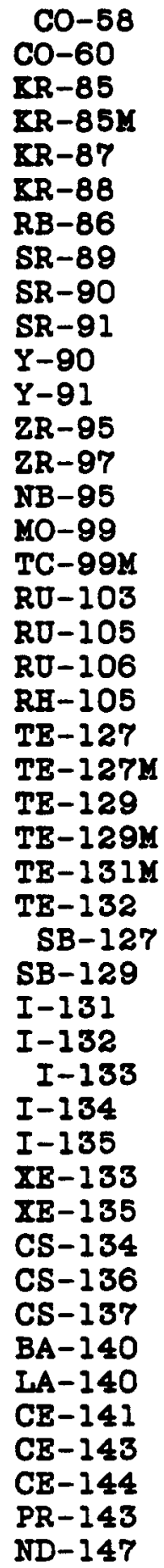 \\
\hline
\end{tabular}


C-3

$\begin{array}{lccc}47 & 2.029 \mathrm{~B}+09 & 2.35 & N P-239 \\ 48 & 1.411 \mathrm{~B}+05 & 32510 . & \mathrm{NP}-238 \\ 49 & 3.578 \mathrm{~B}+04 & 8.912 \mathrm{~B}+06 & \mathrm{PU}-239 \\ 50 & 4.479 \mathrm{~B}+04 & 2.469 \mathrm{~B}+06 & \mathrm{PO}-240 \\ 51 & 7.711 \mathrm{~B}+06 & 5333 . & \mathrm{PO}-241 \\ 52 & 7.838 \mathrm{~B}+03 & 1.581 \mathrm{~B}+05 & \mathrm{AM}-241 \\ 53 & 2.073 \mathrm{~B}+06 & 163 . & \mathrm{CM}-242 \\ 54 & 1.117 \mathrm{~B}+05 & 6611 . & \mathrm{CM}-244\end{array}$

Grid distances ( 10 DISTANCES) avg. radius in m. 10 402. 1210. 3218. 4828. 6437 .

8047. 16100. 30200. 84500. 684000 .

Default conversion factors (CRAC2) IFG, IFIMAR, IFILLIW, IFITHY, IFILUN $\begin{array}{lllll}1 & 2 & 4 & 4 & 5\end{array}$ Curve fitting parameters

$-3.550349462600479$

$\begin{array}{cc}2 & 1 \\ -2.816749412492209 & \end{array}$ 31

$-2.546075845819127$ 41

$-1.969425829970786$ 51

$-1.960802209317214$ 61

$-1.790242998442716$ 12

$-4.539003975280546$

$-4.2132460^{2} 1985861$ 32

$-3.162197496882786$ 42

$-2.981190111191164$ 52

2. 693340867043741 622

9.430199759984714 Deposition velocity and breathing rate $0.012 .660 \mathrm{E}-04$

1.160048586537639

1.065570910709667

1.077350459808095

1.021851293791542

1.110646206756064

1. 150797093701679

1.411814492169336

1.443245116001938

1. 196700871322801

1.212371210070850

$-0.7812153059161314$

$-3.392720906582776$
$-1.7190794757384000 \mathrm{~B}-02$

$-1.1470301822137058 B-02$

-1.2523526943953700E-02

$-8.3770326083625144 E-03$

$-1.4053660078375977 E-02$

$-1.7333186632828135 E-02$

$-5.4496510043164801 \mathrm{~B}-02$

$-5.4706872600918071 \mathrm{E}-02$

$-3.4587696416624102 E-02$

$-2.5384904034518616 \mathrm{E}-02$

0.1579966646452930

0.4248442241950466 
Map of nuclides into 9 groups

$66 \begin{array}{llllllllllllllllllllllll}6 & 6 & 1 & 1 & 1 & 3 & 5 & 5 & 5 & 7 & 7 & 7 & 7 & 7 & 6 & 6 & 6 & 6 & 6 & 6 & 4 & 4 & 4 & 4\end{array}$

$\begin{array}{llllllllllllllllllllllll}4 & 4 & 4 & 4 & 2 & 2 & 2 & 2 & 2 & 1 & 1 & 3 & 3 & 3 & 9 & 7 & 8 & 8 & 8 & 7 & 7 & 8 & 8 & 8\end{array}$

8888

Map of parent isotopes

000000000000

$\begin{array}{llllllll}9 & 10 & 0 & 0 & 13 & 0 & 16\end{array}$

$\begin{array}{llllllll}0 & 0 & 0 & 19 & 28 & 0 & 29 & 0\end{array}$

$\begin{array}{lllllll}0 & 0 & 0 & 0 & 26 & 27 & 0\end{array}$

$\begin{array}{lllllllll}0 & 0 & 32 & 34 & 0 & 0 & 0 & 0\end{array}$

400000430053

475405100

Table 1 : Nuclide number, 1nventory for PWR (C1) ref. power 3412 MWTh, Half-life (days)

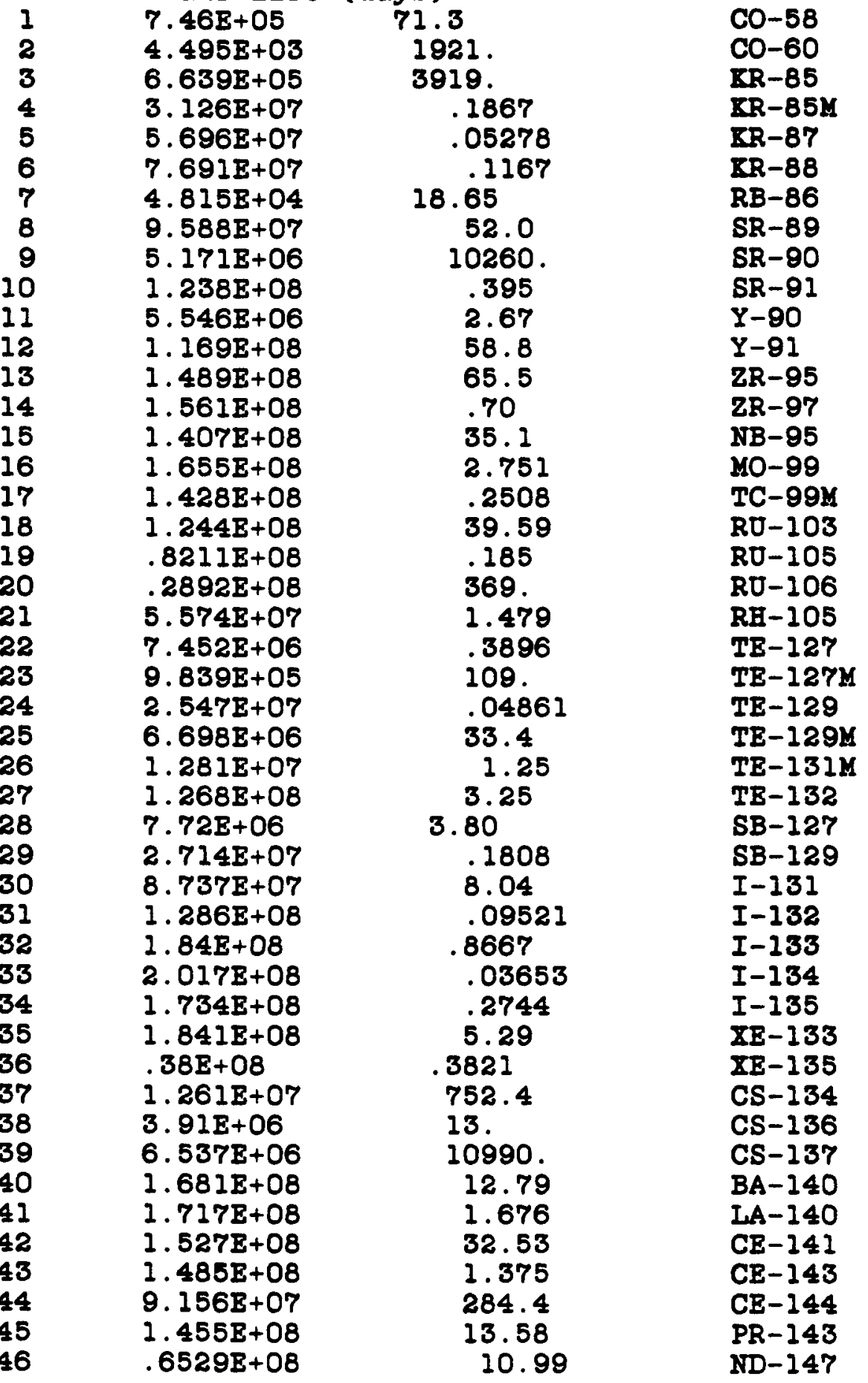


$C-5$

\begin{tabular}{|c|c|c|c|}
\hline $\begin{array}{l}47 \\
48 \\
49 \\
50 \\
51 \\
52 \\
53 \\
54\end{array}$ & $\begin{array}{l}1.85 \mathrm{~B}+09 \\
1.168 \mathrm{~B}+05 \\
2.581 \mathrm{~B}+04 \\
2.839 \mathrm{~B}+04 \\
5.421 \mathrm{~B}+06 \\
3.624 \mathrm{~B}+03 \\
1.369 \mathrm{~B}+06 \\
8.406 \mathrm{E}+04\end{array}$ & $\begin{array}{c}2.35 \\
32510 . \\
8.912 \mathrm{~B}+06 \\
2.469 \mathrm{~B}+06 \\
5333 . \\
1.581 \mathrm{~B}+05 \\
163 . \\
6611 .\end{array}$ & $\begin{array}{c}\text { NP-239 } \\
P D-238 \\
P D-239 \\
P D-240 \\
P D-241 \\
A Y-241 \\
C Y-242 \\
C M-244\end{array}$ \\
\hline
\end{tabular}

Grid distances avg. radius in $\mathrm{m}$. 34

402. 1210. 2010. 3219. 4023. 4828. 5633. 6437. 7242. 8047. 9660. 11300. 13700. 16100.

20100. 22100. 26200. 30200. 36200. 44300. 62300.

60400. 68400. 76400. 84500. 82500. 101000. 109000.

125000. 149000. 201000. 282000. 443000. 684000.

Default conversion factors (CRAC2) IFG, IFIKAR, IFIIIIN, IFITHY, IFILUN

$\begin{array}{lllll}2 & 2 & 4 & 4 & \end{array}$

Curve fitting parameters 11

$-3.559349462600479$ 21

$-2.816749412492209$ 31

$-2.546075845819127$ 41

$-1.969425829970786$ 51

$-1.960802209317214$ 61

$-1.790242998442716$ 12

$-4.539003975280546$ 22

$-4.213246071885861$ 32

$-3.162197496882786$ 42

$-2.981190111191164$ 52

2.693340867043741 62

1.160048586537639

1.065570910709667

1.077350459808095

1.021951293791542

1.110646206756064

1.150797093701679

1.411814492169336

1.443245116001938

1.196700871322801

1.212371210070850

$-0.7812153059161314$

$-3.392720906582776$

9.430199759984714

Deposition velocit

$0.012 .660 \mathrm{E}-04$

$y$ and breathing rate
$-1.7180794757384000 E-02$

$-1.1470301922137058 \mathrm{E}-02$

-1.2523526943953700E-02

$-8.3770326083625144 E-03$

$-1.4053660078375977 \mathrm{E}-02$

$-1.7333186632828135 E-02$

$-5.4496510043164801 E-02$

$-5.4706872600918071 E-02$

$-3.4587696416624102 E-02$

$-2.5384904034518616 \mathrm{~B}-02$

0.1579966646452930

0.4248442241950466 
D-1

APPENDIX D

CRAC2 and MACCS Dose Conversion Factors 
Table 2 :Radionuclide, Thole Body, Total Marrow, Lung, THYROID, ILIW Immersion in contaminated alr (Rem per $\mathrm{C} 1-8 \theta \mathrm{c} / \mathrm{m} * 3$ )

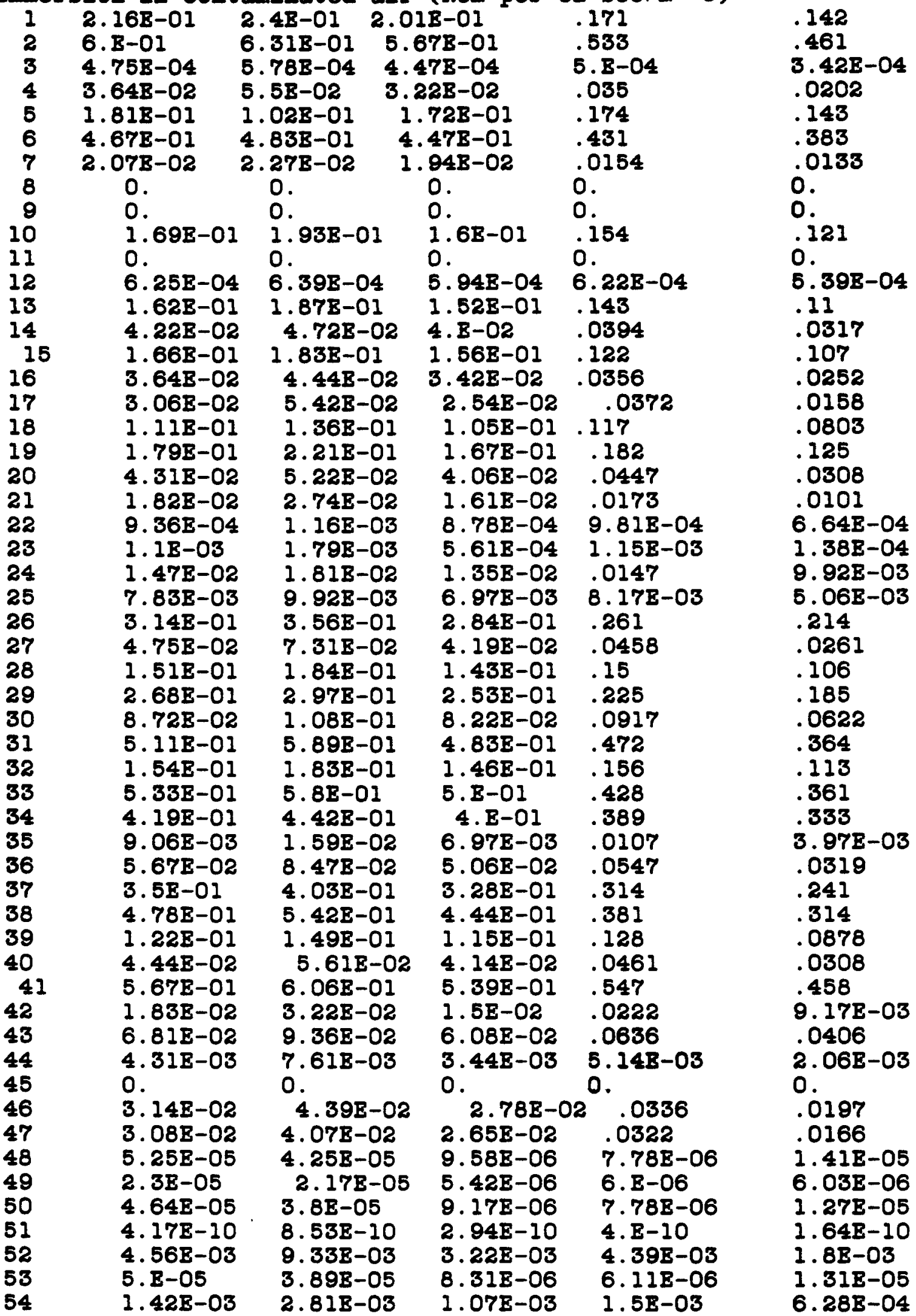

Table 3 : per 1 Day ' Nucl., Whole Body, Marrow, Iung, THYR., ILIW, exposure to contaminated ground (Rem per $\mathrm{C} 1 / \mathrm{m} * 2$ )
I $3.29 \mathrm{E}+02$
$3.67 \mathrm{~B}+02$
$3.08 E+02$
87.
251.
72.7
217. 
D-3

\begin{tabular}{|c|c|c|c|c|}
\hline 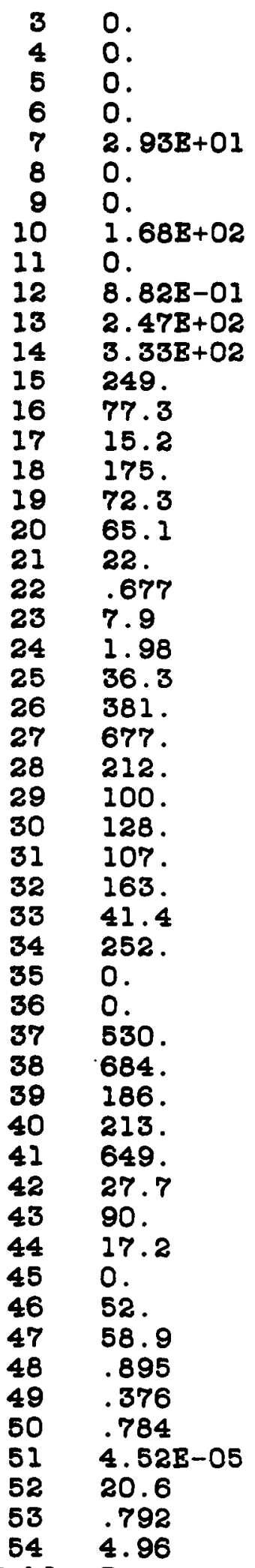 & $\begin{array}{l}0 . \\
0 . \\
0 . \\
0 . \\
3.22 \mathrm{~B}+01 \\
0 . \\
0 . \\
1.96 \mathrm{~B}+02 \\
0 . \\
8.98 \mathrm{~B}-01 \\
2.85 \mathrm{~B}+02 \\
4.02 \mathrm{~B}+02 \\
273 . \\
107 . \\
27 . \\
214 . \\
90.4 \\
79.6 \\
33.2 \\
.843 . \\
12.7 \\
2.44 \\
45.4 \\
436 . \\
804 . \\
257 . \\
112 . \\
159 . \\
123 . \\
193 . \\
45.6 \\
277 . \\
0 . \\
0.1 \\
610 . \\
779 . \\
228 . \\
242 . \\
688 . \\
49.3 \\
124 . \\
23.9 \\
0 . \\
72.8 \\
95.3 \\
.717 \\
.356 \\
.653 \\
9.23 \mathrm{E}-05 \\
42.1 \\
.614 \\
9.73 \\
\end{array}$ & $\begin{array}{l}0 . \\
0 . \\
0 . \\
0 . \\
2.75 \mathrm{~B}+01 \\
0 . \\
0 . \\
1.59 \mathrm{~B}+02 \\
0 . \\
8.39 \mathrm{~B}-01 \\
2.32 \mathrm{~B}+02 \\
3.14 \mathrm{~B}+02 \\
233 . \\
69.5 \\
12.6 \\
165 . \\
67.7 \\
61.7 \\
19.5 \\
.638 \\
4.4 \\
1.83 \\
32.8 \\
356 . \\
636 . \\
200 . \\
94.7 \\
121 . \\
101 . \\
154 . \\
38.8 \\
238 . \\
0 . \\
0 . \\
407 . \\
637 . \\
176 . \\
202 . \\
612 . \\
22.8 \\
30.6 \\
15.2 \\
0 . \\
46.3 \\
50.9 \\
.182 \\
.0882 \\
.155 \\
3.18 \mathrm{~B}-05 \\
14.5 \\
.131 \\
3.73 \\
\end{array}$ & $\begin{array}{l}1255 \\
10 . \\
17.7 \\
108 . \\
7.3 \\
0 . \\
0 . \\
83 . \\
0 . \\
1293 \\
72.4 \\
144 . \\
62.3 \\
24.2 \\
11.8 \\
61.4 \\
52.6 \\
22.7 \\
8.2 \\
.383 \\
2.66 \\
1.96 \\
11.6 \\
124 . \\
168 . \\
74.3 \\
61.5 \\
46.5 \\
90 . \\
69.7 \\
33.3 \\
138 . \\
8.9 \\
20.5 \\
159 . \\
186 . \\
65.4 \\
42.7 \\
237 . \\
11.3 \\
32.9 \\
6.06 \\
0 . \\
19.1 \\
22.7 \\
.044 \\
.032 \\
.045 \\
4.81-06 \\
6.6 \\
.032 \\
1.74 \\
\end{array}$ & $\begin{array}{l}176 \\
5.76 \\
14.4 \\
95 . \\
6.39 \\
0 . \\
0 . \\
62.4 \\
0 . \\
.254 \\
55.8 \\
101 . \\
53.8 \\
15.6 \\
5.06 \\
42.2 \\
36.2 \\
15.7 \\
4.71 \\
.259 \\
.386 \\
1.33 \\
7.46 \\
101 . \\
125 . \\
52.6 \\
51.2 \\
31.4 \\
69.3 \\
50.3 \\
28 . \\
116 . \\
3.28 \\
12 . \\
122 . \\
153 . \\
44.6 \\
31.3 \\
198 . \\
4.68 \\
20.9 \\
3.69 \\
0 . \\
11.1 \\
11.7 \\
.0796 \\
.0329 \\
10711 \\
1.98 B- \\
2.71 \\
.0692 \\
.727\end{array}$ \\
\hline
\end{tabular}

Table 3 : same per 7 Day ‘ Nucl., Whole Body, Marrow, Iung, THYROID, LIIW,

$\begin{array}{llllll}1 & 2.24 \mathrm{~B}+03 & 2.50 \mathrm{E}+03 & 2.10 \mathrm{E}+03 & 1780 . & 1480 . \\ 2 & 5.88 \mathrm{E}+03 & 6.22 \mathrm{E}+03 & 5.58 \mathrm{~B}+03 & 5280 . & 4540 . \\ 3 & 0 . & 0 . & 0 . & 5.38 & 3.68 \\ 4 & 0 . & 0 . & 0 . & 14 . & 8.11 \\ 5 & 0 . & 0 . & 0 . & 17.9 & 14.6 \\ 6 & 0 . & 0 . & 0 . & 126 . & 111 . \\ 7 & 1.85 \mathrm{E}+02 & 2.02 \mathrm{E}+02 & 1.73 \mathrm{E}+02 & 137 . & 119 .\end{array}$




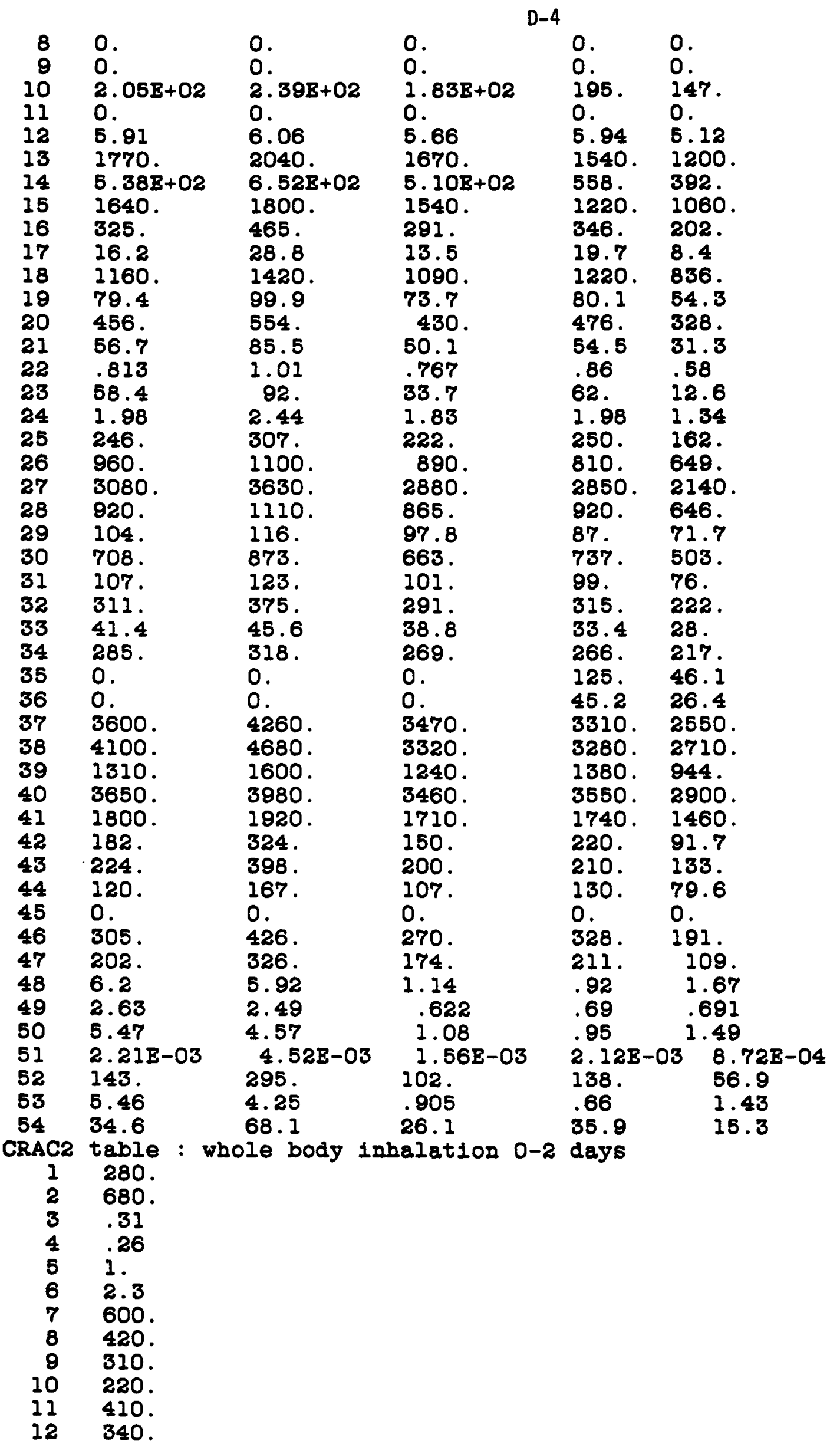




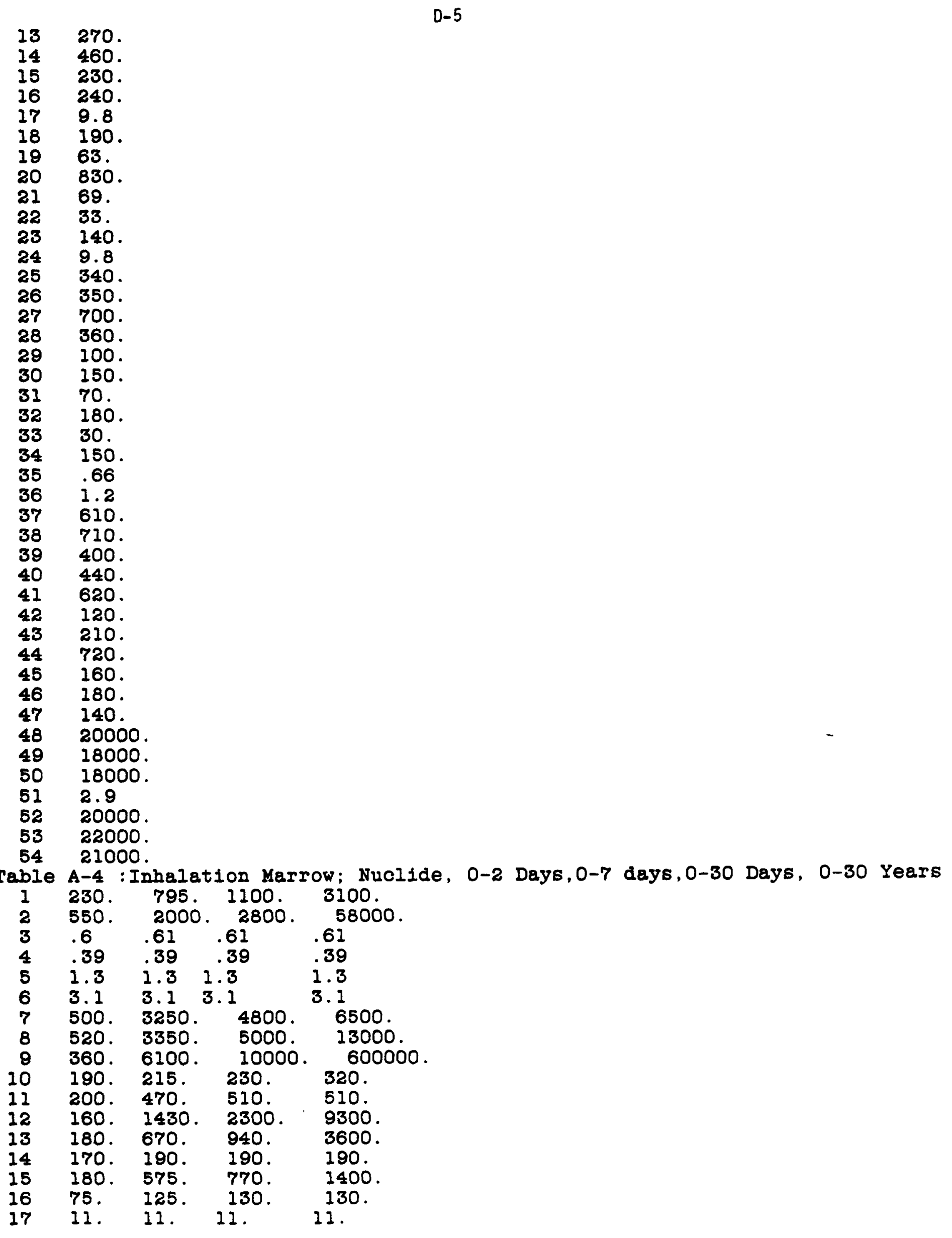


18 130. 405. 550. 1100 .

19 23. 24. 24. 24.

20 76. 440. 660. 6200.

2126.23 .23$.

$\begin{array}{lllll}22 & 3.7 & 3.9 & 3.9 & 3.9\end{array}$

23 26. 182. 270. 800 .

$\begin{array}{lllll}24 & 1.1 & 1.1 & 1.1 & 1.1\end{array}$

2567.375 .630 .640$.

26 210. 300. 310. 310.

27 480. 940. 1000. 1000.

28 170. 310. 330. 330.

2945.46 .46 .46$.

30 77. 150. 180. 180.

3150.50 .50 .50$.

32 88. 93.594 .94$.

33 20. 20. 20. 20.

34 91. 91. 91. 91.

$\begin{array}{lllll}35 & 1.5 & 1.6 & 1.6 & 1.6\end{array}$

$\begin{array}{lllll}36 & 2.1 & 2.1 & 2.1 & 2.1\end{array}$

37 580. 4950. 7000. 48000.

38 680. 3550. 5000. 6000.

39 360. 3250. 5200. 37000.

40 480. 2100. 2800. 3400.

41 440. 670. 680. 680.

42 37. 113. 150. 270.

43 66. 95.5100 .9210$.

44 62. 235. 350. 9200.

$45 \quad 3.37 .8$ 26. 34.

46 55. 140. 170. 200.

47 40. 62. 64. 64.

48 18. 171. 280. 870000 .

49 16. 159. 260. 920000.

50 16. 164. 260. 920000 .

$\begin{array}{lllll}51 & .0033 & .042 & .072 & 15000 .\end{array}$

5240.265 .420 .490000 .

53 21. 203. 330. 8500 .

54 20. 201. 330. 580000.

Table A-4 : Same, ILIW

$\begin{array}{lllll}1 & 3200 . & 6900 . & 7100 . & 4280 . \\ 2 & 8000 . & 18000 . & 18000 . & 10100 . \\ 3 & .18 & .18 & .18 & .0612 \\ 4 & .22 & .22 & .22 & .0946 \\ 5 & 1 . & 1 . & 1 . & .81 \\ 6 & 2.3 & 2.3 & 2.3 & 2.07 \\ 7 & 1200 . & 2700 . & 5800 . & 1400 . \\ 8 & 9200 . & 14000 . & 14000 . & 6860 . \\ 8 & 7300 . & 14000 . & 16000 . & 9100 . \\ 10 & 2400 . & 2600 . & 2600 . & 1430 . \\ 11 & 22000 . & 40000 . & 40000 . & 26000 . \\ 12 & 20000 . & 46000 . & 49000 . & 23000 . \\ 13 & 6100 . & 14000 . & 14000 . & 3920 . \\ 14 & 15000 . & 18000 . & 19000 . & 11000 . \\ 15 & 3200 . & 6900 . & 7000 . & 3110 . \\ 16 & 12000 . & 20000 . & 21000 . & 7400 . \\ 17 & 11.0 & 11.0 .0 & 11 . & 6.93 \\ 18 & 4800 . & 10000 . & 11000 . & 2000 . \\ 19 & 910 . & 1200 . & 1200 . & 492 . \\ 20 & 55000 . & 120000 . & 130000 . & 88800 . \\ 21 & 3300 . & 5100 . & 5100 . & 408 . \\ 22 & 730 . & 780 . & 780 . & 179 .\end{array}$




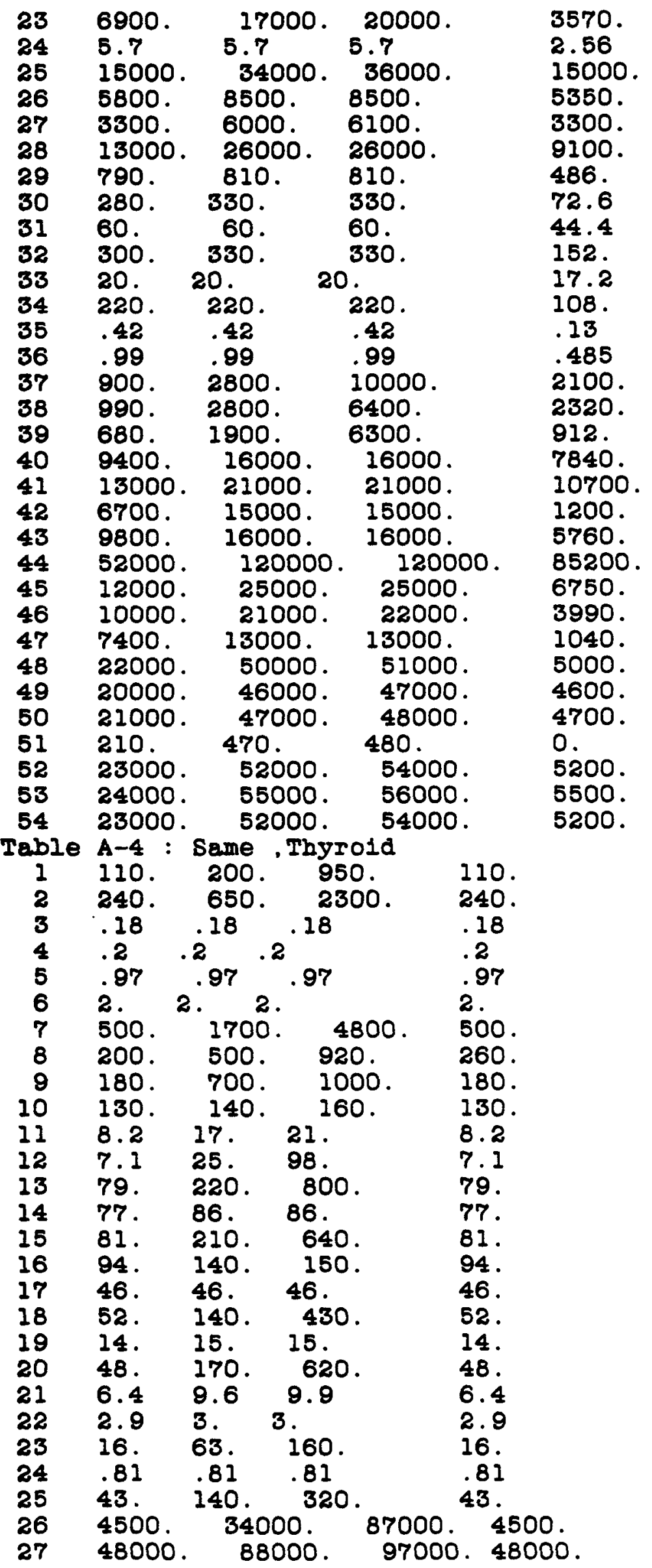


28 100. 280. 220. 100.

2937.37 .38 .37$.

30 130000. 480000. 1.B+06 130000 .

31 6600. 6600. 6600. 6600.

32 120000. 180000. 180000. 120000 .

33 1100. 1100. 1100. 1100.

34 43000. 44000. 44000. 43000.

$\begin{array}{lllll}35 & .39 & .4 & .4 & .39\end{array}$

$\begin{array}{lllll}36 & .91 & .91 & .91 & .91\end{array}$

37 580. 2000. 7900. 580.

38 690. 2100. 5000. 690.

39 360. 1300. 5100. 360.

40 220. 590. 1000. 220.

41 150. 220. 230. 150.

426.16 .46 .6 . 6.

43 18. 24. 25. 18.

445.1 13. 45.5 .1

$\begin{array}{lllll}45 & .093 & .29 & .79 & .093\end{array}$

46 12. 28. 60. 12 .

$478.2 \quad 14 . \quad 15.8 .2$

48 18. 62. 280. 18 .

49 16. 58. 260. 16.

50 16. 58. 260. 16.

$\begin{array}{lllll}51 & .0017 & .0069 & .045 & 1.7 \mathrm{E}-03\end{array}$

52 20. 73. 330. 20.

53 21. 75. 330. 21.

54 20. 73. 330. 20.

Table A-4 : same, Lung

1 1900. 17000. 59000. 61000. 59000.

$\begin{array}{lllllll}2 & 4800 . & 49000 . & 4.6 \mathrm{E}+05 & 1.3 \mathrm{E}+06 & 4.6 \mathrm{~B}+05 \\ 3 & .18 & .18 & .18 & .18 & .18 & \end{array}$

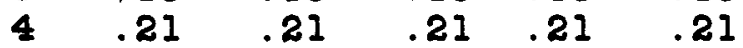

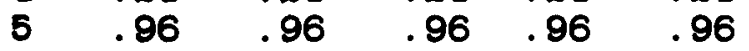

$\begin{array}{llllll}6 & 2 . & 2 . & 2 . & 2.22 . & \\ 7 & 7200 . & 12000 . & 14000 . & 14000 . & 14000\end{array}$

8 6000.7200.7800.7800. 7800.

9 4600. 12000. 16000. 18000. 16000.

10 3400. 3800. 4300 . 4300 . 4300

11 17000. 33000. 33000. 33000. 33000 .

12 13000. 100000. 200000. 200000. 200000.

13 3500. 34000. 130000. 130000. 130000.

14 14000. 15000. 15000. 15000. 15000.

15 1800. 15000. 31000. 31000. 31000.

16 7700. 16000. 16000. 16000. 16000.

17 89. 89.89. 89. 89.

18 2900. 24000. 54000. 54000. 54000.

19 2100. 2200. 2200. 2200. 2200.

$2033000 . \quad 330000.2 .5 \mathrm{E}+06 \quad 3.9 \mathrm{E}+06 \quad 2.5 \mathrm{E}+06$

21 2500. 3600. 3600. 3600. 3600.

22 1500. 1600. 1600. 1600. 1600 .

23 5200. 52000. 120000. 120000. 120000.

24 560. 560. 560. 560. 560.

25 13000. 95000. 150000. 150000. 150000.

26 6600. 11000. 11000. 11000. 11000.

27 13000. 30000. 30000. 30000. 30000.

28 9100. 24000. 25000. 25000. 25000.

293100.3100 .3200 .3200 .3200$.

30 2100. 2400. 2400. 2400. 2400.

31 1000. 1000. 1000. 1000. 1000.

32 3100. 3100. 3100. 3100. 3100. 


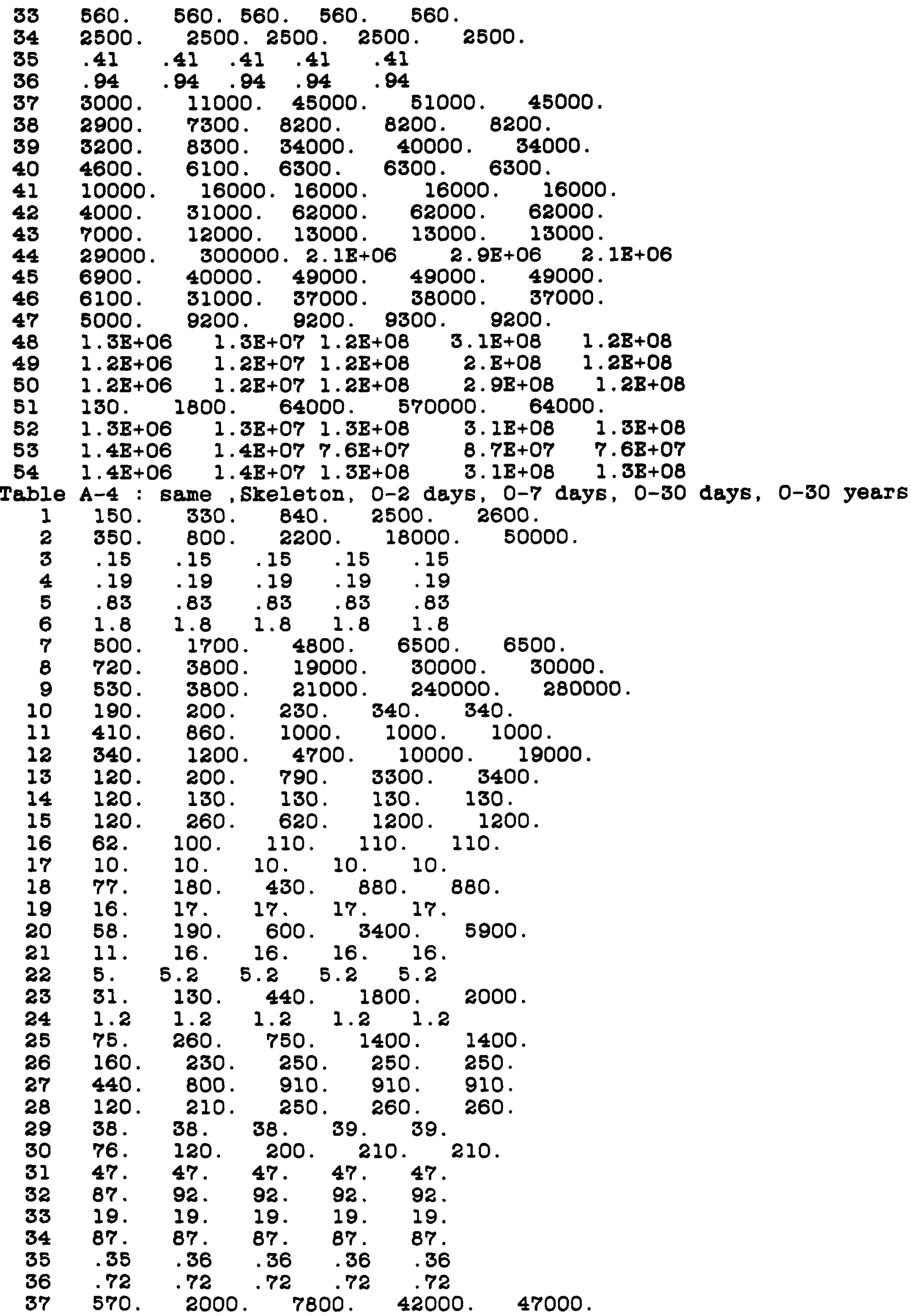




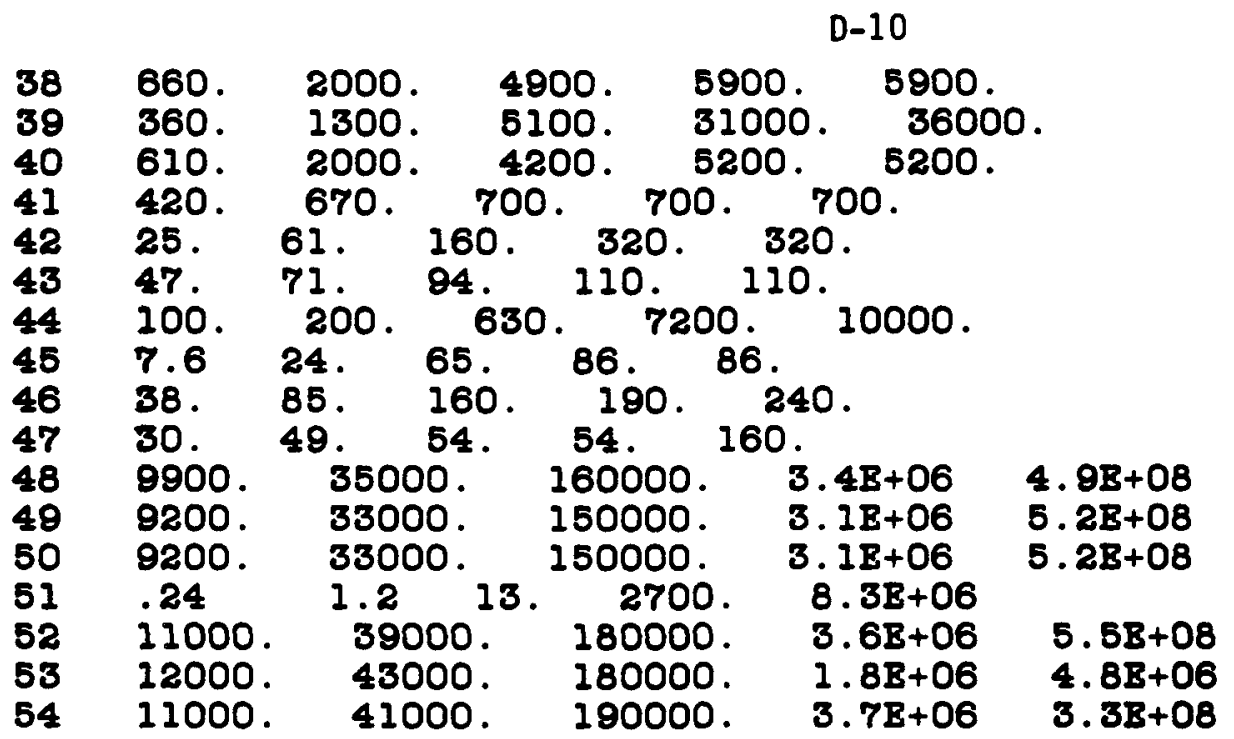


D-11

Mecos conversion factors, by nuclide, 6 organs, os,gs 8hrs, gs 7days, 1nh for each 1sotope, dose conv fact. In Bq, six records per isotope

$3.520 \mathrm{~B}-141.979 \mathrm{~B}-11 \quad 4.023 \mathrm{~B}-10 \quad 1.558 \mathrm{~B}-10$

$3.203 \mathrm{E}-141.796 \mathrm{E}-11 \mathrm{3} .652 \mathrm{E}-10 \quad 3.307 \mathrm{E}-10$

$3.805 \mathrm{E}-142.143 \mathrm{~B}-11 \quad 4.356 \mathrm{~B}-10 \quad 1.039 \mathrm{~B}-09$

$3.869 \mathrm{E}-142.179 \mathrm{E}-11$ 4.430B-10 $1.577 \mathrm{E}-10$

$4.78 B \mathrm{~B}-142.690 \mathrm{E}-11 \quad 5.469 \mathrm{~B}-106.142 \mathrm{E}-11$

$3.456 \mathrm{E}-14$ l.942E-11 $3.948 \mathrm{~B}-10 \quad 9.144 \mathrm{~B}-10$

$9.132 \mathrm{E}-14 \quad 4.602 \mathrm{E}-11 \quad 9.655 \mathrm{~B}-10 \quad 3.840 \mathrm{E}-10$

8.530E- 14 4.301E- II $9.022 \mathrm{E}-10$ 8.077E-10

9.862E-14 4.986E-11 $1.046 \mathrm{~B}-095.186 \mathrm{E}-09$

$9.957 \mathrm{~B}-14 \quad 5.032 \mathrm{~B}-11 \quad 1.055 \mathrm{E}-09 \quad 3.986 \mathrm{E}-10$

$1.230 \mathrm{E}-136.219 \mathrm{E}-11 \quad 1.305 \mathrm{E}-09 \quad 1.465 \mathrm{E}-10$

$9.069 \mathrm{E}-14$ 4.575E-II $9.597 \mathrm{E}-102.386 \mathrm{E}-09$

$7.674 \mathrm{E}-17 \quad .000 \mathrm{~B}+00 \quad .000 \mathrm{~B}+00 \quad 6.757 \mathrm{E}-14$

$6.881 \mathrm{E}-17 \quad .000 \mathrm{E}+00 \quad .000 \mathrm{~B}+00 \quad 6.781 \mathrm{E}-14$

$8.340 \mathrm{E}-17 \quad .000 \mathrm{E}+00 \quad .000 \mathrm{E}+00 \quad 4.754 \mathrm{E}-13$

$8.562 \mathrm{E}-17$.0OOE +00 .0OOE $+00 \quad 6.808 \mathrm{E}-14$

$1.037 \mathrm{E}-16 \quad .000 \mathrm{E}+00$

$7.484 \mathrm{E}-17 \quad .000 \mathrm{E}+00$

$5.232 \mathrm{~B}-15 \quad .000 \mathrm{E}+00$

$4.566 \mathrm{E}-15 \quad .000 \mathrm{~B}+00$

$5.771 E-15$. OOOE +00

$5.549 \mathrm{E}-15$. OOOE +00

$7.737 \mathrm{E}-15 \quad .000 \mathrm{E}+00$

5. 105E-15 .000E+00

3. $161 \mathrm{E}-14$

2. $946 \mathrm{E}-14$

$3.393 B-14$

$3.456 \mathrm{E}-14$

$4.091 \mathrm{E}-14$

3. $133 E-14$

$1.064 \mathrm{E}-13$

$1.001 \mathrm{E}-13$

1. $140 \mathrm{E}-13$

$1.156 \mathrm{~B}-13$

$1.367 \mathrm{E}-13$

$1.059 \mathrm{~B}-13$

$3.488 \mathrm{E}-15$

$3.203 \mathrm{E}-15$

$3.742 E-15$

$3.805 \mathrm{E}-15$

$4.725 \mathrm{E}-15$

$3.425 \mathrm{E}-15$

$5.042 E-18$

$4.598 \mathrm{E}-18$

5. $422 E-18$

5. $518 \mathrm{E}-18$

6. $849 \mathrm{E}-18$

4. $947 \mathrm{E}-18$

$.000 \mathrm{E}+00$

$.000 \mathrm{E}+00$

$.000 \mathrm{~B}+00$

$.000 B+00$

$.000 E+00$

$.000 \mathrm{O}+00$

$3.567 \mathrm{E}-14$

241E-14 1.319E-11

$3.857 E-141.568 E-11$

3. 920E-14 1.593E-11
$.000 \mathrm{E}+00$

$.000 \mathrm{E}+00$

$.000 \mathrm{E}+00$

$6.689 \mathrm{~B}-14$

$6.102 \mathrm{E}-14$

OOOE+00 6.102E-14

$.000 E+004.890 E-13$

$.000 E+006.372 E-14$

$.000 E+005.531 E-14$

$.000 \mathrm{E}+00 \quad 5.912 \mathrm{E}-14$

$.000 E+00$ 2.220E-13

$.000 E+00 \quad 2.210 E-13$

$.000 \mathrm{~B}+00 \quad 2.430 \mathrm{E}-12$

$.000 E+00 \quad 2.180 E-13$

$.000 E+002.150 E-13$

$.000 \mathrm{E}+002.250 \mathrm{E}-13$

$.000 \mathrm{~B}+003.749 \mathrm{E}-13$

$.000 E+00$ 3.7BOE-13

$.000 E+00 \quad 4.263 E-12$

$.000 \mathrm{E}+00 \quad 3.669 \mathrm{E}-13$

$.000 E+00$ 3.54OE-13

$.000 \mathrm{E}+003.972 \mathrm{E}-13$

$3.361 \mathrm{E}-113.020 \mathrm{E}-10$

3. 108E-11 2.042E-10

$3.631 \mathrm{E}-111.595 \mathrm{E}-09$

$3.682 \mathrm{E}-118.078 \mathrm{E}-10$

$4.577 \mathrm{E}-112.497 \mathrm{E}-10$

3.327E-11 2.041E-10

$5.505 \mathrm{E}-14$ 1.832E-10

$5.011 \mathrm{E}-142.672 \mathrm{E}-10$

$5.925 \mathrm{E}-141.328 \mathrm{E}-09$

$6.017 \mathrm{E}-149.471 \mathrm{E}-10$

$7.480 \mathrm{E}-14$ 8.280B- 11

5.413E-14 1.975E-09

$.000 \mathrm{E}+001.137 \mathrm{E}-10$

$.000 \mathrm{E}+001.596 \mathrm{E}-10$

$.000 \mathrm{E}+00 \quad 7.430 \mathrm{E}-10$

$.000 \mathrm{E}+001.726 \mathrm{E}-09$

$.000 \mathrm{E}+001.074 \mathrm{E}-10$

$.000 \mathrm{E}+001.606 \mathrm{E}-09$

$3.408 \mathrm{E}-111.634 \mathrm{E}-10$

$3.098 \mathrm{E}-112.312 \mathrm{E}-10$

$3.685 \mathrm{E}-118.682 \mathrm{E}-10$

$3.743 E-118.976 E-11$
STOYACE CO-58

SMAII INT.

IONGS

RY

THY

ILIV 
4.849B-14 $1.963 \mathrm{~B}-11 \quad 4.612 \mathrm{~B}-11 \quad 3.424 \mathrm{~B}-11$

$3.5028-14$

$.000 B+00$

$.000 \mathrm{~B}+00$

$.000 \mathrm{~B}+00$

$.000 \mathrm{~B}+00$

$.000 \mathrm{~B}+00$

$.000 \mathrm{~B}+00$

$1.316 \mathrm{~B}-16$

$1.224 \mathrm{~B}-16$

$1.424 B-16$

$1.436 \mathrm{E}-16$

$1.782 \mathrm{~B}-16$

$1.306 \mathrm{~B}-16$

$2.660 \mathrm{~B}-14$

2. $407 \mathrm{~B}-14$

2. 876B-14

2. 924B-14

3.615B-14

2.607B-14

5. 595B-14

$5.066 \mathrm{E}-14$

6. 049E-14

6. $159 \mathrm{~B}-14$

7. 574E-14

5. 486E-14

2. $778 \mathrm{~B}-14$

2. 515B-14

3.000E-14

$3.051 \mathrm{E}-14$

$3.773 \mathrm{~B}-14$

2.724E-14

5. 518B-15

4. $978 \mathrm{~B}-15$

5. 993E-15

6.057B-15

7. 579E-15

5. 422E-15

4. 154E-15

3. 583E-15

$4.598 \mathrm{E}-15$

4.217E-15

6. 342E-15

4. 027B-15

1. 662E- 14

$1.487 \mathrm{~B}-14$

$1.80 \mathrm{BE}-14$

$1.849 \mathrm{E}-14$

$2.246 \mathrm{~B}-14$

$1.624 \mathrm{~B}-14$

2. 809E- 14

2. 532E-14

3. 046B-14

3. $100 \mathrm{~B}-14$

3. $844 \mathrm{E}-14$

2. 751E-14

7.293B-15

6. 564E-15

$7.896 \mathrm{~B}-15$

8. 054E-15
$1.418 \mathrm{~B}-11$

.000B+00

$.000 B+00$

$.000 \mathrm{~B}+00$

$.000 \mathrm{~B}+00$

$.000 \mathrm{~B}+00$

$.000 \mathrm{~B}+00$

$6.690 \mathrm{~B}-14$

$6.234 \mathrm{~B}-14$

7. $246 \mathrm{~B}-14,1.463 \mathrm{~B}-12$

$7.310 \mathrm{E}-141.476 \mathrm{~B}-12$

$9.060 \mathrm{E}-141.830 \mathrm{E}-12$

$6.644 \mathrm{~B}-141.342 \mathrm{E}-12$

$1.504 \mathrm{E}-11$

$1.358 \mathrm{E}-11$

$1.623 \mathrm{E}-11$

$1.650 \mathrm{~B}-11$

2. 042B-11

$1.468 \mathrm{E}-11$

$2.467 \mathrm{E}-11$

2. 235E-11

$2.665 \mathrm{E}-11$

2.712E-11

$3.350 \mathrm{E}-11$

$2.422 \mathrm{E}-11$

$1.557 \mathrm{E}-11$

$1.411 \mathrm{E}-11$

$1.684 \mathrm{E}-11$

$1.711 \mathrm{E}-11$

2.121E-11

$1.529 \mathrm{E}-11$

$3.814 E-12$

$3.404 \mathrm{E}-12$

$4.157 \mathrm{~B}-12$

4. $105 \mathrm{~B}-12$

5. 367E-12

3.734E-12

1.731E-12

$1.498 \mathrm{E}-12$

$1.928 \mathrm{~B}-12$

$1.755 \mathrm{~B}-12$

$2.656 \mathrm{~B}-12$

$1.689 \mathrm{E}-12$

$9.838 \mathrm{E}-12$

8. $816 \mathrm{~B}-12$

$1.075 \mathrm{~B}-11$

$1.093 \mathrm{E}-11$

$1.331 \mathrm{E}-11$

9.656B-12

9.331E-12

8.371E-12

$1.008 \mathrm{E}-11$

$1.027 \mathrm{E}-11$

1. 27OB-11

9.118E-12

4. $175 \mathrm{E}-12$

3. 765E-12

$4.531 E-12$

$4.622 E-12$

$3.335 \mathrm{E}-11$

$.000 \mathrm{E}+00$

$.000 \mathrm{~B}+00$

$.000 \mathrm{E}+00$

$.000 \mathrm{~B}+00$

$.000 \mathrm{~B}+00$

$.000 \mathrm{E}+00$

$1.351 \mathrm{~B}-12$

9.660E-11
$5.211 \mathrm{~B}-10$

3.745E-10

8.713E-10

3. 546E-09

8.668B-12

$3.153 \mathrm{~B}-13$

$6.544 \mathrm{E}-09$

2. 740E-10

$6.656 \mathrm{~B}-10$

6. 923B-09

2. $798 \mathrm{~B}-11$

$6.243 \mathrm{E}-13$

6. $908 \mathrm{E}-09$

$3.048 \mathrm{E}-101.541 \mathrm{E}-10$

$2.752 \mathrm{E}-103.296 \mathrm{E}-10$

$3.288 \mathrm{E}-101.505 \mathrm{~B}-09$

$3.343 \mathrm{E}-102.846 \mathrm{E}-10$

$4.138 \mathrm{E}-106.141 \mathrm{E}-11$

$2.974 \mathrm{E}-10 \quad 1.573 \mathrm{E}-09$

$9.615 \mathrm{E}-11 \quad 3.772 \mathrm{E}-10$

8.706E-11 $7.834 \mathrm{E}-10$

$1.039 \mathrm{E}-10 \quad 2.836 \mathrm{E}-09$

$1.057 \mathrm{E}-101.079 \mathrm{E}-10$

$1.306 \mathrm{E}-102.788 \mathrm{E}-11$

$9.440 E-112.609 E-09$

$3.063 E-101.287 E-10$

$2.776 \mathrm{E}-102.838 \mathrm{E}-10$

3.314E-10 7.399E-10

3.367E-10 1.212E-10

$4.173 E-10 \quad 4.278 E-11$

$3.009 \mathrm{E}-10$ 9.234E-10

$5.353 \mathrm{E}-111.895 \mathrm{E}-10$

$4.738 \mathrm{E}-114.221 \mathrm{E}-10$

$5.867 \mathrm{E}-111.592 \mathrm{E}-09$

5.672E-11 3.096E-11

$7.714 E-11 \quad 5.914 E-12$

5.236E-11 2.860E-09

2.875E-12 1.437E-11

$2.489 E-12 \quad 3.397 E-12$

3.203E-12 2.924E-11

$2.915 \mathrm{E}-12 \quad 2.296 \mathrm{~B}-12$

$4.412 \mathrm{E}-121.968 \mathrm{E}-11$

2.806E-12 3.371E-12

1.950E-10 1.212E-10

$1.747 \mathrm{E}-102.683 \mathrm{E}-10$

2.131E-10 1.307E-09

2. $166 \mathrm{E}-10$ 8.176E-11

$2.638 \mathrm{E}-102.856 \mathrm{E}-11$

$1.914 \mathrm{~B}-101.489 \mathrm{~B}-09$

$1.389 \mathrm{E}-11 \quad 7.924 \mathrm{E}-11$

$1.246 \mathrm{E}-11$ 1.205E-10

$1.502 \mathrm{E}-115.005 \mathrm{E}-10$

$1.532 \mathrm{E}-117.221 \mathrm{E}-12$

$1.892 \mathrm{E}-113.876 \mathrm{E}-12$

$1.358 \mathrm{E}-112.058 \mathrm{E}-10$

8.726E-11 6.984E-10

7.869E-11 $1.589 \mathrm{E}-09$

$9.469 \mathrm{E}-113.044 \mathrm{E}-08$

8.744E-11 
D-13

9.862E-15 5.652E-12 $1.181 \mathrm{~B}-10 \quad 4.022 \mathrm{E}-11$ $7.135 \mathrm{~B}-16 \quad 4.093 \mathrm{E}-12 \quad 8.555 \mathrm{~B}-11 \quad 1.604 \mathrm{~B}-08$ $2.600 \mathrm{~B}-15 \quad 1.488 \mathrm{~B}-12 \quad 9.870 \mathrm{~B}-12 \quad 6.353 \mathrm{~B}-11$ $2.315 \mathrm{~B}-15 \quad 1.327 \mathrm{~B}-12 \quad 8.804 \mathrm{~B}-12 \quad 1.353 \mathrm{~B}-10$ $2.841 \mathrm{~B}-15 \quad 1.631 \mathrm{~B}-12 \quad 1.082 \mathrm{~B}-114.985 \mathrm{E}-10$ $2.936 \mathrm{~B}-15 \quad 1.682 \mathrm{~B}-12 \quad 1.116 \mathrm{~B}-11 \quad 5.385 \mathrm{~B}-12$ $3.615 \mathrm{~B}-15 \quad 2.071 \mathrm{~B}-12 \quad 1.374 \mathrm{~B}-11 \quad 1.432 \mathrm{~B}-12$ $2.556 \mathrm{E}-15 \quad 1.462 \mathrm{E}-12 \quad 9.701 \mathrm{~B}-12 \quad 7.389 \mathrm{E}-10$ $1.639 \mathrm{~B}-16 \quad 7.509 \mathrm{~B}-14 \quad 1.679 \mathrm{~B}-13 \quad 4.321 \mathrm{~B}-11$ $1.462 \mathrm{~B}-16 \quad 6.717 \mathrm{~B}-14 \quad 1.502 \mathrm{~B}-13 \quad 6.822 \mathrm{~B}-11$

$1.788 \mathrm{E}-16 \quad 8.198 \mathrm{~B}-14 \quad 1.833 \mathrm{E}-13 \quad 3.748 \mathrm{E}-10$

$1.836 \mathrm{E}-16 \quad 8.405 \mathrm{E}-14 \quad 1.879 \mathrm{E}-13 \quad 3.342 \mathrm{E}-12$ $2.245 \mathrm{E}-16 \quad 1.033 \mathrm{E}-13 \quad 2.310 \mathrm{~B}-13 \quad 1.590 \mathrm{E}-12$ $1.605 \mathrm{E}-16 \quad 7.371 \mathrm{E}-14 \quad 1.648 \mathrm{~B}-13 \quad 1.640 \mathrm{~B}-10$ $4.566 \mathrm{~B}-17 \quad 7.804 \mathrm{~B}-14 \quad 2.953 \mathrm{~B}-12 \quad 8.892 \mathrm{E}-11$ $3.165 \mathrm{E}-17$ 5.837E-14 2.406E-12 $1.832 \mathrm{E}-10$ $6.247 \mathrm{E}-17 \quad 1.013 \mathrm{E}-13 \quad 3.555 \mathrm{E}-12 \quad 2.476 \mathrm{~B}-09$ $2.632 \mathrm{E}-175.643 \mathrm{~B}-142.669 \mathrm{E}-12 \quad 2.769 \mathrm{~B}-10$ $1.237 \mathrm{~B}-16 \quad 1.852 \mathrm{E}-13 \quad 5.663 \mathrm{~B}-12 \quad 1.337 \mathrm{E}-11$ $4.059 \mathrm{E}-17 \quad 7.121 \mathrm{E}-14 \quad 2.788 \mathrm{E}-12 \quad 2.309 \mathrm{E}-09$ $1.842 \mathrm{E}-15 \quad 2.273 \mathrm{E}-13 \quad 2.293 \mathrm{E}-13 \quad 1.553 \mathrm{E}-11$ $1.652 \mathrm{~B}-15 \quad 2.027 \mathrm{E}-13 \quad 2.044 \mathrm{E}-13 \quad 1.083 \mathrm{E}-11$ $2.007 \mathrm{E}-15 \quad 2.482 \mathrm{E}-13 \quad 2.503 \mathrm{E}-13 \quad 1.526 \mathrm{E}-10$ 2.042E-15 2.501E-13 2.522E-13 $6.131 \mathrm{E}-13$ $2.527 E-15 \quad 3.145 \mathrm{E}-13 \quad 3.172 \mathrm{E}-13 \quad 5.088 \mathrm{~B}-13$ $1.804 \mathrm{E}-15 \quad 2.217 \mathrm{E}-13 \quad 2.235 \mathrm{E}-13 \quad 1.838 \mathrm{E}-12$ $1.157 \mathrm{E}-15 \quad 1.223 \mathrm{E}-12 \quad 2.666 \mathrm{E}-11 \quad 2.603 \mathrm{E}-10$ $1.040 \mathrm{E}-15 \quad 1.089 \mathrm{E}-12 \quad 2.375 \mathrm{~B}-11 \quad 5.055 \mathrm{E}-10$ $1.262 \mathrm{E}-15 \quad 1.339 \mathrm{E}-12 \quad 2.919 \mathrm{E}-11 \quad 4.429 \mathrm{E}-09$ $1.259 \mathrm{E}-15 \quad 1.325 \mathrm{E}-12 \quad 2.893 \mathrm{E}-11 \mathrm{l}$ 4.854E-10 $1.617 \mathrm{E}-15 \quad 1.729 \mathrm{E}-12$ 3.761E- $113.040 \mathrm{E}-11$ 1. $132 \mathrm{E}-15 \quad 1.191 \mathrm{E}-12 \quad 2.597 \mathrm{E}-11 \quad 4.897 \mathrm{E}-09$ $5.522 \mathrm{~B}-142.765 \mathrm{E}-11$ 1.750E-10 2.201E-10 $5.014 \mathrm{E}-142.513 \mathrm{E}-11 \quad 1.588 \mathrm{E}-10 \quad 3.919 \mathrm{E}-10$ $5.963 \mathrm{~B}-142.990 \mathrm{E}-11$ 1.894E-10 $1.244 \mathrm{E}-09$ $6.025 \mathrm{~B}-143.022 \mathrm{E}-11 \quad 1.917 \mathrm{E}-10 \quad 9.406 \mathrm{E}-11$ $7.488 \mathrm{E}-14$ 3.772E-11 $2.388 \mathrm{E}-106.406 \mathrm{E}-09$ $5.421 \mathrm{~B}-142.720 \mathrm{~B}-111.721 \mathrm{~B}-101.333 \mathrm{E}-09$ $6.976 \mathrm{E}-15 \quad 3.219 \mathrm{E}-11 \quad 5.471 \mathrm{E}-10 \quad 1.874 \mathrm{E}-10$ $6.152 \mathrm{~B}-15 \quad 2.912 \mathrm{E}-11 \quad 4.957 \mathrm{~B}-10 \quad 2.624 \mathrm{E}-10$ $7.706 \mathrm{E}-15 \quad 3.493 \mathrm{E}-11 \quad 5.930 \mathrm{E}-10 \quad 5.591 \mathrm{E}-10$ $7.642 \mathrm{E}-15 \quad 3.531 \mathrm{E}-11 \quad 6.006 \mathrm{E}-10 \quad 2.788 \mathrm{E}-10$ $1.021 \mathrm{E}-14 \quad 4.414 \mathrm{E}-117.469 \mathrm{E}-107.757 \mathrm{E}-08$ $6.849 \mathrm{E}-15 \quad 3.154 \mathrm{E}-11$ 5.362E-10 $7.713 \mathrm{E}-10$ $2.337 \mathrm{E}-14$ 1.314E-11 $1.623 \mathrm{E}-102.278 \mathrm{E}-10$ 2. $106 \mathrm{E}-141.181 \mathrm{E}-11 \quad 1.459 \mathrm{E}-10 \quad 5.199 \mathrm{E}-10$ $2.534 \mathrm{~B}-14$ 1.420E-11 $1.755 \mathrm{E}-10 \quad 1.907 \mathrm{~B}-09$ $2.584 \mathrm{E}-141.456 \mathrm{E}-11 \quad 1.799 \mathrm{E}-10 \quad 9.334 \mathrm{E}-11$ $3.171 \mathrm{~B}-14 \quad 1.784 \mathrm{E}-112.204 \mathrm{E}-10 \quad 2.443 \mathrm{~B}-11$ $2.289 \mathrm{~B}-141.287 \mathrm{E}-11 \quad 1.590 \mathrm{E}-10 \quad 3.663 \mathrm{E}-09$ $5.264 \mathrm{E}-14 \quad 1.654 \mathrm{E}-112.319 \mathrm{E}-11 \quad 1.226 \mathrm{E}-10$ $4.820 \mathrm{E}-141.514 \mathrm{E}-112.123 \mathrm{E}-11 \mathrm{l} 1.888 \mathrm{E}-10$ $5.676 \mathrm{E}-14 \quad 1.788 \mathrm{E}-11$ 2.507E- 11 8.374E-10 $5.771 \mathrm{~B}-142.814 \mathrm{E}-112.544 \mathrm{E}-111.608 \mathrm{E}-11$ $7.103 \mathrm{~B}-14$ 2.237E-I1 $3.137 \mathrm{E}-11$ 9.521E-12 $5.169 \mathrm{E}-14 \quad 1.627 \mathrm{E}-11$ 2.281E-11 2.014E-10 $1.291 \mathrm{E}-14 \quad 7.742 \mathrm{E}-12 \quad 1.238 \mathrm{~B}-10 \quad 5.997 \mathrm{E}-11$ $1.154 \mathrm{E}-146.914 \mathrm{E}-12 \quad 1.106 \mathrm{E}-10 \quad 1.572 \mathrm{E}-11$ $1.408 \mathrm{E}-14$ 8.444E-12 $1.351 \mathrm{E}-10 \quad 4.616 \mathrm{E}-10$ $1.449 \mathrm{E}-14$ 8.678E-12 $1.388 \mathrm{E}-10 \quad 3.518 \mathrm{E}-11$ 
$1.776 \mathrm{~B}-141.062 \mathrm{~B}-11 \quad 1.699 \mathrm{E}-106.395 \mathrm{~B}-08$

$1.265 \mathrm{~B}-14 \quad 7.689 \mathrm{~B}-12 \quad 1.214 \mathrm{~B}-10 \quad 1.465 \mathrm{~B}-11$

8.308E-14 $1.738 \mathrm{~B}-11$ l.909E-11 $9.896 \mathrm{~B}-11$

$7.547 \mathrm{~B}-141.679 \mathrm{~B}-111.735 \mathrm{~B}-111.245 \mathrm{~B}-11$

8.974B-14 1.879E-11 2.065B-11 2.702B-10

9.132B-14 1.910B-11 2.099B-11 $1.401 \mathrm{~B}-11$

$1.126 \mathrm{~B}-13 \quad 2.352 \mathrm{~B}-112.584 \mathrm{~B}-11 \quad 1.721 \mathrm{~B}-09$

$8.149 \mathrm{~B}-141.703 \mathrm{~B}-111.871 \mathrm{~B}-111.126 \mathrm{E}-11$

$2.121 \mathrm{~B}-14 \quad 1.074 \mathrm{~B}-11 \quad 4.674 \mathrm{~B}-11 \quad 1.023 \mathrm{~B}-10$

$1.915 \mathrm{~B}-14 \quad 9.700 \mathrm{~B}-12 \quad 4.130 \mathrm{~B}-112.006 \mathrm{~B}-11$

$2.305 \mathrm{~B}-141.170 \mathrm{~B}-114.983 \mathrm{~B}-11 \quad 7.128 \mathrm{~B}-10$

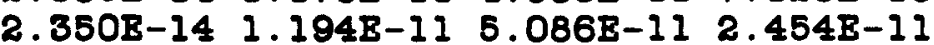

$2.873 \mathrm{~B}-141.459 \mathrm{~B}-11$ 6.212B-1I $2.389 \mathrm{E}-0 \mathrm{~B}$

2.077E-14 1.050E-11 4.471B-1I $1.910 \mathrm{~B}-11$

9.672B-14 8.230B-12 B.245B-12 $7.081 \mathrm{~B}-11$

$8.847 \mathrm{~B}-14 \quad 7.524 \mathrm{~B}-12 \quad 7.537 \mathrm{~B}-12 \quad 5.521 \mathrm{~B}-12$

$1.043 \mathrm{~B}-13 \quad 8.893 \mathrm{~B}-12 \quad 8.909 \mathrm{E}-12 \quad 1.429 \mathrm{~B}-10$

$1.059 \mathrm{~B}-13 \quad 9.008 \mathrm{~B}-12 \quad 9.025 \mathrm{~B}-12 \quad 6.067 \mathrm{~B}-12$

$1.306 \mathrm{E}-13 \quad 1.114 \mathrm{~B}-11$ 1.116B-11 $2.848 \mathrm{~B}-10$

$9.513 \mathrm{~B}-14$ 8.100B-12 $8.115 \mathrm{~B}-12 \quad 4.800 \mathrm{~B}-12$

$5.866 \mathrm{~B}-14 \quad 1.084 \mathrm{~B}-11 \quad 3.495 \mathrm{E}-11 \quad 9.819 \mathrm{E}-11$

$5.486 \mathrm{E}-141.854 \mathrm{~B}-11 \quad 3.266 \mathrm{E}-11 \quad 1.878 \mathrm{E}-11$

$6.342 \mathrm{E}-142.151 \mathrm{E}-11 \quad 3.789 \mathrm{E}-11 \quad 4.295 \mathrm{E}-10$

$6.405 \mathrm{~B}-14$ 2.170B-11 3.821E-11 2.194E-11

$7.864 \mathrm{~B}-14$ 2.658E-11 4.681B-11 $7.172 \mathrm{E}-09$

$6.835 \mathrm{~B}-14$ 1.972B-11 3.473E-11 $1.765 \mathrm{E}-11$

$9.450 \mathrm{E}-16 \quad .000 \mathrm{E}+00 \quad .000 \mathrm{E}+00 \quad 1.312 \mathrm{E}-13$

$\begin{array}{lll}7.091 \mathrm{~B}-16 \quad .000 \mathrm{E}+00 \quad .000 \mathrm{E}+00 \quad 1.368 \mathrm{E}-13 & 13\end{array}$

$1.113 \mathrm{E}-15 \quad .000 \mathrm{~B}+00 \quad .000 \mathrm{E}+00 \quad 3.562 \mathrm{~B}-13$

$\begin{array}{llll}7.293 \mathrm{E}-16 \quad .000 \mathrm{E}+00 \quad .000 \mathrm{E}+00 & 1.558 \mathrm{E}-13\end{array}$

$1.719 \mathrm{E}-15 \quad .000 \mathrm{E}+00 \quad .000 \mathrm{E}+00 \quad 1.212 \mathrm{E}-13$

$8.689 \mathrm{~B}-16 \quad .000 \mathrm{~B}+00 \quad .000 \mathrm{E}+00 \quad 1.357 \mathrm{~B}-13$

$8.213 \mathrm{E}-15 \quad .000 \mathrm{E}+00 \quad .000 \mathrm{E}+00 \quad 2.547 \mathrm{E}-13$

$7.293 \mathrm{E}-15 \quad .000 \mathrm{E}+00 \quad .000 \mathrm{~B}+002.560 \mathrm{~B}-13$

$9.006 \mathrm{E}-15 \quad .000 \mathrm{E}+00 \quad .000 \mathrm{E}+00 \quad 7.754 \mathrm{E}-13$

9.228B-15 .00OE+00 .000E+00 2.532E-13

$1.167 \mathrm{~B}-14 \quad .000 \mathrm{E}+00 \quad .000 \mathrm{E}+00 \quad 2.308 \mathrm{E}-13$

8.118E-15 .0OOE+00 .0OOE+00 $2.479 \mathrm{E}-13$

$5.581 \mathrm{~B}-14 \quad 3.159 \mathrm{E}-11 \quad 6.615 \mathrm{E}-10 \quad 3.462 \mathrm{E}-10$

$5.042 \mathrm{E}-142.858 \mathrm{E}-11$ 5.984E-10 3.382E-10

$6.025 \mathrm{E}-143.424 \mathrm{E}-11 \quad 7.169 \mathrm{E}-10 \quad 1.036 \mathrm{E}-09$

$6.152 \mathrm{~B}-143.488 \mathrm{E}-117.303 \mathrm{~B}-109.057 \mathrm{~B}-10$

$7.579 \mathrm{E}-14$ 4.292E- 11 8.986E-10 $4.736 \mathrm{~B}-10$

$5.454 \mathrm{E}-14$ 3.095E-I1 $6.481 \mathrm{E}-10 \quad 3.349 \mathrm{E}-10$

$7.892 \mathrm{E}-14$ 4.255E-11 $7.539 \mathrm{E}-10$ 3.756E-10

$7.191 \mathrm{~B}-14 \quad 3.884 \mathrm{E}-11 \quad 6.882 \mathrm{E}-10 \quad 3.663 \mathrm{E}-10$

8.528E-14 4.608E-11 $8.165 \mathrm{E}-10 \quad 7.041 \mathrm{E}-10$

$8.624 \mathrm{~B}-14 \quad 4.653 \mathrm{E}-11 \quad 8.245 \mathrm{E}-10 \quad 7.018 \mathrm{E}-10$

$1.076 \mathrm{E}-13$ 5.830E-11 $1.033 \mathrm{E}-093.385 \mathrm{E}-10$

$7.764 \mathrm{~B}-14 \quad 4.191 \mathrm{E}-11 \quad 7.427 \mathrm{E}-10 \quad 3.617 \mathrm{E}-10$

$2.010 \mathrm{~B}-14 \quad 1.149 \mathrm{E}-112.430 \mathrm{E}-10 \quad 2.251 \mathrm{E}-10$

$1.812 \mathrm{E}-14 \quad 1.037 \mathrm{E}-112.194 \mathrm{E}-10 \quad 1.956 \mathrm{E}-10$

$2.178 \mathrm{E}-141.243 \mathrm{E}-11$ 2.630E-10 $9.533 \mathrm{E}-10$

$2.217 \mathrm{E}-14 \quad 1.260 \mathrm{E}-112.666 \mathrm{E}-10 \quad 5.625 \mathrm{E}-10$

$2.730 \mathrm{~B}-14 \quad 1.560 \mathrm{~B}-11 \quad 3.301 \mathrm{E}-10 \quad 2.960 \mathrm{E}-10$

$1.968 \mathrm{E}-141.123 \mathrm{E}-112.376 \mathrm{E}-10 \quad 1.953 \mathrm{E}-10$

$6.405 \mathrm{~B}-15$ 6.623E-12 $5.941 \mathrm{E}-101.376 \mathrm{E}-10$

$5.708 \mathrm{~B}-15 \quad 6.025 \mathrm{E}-12 \quad 5.512 \mathrm{E}-10 \quad 2.827 \mathrm{~B}-10$

$6.976 \mathrm{E}-15 \quad 7.209 \mathrm{E}-12 \quad 6.438 \mathrm{E}-10 \quad 9.563 \mathrm{E}-10$

$7.071 \mathrm{~B}-15 \quad 7.296 \mathrm{E}-12 \quad 6.525 \mathrm{E}-10 \quad 4.728 \mathrm{E}-10$ 
8.752E-15 9.019B-12 $7.951 \mathrm{~B}-10 \quad 6.494 \mathrm{E}-11$

$6.247 \mathrm{~B}-15$ 6.515E-12 5.891B-10 2.331B-09

$8.657 \mathrm{~B}-14 \quad 4.027 \mathrm{~B}-112.954 \mathrm{~B}-10 \quad 3.570 \mathrm{~B}-10$

8.086B-14 3.754B-11 2.754B-10 $7.481 \mathrm{~B}-10$

$9.354 \mathrm{~B}-14 \quad 4.359 \mathrm{~B}-11$ 3.198E-10 2.048B-09

$9.481 \mathrm{~B}-14 \quad 4.419 \mathrm{~B}-11 \quad 3.242 \mathrm{~B}-10 \quad 1.440 \mathrm{~B}-10$

$1.148 \mathrm{E}-13 \quad 5.366 \mathrm{E}-11$ 3. $336 \mathrm{~B}-10 \quad 3.768 \mathrm{E}-11$

8.593E-14 4.001E-11 2.935B-10 2.946B-00

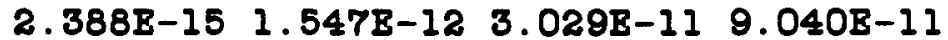

$2.074 \mathrm{~B}-15$ 1.338E-12 2.619B-11 2.167E-10

$2.664 \mathrm{E}-15 \quad 1.729 \mathrm{E}-12 \quad 3.385 \mathrm{E}-11 \mathrm{l}$ 1.538E-09

$2.419 \mathrm{~B}-15$ 1.556E-12 $3.047 \mathrm{E}-112.434 \mathrm{E}-11$

$3.678 \mathrm{E}-15 \quad 2.412 \mathrm{E}-12 \quad 4.721 \mathrm{E}-11 \mathrm{3}$. $186 \mathrm{~B}-12$

2.328B-15 1.502E-12 2.940B-11 $1.972 \mathrm{~B}-09$

8.720E-15 $4.926 \mathrm{E}-12 \quad 3.092 \mathrm{E}-11$ l. $1254 \mathrm{E}-10$

$7.769 \mathrm{~B}-15$ 4.380B-12 $2.749 \mathrm{~B}-11$ 4.174E-10

$9.545 \mathrm{~B}-15 \quad 5.422 \mathrm{~B}-12 \quad 3.403 \mathrm{~B}-11 \quad 1.512 \mathrm{~B}-09$

9.545B-15 5.330B-12 3.345B-11 $2.039 \mathrm{~B}-11$

$1.234 \mathrm{~B}-14 \quad 7.087 \mathrm{~B}-12$ 4.448B-11 $3.686 \mathrm{~B}-12$

8.498E-15 4.792E-12 $3.007 \mathrm{E}-11 \quad 2.311 \mathrm{E}-09$

$1.796 \mathrm{~B}-15 \quad 9.327 \mathrm{~B}-13 \quad 2.005 \mathrm{~B}-11 \quad 6.003 \mathrm{E}-10$

$1.639 \mathrm{E}-15 \quad 8.429 \mathrm{E}-13 \quad 1.813 \mathrm{E}-11 \quad 1.461 \mathrm{E}-09$

$1.963 \mathrm{E}-15 \quad 1.026 \mathrm{E}-12 \quad 2.204 \mathrm{E}-112.631 \mathrm{E}-08$

$1.886 \mathrm{E}-15 \quad 9.629 \mathrm{E}-13 \quad 2.073 \mathrm{E}-11 \quad 4.025 \mathrm{E}-11$

$2.509 \mathrm{E}-15$ 1.345E-12 $2.883 \mathrm{~B}-11$ 3.906E-12

$1.764 \mathrm{E}-15 \quad 9.127 \mathrm{E}-13 \quad 1.963 \mathrm{E}-11 \mathrm{l} \quad 1.526 \mathrm{E}-08$

$3.234 \mathrm{E}-22 \quad 1.802 \mathrm{E}-19 \quad 3.209 \mathrm{E}-18 \quad 1.398 \mathrm{E}-10$

$2.917 \mathrm{E}-22 \quad 1.630 \mathrm{E}-19 \quad 2.902 \mathrm{E}-18 \quad 3.371 \mathrm{E}-10$

$3.488 \mathrm{E}-22 \quad 1.947 \mathrm{E}-18 \quad 3.467 \mathrm{E}-18 \quad 1.960 \mathrm{E}-09$

$3.552 \mathrm{E}-22 \quad 1.983 \mathrm{E}-19 \quad 3.531 \mathrm{E}-18 \quad 4.864 \mathrm{E}-12$

$4.376 \mathrm{E}-22 \quad 2.454 \mathrm{E}-19 \quad 4.370 \mathrm{~B}-18$ 8.229E-14

$3.158 \mathrm{E}-22 \quad 1.766 \mathrm{E}-19 \quad 3.144 \mathrm{E}-18 \quad 3.304 \mathrm{E}-09$

$4.313 \mathrm{~B}-15 \quad 2.675 \mathrm{~B}-12 \quad 4.589 \mathrm{~B}-11 \quad 1.419 \mathrm{E}-10$

$3.805 \mathrm{~B}-15 \quad 2.359 \mathrm{~B}-12 \quad 4.046 \mathrm{~B}-11 \quad 3.388 \mathrm{E}-10$

$4.756 \mathrm{~B}-15 \quad 2.982 \mathrm{E}-12 \quad 5.116 \mathrm{~B}-11 \quad 1.634 \mathrm{E}-09$

$4.471 \mathrm{~B}-15 \quad 2.729 \mathrm{E}-12 \quad 4.682 \mathrm{E}-11 \quad 3.426 \mathrm{E}-11$

$6.279 \mathrm{~B}-15 \quad 4.003 \mathrm{E}-12 \quad 6.868 \mathrm{E}-11 \mathrm{4} .598 \mathrm{E}-12$

$4.154 \mathrm{E}-15 \quad 2.567 \mathrm{E}-12 \quad 4.403 \mathrm{E}-112.868 \mathrm{E}-09$

$5.296 \mathrm{E}-15 \quad 3.236 \mathrm{E}-12 \quad 3.022 \mathrm{E}-11 \mathrm{l} \quad 1.061 \mathrm{E}-10$

$4.630 \mathrm{~B}-15 \quad 2.818 \mathrm{E}-12 \quad 2.632 \mathrm{E}-112.392 \mathrm{E}-10$

$5.898 \mathrm{E}-15 \quad 3.610 \mathrm{E}-12 \quad 3.371 \mathrm{E}-11 \quad 9.589 \mathrm{E}-10$

$5.454 \mathrm{E}-15 \quad 3.314 \mathrm{E}-12 \quad 3.095 \mathrm{~B}-11 \quad 5.671 \mathrm{E}-11$

$7.991 \mathrm{E}-15$ 4.915E-12 $4.590 \mathrm{E}-11$ 4.052E-12

$5.137 \mathrm{E}-15 \quad 3.149 \mathrm{E}-12 \quad 2.941 \mathrm{E}-11 \quad 1.496 \mathrm{E}-09$

$6.723 \mathrm{E}-19 \quad 1.397 \mathrm{E}-15 \quad 2.934 \mathrm{E}-14 \quad 5.398 \mathrm{E}-10$

$4.566 \mathrm{~B}-19 \quad 4.256 \mathrm{E}-16 \quad 8.937 \mathrm{E}-15 \quad 1.263 \mathrm{E}-09$

$1.008 \mathrm{E}-18 \quad 3.023 \mathrm{E}-15 \quad 6.348 \mathrm{E}-14 \quad 2.872 \mathrm{E}-06$

$4.535 \mathrm{E}-19 \quad 1.114 \mathrm{E}-15 \quad 2.340 \mathrm{E}-14 \quad 5.105 \mathrm{E}-09$

$1.465 \mathrm{E}-18 \quad 3.726 \mathrm{E}-15 \quad 7.825 \mathrm{E}-14 \quad 2.959 \mathrm{E}-11$

$6.659 \mathrm{~B}-19$ 1.781E-15 $3.740 \mathrm{E}-14 \quad 1.308 \mathrm{E}-08$

$1.776 \mathrm{E}-18 \quad 1.489 \mathrm{E}-15 \quad 3.126 \mathrm{E}-14 \quad 5.034 \mathrm{E}-10$

$1.481 \mathrm{E}-18 \quad 9.863 \mathrm{E}-16 \quad 2.071 \mathrm{E}-14 \quad 1.182 \mathrm{E}-09$

$2.074 \mathrm{~B}-18 \quad 2.210 \mathrm{~B}-15 \quad 4.642 \mathrm{E}-14 \quad 2.704 \mathrm{~B}-06$

$1.671 \mathrm{E}-18 \quad 1.379 \mathrm{~B}-15 \quad 2.896 \mathrm{~B}-14 \quad 4.799 \mathrm{E}-09$

$2.9018-18 \quad 2.877 \mathrm{~B}-15 \quad 6.042 \mathrm{E}-14 \quad 2.761 \mathrm{E}-11$

$1.735 \mathrm{~B}-18 \quad 1.616 \mathrm{~B}-15 \quad 3.395 \mathrm{~B}-14 \quad 1.227 \mathrm{E}-08$

$6.976 \mathrm{~B}-19 \quad 1.388 \mathrm{~B}-15 \quad 2.815 \mathrm{~B}-14 \quad 5.053 \mathrm{~B}-10$

$4.820 \mathrm{~B}-19 \quad 4.521 \mathrm{~B}-16 \quad 9.494 \mathrm{~B}-15 \quad 1.188 \mathrm{~B}-09$

$1.034 \mathrm{E}-18 \quad 2.950 \mathrm{E}-15 \quad 6.195 \mathrm{E}-14 \quad 2.704 \mathrm{E}-06$

$4.661 \mathrm{E}-191.096 \mathrm{E}-15 \quad 2.302 \mathrm{E}-14 \quad 4.800 \mathrm{E}-09$ 
$1.522 \mathrm{~B}-18 \quad 3.662 \mathrm{~B}-15 \quad 7.691 \mathrm{~B}-142.761 \mathrm{~B}-11$

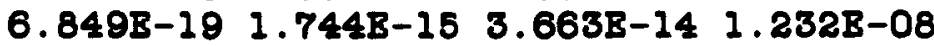

$.000 B+00 \quad .000 B+00 \quad .000 B+002.421 B-12$

$.000 \mathrm{~B}+00 \quad .000 \mathrm{~B}+00 \quad .000 \mathrm{~B}+00 \quad 5.854 \mathrm{~B}-12$

$.000 \mathrm{~B}+00 \quad .000 \mathrm{~B}+00 \quad .000 \mathrm{~B}+00 \quad 1.575 \mathrm{~B}-09$

$.000 \mathrm{~B}+00 \ldots .000 \mathrm{~B}+00 \quad .000 \mathrm{~B}+00 \quad 6.371 \mathrm{~B}-13$

$.000 \mathrm{~B}+00 \quad .000 \mathrm{~B}+00 \quad .000 \mathrm{~B}+00 \quad 2.238 \mathrm{~B}-15$

$.000 \mathrm{~B}+00 \quad .000 \mathrm{~B}+00 \quad .000 \mathrm{~B}+00 \quad 6.220 \mathrm{~B}-11$

$4.883 B-16 \quad 4.037 \mathrm{~B}-13 \quad 8.477 \mathrm{~B}-12 \quad 9.959 \mathrm{~B}-10$

$4.122 \mathrm{~B}-16 \quad 3.379 \mathrm{E}-13 \quad 7.096 \mathrm{~B}-12 \quad 1.641 \mathrm{~B}-09$

$5.930 \mathrm{~B}-16 \quad 4.959 \mathrm{~B}-13 \quad 1.041 \mathrm{~B}-11 \quad 1.276 \mathrm{~B}-06$

$3.203 \mathrm{~B}-16$ 2.658B-13 $5.581 \mathrm{~B}-12 \quad 9.669 \mathrm{E}-08$

$9.418 \mathrm{~B}-16 \quad 7.836 \mathrm{~B}-13 \quad 1.646 \mathrm{~B}-115.507 \mathrm{~B}-10$

$4.313 \mathrm{~B}-163.589 \mathrm{~B}-13 \quad 7.538 \mathrm{~B}-12 \quad 1.213 \mathrm{~B}-08$

$7.008 \mathrm{~B}-19 \quad 1.652 \mathrm{~B}-15 \quad 3.420 \mathrm{~B}-14 \quad 1.086 \mathrm{~B}-09$

$4.439 \mathrm{E}-19 \quad 4.317 \mathrm{~B}-16 \quad 8.939 \mathrm{~B}-15 \quad 1.776 \mathrm{~B}-09$

$1.081 \mathrm{~B}-18 \quad 3.541 \mathrm{~B}-15 \quad 7.332 \mathrm{~B}-14 \quad 1.229 \mathrm{~B}-06$

$4.915 \mathrm{~B}-191.296 \mathrm{~B}-15 \quad 2.683 \mathrm{~B}-14 \quad 1.022 \mathrm{~B}-07$

$1.560 \mathrm{~B}-18 \quad 4.581 \mathrm{~B}-15 \quad 9.487 \mathrm{~B}-14 \quad 6.093 \mathrm{~B}-10$

$7.135 \mathrm{~B}-19 \quad 2.090 \mathrm{~B}-15 \quad 4.328 \mathrm{~B}-14 \quad 1.302 \mathrm{~B}-08$

$5.105 B-19 \quad 1.388 B-15 \quad 2.914 B-14 \quad 1.034 B-09$

$3.000 \mathrm{~B}-193.087 \mathrm{~B}-16 \quad 6.480 \mathrm{~B}-15 \quad 1.690 \mathrm{~B}-09$

8.308E-19 3.05OE-15 6.404E-14 $1.343 \mathrm{E}-06$

$3.583 \mathrm{E}-19 \quad 1.096 \mathrm{E}-15 \quad 2.301 \mathrm{E}-14 \quad 1.019 \mathrm{E}-07$

$1.186 \mathrm{~B}-18 \quad 3.927 \mathrm{~B}-15 \quad 8.244 \mathrm{~B}-14 \quad 5.815 \mathrm{~B}-10$

$5.359 \mathrm{E}-191.790 \mathrm{E}-15 \quad 3.758 \mathrm{E}-14 \quad 1.249 \mathrm{E}-08$ 


\section{$E-1$}

APPENDIX E

Sample Interactive Input and Output 


\section{SMDAIN}

ENTER REACTOR TYPB : $1=$ PWR, 2=BWR

1

ENTER DOSB CONVERSION FACTORS TABLES TO OSE :

$1=$ CRACZ ;

$2=$ KACCS

1

ENTER CHOICE OF SIGMA CALCUIATION:

1 = POLYNOMIAL;

2 - CRACZ OR MACCS MODEL

2

SELECT OUTPUT CONTROL :

1 = DETAILED NOCLIDE INVENTORY

$2=$ ABBREVIATBD OUTPUT

2

IF YOU VISH TO REPEAT THE RON VITHOUT CHANGING REYAINING INPUT PARAMETERS, ENTER 1

0

IF YOU MANT TO CEANGE VBATHER CLASS ONLY ENTBR 1

0

ENTER SCALING FACTOR FOR CORE INV.

REFERENCE POWER $=3412$. MWTH

1 .

ENTER NUMBER OF PUFFS, OP TO 2 ALLOWED

1

ENTER RELEASE FRACTIONS FOR 9 GROOPS FOR POFF 1

NG I CS TE SR RU IA $C E$ BA

$\begin{array}{lllllllllll}.9 & .706 & .4 & .4 & .05 & .3 & .001 & .001 & .05\end{array}$

SELECT OPTION FOR DOSE CALCULATION:

1 = TOP HAT PROFILE (AS USED IN CRAC2)

2 - GAUSSIAN PROFIIE (AS USED IN MACCS)

1

ENTER WIDTH AND HEIGHT OF BUIIDING (M)

100. 25.

BNTER RELEASE TIME (HRS) FOR PUFF 1

0 .

ENTER DURATION (BRS) FOR PUFF I

1 .

DEFAULT DEPOSITION VELOCITY $=1.0000 \mathrm{E}-02 \mathrm{\textrm {m }} / \mathrm{S}$

BREATHING RATE $=2.660 \mathrm{E}-04 \mathrm{M} * 3 / \mathrm{S}$

ENTER NEW YALUES; OSE REAL NUMBERS AND NOT INTEGERS; IF

NBGATIVE, DEFAULT WILL BE USED

-1 . -1 .

ENTER VEATEER CONDITIONS :

1 = MOD. STABLE, 2 = SLIGHTLY STABLE,

3 = NEUTRAL, 4 - SLIGHTLY UNSTABLE,

5 = YOD. UNSTABLE, 6 - EXTREM. UNSTABLE

7 = CLASS G (EXTRAPOLATED)

3

ENTER AVERAGE WIND SPEED, M/S

5.

ENTER RELEASE HEIGHT, M FOR PUFF 1

0 .

ENTER ENERGY OF RBLBASE (WATTS) FOR PUFF 1

1. $\mathrm{B}+08$

ENTER DURATION OF RAIN, S 


$$
E-3
$$

0 .

ENTER THRBE SHIBLDING FACTORS, RESPBCTIVBLY :

CLOUD-SHINE

GROOND-SHINE

INHAILATION

$.75 \quad .33 \quad 1$.

DOSE CONVBRSION TABLBS OSED FROM EITHER YACCS OR CRAC2 DATA ARE DEFAULT;

IF YOU VISH TO SBLECT DIFFERENT TABLES IN CRAC2 DATA BASB, ENTBR 1

DATA BASB PROVIDBD FOR MACCS HAS ONLY DEFAULT OPTION

0

IF YOU VISH TO REPEAT, BNTER 1

0

Execution terminated : 0 


$$
\text { E-4 }
$$

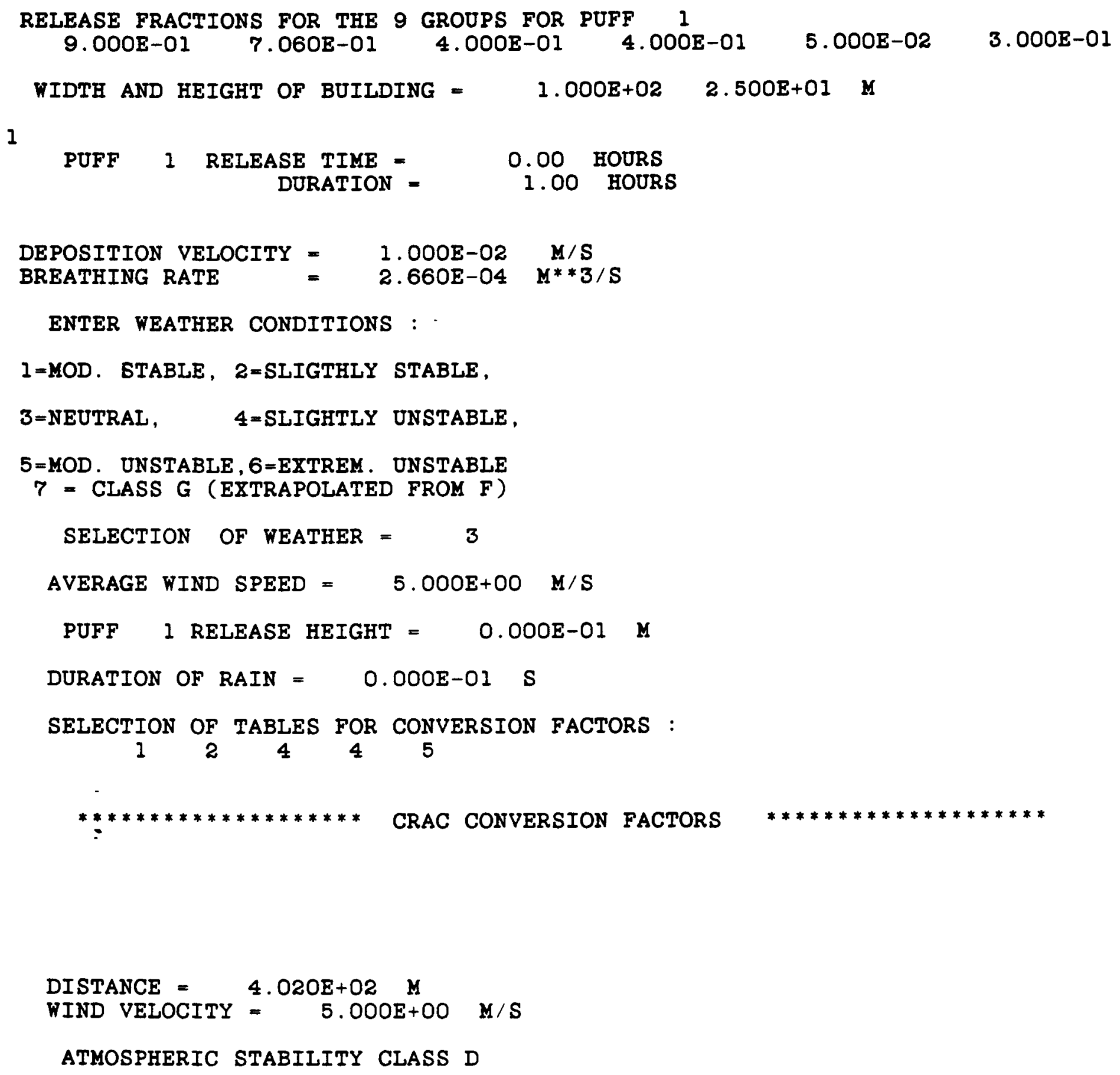




\begin{tabular}{|c|c|c|c|c|c|}
\hline \multirow[t]{3}{*}{ TOTAI } & \multicolumn{2}{|c|}{$5.395 E+02 \quad 5.946 E+02$} & $5.090 E+02$ & $4.900 \mathrm{E}+02$ & $3.935 \mathrm{E}+02$ \\
\hline & \multirow[b]{2}{*}{ WHOLE BODY } & \multirow[b]{2}{*}{ MARROW } & \multicolumn{3}{|c|}{ GROUND SHINE } \\
\hline & & & LUNG & THYROID & LIIW \\
\hline \multirow[t]{3}{*}{ TOTAL } & \multirow[t]{2}{*}{$5.841 E+03$} & $6.852 \mathrm{E}+03$ & $5.473 \mathrm{E}+03$ & \multicolumn{2}{|c|}{$5.242 E+03 \quad 3.914 E+03$} \\
\hline & & & \multicolumn{3}{|c|}{ INHALATION } \\
\hline & WHOLE BODY & MARROW & LUNG & THYROID & ILIW \\
\hline TOTAL & $4.447 E+02$ & $5.992 E+02$ & $8.796 E+04$ & \multirow[t]{2}{*}{$9.836 \mathrm{E}+04$} & $5.193 \mathrm{E}+03$ \\
\hline $\begin{array}{l}\text { TOTAL } \\
\text { TOTAL } \\
\text { TOTAL } \\
\text { TOTAL } \\
\text { TOTAL }\end{array}$ & $\begin{array}{l}\text { BODY DOSE } \\
\text { MARROW DOSE } \\
\text { LUNG DOSE } \\
\text { LLIW DOSE } \\
\text { THYROID DOSE }\end{array}$ & \multicolumn{2}{|c|}{$\begin{array}{ll}= & 6.826 \mathrm{E}+03 \\
= & 8.046 \mathrm{E}+03 \\
= & 9.395 \mathrm{E}+04 \\
= & 9.500 \mathrm{E}+03 \\
= & 1.041 \mathrm{E}+05\end{array}$} & & \\
\hline
\end{tabular}

CRAC2 PROBABILITY OF EARIY FATALITIES $=\quad 1.000$

CRAC CONVERSION FACTORS

$\begin{array}{lrl}\text { DISTANCE }= & 1.210 \mathrm{E}+03 \mathrm{M} \\ \text { WIND VELOCITY }= & 5.000 \mathrm{E}+00 \mathrm{M} / \mathrm{S}\end{array}$

ATMOSPHERIC STABILITY CLASS D

PUFF NUMBER 1

HORIZONTAL DISPERSION COEFFICIENT = VERTICAL DISPERSION COEFFICIENT =

$2.115 E+02$
$4.493 E+O 1$

CLOUD SHINE

WHOLE BODY MARROW IUNG THYROID ILIW 


\begin{tabular}{|c|c|c|c|c|c|}
\hline \multirow[t]{3}{*}{ TOTAL } & \multirow[t]{2}{*}{$3.326 E+02$} & \multicolumn{2}{|c|}{$3.667 E+023.138 E+02$} & \multirow{2}{*}{\multicolumn{2}{|c|}{$3.023 E+022.427 E+02$}} \\
\hline & & \multirow[b]{2}{*}{ MARROW } & GROUND SHINE & & \\
\hline & WHOLE & & LUNG & THYROID & ILIW \\
\hline \multirow[t]{3}{*}{ TOTAL } & \multirow[t]{2}{*}{$2.647 E+03$} & $3.106 E+03$ & $2.480 E+03$ & \multicolumn{2}{|c|}{$2.377 \mathrm{E}+03 \quad 1.774 \mathrm{E}+03$} \\
\hline & & & \multicolumn{3}{|c|}{ INHALATION } \\
\hline & WHOLE BODY & MARROW & LUNG & THYROID & LIIN \\
\hline TOTAI & $2.014 E+02$ & $2.716 E+02$ & $3.990 \mathrm{E}+04$ & $4.456 \mathrm{E}+04$ & $2.356 \mathrm{E}+03$ \\
\hline $\begin{array}{l}\text { TOTAL } \\
\text { TOTAL } \\
\text { TOTAI } \\
\text { TOTAI } \\
\text { TOTAL }\end{array}$ & $\begin{array}{l}\text { BODY DOSE } \\
\text { MARROW DOSE } \\
\text { LUNG DOSE } \\
\text { LLIW DOSE } \\
\text { THYROID DOSE }\end{array}$ & \multicolumn{2}{|c|}{$\begin{array}{l}=\quad 3.181 E+03 \\
=\quad 3.744 E+03 \\
=\quad 4.270 E+04 \\
=\quad 4.373 E+03 \\
=\quad 4.724 E+04\end{array}$} & & \\
\hline
\end{tabular}

CRAC2 PROBABILITY OF EARLY FATALITIES $=\quad 1.000$

CRAC CONVERSION FACTORS

$\begin{array}{ll}\text { DISTANCE }= & 2.010 \mathrm{E}+03 \mathrm{M} \\ \text { WIND VELOCITY }= & 5.000 \mathrm{E}+00 \mathrm{M} / \mathrm{S}\end{array}$

ATMOSPHERIC STABILITY CLASS D

PUFF NUMBER 1

HORIZONTAL DISPERSION COEFFICIENT = VERTICAL DISPERSION COEFFICIENT =

\author{
$3.041 E+02 \quad M$ \\ $6.948 E+01 \quad M$
}




$$
E-7
$$

WHOLE BODY MARROW IUNG THYROID ILIW

\begin{tabular}{|c|c|c|c|c|c|}
\hline \multirow[t]{3}{*}{ TOTAL } & \multicolumn{2}{|c|}{$1.988 \mathrm{E}+022.192 \mathrm{E}+02$} & $1.876 \mathrm{E}+02$ & $1.809 \mathrm{E}+02$ & $1.452 \mathrm{E}+02$ \\
\hline & \multirow[b]{2}{*}{ WHOLE } & \multirow[b]{2}{*}{ MARROW } & \multicolumn{3}{|c|}{ GROUND SHINE } \\
\hline & & & LUNG & THYROID & ILIN \\
\hline \multirow[t]{3}{*}{ TOTAL } & \multirow[t]{2}{*}{$1.159 \mathrm{E}+03$} & \multirow[t]{2}{*}{$1.360 \mathrm{E}+03$} & $1.086 \mathrm{E}+03$ & $1.041 \mathrm{E}+03$ & $7.772 E+02$ \\
\hline & & & \multicolumn{3}{|c|}{ INHALATION } \\
\hline & WHOLE BODY & MARROW & LUNG & THYROID & LLIN \\
\hline TOTAL & $8.797 E+01$ & $1.188 \mathrm{E}+02$ & $1.747 E+04$ & $1.948 E+04$ & 1.031 \\
\hline
\end{tabular}

$\begin{array}{lll}\text { TOTAL BODY DOSE } & 1.446 E+03 \\ \text { TOTAL MARROW DOSE } & 1.698 E+03 \\ \text { TOTAL LUNG DOSE } & 1.874 E+04 \\ \text { TOTAL LLIW DOSE } & 1.953 E+03 \\ \text { TOTAL THYROID DOSE } & =2.070 E+04\end{array}$

CRAC2-PROBABILITY OF EARLY FATALITIES $=\quad 1.000$

CRAC CONVERSION FACTORS

\begin{abstract}
DISTANCE $=3.219 \mathrm{E}+03 \mathrm{M}$
WIND VELOCITY $=5.000 E+00 \mathrm{M} / \mathrm{S}$

ATMOSPHERIC STABILITY CLASS D
\end{abstract}

PUFF NUMBER 1

HORIZONTAL DISPERSION COEFFICIENT $=$
VERTICAL DISPERSION COEFFICIENT $=$
$\begin{gathered}4.387 \mathrm{E}+02 \\ \mathrm{M}\end{gathered} \mathbf{M}$ 


\section{E-8}

WHOLE BODY KARROW IUNG THYROID ILIW

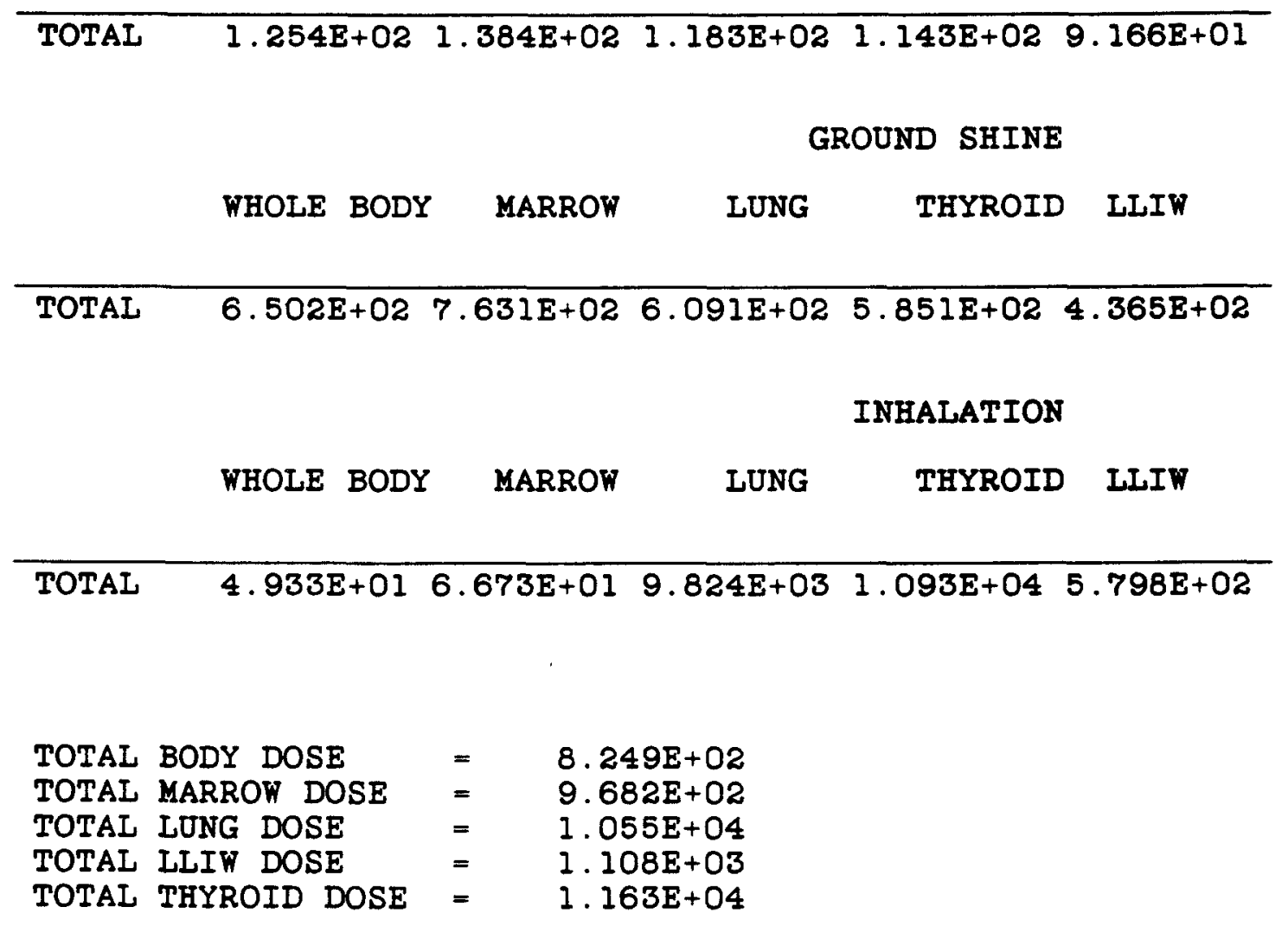

CRAC2 ${ }^{-}$PROBABILITY OF EARLY FATALITIES $=\quad 1.000$

CRAC CONVERSION FACTORS

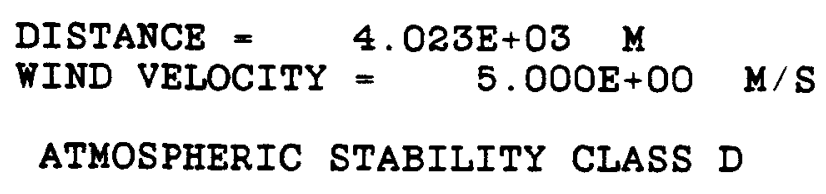

PUFF NUMBER 1

HORIZONTAL DISPERSION COEFFICIENT =

VERTICAL DISPERSION COEFFICIENT =

$5.257 E+02$
$9.551 E+01$ 
CLOUD SHINE

WHOLE BODY MARROW IUNG THYROID ILIW

$\begin{array}{lllllll}\text { TOTAL. } & 9.857 \mathrm{E}+01 & 1.088 \mathrm{E}+02 & 9.300 \mathrm{E}+01 & 8.993 \mathrm{E}+01 & 7.206 \mathrm{E}+01\end{array}$

GROUND SHINE

WHOLE BODY MARROW IUNG THYROID ILIW

TOTAL $4.750 E+02 \quad 5.576 E+02 \quad 4.450 E+02 \quad 4.278 E+02 \quad 3.191 E+02$

INHAIATION

WHOLE BODY MARROW IUNG THYROID LIIW

$\begin{array}{lllllll}\text { TOTAL } & 3.601 E+01 & 4.877 E+01 & 7.186 E+03 & 7.982 E+03 & 4.241 E+02\end{array}$

TOTAL BODY DOSE $=6.096 \mathrm{E}+02$

TOTAL MARROW DOSE $=7.152 \mathrm{E}+02$

TOTAL LUNG DOSE $=7.724 \mathrm{E}+03$

TOTAL LIIW DOSE $=8.153 \mathrm{E}+02$

TOTAL THYROID DOSE $=8.499 E+03$

CRAC2" PROBABILITY OF EARLY FATALITIES $=1.000$

CRAC CONVERSION FACTORS

$\begin{array}{llrl}\text { DISTANCE }= & 4.828 E+03 \quad M \\ \text { WIND VELOCITY } & =5.000 E+00 \quad M / S\end{array}$

ATMOSPHERIC STABIIITY CLASS D

PUFF NUMBER 1

HORIZONTAL DISPERSION COEFFICIENT =

VERTICAL DISPERSION COEFFICIENT =

$6.113 E+02 \quad \mathrm{M}$

$1.059 E+02 \quad M$ 
CIOUD SHINE

WHOLE BODY MARROW IUNG THYROID LLIW

\begin{tabular}{lllllll}
\hline TOTAL & $7.934 \mathrm{E}+01$ & $8.761 \mathrm{E}+01$ & $7.485 \mathrm{E}+01$ & $7.245 \mathrm{E}+01$ & $5.803 \mathrm{E}+01$
\end{tabular}

GROUND SHINE

WHOLE BODY MARROW LUNG THYROID ILIW

$\begin{array}{llllll}\text { TOTAL } & 3.651 E+02 & 4.286 E+02 & 3.420 E+02 & 3.291 E+02 & 2.454 E+02\end{array}$

INHALATION

WHOLE BODY MARROW IUNG THYROID LLIW

$\begin{array}{llllll}\text { TOTAL } & 2.765 E+01 & 3.750 E+01 & 5.530 E+03 & 6.132 E+03 & 3.263 E+02\end{array}$

TOTAL BODY DOSE $=4.721 \mathrm{E}+02$

TOTAL MARROW DOSE $=5.537 \mathrm{E}+02$

TOTAL LUNG DOSE $=5.946 \mathrm{E}+03$

TOTAL LLIW DOSE $=6.297 \mathrm{E}+02$

TOTAL THYROID DOSE $=6.533 \mathrm{E}+03$

CRAC2 PROBABILITY OF EARLY FATALITIES $=0.109$

CRAC CONVERSION FACTORS

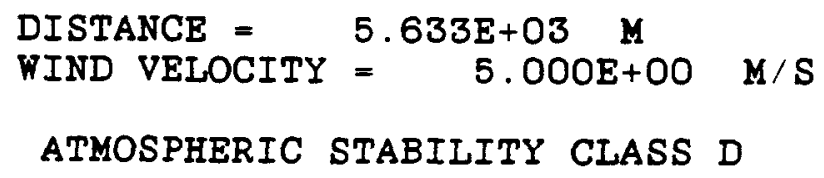

PUFF NUMBER 1

HORIZONTAL DISPERSION COEFFICIENT $=6.956 \mathrm{E}+02 \mathrm{M}$

VERTICAL DISPERSION COEFFICIENT $=1.158 \mathrm{E}+02 \mathrm{M}$ 


\section{CLOUD SHINE}

WHOLE BODY MARROW IUNG THYROID LLIW

TOTAL $6.511 \mathrm{E}+01 \quad 7.194 \mathrm{E}+01 \quad 6.143 \mathrm{E}+01 \quad 5.952 \mathrm{E}+01 \quad 4.764 \mathrm{E}+01$

GROUND SHINE

WHOLE BODY MARROW IUNG THYROID ILIW

$\begin{array}{lllllll}\text { TOTAL } & 2.911 \mathrm{E}+02 & 3.418 \mathrm{E}+02 & 2.727 \mathrm{E}+02 & 2.626 \mathrm{E}+02 & 1.958 \mathrm{E}+02\end{array}$

INHALATION

WHOLE BODY MARROW IUNG THYROID ILIW

TOTAL $2.203 E+01 \quad 2.990 E+01 \quad 4.413 E+03 \quad 4.886 E+03 \quad 2.604 E+02$

$\begin{array}{lll}\text { TOTAL BODY DOSE } & 3.782 \mathrm{E}+02 \\ \text { TOTAL MARROW DOSE } & =4.436 \mathrm{E}+02 \\ \text { TOTAL LUNG DOSE } & 4.748 \mathrm{O}+03 \\ \text { TOTAL LLIW DOSE } & =5.038 \mathrm{E}+02 \\ \text { TOTAL THYROID DOSE } & =5.209 \mathrm{E}+03\end{array}$

CRAC2 PROBABILITY OF EARLY FATALITIES $=\quad 0.046$

DISTANCE $=6.437 \mathrm{E}+03 \mathrm{M}$

WIND VELOCITY $=5.000 E+00 \mathrm{M} / \mathrm{S}$

ATMOSPHERIC STABILITY CLASS D

PUFF NUMBER 1 
CLOUD SHINE

WHOLE BODY MARROW IUNG THYROID LLIW

\begin{tabular}{llllllll}
\hline TOTAL & $5.468 E+01$ & $6.045 E+01$ & $5.159 E+01$ & $5.003 E+01$ & $4.003 E+01$
\end{tabular}

\begin{tabular}{|c|c|c|c|c|c|c|}
\hline & \multirow[b]{2}{*}{ WHOLE } & \multirow[b]{2}{*}{ BODY } & \multirow[b]{2}{*}{ MARROW } & \multicolumn{3}{|c|}{ GROUND SHINE } \\
\hline & & & & LUNG & THYROID & ILIV \\
\hline \multirow[t]{3}{*}{ TOTAL } & \multirow{2}{*}{\multicolumn{3}{|c|}{$2.386 \mathrm{E}+022$}} & $2.235 E+02$ & $2.154 E+02$ & \multirow[t]{2}{*}{$1.605 \mathrm{E}+02$} \\
\hline & & & & \multicolumn{2}{|r|}{ INHALATION } & \\
\hline & WHOLE & BODY & MARROW & LUNG & THYROID & LIIW \\
\hline TOTAI & \multicolumn{3}{|c|}{$1.804 \mathrm{E}+012.452 \mathrm{E}+01$} & $3.621 E+03$ & $4.003 E+03$ & 2.137 \\
\hline
\end{tabular}

$\begin{array}{lll}\text { TOTAL BODY DOSE } & 3.113 \mathrm{E}+02 \\ \text { TOTAL MARROW DOSE } & =3.651 \mathrm{E}+02 \\ \text { TOTAL LUNG DOSE } & =3.896 \mathrm{E}+03 \\ \text { TOTAL LIIW DOSE } & =4.142 \mathrm{E}+02 \\ \text { TOTAL THYROID DOSE } & =4.269 \mathrm{E}+03\end{array}$

CRAC2 PROBABILITY OF EARLY FATALITIES $=\quad 0.017$

\title{
CRAC CONVERSION FACTORS
}

\author{
DISTANCE $=7.242 E+03 \mathrm{M}$ \\ WIND VELOCITY $=5.000 E+00 \mathrm{M} / \mathrm{S}$ \\ ATMOSPHERIC STABILITY CLASS D
}

PUFF NUMBER 1 


\title{
CLOUD SHINE
}

WHOLE BODY MARROW IUNG THYROID ILIW

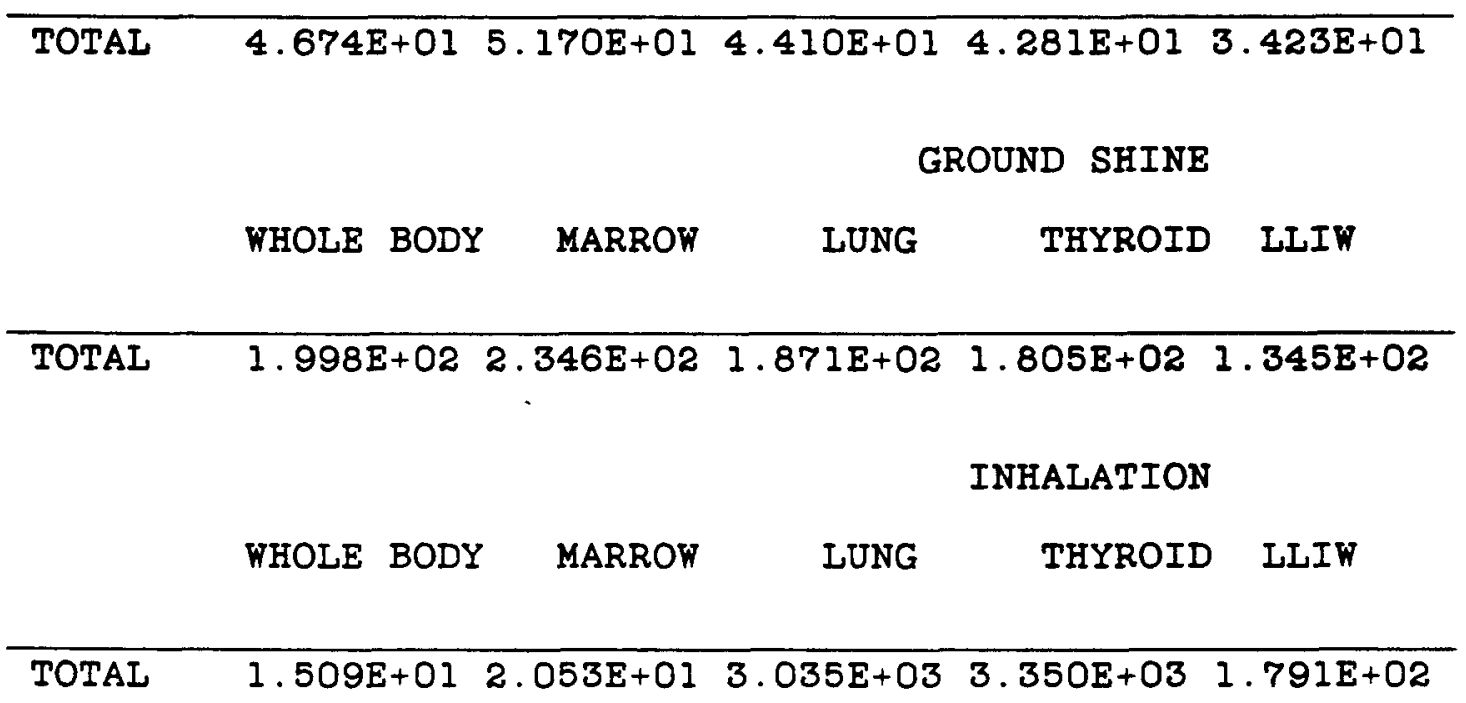

TOTAL BODY DOSE $=2.616 \mathrm{E}+02$

TOTAL MARROW DOSE $=3.069 E+02$

TOTAL LUNG DOSE $=3.267 \mathrm{E}+03$

TOTAL LLIW DOSE $=3.478 E+02$

TOTAL THYROID DOSE $=3.574 \mathrm{E}+03$

CRAC2 PROBABILITY OF EARLY FATALITIES $=\quad 0.000$

CRAC CONVERSION FACTORS

\begin{abstract}
DISTANCE $=8.047 \mathrm{E}+03 \mathrm{M}$
WIND VELOCITY $=5.000 E+00 \mathrm{M} / \mathrm{S}$

ATMOSPHERIC STABILITY CLASS D
\end{abstract}

PUFF NUMBER 1

HORIZONTAL DISPERSION COEFFICIENT $=9.425 E+02 M$ 


\section{$E-14$}

VERTICAL DISPERSION COEFFICIENT $=1.474 E+02 \quad \mathrm{M}$

\section{CLOUD SHINE}

WHOLE BODY MARROW IUNG THYROID LLIW

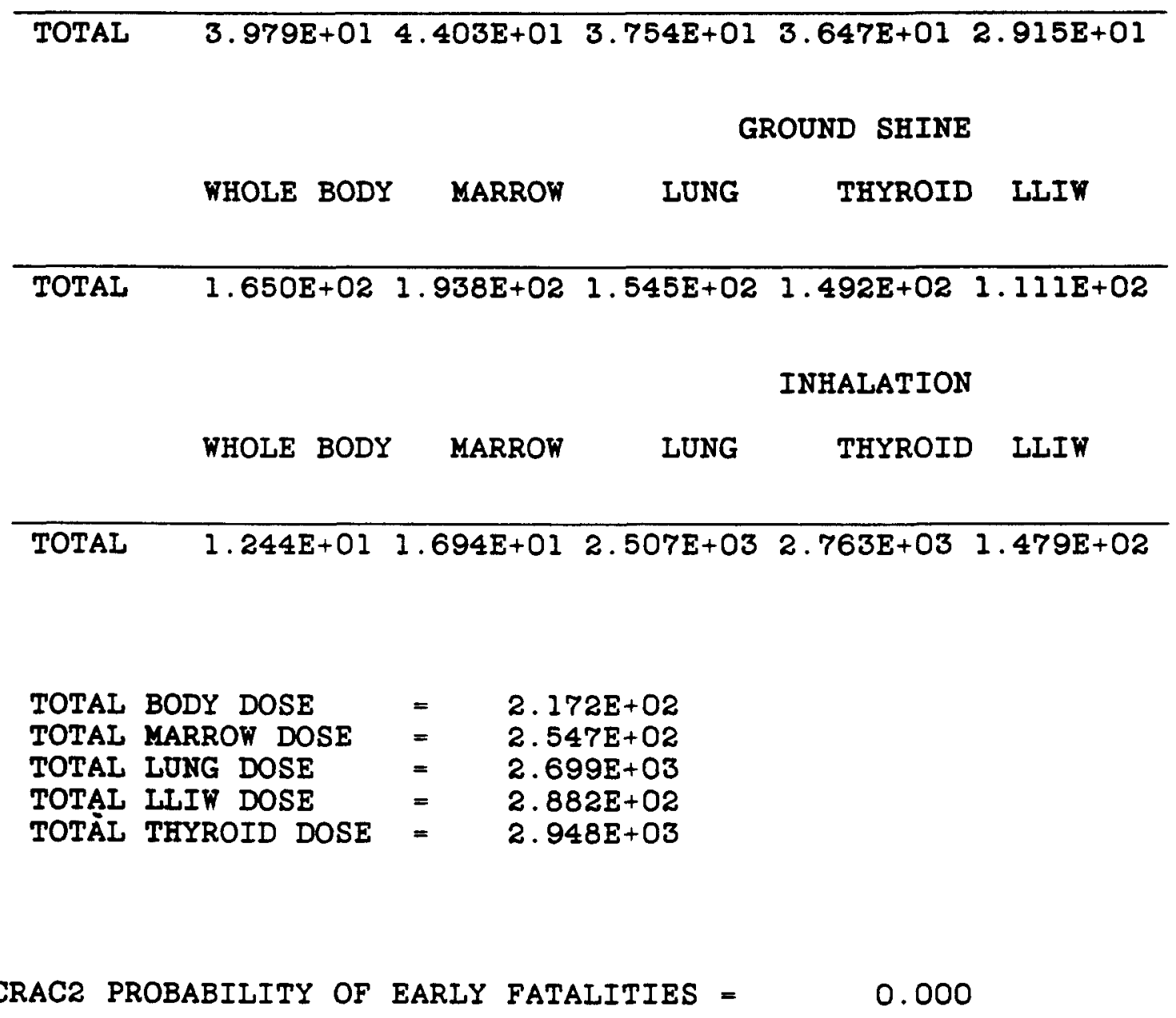

CRAC CONVERSION FACTORS

DISTANCE $=9.660 \mathrm{E}+03 \mathrm{M}$

WIND VELOCITY $=5.000 E+00 \mathrm{M} / \mathrm{S}$

ATMOSPHERIC STABILITY CLASS D 


\section{$E-15$}

HORIZONTAI DISPERSION COEFFICIENT = VERTICAL DISPERSION COEFFICIENT =
$1.104 \mathrm{E}+03$
$1.641 \mathrm{E}+02$
$\mathbf{M}$
$\mathbf{M}$

\begin{tabular}{|c|c|c|c|c|c|}
\hline & \multirow[b]{2}{*}{ WHOLE } & \multirow[b]{2}{*}{ BODY } & \multirow[b]{2}{*}{ MARROW } & \multicolumn{2}{|l|}{ CLOUD SHINE } \\
\hline & & & & THYROID & LLIW \\
\hline \multirow[t]{3}{*}{ TOTAL } & \multirow{2}{*}{\multicolumn{3}{|c|}{$3.100 E+013.434 E+01$}} & $2.924 E+012.846 E+01$ & \multirow[t]{2}{*}{$2.272 \mathrm{E}+01$} \\
\hline & & & & GROUND SHINE & \\
\hline & WHOLE & BODY & MARROW & THYROID & LLIW \\
\hline
\end{tabular}

\begin{tabular}{llllll}
\hline TOTAL & $1.251 E+02$ & $1.470 E+02$ & $1.172 E+02$ & $1.133 E+02$ & $8.438 E+01$
\end{tabular}

INHALATION

WHOLE BODY MARROW LUNG THYROID LLIW

$\begin{array}{lllllll}\text { TOTAL } & 9.415 E+00 & 1.285 E+01 & 1.904 E+03 & 2.092 E+03 & 1.123 E+02\end{array}$

TOTAI BODY DOSE $=1.655 \mathrm{E}+02$

TOTAI MARROW DOSE $=1.942 E+02$

TOTAL LUNG DOSE $=2.051 \mathrm{E}+03$

TOTAL ILIW DOSE $=2.194 \mathrm{E}+02$

TOTAI THYROID DOSE $=2.234 \mathrm{E}+03$

CRAC2 PROBABILITY OF EARLY FATALITIES $=\quad 0.000$

CRAC CONVERSION FACTORS

DISTANCE $=1.130 \mathrm{E}+04 \mathrm{M}$

WIND VELOCITY $=5.000 E+00 \mathrm{M} / \mathrm{S}$

ATMOSPHERIC STABILITY CIASS D 


\title{
$E-16$
}

HORIZONTAL DISPERSION COEFFICIENT =

VERTICAL DISPERSION COEFFICIENT =

$1.265 \mathrm{E}+03$
$1.836 \mathrm{E}+02$

CLOUD SHINE

WHOLE BODY MARROW IUNG THYROID LIIW

$\begin{array}{lllllll}\text { TOTAL } & 2.458 E+01 & 2.727 E+01 & 2.319 E+01 & 2.261 E+01 & 1.803 E+01\end{array}$

GROUND SHINE

WHOLE BODY MARROW IUNG THYROID ILIW

$\begin{array}{lllllll}\text { TOTAL } & 9.639 \mathrm{E}+01 & 1.133 \mathrm{E}+02 & 9.029 \mathrm{E}+01 & 8.743 \mathrm{E}+01 & 6.510 \mathrm{E}+01\end{array}$

INHALATION

WHOLE BODY MARROW IUNG THYROID LLIW

TOTAL $\quad 7.234 E+00 \quad 9.896 E+00 \quad 1.469 E+03 \quad 1.608 E+03 \quad 8.660 E+01$

$\begin{array}{lll}\text { TOTAL BODY DOSE } & =1.282 E+02 \\ \text { TOTAI MARROW DOSE } & =1.504 E+02 \\ \text { TOTAI LUNG DOSE } & =1.582 E+03 \\ \text { TOTAI LIIW DOSE } & =1.697 E+02 \\ \text { TOTAL THYROID DOSE } & =1.719 E+03\end{array}$

CRAC2 PROBABILITY OF EARLY FATALITIES $=\quad 0.000$

CRAC CONVERSION FACTORS

\author{
DISTANCE $=1.370 E+04 \mathrm{M}$ \\ WIND VELOCITY $=5.000 E+00 \mathrm{M} / \mathrm{S}$ \\ ATMOSPHERIC STABILITY CLASS D
}




\section{$E-17$}

PUFF NUMBER 1

HORIZONTAL DISPERSION COEFFICIENT $=$
VERTICAL DISPERSION COEFFICIENT $=$
$2.055 \mathrm{E}+02$

CLOUD SHINE

WHOLE BODY MARROW IUNG THYROID ILIW

\begin{tabular}{lllllll}
\hline TOTAI & $1.859 \mathrm{E}+01$ & $2.065 \mathrm{E}+01$ & $1.754 \mathrm{E}+01$ & $1.714 \mathrm{E}+01$ & $1.364 \mathrm{E}+01$
\end{tabular}

GROUND SHINE

WHOLE BODY MARROW IUNG THYROID LLIW

\begin{tabular}{lllllll}
\hline TOTAL & $7.177 E+01$ & $8.439 E+01$ & $6.723 E+01$ & $6.525 E+01$ & $4.855 E+01$
\end{tabular}

INHALATION

WHOLE BODY MARROW IUNG THYROID LLIW

TOTAL $\quad 5.371 E+00 \quad 7.369 E+00 \quad 1.096 E+03 \quad 1.195 E+03 \quad 6.461 E+01$

TOTAL BODY DOSE $=9.573 \mathrm{E}+01$

TOTALI YARROW DOSE $=1.124 \mathrm{E}+02$

TOTAL LUNG DOSE $=1.181 \mathrm{E}+03$

TOTAL LLIW DOSE $=1.268 E+02$

TOTAL THYROID DOSE $=1.277 \mathrm{E}+03$

CRAC2 PROBABILITY OF EARLY FATALITIES $=\quad 0.000$

CRAC CONVERSion factors

$\begin{array}{llrl}\text { DISTANCE }= & 1.610 E+04 M & M \\ \text { WIND VELOCITY }= & 5.000 E+00 \quad \mathrm{M} / \mathrm{S}\end{array}$

ATMOSPHERIC STABILITY CLASS D 


\section{$E-18$}

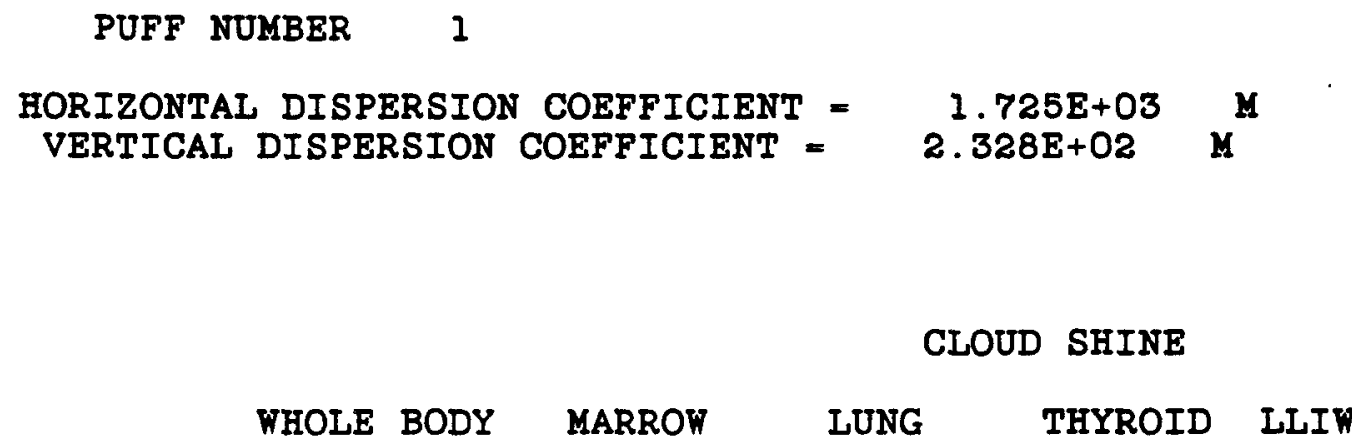

$\begin{array}{lllllll}\text { TOTAL } & 1.405 \mathrm{E}+01 & 1.564 \mathrm{E}+01 & 1.326 \mathrm{E}+01 & 1.299 \mathrm{E}+01 & 1.032 \mathrm{E}+01\end{array}$

GROUND SHINE

WHOLE BODY MARROW IUNG THYROID ILIW

TOTAI $\quad 5.421 E+01 \quad 6.376 E+01 \quad 5.078 E+01 \quad 4.939 E+01 \quad 3.674 E+01$

INHALATION

WHOLE BODY MARROW IUNG THYROID LLIW

TOTAL $4.036 E+00 \quad 5.554 E+00 \quad 8.279 E+02 \quad 8.985 E+02 \quad 4.878 E+01$

TOTAL BODY DOSE $=7.230 E+01$

TOTAL MARROW DOSE $=8.495 \mathrm{E}+01$

TOTAL LUNG DOSE $=8.919 \mathrm{E}+02$

TOTAL LIIW DOSE $=9.584 E+01$

TOTAL THYROID DOSE $=9.609 \mathrm{E}+02$

CRAC2 PROBABIIITY OF EARLY FATALITIES $=\quad 0.000$

CRAC CONVERSION FACTORS

$\begin{array}{llrl}\text { DISTANCE }= & 2.010 E+04 \mathrm{M} \\ \text { WIND VELOCITY } & =5.000 \mathrm{E}+00 \mathrm{M} / \mathrm{S}\end{array}$

ATMOSPHERIC STABILITY CLASS D 
PUFF NUMBER 1

HORIZONTAL DISPERSION COEFFICIENT $=\frac{2.098 \mathrm{E}+03}{\text { VERTICAL DISPERSION COEFFICIENT }}=2.570 \mathrm{M}+02$
$\mathrm{M}$

CLOUD SHINE

WHOLE BODY MARROW LUNG THYROID LIIW

$\begin{array}{llllll}\text { TOTAL } & 1.009 E+01 & 1.126 E+01 & 9.518 E+00 & 9.360 E+00 & 7.419 E+00\end{array}$

GROUND SHINE

WHOLE BODY MARROW LUNG THYROID LLIW

$\begin{array}{lllllll}\text { TOTAL } & 3.970 E+01 & 4.672 E+01 & 3.718 E+01 & 3.629 E+01 & 2.697 E+01\end{array}$

INHALATION

WHOLE BODY MARROW IUNG THYROID ILIW

TOTAL $2.947 E+00 \quad 4.073 E+00 \quad 6.093 E+02 \quad 6.563 E+02 \quad 3.588 E+01$

TOTAL BODY DOSE $=5.273 E+01$

TOTAL MARROW DOSE $=6.205 \mathrm{E}+01$

TOTAL LUNG DOSE $=6.560 E+02$

TOTAL LIIW DOSE $=7.028 E+0 I$

TOTAL THYROID DOSE $=7.020 E+02$

CRAC2 PROBABILITY OF EARLY FATALITIES $=\quad 0.000$ 
PUFF NUMBER 1

HORIZONTAL DISPERSION COEFFICIENT = VERTICAL DISPERSION COEFFICIENT =

\author{
$2.282 E+03$
$2.804 E+02$
}

CLOUD SHINE

WHOLE BODY MARROW LUNG THYROID ILIW

TOTAL $\quad 8.406 \mathrm{E}+00 \quad 9.397 \mathrm{E}+00 \quad 7.930 \mathrm{E}+00 \quad 7.811 \mathrm{E}+00 \quad 6.184 \mathrm{E}+00$

GROUND SHINE

WHOLE BODY MARROW IUNG THYROID ILIW

$\begin{array}{llllll}\text { TOTAL } & 3.315 E+01 & 3.903 E+01 & 3.105 E+01 & 3.036 E+01 & 2.256 E+01\end{array}$

INHALATION

WHOLE BODY MARROW IUNG THYROID ILIW

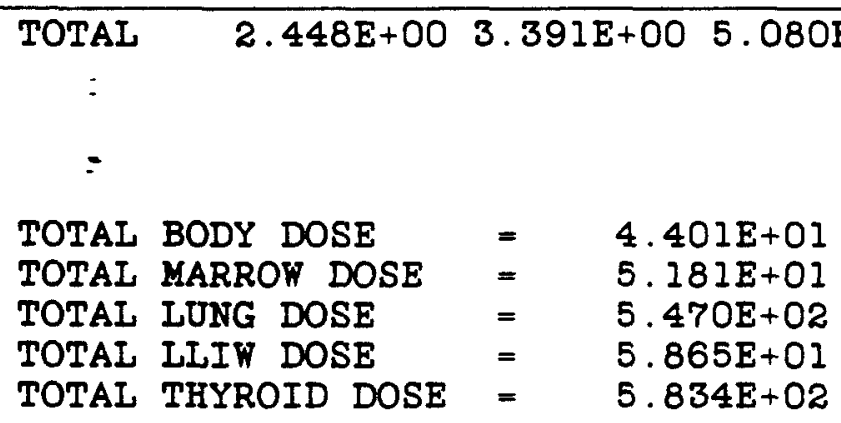

CRAC2 PROBABILITY OF EARLY FATALITIES =

0.000 
ATMOSPHERIC STABILITY CLASS D

PUFF NUMBER 1

HORIZONTAL DISPERSION COEFFICIENT = VERTICAI DISPERSION COEFFICIENT =
2. $655 \mathrm{E}+03$
3. $100 \mathrm{E}+02$
$\mathbf{M}^{\mathbf{M}}$

CLOUD SHINE

WHOLE BODY MARROW LUNG THYROID LLIW

TOTAL $\quad 6.326 E+00 \quad 7.093 E+00 \quad 5.967 E+00 \quad 5.897 E+00 \quad 4.656 E+00$

GROUND SHINE

WHOLE BODY MARROW LUNG THYROID LLIW

$\begin{array}{lllllll}\text { TOTAL } & 2.541 E+01 & 2.993 E+01 & 2.380 E+01 & 2.335 E+01 & 1.734 E+01\end{array}$

INHALATION

WHOLE BODY MARROW IUNG THYROID LIIW

TOTAL $\quad 1.865 E+00 \quad 2.595 E+00 \quad 3.900 E+02 \quad 4.154 E+02 \quad 2.295 E+01$

$=$

TOTAI BODY DOSE $=3.360 \mathrm{E}+01$

TOTAL MARROW DOSE $=3.961 \mathrm{E}+01$

TOTAI LUNG DOSE $=4.198 \mathrm{E}+02$

TOTAL LLIW DOSE $=4.494 \mathrm{E}+01$

TOTAL THYROID DOSE $=4.447 E+02$

CRAC2 PROBABILITY OF EARLY FATALITIES $=\quad 0.000$ 
ATMOSPHERIC STABILITY CLASS D

\author{
PUFF NUMBER 1 \\ HORIZONTAL DISPERSION COEFFICIENT = \\ VERTICAL DISPERSION COEFFICIENT = \\ $3.013 B+03$
$3.445 E+02$
}

CLOUD SHINE

WHOLE BODY MARROW LUNG THYROID ILIW

\begin{tabular}{llllll}
\hline TOTAL & $4.875 E+00$ & $5.481 E+00$ & $4.598 E+00$ & $4.558 E+00$ & $3.590 E+00$
\end{tabular}

GROUND SHINE

WHOLE BODY MARROW IUNG THYROID ILIW

\begin{tabular}{llllllll}
\hline TOTAL & $1.989 E+01$ & $2.344 E+01$ & $1.863 E+01$ & $1.834 E+01$ & $1.361 E+01$
\end{tabular}

INHALATION

WHOLE BODY MARROW LUNG THYROID LLIW

TOTAL $1.447 E+00 \quad 2.022 E+00 \quad 3.048 E+02 \quad 3.223 E+02 \quad 1.793 E+01$ $=$

TOTAL BODY DOSE $=2.621 \mathrm{E}+01$

TOTAL MARROW DOSE $=3.094 \mathrm{E}+01$

TOTAL LUNG DOSE $=3.280 E+02$

TOTAL LLIW DOSE $=3.512 \mathrm{E}+01$

TOTAL THYROID DOSE $=3.452 \mathrm{E}+02$

CRAC2 PROBABILITY OF EARLY FATALITIES $=\quad 0.000$ 
WIND VELOCITY $=5.000 E+00 \mathrm{M} / \mathrm{S}$

ATMOSPHERIC STABILITY CLASS D

PUFF NUMBER 1

HORIZONTAL DISPERSION COEFFICIENT $=3.541 \mathrm{E}+03$
VERTICAL DISPERSION COEFFICIENT $=3.903 \mathrm{M}+02$

CLOUD SHINE

WHOLE BODY MARROW IUNG THYROID LIIW

\begin{tabular}{lllllll}
\hline TOTAI & $3.507 \mathrm{E}+00$ & $3.959 \mathrm{E}+00$ & $3.307 \mathrm{E}+00$ & $3.291 \mathrm{E}+00$ & $2.583 \mathrm{E}+00$
\end{tabular}

GROUND SHINE

WHOLE BODY MARROW IUNG THYROID ILIW

TOTAL . 1.471E+01 $1.734 \mathrm{E}+01 \quad 1.377 \mathrm{E}+01 \quad 1.362 \mathrm{E}+01 \quad 1.010 \mathrm{E}+01$

INHALATION

WHOLE BODY MARROW IUNG THYROID ILIW

TOTAL $\quad 1.057 E+00 \quad 1.485 E+00 \quad 2.248 E+02 \quad 2.351 E+02 \quad 1.321 E+01$

TOTAL BODY DOSE $=1.927 \mathrm{E}+01$

TOTAL MARROW DOSE $=2.279 \mathrm{E}+01$

TOTAL LUNG DOSE $=2.418 E+02$

TOTAL LLIW DOSE $=2.589 E+01$

TOTAL THYROID DOSE $=2.520 E+02$

CRAC2 PROBABILITY OF EARLY FATALITIES $=\quad 0.000$ 


\title{
$E-24^{\prime}$
}

\author{
DISTANCE $=4.430 \mathrm{E}+04 \mathrm{M}$ \\ WIND VELOCITY $=5.000 E+00 \mathrm{M} / \mathrm{S}$ \\ ATMOSPHERIC STABILITY CLASS D
}

PUFF NUMBER 1

HORIZONTAL DISPERSION COEFFICIENT =

VERTICAL DISPERSION COEFFICIENT =

$4.242 E+03$
$4.394 E+02$

CIOUD SHINE

WHOLE BODY MARROW LUNG THYROID ILIW

\begin{tabular}{lllllll}
\hline TOTAL & $2.415 E+00$ & $2.742 E+00$ & $2.277 E+00$ & $2.277 E+00$ & $1.778 E+00$
\end{tabular}

GROUND SHINE

WHOLE BODY MARROW IUNG THYROID LIIW

\begin{tabular}{lllllll}
\hline TOTAL & $1.072 E+01$ & $1.266 E+01$ & $1.004 E+01$ & $9.988 E+00$ & $7.398 E+00$
\end{tabular}

INHALATION

WHOLE BODY MARROW IUNG THYROID ILIW

$\begin{array}{llllll}\text { TOTAL } & 7.597 E-01 & 1.076 E+00 & 1.636 E+02 & 1.688 E+02 & 9.604 E+00\end{array}$

$\begin{array}{lll}\text { TOTAL BODY DOSE } & =1.390 E+01 \\ \text { TOTAL MARROW DOSE } & =1.647 E+01 \\ \text { TOTAL LUNG DOSE } & =1.759 E+02 \\ \text { TOTAL LIIW DOSE } & =1.878 E+01 \\ \text { TOTAL THYROID DOSE } & =1.810 E+02\end{array}$

CRAC2 PROBABILITY OF EARLY FATALITIES $=\quad 0.000$ 
$\begin{array}{lrl}\text { DISTANCE }= & 5.230 E+04 \quad \mathrm{M} \\ \text { WIND VELOCITY }= & 5.000 \mathrm{E}+00 \quad \mathrm{M} / \mathrm{S}\end{array}$

ATMOSPHERIC STABILITY CLASS D

PUFF NUMBER 1

HORIZONTAL DISPERSION COEFFICIENT = VERTICAI DISPERSION COEFFICIENT =
4. $922 \mathrm{E}+\mathrm{O} 3 \quad \mathrm{M}$ $4.857 \mathrm{E}+02 \quad \mathrm{M}$

CLOUD SHINB

WHOLE BODY MARROW IUNG THYROID ILIW

$\begin{array}{lllllll}\text { TOTAL } & 1.758 \mathrm{E}+00 & 2.005 \mathrm{E}+00 & 1.656 \mathrm{E}+00 & 1.663 \mathrm{E}+00 & 1.293 \mathrm{E}+00\end{array}$

GROUND SHINE

WHOLE BODY MARROW LUNG THYROID ILIW

TOTAL $\quad 8.253 E+00 \quad 9.747 E+00 \quad 7.725 E+00 \quad 7.729 E+00 \quad 5.719 E+00$

INHALATION

WHOLE BODY MARROW IUNG THYROID ILIW

$\begin{array}{llllll} & \\ & 5.759 E-01 & 8.209 E-01 & 1.255 E+02 & 1.276 E+02 & 7.356 E+00\end{array}$

$\begin{array}{lll}\text { TOTAL BODY DOSE } & =1.059 \mathrm{E}+01 \\ \text { TOTAL MARROW DOSE } & =1.257 \mathrm{E}+01 \\ \text { TOTAL LUNG DOSE } & 1.349 \mathrm{E}+02 \\ \text { TOTAI LLIW DOSE } & =1.437 \mathrm{E}+01 \\ \text { TOTAL THYROID DOSE } & =1.370 \mathrm{E}+02\end{array}$

CRAC2 PROBABILITY OF EARLY FATALITIES $=\quad 0.000$ 


\section{$E-26$}

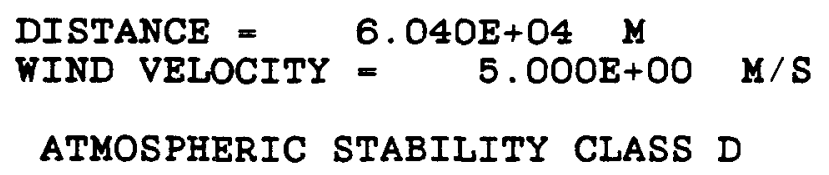

CRAC2 PROBABILITY OF EARLY FATALITIES $=\quad 0.000$ 


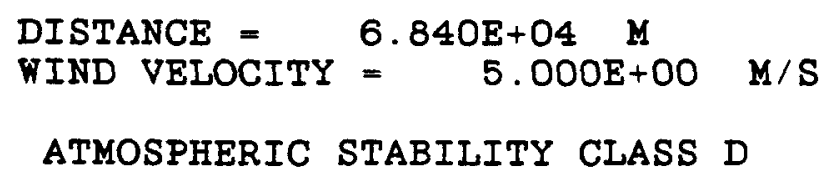




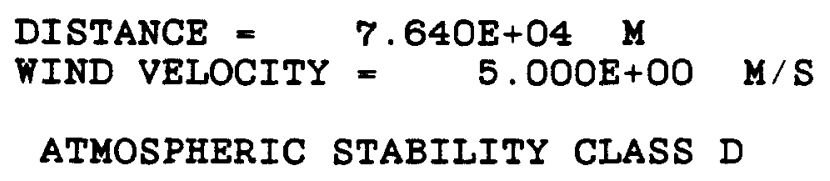




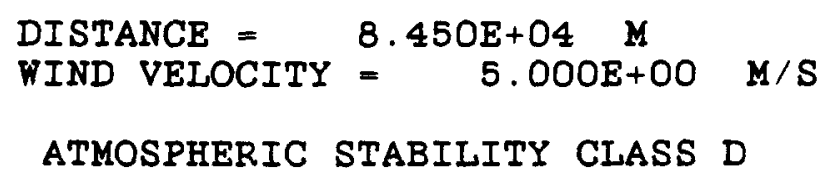

CRAC2 PROBABILITY OF EARLY FATALITIES $=\quad 0.000$ 


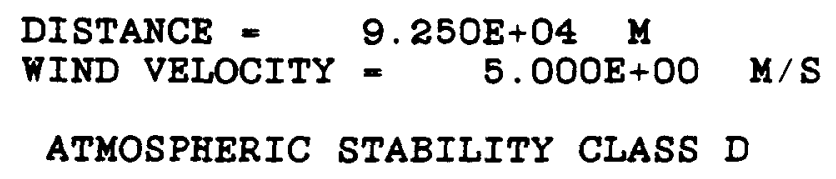




\section{$E-31$}

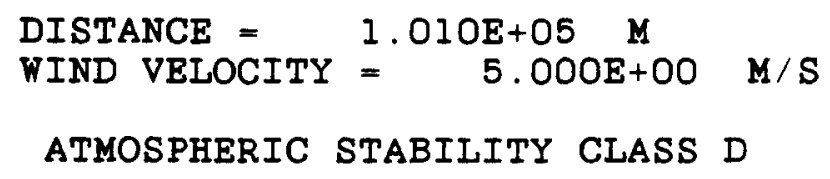




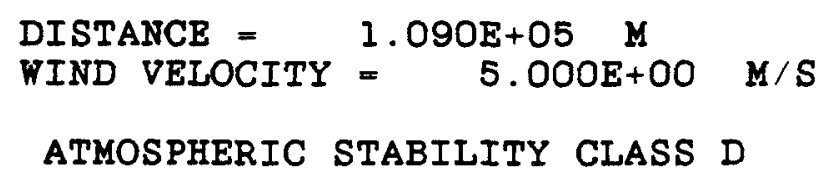




\section{$E-33$}

CRAC CONVERSION FACTORS

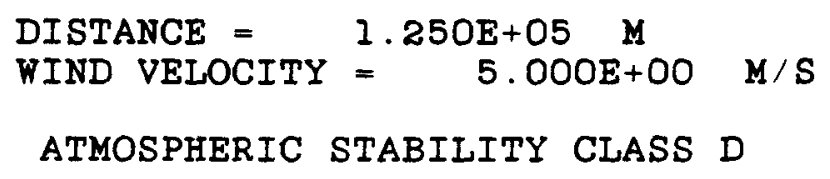

HORIZONTAL DISPERSION COEFFICIENT = VERTICAI DISPERSION COEFFICIENT =

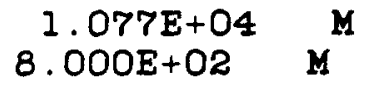

CLOUD SHINE

WHOLE BODY MARROW IUNG THYROID ILIW
GROUND SHINE

WHOLE BODY MARROW LUNG THYROID LIIW
INHALATION

WHOLE BODY MARROW IUNG THYROID ILIW 


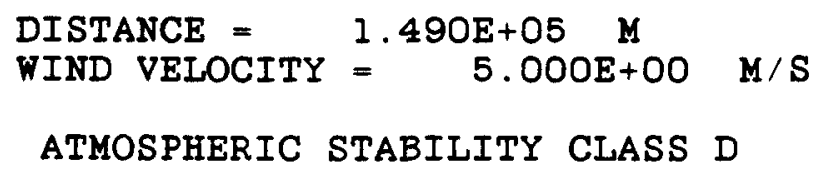

CLOUD SHINE

WHOLE BODY MARROW LUNG THYROID ILIW

\begin{tabular}{lllllll}
\hline TOTAL & $2.202 E-01$ & $2.620 E-01$ & $2.063 E-01$ & $2.122 E-01$ & $1.580 E-01$
\end{tabular}

GROUND SHINE

WHOLE BODY MARROW LUNG THYROID LIIW

\begin{tabular}{llllll}
\hline TOTAL & $1.858 E+00$ & $2.209 E+00$ & $1.736 E+00$ & $1.834 E+00$ & $1.348 E+00$
\end{tabular}

INHALATION

WHOLE BODY MARROW LUNG THYROID LLIW

$\begin{array}{lllllll}\text { TOTAL } & 9.367 E-02 & 1.423 E-01 & 2.269 E+01 & 1.984 E+01 & 1.313 E+00\end{array}$

$\begin{array}{lll}\text { TOTAL BODY DOSE } & =2.171 E+00 \\ \text { TOTAL MARROW DOSE } & =2.613 E+00 \\ \text { TOTAL LUNG DOSE } & =2.463 E+01 \\ \text { TOTAL ILIW DOSE } & =2.819 E+00 \\ \text { TOTAL THYROID DOSE } & =2.188 E+01\end{array}$




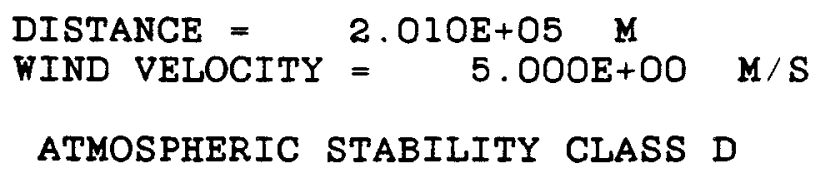


CRAC2 PROBABILITY OF EARLY FATALITIES $=\quad 0.000$

CRAC CO

DISTANCE $=\quad 2.820 E+05 \quad M$
WIND VELOCITY $=5.000 E+00 \quad \mathrm{M} / \mathrm{S}$
ATMOSPHERIC STABIIITY CLASS D

PUFF NUMBER 1

HORIZONTAL DISPERSION COEFFICIENT $=$
VERTICAL DISPERSION COEFFICIENT $=$
$2.241 \mathrm{E}+04$

CLOUD SHINE
WHOLE BODY MARROW IUNG THYROID LIIW

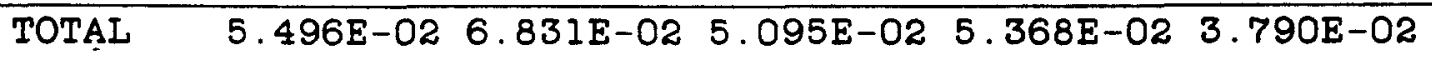

GROUND SHINE

WHOLE BODY MARROW IUNG THYROID LLIW

TOTAL $1.830 \mathrm{E}+00 \quad 2.188 \mathrm{E}+00 \quad 1.708 \mathrm{E}+00 \quad 1.901 \mathrm{E}+00 \quad 1.390 \mathrm{E}+00$

INHALATION

WHOLE BODY MARROW LUNG THYROID LLIW

TOTAL $2.617 E-02 \quad 4.231 E-02 \quad 7.008 E+00 \quad 5.151 E+00 \quad 3.988 E-01$

$\begin{array}{lll}\text { TOTAL BODY DOSE } & =1.911 \mathrm{E}+00 \\ \text { TOTAL MARROW DOSE } & =2.298 \mathrm{E}+00 \\ \text { TOTAL LUNG DOSE } & =8.767 \mathrm{E}+00 \\ \text { TOTAL LLIW DOSE } & =1.827 \mathrm{E}+00 \\ \text { TOTAL THYROID DOSE } & =7.106 \mathrm{E}+00\end{array}$


CRAC2 PROBABIIITY OF EARLY FATALITIES $=\quad 0.000$

\title{
CRAC CONVERSION FACTORS
}

\author{
DISTANCE $=4.430 E+05 \quad \mathrm{M}$ \\ WIND VELOCITY $=5.00 O E+00 \mathrm{M} / \mathrm{S}$ \\ ATMOSPHERIC STABILITY CLASS D
}

PUFF NUMBER 1

HORIZONTAL DISPERSION COEFFICIENT $=$
VERTICAL DISPERSION COEFFICIENT $=$
$8.000 \mathrm{~B}+02$ $\mathrm{M}$

\section{CLOUD SHINE}

WHOLE BODY MARROW IUNG THYROID LIIW

\begin{tabular}{|c|c|c|c|c|}
\hline \multirow[t]{3}{*}{ TOTAL } & $2.354 \mathrm{E}-02$ & $993 E-02$ & $2.167 \mathrm{E}-02 \quad 2.321 \mathrm{E}-02$ & $.586 \mathrm{E}-02$ \\
\hline & - & & \multicolumn{2}{|l|}{ GROUND SHINE } \\
\hline & WHOLE BODY & MARROW & THYROID & LLIW \\
\hline OTAL & $1.330 E-01$ & $35 E-01$ & $1.240 E-01 \quad 1.438 E-01$ & 0501 \\
\hline
\end{tabular}

INHALATION

WHOLE BODY MARROW IUNG THYROID LLIW

TOTAL $1.222 E-02 \quad 2.085 E-02 \quad 3.582 E+00 \quad 2.216 E+00 \quad 2.001 E-01$

$\begin{array}{lll}\text { TOTAL BODY DOSE } & 1.688 E-01 \\ \text { TOTAL MARROW DOSE } & =2.103 \mathrm{E}-01 \\ \text { TOTAL LUNG DOSE } & =3.727 \mathrm{I}+00 \\ \text { TOTAL LIIW DOSE } & =3.210 \mathrm{E}-01 \\ \text { TOTAL THYROID DOSE } & =2.383 \mathrm{E}+00\end{array}$


CRAC2 PROBABILITY OF EARLY FATALITIES $=\quad 0.000$

CRAC CONVERSION FACTORS

\begin{abstract}
DISTANCE $=6.840 E+05 \mathrm{M}$
WIND VELOCITY $=5.000 E+00 \mathrm{M} / \mathrm{S}$

ATMOSPHERIC STABILITY CLASS D
\end{abstract}

PUFF NUMBER 1

HORIZONTAL DISPERSION COEFFICIENT = VERTICAL DISPERSION COEFFICIENT =
$4.985 E+04 \quad M$ $8.000 E+02 \quad M$

CLOUD SHINE

WHOLE BODY MARROW LUNG THYROID LLIW

\begin{tabular}{llllll}
\hline TOTAL & $7.020 \mathrm{E}-03$ & $9.346 \mathrm{E}-03$ & $6.343 \mathrm{E}-03$ & $7.075 \mathrm{E}-03$ & $4.522 \mathrm{E}-03$
\end{tabular}

GROUND SHINE

WHOLE BODY MARROW LUNG THYROID LIIW

TOTAL $\quad 3.662 E-02 \quad 4.394 E-02 \quad 3.410 E-02 \quad 4.109 E-02 \quad 2.999 E-02$

INHALATION

WHOLE BODY MARROW LUNG THYROID LLIW

TOTAL $3.469 \mathrm{E}-03 \quad 6.291 \mathrm{E}-03 \quad 1.122 \mathrm{E}+00 \quad 5.639 \mathrm{E}-01 \quad 6.111 \mathrm{E}-02$

$\begin{array}{lll}\text { TOTAL BODY DOSE } & 4.711 E-02 \\ \text { TOTAL MARROW DOSE } & =5.957 \mathrm{E}-02 \\ \text { TOTAL IUNG DOSE } & 1.162 \mathrm{E}+00 \\ \text { TOTAI ILIW DOSE } & 9.562 \mathrm{E}-02 \\ \text { TOTAL THYROID DOSE } & =6.121 \mathrm{E}-01\end{array}$


$\mathrm{F}-1$

APPENDIX F

Results for the Sensitivity Study to Source

Terms: Doses and Probabilities of Early Injuries for Sampled Weather Conditions DI and D5. 


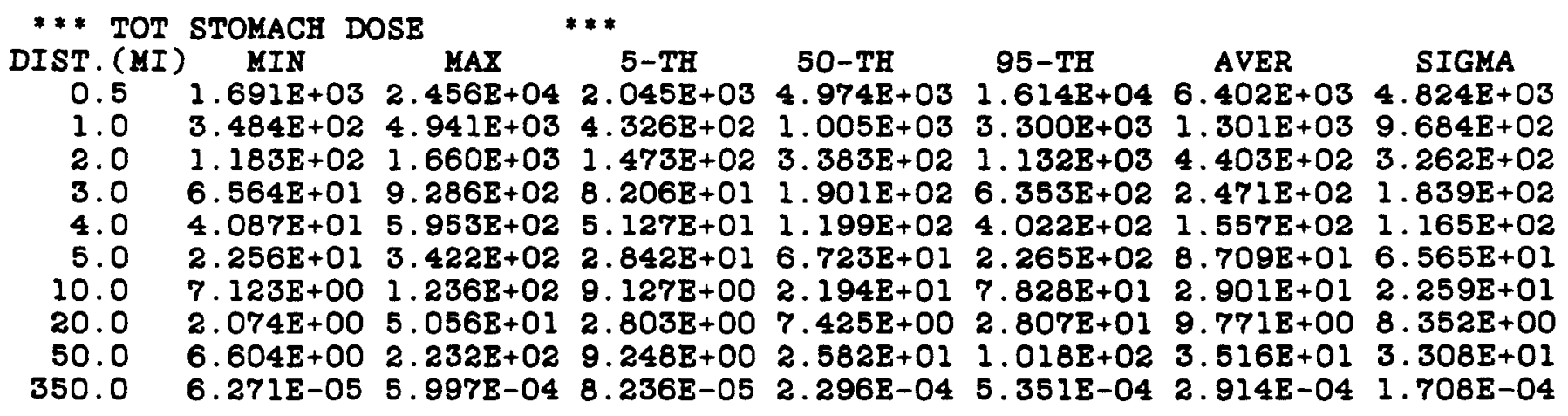

\begin{tabular}{|c|c|c|c|c|c|c|c|}
\hline & & & & & & & \\
\hline $\begin{array}{c}\text { IST. (MI) } \\
0.5 \\
1.0 \\
2.0 \\
3.0 \\
4.0 \\
5.0 \\
10.0 \\
20.0 \\
50.0 \\
350.0\end{array}$ & $\begin{array}{c}M I N \\
1.740 E+03 \\
3.614 E+02 \\
1.235 E+02 \\
6.886 E+01 \\
4.303 E+01 \\
2.386 E+01 \\
7.617 E+00 \\
2.267 E+00 \\
7.306 E+00 \\
5.248 E-05\end{array}$ & $\begin{array}{c}\text { MAZ } \\
2.842 E+04 \\
5.746 E+03 \\
1.939 E+03 \\
1.089 E+03 \\
6.933 E+02 \\
3.976 E+02 \\
1.423 E+02 \\
5.667 E+01 \\
2.456 E+02 \\
5.071 E-04\end{array}$ & $\begin{array}{c}5-\mathrm{TH} \\
2.178 \mathrm{E}+03 \\
4.531 \mathrm{E}+02 \\
1.551 \mathrm{E}+02 \\
8.684 \mathrm{E}+01 \\
5.451 \mathrm{E}+01 \\
3.037 \mathrm{E}+01 \\
9.729 \mathrm{E}+00 \\
3.064 \mathrm{E}+00 \\
1.021 \mathrm{E}+01 \\
7.091 \mathrm{E}-05\end{array}$ & $\begin{array}{c}50-\mathrm{TH} \\
5.332 \mathrm{E}+03 \\
1.092 \mathrm{O}+03 \\
3.725 \mathrm{E}+02 \\
2.088 \mathrm{O}+02 \\
1.312 \mathrm{E}+02 \\
7.307 \mathrm{E}+01 \\
2.419 \mathrm{E}+01 \\
8.268 \mathrm{E}+00 \\
2.857 \mathrm{E}+01 \\
1.914 \mathrm{E}-04\end{array}$ & $\begin{array}{c}\text { 95-TH } \\
1.815 E+04 \\
3.678 E+03 \\
1.244 E+03 \\
7.016 E+02 \\
4.456 E+02 \\
2.513 E+02 \\
8.559 E+01 \\
3.084 E+01 \\
1.120 E+02 \\
4.401 E-04\end{array}$ & $\begin{array}{c}\text { AVER } \\
6.935 E+03 \\
1.416 E+03 \\
4.815 E+02 \\
2.712 E+02 \\
1.713 E+02 \\
9.611 E+01 \\
3.218 E+01 \\
1.086 E+01 \\
3.882 E+01 \\
2.408 E-04\end{array}$ & $\begin{array}{c}\text { SIGMA } \\
5.335 E+03 \\
1.077 \mathrm{E}+03 \\
3.645 \mathrm{E}+02 \\
2.063 \mathrm{E}+02 \\
1.311 \mathrm{O}+02 \\
7.403 \mathrm{E}+01 \\
2.551 \mathrm{E}+01 \\
9.334 \mathrm{O}+00 \\
3.644 \mathrm{E}+01 \\
1.396 \mathrm{E}-04\end{array}$ \\
\hline 01 & LUNG & DSE & & & & & \\
\hline $\begin{array}{c}\text { IST. (MI) } \\
0.5 \\
1.0 \\
2.0 \\
3.0 \\
4.0 \\
5.0 \\
10.0 \\
20.0 \\
50.0 \\
350.0\end{array}$ & $\begin{array}{c}\mathrm{MIN} \\
2.526 \mathrm{E}+\mathrm{C} \\
5.182 \mathrm{E}+\mathrm{C} \\
1.753 \mathrm{E}+\mathrm{C} \\
9.739 \mathrm{E}+\mathrm{C} \\
6.062 \mathrm{E}+\mathrm{C} \\
3.327 \mathrm{E}+\mathrm{C} \\
1.024 \mathrm{E}+\mathrm{C} \\
2.658 \mathrm{E}+\mathrm{C} \\
7.272 \mathrm{E}+\mathrm{C} \\
8.438 \mathrm{E}-\mathrm{C}\end{array}$ & $\begin{array}{c}\text { MAX } \\
3.977 E+04 \\
7.952 \mathrm{~B}+03 \\
2.652 \mathrm{E}+03 \\
1.480 \mathrm{~B}+03 \\
9.267 \mathrm{E}+02 \\
5.104 \mathrm{~B}+02 \\
1.615 \mathrm{E}+02 \\
5.935 \mathrm{E}+01 \\
2.435 \mathrm{~B}+02 \\
8.176 \mathrm{E}-04\end{array}$ & $\begin{array}{c}5-\mathrm{TH} \\
3.226 \mathrm{E}+03 \\
6.555 \mathrm{O}+02 \\
2.213 \mathrm{O}+02 \\
1.241 \mathrm{E}+02 \\
7.776 \mathrm{O}+01 \\
4.291 \mathrm{O}+01 \\
1.338 \mathrm{O}+01 \\
3.554 \mathrm{O}+00 \\
1.029 \mathrm{E}+01 \\
1.135 \mathrm{E}-04\end{array}$ & $\begin{array}{c}50-\mathrm{TH} \\
7.690 \mathrm{E}+03 \\
1.555 \mathrm{E}+03 \\
5.229 \mathrm{E}+02 \\
2.954 \mathrm{E}+02 \\
1.861 \mathrm{E}+02 \\
1.034 \mathrm{E}+02 \\
3.218 \mathrm{E}+01 \\
9.308 \mathrm{E}+00 \\
2.842 \mathrm{E}+01 \\
3.095 \mathrm{E}-04\end{array}$ & $\begin{array}{c}95-\mathrm{TH} \\
2.340 \mathrm{E}+04 \\
4.755 \mathrm{E}+03 \\
1.619 \mathrm{E}+03 \\
9.215 \mathrm{E}+02 \\
5.875 \mathrm{E}+02 \\
3.314 \mathrm{E}+02 \\
1.064 \mathrm{E}+02 \\
3.325 \mathrm{E}+01 \\
1.112 \mathrm{E}+02 \\
7.207 \mathrm{E}-04\end{array}$ & $\begin{array}{c}\text { AVER } \\
9.883 E+03 \\
1.991 E+03 \\
6.684 \mathrm{E}+02 \\
3.740 \mathrm{O}+02 \\
2.347 \mathrm{E}+02 \\
1.298 \mathrm{O}+02 \\
4.149 \mathrm{E}+01 \\
1.216 \mathrm{O}+01 \\
3.857 \mathrm{O}+01 \\
3.933 \mathrm{E}-04\end{array}$ & $\begin{array}{c}\text { SIGMA } \\
7.168 E+03 \\
1.431 E+03 \\
4.783 E+02 \\
2.682 E+02 \\
1.689 E+02 \\
9.387 E+01 \\
3.079 E+01 \\
9.990 E+00 \\
3.611 E+01 \\
2.299 E-04\end{array}$ \\
\hline
\end{tabular}

\begin{tabular}{|c|c|c|c|c|c|c|c|}
\hline $\begin{array}{l}\text { ST. (MI) } \\
0.5 \\
1.0 \\
2.0 \\
3.0 \\
4.0 \\
5.0 \\
10.0\end{array}$ & $\begin{array}{c}M I N \\
2.007 E+04 \\
4.053 E+03 \\
1.358 E+03 \\
7.612 E+02 \\
4.766 E+02 \\
2.591 E+02 \\
7.585 E+01\end{array}$ & $\begin{array}{c}\text { MAX } \\
4.493 \mathrm{E}+05 \\
8.939 \mathrm{E}+04 \\
2.959 \mathrm{E}+04 \\
1.651 \mathrm{E}+04 \\
1.030 \mathrm{E}+04 \\
5.559 \mathrm{E}+03 \\
1.599 \mathrm{O}+03\end{array}$ & $\begin{array}{c}5-\mathrm{TH} \\
2.928 \mathrm{E}+04 \\
5.851 \mathrm{E}+03 \\
1.944 \mathrm{E}+03 \\
1.086 \mathrm{E}+03 \\
6.781 \mathrm{E}+02 \\
3.668 \mathrm{O}+02 \\
1.061 \mathrm{E}+02\end{array}$ & $\begin{array}{c}50-T E \\
6.544 E+04 \\
1.306 E+04 \\
4.332 E+03 \\
2.419 E+03 \\
1.510 E+03 \\
8.162 E+02 \\
2.356 E+02\end{array}$ & $\begin{array}{c}95-T H \\
2.68 I E+05 \\
5.343 E+04 \\
1.772 E+04 \\
9.903 E+03 \\
6.195 E+03 \\
3.367 E+03 \\
9.870 E+02\end{array}$ & $\begin{array}{c}\text { AVER } \\
9.502 E+04 \\
1.898 E+04 \\
6.308 E+03 \\
3.530 E+03 \\
2.208 E+03 \\
1.197 E+03 \\
3.486 E+02\end{array}$ & $\begin{array}{c}\text { SIGMA } \\
8.018 E+04 \\
1.599 E+04 \\
5.310 E+03 \\
2.972 E+03 \\
1.858 E+03 \\
1.007 E+03 \\
2.926 E+02\end{array}$ \\
\hline
\end{tabular}


20.0

50.0

350.0
$1.401 \mathrm{E}+012.666 \mathrm{E}+021.828 \mathrm{E}+01$

$1.281 \mathrm{E}+013.079 \mathrm{E}+021.648 \mathrm{E}+01$

$1.455 \mathrm{E}-04 \quad 1.238 \mathrm{E}-03 \quad 1.854 \mathrm{E}-04$
$4.278 E+011.774 E+02$

$4.623 \mathrm{E}+011.784 \mathrm{E}+02$

$4.584 E-04 \quad 1.048 E-03$
$6.198 E+01$

$6.025 \mathrm{E}+01$

5. 64OE-04
$5.107 E+01$

$5.203 E+01$

$3.063 \mathrm{E}-04$

$\begin{array}{cccccccc}\text { *** TOT SMALI INT. DOSE } & * * * & & & \\ \text { DIST. (MI) } & \text { MIN } & \text { MAX } & 5-T H & 50-T H & 95-T H & \text { AVER } & \text { SIGMA } \\ 0.5 & 1.462 E+03 & 2.207 E+04 & 1.809 E+03 & 4.340 E+03 & 1.468 E+04 & 5.662 E+03 & 4.295 E+03 \\ 1.0 & 3.039 E+02 & 4.462 E+03 & 3.802 E+02 & 8.896 E+02 & 2.974 E+03 & 1.157 E+03 & 8.672 E+02 \\ 2.0 & 1.039 E+02 & 1.525 E+03 & 1.303 E+02 & 3.041 E+02 & 1.012 E+03 & 3.934 E+02 & 2.937 E+02 \\ 3.0 & 5.790 E+01 & 8.781 E+02 & 7.285 E+01 & 1.708 E+02 & 5.732 E+02 & 2.215 E+02 & 1.663 E+02 \\ 4.0 & 3.617 E+01 & 5.665 E+02 & 4.566 E+01 & 1.076 E+02 & 3.638 E+02 & 1.399 E+02 & 1.057 E+02 \\ 5.0 & 2.004 E+01 & 3.256 E+02 & 2.539 E+01 & 6.008 E+01 & 2.051 E+02 & 7.847 E+01 & 5.979 E+01 \\ 10.0 & 6.375 E+00 & 1.174 E+02 & 8.215 E+00 & 1.981 E+01 & 7.191 E+01 & 2.628 E+01 & 2.0715+01 \\ 20.0 & 1.873 E+00 & 4.746 E+01 & 2.539 E+00 & 6.756 E+00 & 2.549 E+01 & 8.898 E+00 & 7.693 E+00 \\ 50.0 & 5.973 E+00 & 2.070 E+02 & 8.358 E+00 & 2.332 E+01 & 9.223 E+01 & 3.199 E+01 & 3.040 E+01 \\ 350.0 & 5.453 E-05 & 5.243 E-04 & 7.220 E-05 & 1.994 E-04 & 4.644 E-04 & 2.532 E-04 & 1.481 E-04\end{array}$

\begin{tabular}{|c|c|c|c|c|c|c|c|}
\hline & & & & & & & \\
\hline $\begin{array}{c}\text { IST.(MI) } \\
0.5 \\
1.0 \\
2.0 \\
3.0 \\
4.0 \\
5.0 \\
10.0 \\
20.0 \\
50.0 \\
350.0\end{array}$ & $\begin{array}{c}M I N \\
1.671 E+03 \\
3.509 E+02 \\
1.209 E+02 \\
6.765 E+01 \\
4.240 E+01 \\
2.356 E+01 \\
7.506 E+00 \\
2.190 E+00 \\
6.527 E+00 \\
5.943 E-05\end{array}$ & $\begin{array}{c}\text { MAX } \\
3.342 E+04 \\
6.825 E+03 \\
2.338 E+03 \\
1.342 E+03 \\
8.618 E+02 \\
4.894 E+02 \\
1.684 E+02 \\
5.887 E+01 \\
2.243 E+02 \\
5.931 E-04\end{array}$ & $\begin{array}{l}5-\mathrm{TH} \\
2.303 \mathrm{E}+03 \\
4.796 \mathrm{E}+02 \\
1.629 \mathrm{E}+02 \\
9.147 \mathrm{E}+01 \\
5.759 \mathrm{O}+01 \\
3.216 \mathrm{E}+01 \\
1.026 \mathrm{E}+01 \\
2.961 \mathrm{E}+00 \\
9.184 \mathrm{E}+00 \\
8.305 \mathrm{E}-05\end{array}$ & $\begin{array}{c}50-\mathrm{TH} \\
5.771 \mathrm{E}+03 \\
1.183 \mathrm{E}+03 \\
4.047 \mathrm{E}+02 \\
2.279 \mathrm{E}+02 \\
1.437 \mathrm{E}+02 \\
7.998 \mathrm{E}+01 \\
2.589 \mathrm{E}+01 \\
7.874 \mathrm{E}+00 \\
2.542 \mathrm{E}+01 \\
2.153 \mathrm{E}-04\end{array}$ & $\begin{array}{c}95-\mathrm{TH} \\
1.906 \mathrm{E}+04 \\
3.885 \mathrm{E}+03 \\
1.322 \mathrm{E}+03 \\
7.368 \mathrm{O}+02 \\
4.596 \mathrm{E}+02 \\
2.538 \mathrm{E}+02 \\
8.572 \mathrm{E}+01 \\
2.935 \mathrm{E}+01 \\
1.003 \mathrm{E}+02 \\
5.027 \mathrm{E}-04\end{array}$ & $\begin{array}{c}\text { AVER } \\
7.385 E+03 \\
1.505 E+03 \\
5.107 E+02 \\
2.878 E+02 \\
1.818 E+02 \\
1.016 E+02 \\
3.339 E+O 1 \\
1.05 O E+O 1 \\
3.485 E+O 1 \\
2.756 E-04\end{array}$ & $\begin{array}{c}\text { SIGMA } \\
5.894 \mathrm{E}+03 \\
1.193 \mathrm{E}+03 \\
4.043 \mathrm{O}+02 \\
2.296 \mathrm{E}+02 \\
1.461 \mathrm{O}+02 \\
8.223 \mathrm{O}+01 \\
2.771 \mathrm{E}+01 \\
9.266 \mathrm{E}+00 \\
3.301 \mathrm{E}+01 \\
1.597 \mathrm{E}-04\end{array}$ \\
\hline
\end{tabular}

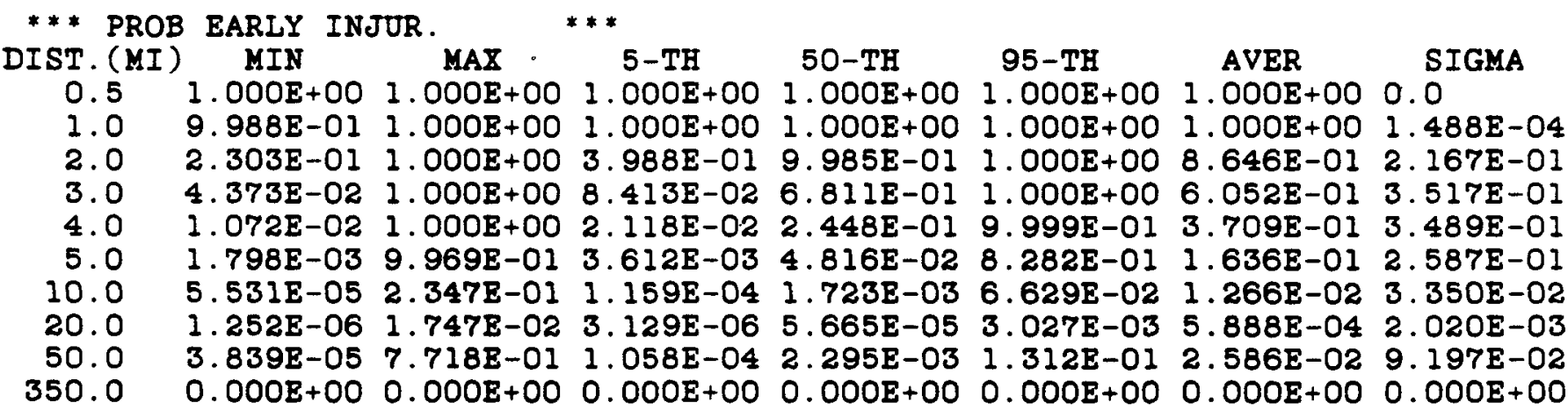

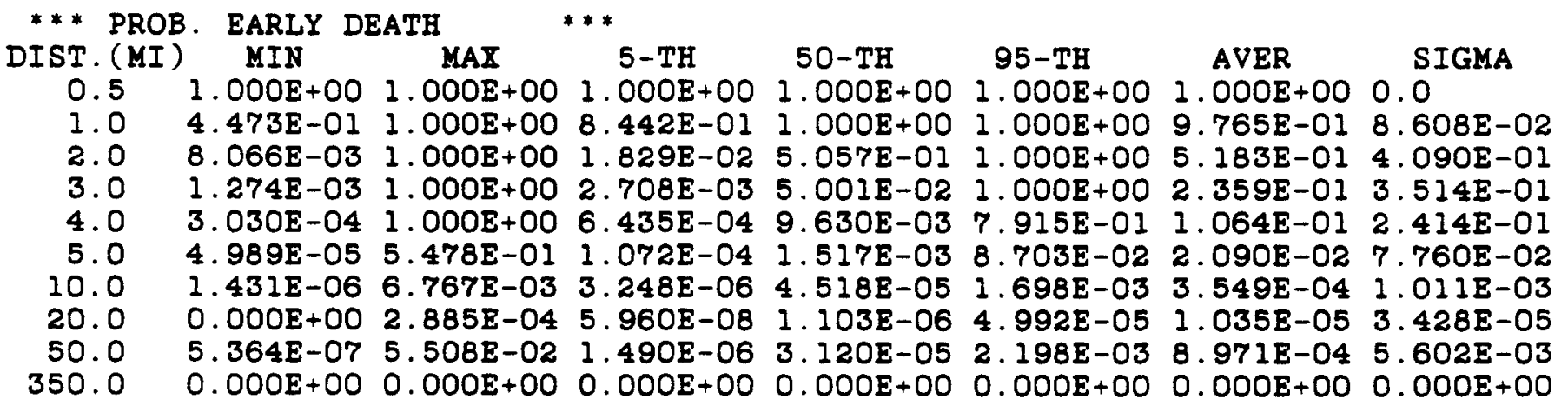




\begin{tabular}{|c|c|c|c|c|c|c|c|}
\hline $\begin{array}{c}* * * \text { TOT } \\
\text { DIST. (MI } \\
0.5 \\
1.0 \\
2.0 \\
3.0 \\
4.0 \\
5.0 \\
10.0 \\
20.0 \\
50.0 \\
350.0\end{array}$ & $\begin{array}{l}\text { I) } M I N \\
1.841 E+02 \\
4.966 E+01 \\
2.016 E+01 \\
5.677 E+00 \\
3.084 E+00 \\
4.887 E+00 \\
1.845 E+00 \\
4.178 E-01 \\
1.229 E-01 \\
1.193 E-03\end{array}$ & $\begin{array}{l}\text { MAX } \\
2.317 \mathrm{E}+03 \\
6.049 \mathrm{E}+02 \\
2.423 \mathrm{E}+02 \\
1.472 \mathrm{E}+02 \\
9.904 \mathrm{E}+01 \\
5.980 \mathrm{O}+01 \\
2.198 \mathrm{E}+01 \\
5.061 \mathrm{E}+00 \\
1.633 \mathrm{E}+00 \\
3.200 \mathrm{E}-02\end{array}$ & $\begin{array}{l}5-\mathrm{TH} \\
2.197 \mathrm{E}+02 \\
5.937 \mathrm{E}+01 \\
2.351 \mathrm{E}+01 \\
1.435 \mathrm{E}+01 \\
9.600 \mathrm{~B}+00 \\
5.855 \mathrm{E}+00 \\
2.232 \mathrm{E}+00 \\
5.058 \mathrm{E}-01 \\
1.544 \mathrm{~B}-01 \\
1.538 \mathrm{E}-03\end{array}$ & $\begin{array}{c}\text { 50-TH } \\
4.871 E+02 \\
1.350 E+02 \\
5.500 E+01 \\
3.318 E+01 \\
2.243 E+01 \\
1.358 E+01 \\
5.006 E+00 \\
1.126 E+00 \\
3.388 E-01 \\
4.097 E-03\end{array}$ & $\begin{array}{c}95-\mathrm{TH} \\
1.450 \mathrm{E}+03 \\
3.854 \mathrm{E}+02 \\
1.557 \mathrm{E}+02 \\
9.476 \mathrm{E}+01 \\
6.379 \mathrm{E}+01 \\
3.846 \mathrm{E}+01 \\
1.405 \mathrm{E}+01 \\
3.198 \mathrm{E}+00 \\
1.133 \mathrm{E}+00 \\
1.445 \mathrm{E}-02\end{array}$ & $\begin{array}{c}\text { AVER } \\
6.079 E+02 \\
1.617 E+02 \\
6.471 E+01 \\
3.911 E+01 \\
2.632 E+01 \\
1.598 E+01 \\
5.945 E+00 \\
1.373 E+00 \\
4.381 E-01 \\
5.485 E-03\end{array}$ & $\begin{array}{c}\text { SIGMA } \\
4.264 E+02 \\
1.097 E+02 \\
4.31 I E+01 \\
2.629 E+01 \\
1.773 E+01 \\
1.063 E+01 \\
3.892 E+00 \\
9.186 E-01 \\
3.13 I E-01 \\
4.776 E-03\end{array}$ \\
\hline TO & $\mathrm{MA}$ & $D$ & & & & & \\
\hline $\begin{array}{c}\text { DIST. (MI } \\
0.5 \\
1.0 \\
2.0 \\
3.0 \\
4.0 \\
5.0 \\
10.0 \\
20.0 \\
50.0 \\
350.0\end{array}$ & $\begin{array}{l}\text { [) } \mathrm{MIN} \\
1.814 \mathrm{E}+02 \\
5.074 \mathrm{E}+01 \\
2.070 \mathrm{O}+01 \\
5.868 \mathrm{E}+00 \\
3.067 \mathrm{E}+00 \\
5.076 \mathrm{E}+00 \\
1.916 \mathrm{E}+00 \\
4.387 \mathrm{E}-01 \\
1.275 \mathrm{E}-01 \\
1.266 \mathrm{E}-03\end{array}$ & $\begin{array}{c}\text { MAX } \\
2.763 E+03 \\
7.186 E+02 \\
2.876 E+02 \\
1.749 E+02 \\
1.178 E+02 \\
7.126 E+01 \\
2.635 E+01 \\
6.181 E+00 \\
2.056 E+00 \\
3.861 E-02\end{array}$ & $\begin{array}{c}5-\mathrm{TH} \\
2.283 \mathrm{E}+02 \\
6.279 \mathrm{E}+01 \\
2.465 \mathrm{E}+01 \\
1.508 \mathrm{E}+01 \\
9.887 \mathrm{E}+0 \mathrm{O} \\
6.161 \mathrm{E}+00 \\
2.354 \mathrm{E}+00 \\
5.344 \mathrm{E}-01 \\
1.607 \mathrm{E}-01 \\
1.670 \mathrm{E}-03\end{array}$ & $\begin{array}{c}50-\mathrm{TH} \\
5.155 \mathrm{E}+02 \\
1.397 \mathrm{E}+02 \\
5.714 \mathrm{E}+01 \\
3.499 \mathrm{E}+01 \\
2.373 \mathrm{E}+01 \\
1.435 \mathrm{E}+01 \\
5.306 \mathrm{E}+00 \\
1.206 \mathrm{E}+00 \\
3.874 \mathrm{E}-01 \\
4.817 \mathrm{E}-03\end{array}$ & $\begin{array}{c}95-\mathrm{TH} \\
1.603 \mathrm{E}+03 \\
4.167 \mathrm{E}+02 \\
1.668 \mathrm{E}+02 \\
1.016 \mathrm{E}+02 \\
6.846 \mathrm{E}+01 \\
4.149 \mathrm{E}+01 \\
1.543 \mathrm{E}+01 \\
3.716 \mathrm{E}+00 \\
1.275 \mathrm{E}+00 \\
1.635 \mathrm{E}-02\end{array}$ & $\begin{array}{c}\text { AVER } \\
6.476 E+02 \\
1.729 E+02 \\
6.940 E+01 \\
4.204 \mathrm{E}+01 \\
2.835 \mathrm{O}+01 \\
1.724 \mathrm{E}+01 \\
6.438 \mathrm{O}+00 \\
1.505 E+00 \\
4.887 \mathrm{E}-01 \\
6.509 \mathrm{E}-03\end{array}$ & $\begin{array}{c}\text { SIGMA } \\
4.692 E+02 \\
1.204 E+02 \\
4.756 E+01 \\
2.906 E+01 \\
1.961 E+01 \\
1.180 E+01 \\
4.351 E+00 \\
1.046 E+00 \\
3.649 E-01 \\
5.917 E-03\end{array}$ \\
\hline
\end{tabular}

\begin{tabular}{|c|c|c|c|c|c|c|c|}
\hline * TOT & . & & & & & & \\
\hline $\begin{array}{c}\text { DIST. (MI } \\
0.5 \\
1.0 \\
2.0 \\
3.0 \\
4.0 \\
5.0 \\
10.0 \\
20.0 \\
50.0 \\
350.0\end{array}$ & $\begin{array}{lc}\text { I) } & M I N \\
3.156 E+02 \\
8.533 E+01 \\
3.481 E+01 \\
1.048 E+01 \\
5.292 E+00 \\
8.700 E+00 \\
3.187 E+00 \\
7.043 E-01 \\
2.079 E-01 \\
2.185 E-03\end{array}$ & $\begin{array}{c}\text { MAZ } \\
4.674 E+03 \\
1.181 E+03 \\
4.656 E+02 \\
2.815 E+02 \\
1.886 E+02 \\
1.138 E+02 \\
4.178 E+01 \\
9.690 E+00 \\
3.191 E+00 \\
5.528 E-02\end{array}$ & $\begin{array}{c}\text { 5-TH } \\
3.823 E+02 \\
1.016 E+02 \\
3.919 E+01 \\
2.369 E+01 \\
1.572 E+O 1 \\
9.603 E+0 O \\
3.668 E+0 O \\
8.335 E-01 \\
2.644 E-01 \\
3.227 E-03\end{array}$ & $\begin{array}{c}50-\mathrm{TH} \\
9.124 \mathrm{E}+02 \\
2.381 \mathrm{O}+02 \\
9.544 \mathrm{E}+01 \\
5.765 \mathrm{O}+01 \\
3.866 \mathrm{E}+01 \\
2.329 \mathrm{O}+01 \\
8.566 \mathrm{O}+00 \\
1.955 \mathrm{O}+00 \\
6.317 \mathrm{E}-01 \\
8.252 \mathrm{E}-03\end{array}$ & $\begin{array}{c}95-\mathrm{TH} \\
2.697 \mathrm{E}+03 \\
6.878 \mathrm{E}+02 \\
2.722 \mathrm{E}+02 \\
1.647 \mathrm{E}+02 \\
1.104 \mathrm{E}+02 \\
6.656 \mathrm{O}+01 \\
2.435 \mathrm{E}+01 \\
5.621 \mathrm{E}+00 \\
1.958 \mathrm{E}+00 \\
2.631 \mathrm{E}-02\end{array}$ & $\begin{array}{c}\text { AVER } \\
1.143 E+03 \\
2.928 E+02 \\
1.150 E+02 \\
6.910 E+01 \\
4.630 E+01 \\
2.807 E+01 \\
1.042 E+01 \\
2.425 E+00 \\
7.930 E-01 \\
1.071 E-02\end{array}$ & $\begin{array}{c}\text { SIGMA } \\
7.966 E+02 \\
2.001 E+02 \\
7.781 E+01 \\
4.728 E+01 \\
3.176 E+01 \\
1.904 E+01 \\
6.955 E+00 \\
1.635 E+00 \\
5.549 E-01 \\
8.826 E-03\end{array}$ \\
\hline * * * TO & THYR & LUS & * & & & & \\
\hline $\begin{array}{c}\text { DIST. (MI } \\
0.5 \\
1.0 \\
2.0 \\
3.0 \\
4.0 \\
5.0 \\
10.0\end{array}$ & $\begin{array}{l}\text { [) } M I N \\
3.163 \mathrm{E}+03 \\
7.886 \mathrm{E}+02 \\
3.091 \mathrm{E}+02 \\
1.365 \mathrm{E}+02 \\
9.169 \mathrm{E}+01 \\
7.577 \mathrm{E}+01 \\
2.800 \mathrm{O}+01\end{array}$ & $\begin{array}{c}\text { MAX } \\
7.171 E+04 \\
1.752 E+04 \\
6.787 E+03 \\
4.084 E+03 \\
2.729 E+03 \\
1.646 E+03 \\
6.066 E+02\end{array}$ & $\begin{array}{c}5-T H \\
4.622 \mathrm{E}+03 \\
1.141 \mathrm{E}+03 \\
4.445 \mathrm{E}+02 \\
2.593 \mathrm{E}+02 \\
1.700 \mathrm{O}+02 \\
1.081 \mathrm{E}+02 \\
3.988 \mathrm{E}+01\end{array}$ & $\begin{array}{c}\text { 50-TH } \\
9.992 \mathrm{E}+03 \\
2.446 \mathrm{O}+03 \\
9.483 \mathrm{E}+02 \\
5.475 \mathrm{O}+02 \\
3.662 \mathrm{O}+02 \\
2.212 \mathrm{O}+02 \\
8.491 \mathrm{O}+01\end{array}$ & $\begin{array}{c}95-\mathrm{TH} \\
4.265 \mathrm{E}+04 \\
1.043 \mathrm{E}+04 \\
3.858 \mathrm{E}+03 \\
2.325 \mathrm{E}+03 \\
1.555 \mathrm{O}+03 \\
9.398 \mathrm{O}+02 \\
3.480 \mathrm{O}+02\end{array}$ & $\begin{array}{c}\text { AVER } \\
1.498 E+04 \\
3.670 E+03 \\
1.403 E+03 \\
8.341 E+02 \\
5.556 E+02 \\
3.372 E+02 \\
1.260 E+02\end{array}$ & $\begin{array}{c}\text { SIGMA } \\
1.274 E+04 \\
3.112 E+03 \\
1.180 E+03 \\
7.102 E+02 \\
4.761 E+02 \\
2.861 E+02 \\
1.057 E+02\end{array}$ \\
\hline
\end{tabular}


20.0

50.0

$6.593 \mathrm{E}+001.435 \mathrm{E}+02$ $2.219 \mathrm{E}+004.906 \mathrm{E}+01$

$3.059 \mathrm{E}-02$
$9.424 \mathrm{E}+002.011 \mathrm{E}+01$ $3.208 \mathrm{E}+00$ $4.357 \mathrm{E}-02$
$6.947 E+00$

$8.360 E+01$

9. $980 \mathrm{E}-02$

$2.933 \mathrm{E}+01$
$3.022 E+01$

$1.042 E+01$

$2.547 \mathrm{E}+01$

350.0

$836 \mathrm{E}+00$
*** $5-\mathrm{TH}$

50-TH

95-TH

AVER

$0.5 \quad 1.547 \mathrm{E}+02 \quad 2.047 \mathrm{E}+03$

$1.883 \mathrm{E}+02 \quad 4.221 \mathrm{E}+02 \quad 1.261 \mathrm{E}+03$

$5.138 \mathrm{~B}+01 \quad 1.149 \mathrm{E}+02$

$3.284 E+02$

$1.318 E+02$

I.

$5.656 \mathrm{O}+01$

$3.428 \mathrm{E}+01$

$2.846 \mathrm{E}+01$

$8.031 \mathrm{E}+01$

$2.312 \mathrm{E}+01$

$8.250 \mathrm{~B}+00$

$1.924 \mathrm{E}+01$

$5.416 \mathrm{E}+01$

$1.406 \mathrm{E}+01$

$5.249 E+00$

$1.951 \mathrm{E}+00$

1. $164 \mathrm{E}+01$

$3.283 \mathrm{E}+0$

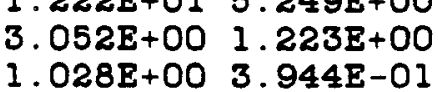

5. 162E-03
20.0

50.0

3. $758 \mathrm{E}-01$

$1.977 \mathrm{E}+01$

350.0

\begin{abstract}
$1.083 E-03$
\end{abstract}
3. 35OE-02
$1.420 \mathrm{~B}-01$
$1.366 \mathrm{~B}-01$

$1.467 \mathrm{E}-03$
3. $789 \mathrm{E}-03$
$3.083 \mathrm{E}-011.028 \mathrm{E}+00$
$1.336 \mathrm{E}-02$
***

$$
\text { 5-TH 50-TH 95- } \mathrm{TH}
$$

AVER

SIGMA

DIST (MI) LLIW

$0.5 \quad 1.840 E+02 \quad 3.628 E+03$

$1.05 .273 \mathrm{E}+01 \quad 9.254 \mathrm{E}+02$

$2.464 \mathrm{E}+02 \quad 6.009 \mathrm{E}+02$

$1.860 \mathrm{E}+03$

$7.740 E+02$

6. $157 \mathrm{E}+02$

$2.0 \quad 2.213 E+01 \quad 3.669 E+02$

$2.510 \mathrm{E}+01$

$1.626 \mathrm{E}+02$

$4.822 \mathrm{E}+\mathrm{O2}$

$2.023 \mathrm{E}+02$

$1.543 E+02$

3.0

$6.764 E+002.226 E+02$

$1.547 \mathrm{E}+01$

6. $680 \mathrm{E}+01$

$1.927 E+02$

$8.057 \mathrm{E}+01$

$6.064 E+01$

4.0

$2.805 \mathrm{E}+001.496 \mathrm{E}+02$

$1.030 E+01$

$2.677 \mathrm{E}+01$

$1.172 E+02$

$4.874 E+01$

3. $696 \mathrm{E}+01$

5.0

$5.658 \mathrm{E}+00$

$9.053 \mathrm{E}+01$

$6.238 \mathrm{E}+00$

$1.624 \mathrm{E}+01$

$.888 \mathrm{E}+01$

$3.282 E+01$

$2.489 E+01$

10.0

$2.086 \mathrm{E}+00$

$3.353 \mathrm{E}+01$

$2.422 E+00$

$6.206 \mathrm{E}+00$

$1.768 \mathrm{E}+01$

$1.994 \mathrm{E}+01$

1. $502 \mathrm{E}+01$

20.0

$4.599 \mathrm{E}-01$

$7.963 \mathrm{E}+00$

$5.611 \mathrm{E}-01$

$1.430 \mathrm{E}+00$

$4.175 E+00$

$7.442 E+00$

$5.569 \mathrm{E}+00$

.325E-01

7. $182 \mathrm{E}-02$

$1.817 \mathrm{E}-01$

$4.486 \mathrm{E}-01$

$1.415 \mathrm{E}+00$

$1.756 \mathrm{E}+00$

1. $363 \mathrm{E}+00$

350.0

$1.425 E-03$

2. 266E-03

2. $075 \mathrm{E}-02$

$8.847 E-01$

$4.928 \mathrm{E}-01$

\section{*** PROB EARIY INJUR.}

DIST. (MI) MIN

1. 0 2 390E-02 1.000E+00

$2.0 \quad 1.588 \mathrm{E}-03 \quad 9.382 \mathrm{E}-01$

$3.0 \quad 3.421 \mathrm{E}-05 \quad 4.625 \mathrm{E}-01$

$4.0 \quad 5.066 \mathrm{E}-06 \quad 1.715 \mathrm{E}-01$

5.0 2.170E-05 $4.051 \mathrm{E}-02$

10.0 1.192E-06 2.05OE-03

$20.0 \quad 0.000 \mathrm{E}+002.527 \mathrm{E}-05$

50.0

$0.000 \mathrm{E}+00$

$8.941 \mathrm{~B}-07$

350.0
$0.000 E+00$
$0.000 \mathrm{E}+00$
***

$$
\text { 5-TH }
$$

$50-\mathrm{TH}$

$95-\mathrm{TH}$

SIGMA

8.589E-01 1.000E+00 1.000E+00 9.783E-01 5.958E-02

$\begin{array}{llllll}3.680 \mathrm{E}-02 & 3.491 \mathrm{E}-01 & 9.999 \mathrm{E}-01 & 4.291 \mathrm{E}-01 & 3.465 \mathrm{E}-01\end{array}$

2.186E-03 2.851E-02 4.697E-01 9.470E-02 $1.729 \mathrm{E}-01$

4.951E-04 6.436E-03 1.329E-01 2.801E-02 $6.650 \mathrm{E}-02$

$1.433 \mathrm{E}-041.974 \mathrm{E}-03$

$4.245 E-02$

$9.196 \mathrm{E}-03$

2. 338E-02

$3.347 \mathrm{E}-05$

4. 34OE-04

$9.45 I E-03$

$2.083 E-03$

$5.411 E-03$

$1.937 \mathrm{E}-06$

2. $185 \mathrm{E}-05$

$4.620 E-04$

$1.051 E-04$

$2.703 E-04$

$0.000 \mathrm{E}+00$

. 384E-07

$5.573 E-06$

$1.327 E-06$

3. 324E-06

$0.000 E+00$

$0.000 E+00$

$2.682 E-07$
$0.000 E+00$

$4.649 \mathrm{E}-08$

1. $263 \mathrm{E}-07$

$0.000 E+00$

$0.000 E+00$

\section{*** PROB. EARLY DEATH}

DIST. (MI) MIN

$0.5 \quad 4.969 E-02 \quad 1.000 E+00$

$1.0 \quad 8.454 \mathrm{E}-04 \quad 1.000 \mathrm{E}+00$

2.0 5.716E-05 2.073E-01

$3.0 \quad 1.550 E-06 \quad 3.443 E-02$

$4.0 \quad 1.788 \mathrm{E}-07 \quad 9.490 \mathrm{E}-03$

$5.0 \quad 8.941 \mathrm{E}-072.013 \mathrm{E}-03$

$10.0 \quad 5.960 \mathrm{E}-08 \quad 9.882 \mathrm{E}-05$

$20.0 \quad 0.000 E+00 \quad 1.252 E-06$

$50.0 \quad 0.000 E+00 \quad 5.960 E-08$

350.0
$0.000 E+00$
$0.000 E+00$
$0.000 E+00$
***

$5-\mathrm{TH}$

50-TH

95-TH

AVER

SIGMA

$1.035 E-01$ 9.912E-01 1.000E+00 7.312E-01 3.482E-01 $1.435 E-03 \quad 1.991 E-02 \quad 7.140 E-01 \quad 1.147 E-012.315 E-01$ 8.148E-05 1.185E-03 2.843E-02 7.357E-03 2.382E-02 $\begin{array}{lllll}1.800 \mathrm{E}-05 & 2.596 \mathrm{E}-04 & 6.114 \mathrm{E}-03 & 1.416 \mathrm{E}-03 & 4.150 \mathrm{E}-03\end{array}$ 5.245E-06 7.823E-05 1.830E-03 4.120E-04 1.166E-03 $\begin{array}{lllll}1.222 E-06 & 1.71 I E-05 & 3.998 E-04 & 8.931 E-05 & 2.489 E-04\end{array}$ 5.960E-08 8.345E-07 1.958E-05 4.436E-06 1.215E-05 $0.000 \mathrm{E}+00 \quad 0.000 \mathrm{E}+00 \quad 2.384 \mathrm{E}-07 \quad 4.947 \mathrm{E}-08 \quad 1.534 \mathrm{E}-07$ $0.000 E+00 \quad 0.000 E+00 \quad 0.000 E+00 \quad 5.960 E-10 \quad 5.931 E-09$ $0.000 E+00 \quad 0.000 E+00 \quad 0.000 E+00 \quad 0.000 E+00 \quad 0.000 E+00$ 


\section{G-1}

\section{APPENDIX G}

Results for the Multiparameter Uncertainty Study:

Doses Calculated Using CRAC2 and MACCS Dose Conversion Factors. 


\begin{tabular}{|c|c|c|c|c|c|c|c|}
\hline $\begin{array}{c}\text { *** TOT } \\
\text { DIST. (MI) } \\
0.5 \\
1.0 \\
2.0 \\
3.0 \\
4.0 \\
5.0 \\
10.0 \\
20.0 \\
50.0 \\
350.0\end{array}$ & $\begin{array}{l}\text { BODY DO } \\
\text { MIN } \\
1.832 E+01 \\
6.375 E+00 \\
5.643 E-05 \\
2.692 E-09 \\
1.400 E-13 \\
7.804 E-18 \\
1.547 E-24 \\
6.845 E-25 \\
1.780 E-25 \\
2.548 E-28\end{array}$ & $\begin{array}{c}\text { NAX } \\
1.092 E+04 \\
3.594 E+03 \\
6.897 E+02 \\
3.621 E+02 \\
2.271 E+02 \\
1.325 E+02 \\
4.038 E+01 \\
1.338 E+01 \\
2.189 E+00 \\
3.564 E-02\end{array}$ & $\begin{array}{l}* * * \\
5-\mathrm{TH} \\
7.238 \mathrm{E}+01 \\
1.855 \mathrm{E}+01 \\
3.239 \mathrm{E}+00 \\
1.910 \mathrm{E}+00 \\
1.448 \mathrm{E}+00 \\
9.136 \mathrm{E}-01 \\
4.443 \mathrm{E}-01 \\
7.381 \mathrm{E}-02 \\
3.966 \mathrm{E}-03 \\
4.017 \mathrm{E}-05\end{array}$ & $\begin{array}{c}50-\mathrm{TH} \\
7.451 \mathrm{E}+02 \\
2.527 \mathrm{O}+02 \\
6.088 \mathrm{O}+01 \\
3.387 \mathrm{O}+01 \\
2.243 \mathrm{E}+01 \\
1.418 \mathrm{O}+01 \\
4.781 \mathrm{E}+00 \\
1.230 \mathrm{O}+00 \\
3.237 \mathrm{E}-01 \\
9.264 \mathrm{E}-04\end{array}$ & $\begin{array}{c}95-\mathrm{TH} \\
4.313 \mathrm{E}+03 \\
1.541 \mathrm{E}+03 \\
3.158 \mathrm{E}+02 \\
1.744 \mathrm{E}+02 \\
1.163 \mathrm{E}+02 \\
7.338 \mathrm{E}+01 \\
2.561 \mathrm{E}+01 \\
7.866 \mathrm{~B}+00 \\
2.022 \mathrm{E}+00 \\
1.664 \mathrm{E}-02\end{array}$ & $\begin{array}{c}\text { AVER } \\
1.459 \mathrm{E}+03 \\
4.907 \mathrm{E}+02 \\
1.020 \mathrm{E}+02 \\
5.623 \mathrm{E}+01 \\
3.637 \mathrm{E}+01 \\
2.194 \mathrm{~B}+01 \\
7.299 \mathrm{E}+00 \\
2.250 \mathrm{E}+00 \\
5.458 \mathrm{E}-01 \\
3.755 \mathrm{E}-03\end{array}$ & $\begin{array}{c}\text { SIGKA } \\
2.055 \mathrm{E}+03 \\
6.562 \mathrm{E}+02 \\
1.161 \mathrm{E}+02 \\
6.263 \mathrm{E}+01 \\
4.018 \mathrm{E}+01 \\
2.436 \mathrm{E}+01 \\
7.987 \mathrm{E}+00 \\
2.606 \mathrm{E}+00 \\
6.148 \mathrm{~B}-01 \\
6.535 \mathrm{E}-03\end{array}$ \\
\hline$* * *$ & $\because \mathrm{Mn}$ & DOSE & & & & & \\
\hline $\begin{array}{c}\text { DIST. (MI } \\
0.5 \\
1.0 \\
2.0 \\
3.0 \\
4.0 \\
5.0 \\
10.0 \\
20.0 \\
50.0 \\
350.0\end{array}$ & $\begin{array}{c}M I N \\
2.114 E+01 \\
7.355 E+00 \\
6.503 E-05 \\
3.102 E-09 \\
1.614 E-13 \\
8.995 E-18 \\
1.785 E-24 \\
7.907 E-25 \\
2.050 E-25 \\
2.886 E-28\end{array}$ & $\begin{array}{c}\text { MAX } \\
1.266 E+04 \\
4.265 E+03 \\
8.191 E+02 \\
4.306 E+02 \\
2.705 E+02 \\
1.580 E+02 \\
4.844 E+01 \\
1.602 E+01 \\
2.996 E+00 \\
6.544 E-02\end{array}$ & $\begin{array}{c}5-\mathrm{TH} \\
1.042 \mathrm{E}+02 \\
2.416 \mathrm{E}+01 \\
5.094 \mathrm{E}+00 \\
2.896 \mathrm{E}+00 \\
1.980 \mathrm{E}+00 \\
1.255 \mathrm{E}+00 \\
5.351 \mathrm{E}-01 \\
8.835 \mathrm{E}-02 \\
5.305 \mathrm{E}-03 \\
7.368 \mathrm{E}-05\end{array}$ & $\begin{array}{c}50-\mathrm{TH} \\
9.397 \mathrm{E}+02 \\
3.114 \mathrm{E}+02 \\
7.683 \mathrm{E}+01 \\
4.532 \mathrm{E}+01 \\
2.888 \mathrm{E}+01 \\
1.729 \mathrm{E}+01 \\
5.929 \mathrm{E}+00 \\
1.600 \mathrm{~B}+00 \\
4.433 \mathrm{E}-01 \\
1.815 \mathrm{E}-03\end{array}$ & $\begin{array}{c}95-\mathrm{TH} \\
5.061 \mathrm{E}+03 \\
1.841 \mathrm{E}+03 \\
3.662 \mathrm{E}+02 \\
2.094 \mathrm{E}+02 \\
1.397 \mathrm{E}+02 \\
9.206 \mathrm{E}+01 \\
3.375 \mathrm{E}+01 \\
9.944 \mathrm{E}+00 \\
2.530 \mathrm{E}+00 \\
3.001 \mathrm{E}-02\end{array}$ & $\begin{array}{c}\text { AVER } \\
1.774 \mathrm{E}+03 \\
6.035 \mathrm{E}+02 \\
1.266 \mathrm{E}+02 \\
6.988 \mathrm{O}+01 \\
4.529 \mathrm{E}+01 \\
2.738 \mathrm{E}+01 \\
9.169 \mathrm{E}+00 \\
2.842 \mathrm{E}+00 \\
7.074 \mathrm{E}-01 \\
6.598 \mathrm{E}-03\end{array}$ & $\begin{array}{c}\text { SIGMA } \\
2.401 \mathrm{E}+03 \\
7.768 \mathrm{E}+02 \\
1.410 \mathrm{E}+02 \\
7.656 \mathrm{E}+01 \\
4.932 \mathrm{E}+01 \\
3.007 \mathrm{E}+01 \\
9.932 \mathrm{E}+00 \\
3.235 \mathrm{E}+00 \\
7.825 \mathrm{E}-01 \\
1.115 \mathrm{E}-02\end{array}$ \\
\hline
\end{tabular}

\begin{tabular}{|c|c|c|c|c|c|c|c|}
\hline $\begin{array}{c}\text { DIST. (MI) } \\
0.5 \\
1.0 \\
2.0 \\
3.0 \\
4.0 \\
5.0 \\
10.0 \\
20.0 \\
50.0 \\
350.0\end{array}$ & $\begin{array}{c}\text { MIN } \\
3.572 E+01 \\
1.239 E+01 \\
5.397 E-05 \\
2.565 E-09 \\
1.331 E-13 \\
7.387 E-18 \\
1.463 E-24 \\
6.445 E-25 \\
1.671 E-25\end{array}$ & $\begin{array}{c}\text { MAZ } \\
7.222 E+04 \\
2.598 E+04 \\
5.021 E+03 \\
2.661 E+03 \\
1.676 E+03 \\
9.733 E+02 \\
3.887 E+02 \\
1.463 E+02 \\
4.558 E+01 \\
5.638 E-01\end{array}$ & $\begin{array}{c}5-\mathrm{TH} \\
1.823 \mathrm{E}+02 \\
4.245 \mathrm{O}+01 \\
1.431 \mathrm{E}+01 \\
9.159 \mathrm{O}+00 \\
6.456 \mathrm{O}+00 \\
3.521 \mathrm{E}+00 \\
1.088 \mathrm{O}+00 \\
9.767 \mathrm{E}-02 \\
8.561 \mathrm{E}-03 \\
3.253 \mathrm{E}-05\end{array}$ & $\begin{array}{c}\text { 5O-TH } \\
2.579 \mathrm{E}+03 \\
7.402 \mathrm{O}+02 \\
1.563 \mathrm{O}+02 \\
9.304 \mathrm{O}+01 \\
6.321 \mathrm{O}+01 \\
3.802 \mathrm{O}+01 \\
1.276 \mathrm{E}+01 \\
3.642 \mathrm{O}+00 \\
1.036 \mathrm{O}+00 \\
1.589 \mathrm{E}-03\end{array}$ & $\begin{array}{c}95-T H \\
1.843 E+04 \\
7.431 E+03 \\
1.906 E+03 \\
1.088 E+03 \\
7.104 E+02 \\
3.909 E+02 \\
1.258 E+02 \\
3.425 E+01 \\
9.237 E+00 \\
2.412 E-01\end{array}$ & $\begin{array}{c}\text { AVER } \\
5.669 E+03 \\
2.202 E+03 \\
4.901 E+02 \\
2.722 E+02 \\
1.772 E+02 \\
1.076 E+02 \\
3.606 E+01 \\
1.075 E+01 \\
2.895 E+00 \\
5.020 E-02\end{array}$ & $\begin{array}{c}\text { SIGKA } \\
8.712 \mathrm{E}+03 \\
3.375 \mathrm{E}+03 \\
7.368 \mathrm{O}+02 \\
4.093 \mathrm{O}+02 \\
2.675 \mathrm{O}+02 \\
1.623 \mathrm{E}+02 \\
5.540 \mathrm{O}+01 \\
1.792 \mathrm{E}+01 \\
5.333 \mathrm{O}+00 \\
9.871 \mathrm{E}-02\end{array}$ \\
\hline
\end{tabular}

$\begin{array}{ccccccccc}\text { **** TOT. THYROID DOSE } & * * * & & & \\ \text { DIST. (MI) } & \text { MIN } & \text { MAX } & 5-T H & 50-T H & 95-T H & \text { AVER } & \text { SIGMA } \\ 0.5 & 2.196 E+02 & 1.482 E+05 & 4.930 E+02 & 1.044 E+04 & 8.140 E+04 & 2.004 E+04 & 2.843 E+04 \\ 1.0 & 2.897 E+01 & 8.295 E+04 & 1.036 E+02 & 3.906 E+03 & 3.664 E+04 & 8.290 E+03 & 1.314 E+04 \\ 2.0 & 7.518 E-05 & 2.626 E+04 & 3.346 E+01 & 7.528 E+02 & 8.837 E+03 & 1.989 E+03 & 3.614 E+03 \\ 3.0 & 3.499 E-09 & 1.623 E+04 & 2.157 E+01 & 4.110 E+02 & 4.754 E+03 & 1.121 E+03 & 2.130 E+03 \\ 4.0 & 1.796 E-13 & 1.124 E+04 & 1.650 E+01 & 2.551 E+02 & 3.006 E+03 & 7.361 E+02 & 1.439 E+03 \\ 5.0 & 9.701 E-18 & 6.959 E+03 & 1.049 E+01 & 1.385 E+02 & 1.780 E+03 & 4.563 E+02 & 9.029 E+02 \\ 10.0 & 1.993 E-24 & 2.580 E+03 & 2.775 E+00 & 4.299 E+01 & 6.104 E+02 & 1.536 E+02 & 3.166 E+02\end{array}$


20.0

50.0

350.0
9. $049 \mathrm{E}-25 \quad 8.172 \mathrm{E}+02$

$2.648 E-25 \quad 2.324 E+02$

$4.967 E-28 \quad 4.909 E+00$
$1.978 \mathrm{E}-01$

$2.005 \mathrm{E}-02$

$4.557 \mathrm{E}-05$
$1.136 \mathrm{E}+01 \quad 1.853 \mathrm{E}+02 \quad 4.488 \mathrm{E}+01 \quad 9.625 \mathrm{E}+01$

$2.764 E+003.850 E+01 \quad 1.072 E+01 \quad 2.547 E+01$

2.396E-03 5.448E-01 1.417E-01 5.226E-01

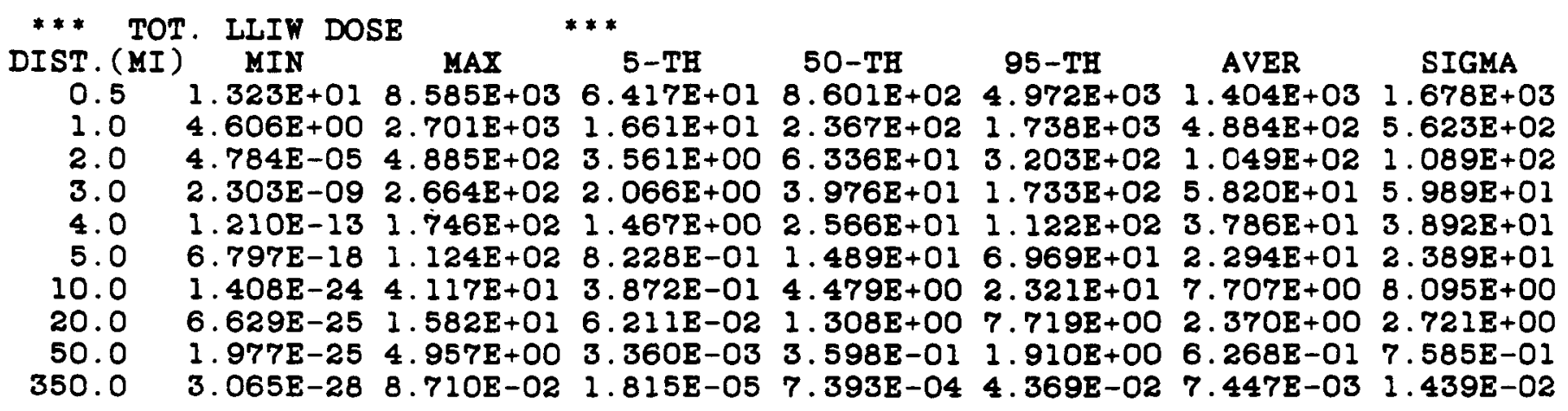

\begin{tabular}{|c|c|c|c|c|c|c|c|}
\hline & & & & & & & \\
\hline $\begin{array}{c}\text { IST. (MI) } \\
0.5 \\
1.0 \\
2.0 \\
3.0 \\
4.0 \\
5.0 \\
10.0 \\
20.0 \\
50.0\end{array}$ & $\begin{array}{c}\text { MIN } \\
0.000 E+00 \\
0.000 E+00 \\
0.000 E+00 \\
0.000 E+00 \\
0.000 E+00 \\
0.000 E+00 \\
0.000 E+00\end{array}$ & $\begin{array}{l}\text { MAX } \\
1.00 O E+00 \\
1.000 E+00 \\
1.00 O E+00 \\
4.148 E-02 \\
0.00 O E+00 \\
0.00 O E+00 \\
0.00 O E+00 \\
0.00 O E+00 \\
0.00 O E+00 \\
0.00 O E+00\end{array}$ & 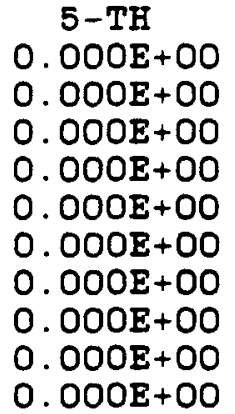 & 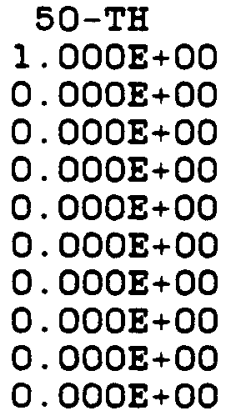 & $\begin{array}{l}95-\mathrm{TH} \\
1.00 O E+00 \\
1.000 E+00 \\
1.731 E-02 \\
0.000 E+00 \\
0.00 O E+00 \\
0.00 O E+00 \\
0.000 E+00 \\
0.00 O E+00 \\
0.00 O E+00 \\
0.00 O E+00\end{array}$ & $\begin{array}{c}\text { AVER } \\
6.286 E-01 \\
3.129 E-01 \\
1.274 E-02 \\
4.148 E-04 \\
0.000 E+00 \\
0.000 E+00\end{array}$ & $\begin{array}{c}\text { SIGMA } \\
4.752 E-01 \\
4.512 E-01 \\
9.979 E-02 \\
4.127 E-03 \\
0.000 E+00 \\
0.000 E+00 \\
0.000 E+00 \\
0.000 E+00 \\
0.000 E+00 \\
0.000 E+00\end{array}$ \\
\hline
\end{tabular}




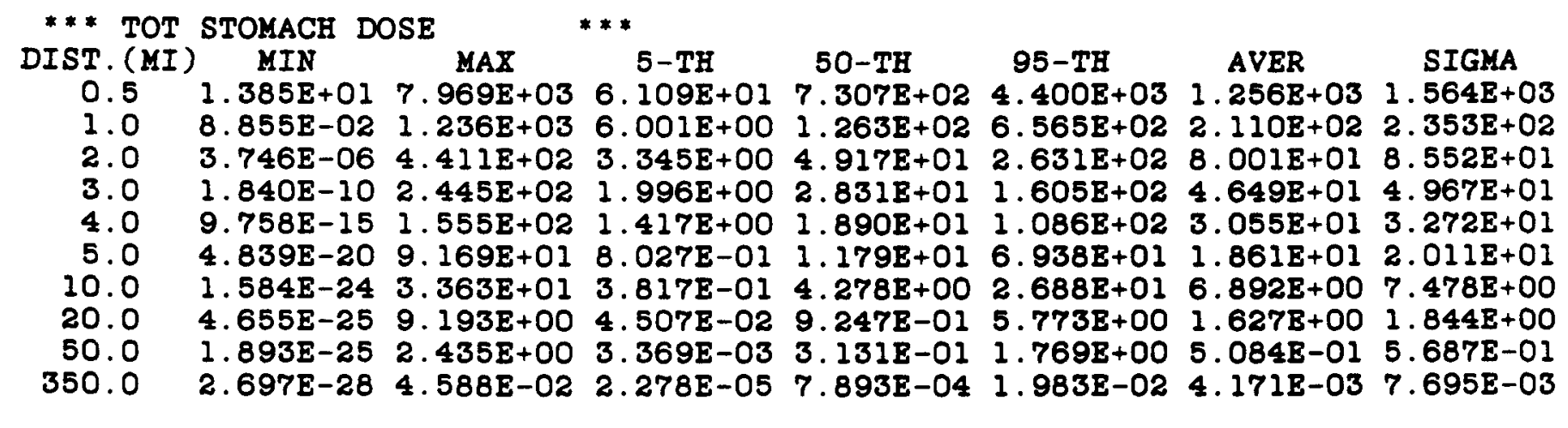

\begin{tabular}{|c|c|c|c|c|c|c|c|}
\hline TOT & MARROW & & $* * *$ & & & & \\
\hline $\begin{array}{c}\text { DIST. (MI) } \\
0.5 \\
1.0 \\
2.0 \\
3.0 \\
4.0 \\
5.0 \\
10.0 \\
20.0 \\
50.0 \\
350.0\end{array}$ & $\begin{array}{c}\text { MIN } \\
1.439 E+01 \\
9.767 E-02 \\
4.132 E-06 \\
2.030 E-10 \\
1.076 E-14 \\
5.338 E-20 \\
1.748 E-24 \\
5.138 E-25 \\
2.089 E-25 \\
3.006 E-28\end{array}$ & $\begin{array}{c}\text { MAX } \\
8.697 E+03 \\
1.304 E+03 \\
4.673 E+02 \\
2.599 E+02 \\
1.658 E+02 \\
9.816 E+01 \\
3.472 E+01 \\
1.012 E+01 \\
2.515 E+00 \\
5.413 E-02\end{array}$ & $\begin{array}{c}5-\mathrm{TH} \\
6.538 \mathrm{E}+01 \\
6.066 \mathrm{E}+0 \mathrm{O} \\
3.203 \mathrm{E}+0 \mathrm{O} \\
1.887 \mathrm{E}+0 \mathrm{O} \\
1.330 \mathrm{E}+0 \mathrm{O} \\
8.481 \mathrm{E}-01 \\
4.303 \mathrm{E}-01 \\
4.981 \mathrm{E}-02 \\
3.675 \mathrm{E}-03 \\
2.080 \mathrm{E}-05\end{array}$ & $\begin{array}{l}\text { 50-TH } \\
7.572 \mathrm{E}+02 \\
1.372 \mathrm{E}+02 \\
5.287 \mathrm{E}+01 \\
3.083 \mathrm{E}+01 \\
2.057 \mathrm{E}+01 \\
1.269 \mathrm{E}+01 \\
4.816 \mathrm{E}+00 \\
1.009 \mathrm{E}+00 \\
3.557 \mathrm{E}-01 \\
6.906 \mathrm{E}-04\end{array}$ & $\begin{array}{c}95-\mathrm{TH} \\
4.833 \mathrm{E}+03 \\
7.136 \mathrm{E}+02 \\
2.749 \mathrm{E}+02 \\
1.532 \mathrm{E}+02 \\
1.010 \mathrm{E}+02 \\
6.394 \mathrm{E}+01 \\
2.578 \mathrm{E}+01 \\
6.187 \mathrm{E}+00 \\
2.028 \mathrm{E}+00 \\
2.944 \mathrm{E}-02\end{array}$ & $\begin{array}{c}\text { AVER } \\
1.357 \mathrm{E}+03 \\
2.268 \mathrm{E}+02 \\
8.600 \mathrm{E}+01 \\
5.004 \mathrm{E}+01 \\
3.293 \mathrm{E}+01 \\
2.010 \mathrm{E}+01 \\
7.481 \mathrm{E}+00 \\
1.794 \mathrm{E}+00 \\
5.725 \mathrm{E}-01 \\
5.433 \mathrm{E}-03\end{array}$ & $\begin{array}{c}\text { SIGKA } \\
1.709 \mathrm{E}+03 \\
2.531 \mathrm{E}+02 \\
9.094 \mathrm{E}+01 \\
5.267 \mathrm{E}+01 \\
3.465 \mathrm{E}+01 \\
2.127 \mathrm{E}+01 \\
7.937 \mathrm{E}+00 \\
1.998 \mathrm{E}+00 \\
6.282 \mathrm{E}-01 \\
9.953 \mathrm{E}-03\end{array}$ \\
\hline
\end{tabular}

\begin{tabular}{|c|c|c|c|c|c|c|c|}
\hline *** & & & & & & & \\
\hline $\begin{array}{c}\text { DST. (MI) } \\
0.5 \\
1.0 \\
2.0 \\
3.0 \\
4.0 \\
5.0 \\
10.0 \\
20.0 \\
50.0 \\
350.0\end{array}$ & $\begin{array}{c}\text { MIN } \\
2.119 E+01 \\
9.773 E-02 \\
4.109 E-06 \\
2.015 E-10 \\
1.067 E-14 \\
5.282 E-20 \\
1.727 E-24 \\
5.071 E-25 \\
2.060 E-25\end{array}$ & $\begin{array}{c}\text { MAX } \\
1.252 E+04 \\
1.932 E+03 \\
8.831 E+02 \\
5.656 E+02 \\
3.939 E+02 \\
2.499 E+02 \\
9.965 E+01 \\
2.504 E+01 \\
8.377 E+00 \\
1.661 E-01\end{array}$ & $\begin{array}{c}5-\mathrm{TH} \\
1.027 \mathrm{E}+02 \\
1.197 \mathrm{E}+01 \\
6.908 \mathrm{O}+00 \\
4.176 \mathrm{E}+00 \\
2.973 \mathrm{E}+00 \\
1.454 \mathrm{E}+00 \\
6.665 \mathrm{E}-01 \\
5.619 \mathrm{E}-02 \\
4.598 \mathrm{E}-03 \\
3.375 \mathrm{E}-05\end{array}$ & $\begin{array}{c}\text { 50-TE } \\
1.314 \mathrm{E}+03 \\
2.348 \mathrm{E}+02 \\
8.343 \mathrm{E}+01 \\
5.308 \mathrm{I}+01 \\
3.284 \mathrm{E}+01 \\
1.968 \mathrm{I}+01 \\
6.907 \mathrm{E}+00 \\
1.568 \mathrm{E}+00 \\
5.516 \mathrm{E}-01 \\
1.112 \mathrm{E}-03\end{array}$ & $\begin{array}{c}95-\mathrm{TE} \\
7.292 \mathrm{E}+03 \\
1.308 \mathrm{E}+03 \\
5.665 \mathrm{E}+02 \\
3.369 \mathrm{E}+02 \\
2.213 \mathrm{E}+02 \\
1.397 \mathrm{E}+02 \\
4.983 \mathrm{E}+01 \\
1.064 \mathrm{E}+01 \\
2.794 \mathrm{E}+00 \\
5.688 \mathrm{E}-02\end{array}$ & $\begin{array}{c}\text { AVER } \\
2.226 E+03 \\
4.064 E+02 \\
1.568 E+02 \\
9.148 E+01 \\
6.031 E+01 \\
3.697 E+01 \\
1.377 E+01 \\
3.177 E+00 \\
9.920 E-01 \\
1.176 E-02\end{array}$ & $\begin{array}{c}\text { SIGMA } \\
2.382 E+03 \\
4.469 E+02 \\
1.775 E+02 \\
1.056 E+02 \\
7.071 E+01 \\
4.417 E+01 \\
1.687 E+01 \\
4.041 E+00 \\
1.315 E+00 \\
2.377 E-02\end{array}$ \\
\hline
\end{tabular}

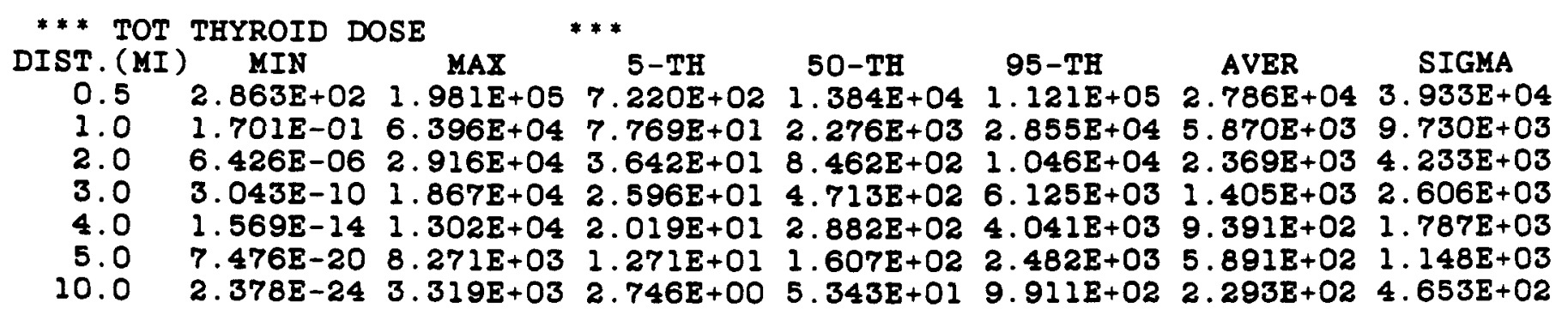


20.0

50.0

350.0
$6.846 \mathrm{E}-25 \quad 8.613 \mathrm{E}+02$

$2.728 E-25 \quad 3.075 E+02$

$6.780 E-28 \quad 8.114 E+00$
$1.734 \mathrm{E}-01$

$2.521 \mathrm{E}-02 \quad 4.063 \mathrm{E}+00$

3.687E-05
3. 185E-03
$1.895 E+025.421 E+01 \quad 1.182 E+02$ $5.969 E+01 \quad 1.749 E+014.127 E+01$ $1.240 E+002.813 E-018.983 E-01$

$\begin{array}{cccccccc}* * * & \text { TOT SM. INT.DOSE } & * * * & & \\ \text { DIST. (MI) } & \text { MIN } & \text { MAX } & 5-T H & 50-T H & 95-T H & \text { AVER } & \text { SIGMA } \\ 0.5 & 1.188 E+01 & 7.150 E+03 & 5.460 E+01 & 6.294 E+02 & 4.008 E+03 & 1.107 E+03 & 1.399 E+03 \\ 1.0 & 8.106 E-02 & 1.054 E+03 & 5.035 E+00 & 1.101 E+02 & 5.691 E+02 & 1.841 E+02 & 2.043 E+02 \\ 2.0 & 3.431 E-06 & 3.778 E+02 & 2.427 E+00 & 4.410 E+01 & 2.209 E+02 & 6.966 E+01 & 7.265 E+01 \\ 3.0 & 1.685 E-10 & 2.100 E+02 & 1.460 E+00 & 2.573 E+01 & 1.228 E+02 & 4.050 E+01 & 4.195 E+01 \\ 4.0 & 8.940 E-15 & 1.339 E+02 & 1.021 E+00 & 1.705 E+01 & 8.093 E+01 & 2.663 E+01 & 2.755 E+01 \\ 5.0 & 4.434 E-20 & 7.927 E+01 & 6.646 E-01 & 1.061 E+01 & 4.998 E+01 & 1.623 E+01 & 1.686 E+01 \\ 10.0 & 1.452 E-24 & 2.806 E+01 & 3.172 E-01 & 3.814 E+00 & 2.033 E+01 & 6.028 E+00 & 6.284 E+00 \\ 20.0 & 4.267 E-25 & 8.209 E+00 & 4.089 E-02 & 8.367 E-01 & 4.809 E+00 & 1.441 E+00 & 1.596 E+00 \\ 50.0 & 1.737 E-25 & 2.274 E+00 & 3.083 E-03 & 2.872 E-01 & 1.581 E+00 & 4.565 E-01 & 5.024 E-01 \\ 350.0 & 2.516 E-28 & 3.397 E-02 & 2.048 E-05 & 7.231 E-04 & 2.236 E-02 & 3.994 E-03 & 7.064 E-03\end{array}$

*** TOT
DIST. ( MI
0.5
1.0
2.0
3.0
4.0
5.0
10.0
20.0
50.0
350.0

OT LLIW

\section{DOSE}

MAX $1.362 E+01 \quad 8.987 E+03$

8.825E-02 1.191E+03

3.720E-06 4.603E+02

1. $825 \mathrm{E}-102.720 \mathrm{E}+02$

$9.673 E-151.816 E+02$

4.791E-20 1.166E+02

$1.567 \mathrm{E}-245.525 \mathrm{E}+01$

4.607E-25 1.628E+OI

$1.875 \mathrm{E}-256.189 \mathrm{E}+00$

2. $980 \mathrm{E}-28$ 1.082E-01

$$
5-\mathrm{TH}
$$

$6.71 O E+O I$

$6.735 \mathrm{E}+00$

$3.280 \mathrm{E}+00$

$2.004 E+00$

$1.446 E+00$

$9.542 E-01$

4. $253 \mathrm{E}-01$

$4.740 E-02$

$3.730 E-03$

2. $221 E-05$

\section{0-TH}

$9.208 E+02$

$1.455 \mathrm{E}+02$

$6.379 E+01$

$3.580 E+01$

$2.329 E+01$

$1.452 E+01$

$4.974 E+00$

$1.184 E+00$

$4.010 \mathrm{E}-01$

8. 34OE-04
95-TH

$5.869 \mathrm{E}+03$

$8.827 \mathrm{E}+02$

$3.253 \mathrm{E}+02$

$1.802 E+02$

1. $154 \mathrm{E}+02$

$7.518 E+01$

$2.792 E+01$

$6.545 \mathrm{E}+00$

2. $166 \mathrm{E}+00$

$4.934 \mathrm{~B}-02$
AVER

$1.559 \mathrm{E}+03 \quad 1.787 \mathrm{E}+03$

$2.699 \mathrm{E}+022.876 \mathrm{E}+02$

$1.028 E+021.064 E+02$

$5.991 E+016.191 E+01$

3. $947 E+01 \quad 4.093 E+01$

$2.414 \mathrm{E}+012.538 \mathrm{E}+01$

$9.013 E+00 \quad 9.826 E+00$

2. $160 \mathrm{E}+002.552 \mathrm{E}+00$

7.045E-01 8.824E-01

8.762E-03 1.706E-02

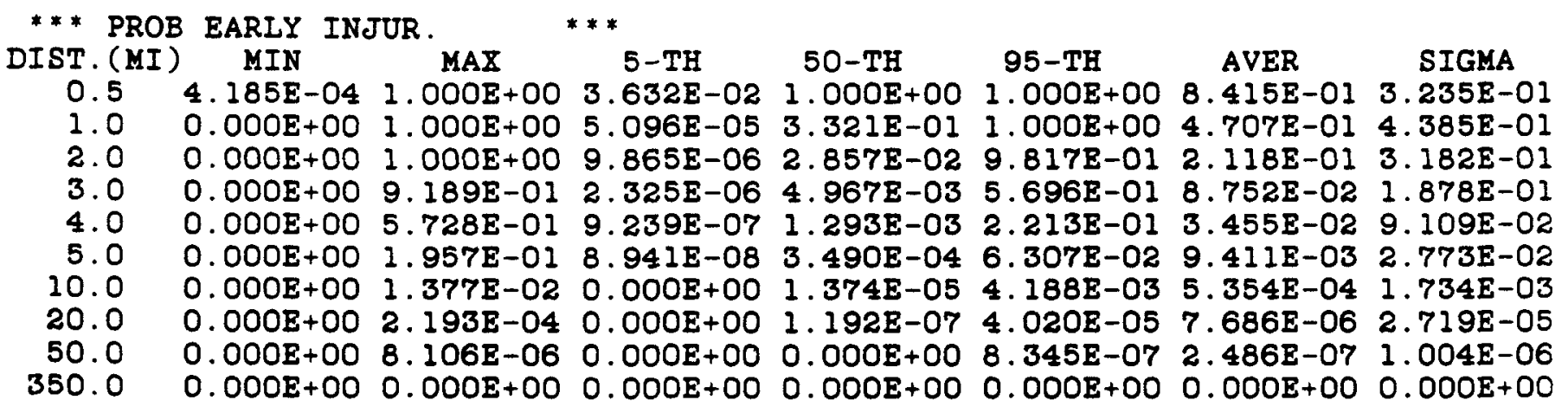

\begin{tabular}{|c|c|c|c|c|c|c|c|}
\hline $\begin{array}{c}* * * \text { PROB } \\
\text { DIST. (MI) } \\
0.5 \\
1.0 \\
2.0 \\
3.0 \\
4.0 \\
5.0 \\
10.0 \\
20.0 \\
50.0 \\
350.0\end{array}$ & $\begin{array}{l}\text { B. EARLY D } \\
\text { MIN } \\
1.287 E-05 \\
0.000 E+00 \\
0.000 E+00 \\
0.000 E+00 \\
0.000 E+00 \\
0.000 E+00 \\
0.000 E+00 \\
0.000 E+00 \\
0.000 E+00 \\
0.000 E+00\end{array}$ & $\begin{array}{c}\text { MATH } \\
\text { MAX } \\
1.000 E+00 \\
1.000 E+00 \\
8.869 E-01 \\
2.179 E-01 \\
7.948 E-02 \\
2.091 E-02 \\
1.339 E-03 \\
2.128 E-05 \\
7.749 E-07 \\
0.000 E+00\end{array}$ & $\begin{array}{c}* * \\
5-\mathrm{TH} \\
1.541 \mathrm{E}-03 \\
2.414 \mathrm{E}-06 \\
4.768 \mathrm{E}-07 \\
1.192 \mathrm{E}-07 \\
2.980 \mathrm{E}-08 \\
0.000 \mathrm{D}+00 \\
0.000 \mathrm{E}+00 \\
0.000 \mathrm{E}+00 \\
0.000 \mathrm{D}+00 \\
0.000 \mathrm{E}+00\end{array}$ & $\begin{array}{c}\text { 5O-TH } \\
1.000 E+00 \\
2.582 E-02 \\
8.122 E-04 \\
2.078 E-04 \\
4.873 E-05 \\
1.040 E-05 \\
4.470 E-07 \\
0.000 E+00 \\
0.000 E+00 \\
0.000 E+00\end{array}$ & $\begin{array}{l}95-\mathrm{TH} \\
1.000 \mathrm{E}+00 \\
1.000 \mathrm{E}+00 \\
2.864 \mathrm{E}-01 \\
5.437 \mathrm{E}-02 \\
1.489 \mathrm{E}-02 \\
3.765 \mathrm{E}-03 \\
1.733 \mathrm{E}-04 \\
1.669 \mathrm{E}-06 \\
2.980 \mathrm{E}-08 \\
0.00 \mathrm{E}+00\end{array}$ & $\begin{array}{c}\text { AVER } \\
7.32 I E-01 \\
2.755 E-01 \\
4.423 E-02 \\
8.593 E-03 \\
2.495 E-03 \\
6.043 E-04 \\
3.438 E-05 \\
4.870 E-07 \\
1.490 E-08 \\
0.000 E+00\end{array}$ & $\begin{array}{c}\text { SIGKA } \\
4.066 E-01 \\
3.922 E-01 \\
1.278 E-01 \\
2.762 E-02 \\
8.976 E-03 \\
2.307 E-03 \\
1.450 E-04 \\
2.369 E-06 \\
9.363 E-08 \\
0.000 E+00\end{array}$ \\
\hline
\end{tabular}

